\title{
Skill matching and outcomes
}

Citation for published version (APA):

Fregin, M-C. M. (2019). Skill matching and outcomes: new cross-country evidence. [Doctoral Thesis, Maastricht University]. ROA. https://doi.org/10.26481/dis.20191031mf

Document status and date:

Published: 01/01/2019

DOI:

10.26481/dis.20191031mf

Document Version:

Publisher's PDF, also known as Version of record

\section{Please check the document version of this publication:}

- A submitted manuscript is the version of the article upon submission and before peer-review. There can be important differences between the submitted version and the official published version of record.

People interested in the research are advised to contact the author for the final version of the publication, or visit the DOI to the publisher's website.

- The final author version and the galley proof are versions of the publication after peer review.

- The final published version features the final layout of the paper including the volume, issue and page numbers.

Link to publication

\footnotetext{
General rights rights.

- You may freely distribute the URL identifying the publication in the public portal. please follow below link for the End User Agreement:

www.umlib.nl/taverne-license

Take down policy

If you believe that this document breaches copyright please contact us at:

repository@maastrichtuniversity.nl

providing details and we will investigate your claim.
}

Copyright and moral rights for the publications made accessible in the public portal are retained by the authors and/or other copyright owners and it is a condition of accessing publications that users recognise and abide by the legal requirements associated with these

- Users may download and print one copy of any publication from the public portal for the purpose of private study or research.

- You may not further distribute the material or use it for any profit-making activity or commercial gain

If the publication is distributed under the terms of Article $25 \mathrm{fa}$ of the Dutch Copyright Act, indicated by the "Taverne" license above, 
Skill Matching and Dutcomes

New Crass-Cauntry Evidence 
(C) Marie-Christine Martha Fregin, Maastricht 2019

All rights reserved. No part of this publication may be reproduced, stored in a retrieval system, or transmitted in any form, or by any means, electronic, mechanical, photocopying, recording, or otherwise, without the prior permission in writing, from the author.

Published by ROA

Postbus 616

6200 MD Maastricht

ISBN: 978-90-5321-582-1

Printed in the Netherlands by Canon 


\title{
Skill Matching and Dutcomes New Cruss-Cuuntry Evidence
}

\author{
Dissertation
}

To obtain the degree of Doctor at Maastricht University,

On the authority of the Rector Magnificus,

Prof. dr. Rianne M. Letschert

in accordance with the decision of the Board of Deans,

to be defended in public on

Thursday, 31 October 2019, at 16:00 hours

by

Marie-Christine Martha Fregin 


\section{Supervisors}

Prof. Dr. Rolf van der Velden

Prof. Dr. Mark Levels

\section{Assessment Committee}

Prof. Dr. Ken Mayhew (Chairman)

Dr. Tim Huijts

Dr. Glenda Quintini, OECD

Prof. Dr. Maarten Wolbers, Radboud Universiteit 
For all dreamers and doers, for those who open the way, for the young women who keep going, and for one woman in particular

- my grandmother Anne Fregin who so strongly believed that I can achieve what I want. 



\section{The Importance of Matches}

I did not end up where I intended to go. Instead, I ended up where I needed to be. The road I took was sometimes rocky. But - and that is what counts in the end - I had great people that went along with me. Therefore, this chapter is not the introduction. This is me acknowledging the importance of matches. This is me saying thank you, dankjewel, and Dankeschön to the people that helped me find my way through the PhD. First, foremost, and from the bottom of my heart, I want to say heel and incredibly veel dank to my promoters, co-authors, and the best coaches one could wish: Rolf van der Velden and Mark Levels. You made this $\mathrm{PhD}$ possible, not only because you took over my supervision. Thank you so much for believing in me and my ideas, for helping me acquire my research topic, for letting me grow, challenging me, for sharing my enthusiasm and curiosity, for long and inspiring walks, for helping me rise and shine, and for simply saying "Let's do it" to things I thought would be impossible. Thank you for your praise as much as for constructive debates. Thank you for pushing me, and for holding me back when I pushed too far. You took very good care of both the science and the scientist. It always was, and still is, a great pleasure working with you - and I am so looking forward to the new projects and papers that are about to come.

With deep gratitude, I also want to thank Ineke Bijlsma, awesome lady, great co-author, solid as a rock when it comes to dealing with small, big and bigger data issues. Thank you for being by my side, helping me out, and celebrating the victories along the road. Hartelijk dank aan Andries de Grip and the whole ROA Management Board for investing in me and my research, for financial support, and for providing me with the chance to find an intellectual home at ROA. Working for and with ROA is challenging in a good and very interesting way, and great fun. I also want to thank my manuscript committee - Ken Mayhew, Tim Huijts, Glenda Quintini, and Maarten Wolbers - for taking the time to read my thesis and comment on it. Herzlichen Dank to Katarina Wessling and Friederike Bornträger for being my paranymphs! Also, heel veel dank to Mariëlle Retz for all her help during the process of formatting the thesis, finishing and printing the book.

To Josef Schmid and Martin Groß: Thank you very much for encouraging me to work with PIAAC and on the topic of skill matching. Thank you for your support while I was in Tübingen, and for letting me move on and finish the thesis at ROA. Josef Schmid, thank you for being a very helpful mentor, and for providing me with both a job and interesting 
challenges. Martin Groß, thank you for the great motto „Torment your computer, not yourself". It still makes me laugh. Furthermore, I want to thank my Tübingen colleagues Claudia and Markus for good times that we spent together. I'm very happy that you, too, (almost) managed to get through the $\mathrm{PhD}$. From Tübingen to Maastricht, heel veel dank to Katarina Wessling. She was (twice!) the one to make the difference when it came to building my professional future, be it on a bus ride in Tübingen or on the unforgettable road trip from Maastricht back home, when she brought up the idea that was now turned into my Postdoc. Also, Katarina, thank you for great girls' nights, and (this goes also to you, Dominik Becker) for letting me stay in your apartment repeatedly. Thanks to both Katarina and Christoph Meng for opening doors when I found myself surrounded by walls. To Joyce, Mariëlle, Esther and the whole ROA secretary team: Dankjewel for your kind support and for helping me to get all the stamps and support I needed to move on with my research.

To the inspiring and truly great group of ROA colleagues (especially but not exclusively Alex, Inge, Ineke, Jessie, Kim, Lynn, Melline, Sanne, ...): Thank you for being such great colleagues and for out-of-work fun! You made my stays in Maastricht even more enjoyable. Lynn, thank you for letting me stay at your house repeatedly, and even more for friendship, support, and for the good times and discussions that we had in Maastricht and in Seoul together with Alex. Jim Allen, thank you for sharing your office with me, and even more for helping me find stories in data and analyses. Particularly, thank you for the debates that we had when I started at ROA in April 2017. Furthermore, I want to thank Jan Heisig for his inspiring teaching and helpful courses about PIAAC, jackknife procedures and multilevel modelling. Many thanks also to Jan Koucky for providing me with CEDEFOP OSP data that I needed for "The Future is Now". Moreover, thanks to the (anonymous) reviewers and the audiences in Bamberg, Konstanz, Mannheim, Paris, Seoul, Singapore, and Tübingen for suggestions and fruitful discussions. Particularly, I want to say vielen Dank to Karin Amos, Uwe Blien, Daniel Bubr, Michael Gebel, Henning Lohmann, Josef Schrader, Guido Schwerdt, Herman van de Werfhorst and Alexander Wiseman for valuable comments at the very beginning of the $\mathrm{PhD}$ process. Doing a $\mathrm{PhD}$ as external candidate while working as researcher and academic consultant on completely different projects $75 \%$ of my time was not an easy task. It was only possible because my boss, Claus Zanker, and my dear colleague, Ines Roth, provided me with the opportunity to shape my own ways of work with flexible working hours. What is next? Well, thanks to Mark Levels, Rolf van der Velden, Raymond Montizaan, Heike Solga, Kristin Bothur and several others I now can't wait to start working on the really big questions about future skills and societal consequences of AI and robotics together with the Horizon 2020 TECHNEQUALITY consortium. Related to this, vielen Dank to Sven Semet and Lothar Schröder for thinking along when it comes to turning academic knowledge into societal impact. 
Last but far from least, it is important to me to acknowledge that this $\mathrm{PhD}$ and the way $\mathrm{I}$ did it would never have been possible without great support from my husband, family, and friends. I want to thank my parents for so much more than I can say. Concerning the PhD, thank you for going with me through all this. For encouraging me to go on when I was about to give up. Thank you for accompanying me on the transition to Maastricht, and for enjoying the city as much as I do. I wish I could thank my grandma for leaving hope when she left. Herzlichen Dank also to my brother Simon for great support during the life events that took place besides the PhD. The same holds for my whole family, my parents in law (for housing and general life support), and for my friends. Particularly, I want to thank my circle of strong women: Friederike, Tanja, Magda, Amal, and Laura for everlasting company through good and bad. Thank you for proactively designing good situations in both life and work, withstanding strain, and for 100 origami diamonds. Special thanks to you, Friederike Bornträger, for more than one great speech, for all the postcards, and for helping me rise while keeping both feet on the ground - in the right pair of shoes. Finally, and from the very depth of my soul, I want to thank the man who always said "yes" to me and my life decisions. He was by my side no matter at which place or in which state of mind I was my husband Ralf, who was, is, and who will always be my perfect match. 

"When it comes to education and skills,

we have to believe in hiring for skills, not just degrees and diplomas,

and exploring new paradigms and pathways that don't all include college education but rather focus on the development of key skills."

Ginni Rometty 



\title{
Content
}

CHAPTER 1

\author{
THE SKILL MATCHING CHALLENGE \\ INTRODUCTION TO THE DISSERTATION
}

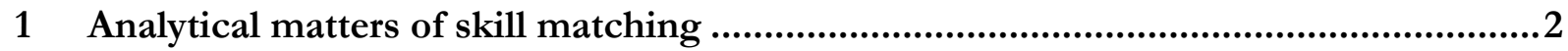

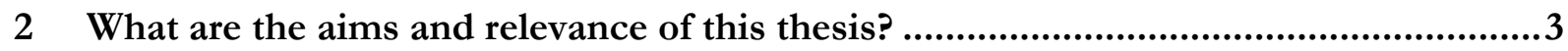

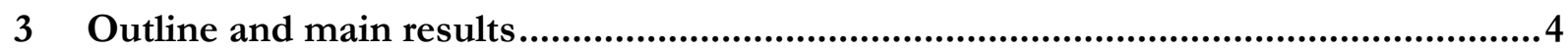

4 Positioning of the thesis in the literature: What is my contribution?............................8

4.1 Which gaps do I fill when it comes to explaining the likelihood that workers get a job that matches their skills? ............................................................................................... 8

4.2 Which gaps do I fill when it comes to explaining individual labour market outcomes

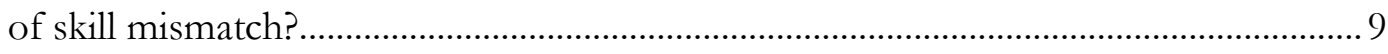

4.3 Which gaps do I fill when it comes to measuring worker-job matches?........................11

CHAPTER 2 SKILL-TO-JOB MATCHES

CONCEPTUAL FRAMEWORK OF AN INTERNATIONAL COMPARATIVE STUDY

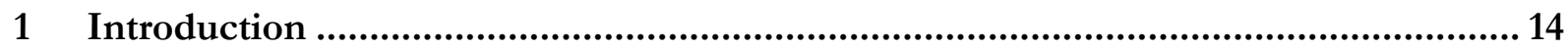

2 Skills and skill mismatch: Concepts, definitions, measurement ................................ 15

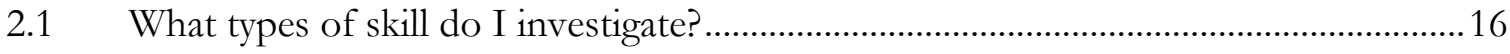

2.1.1 Is it enough to look at key information-processing skills when examining skill-to-job matches and outcomes?

2.1.2 Assessment domains in PIAAC: Defining numeracy, literacy, and digital problemsolving skills

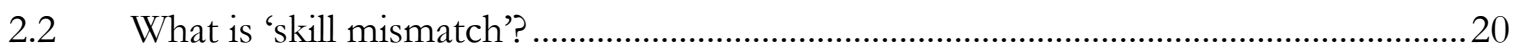

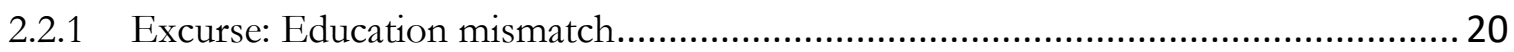

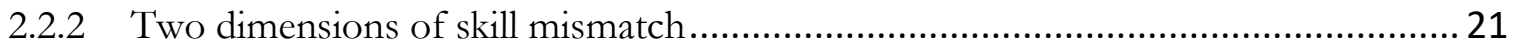

2.2.3 Measuring skill mismatch by level: Conceptual approaches .................................... 21

3 Skill mismatch research: Where did the literature start? Where are we now?.............24

3.1 The political economy of skill utilisation as opposed to skill formation ............................25 
3.2 Challenges for social policy

4 What causes skill-to-job matches? Theoretical explanations....................................22

4.1 State of the art: What do we know about determinants of skill mismatch? What not?

4.2 Policy-related determinants of skill-to-job matches............................................................22

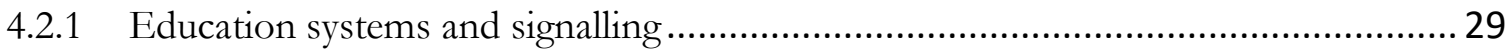

4.2.2 Labour market activation and employment policies ............................................. 30

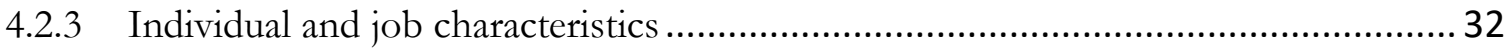

5 Skill mismatch and individual outcomes. Explanations and evidence .......................33

5.1 State of the art: What do we know about individual labour market outcomes?

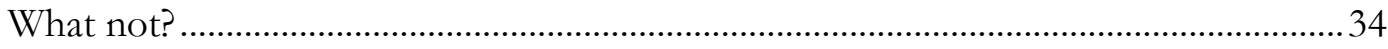

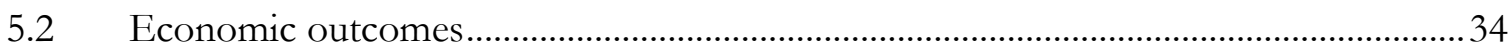

5.3 Non-monetary and potential social outcomes.................................................................. 35

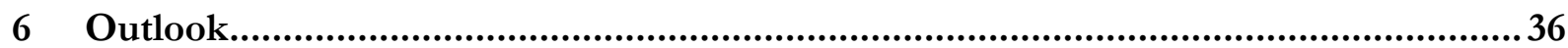

CHAPTER 3

SOCIAL POLICY AND THE CHALLENGE OF ALLOCATING
THE RIGHT PEOPLE TO THE RIGHT JOBS
EVIDENCE ON THE RELATION BETWEEN INSTITUTIONS
AND OPTIMAL SKILL MATCHING FROM 28 INDUSTRIAL
COUNTRIES

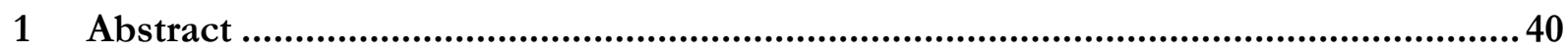

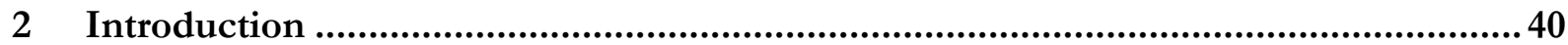

3 How is social policy related to optimal skill matching? - Theory and hypotheses .... 42

3.1 Vocational orientation and vocational specificity of education systems........................44

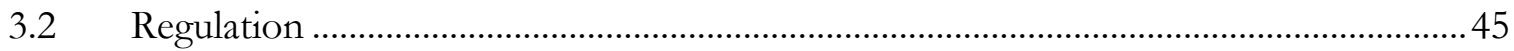

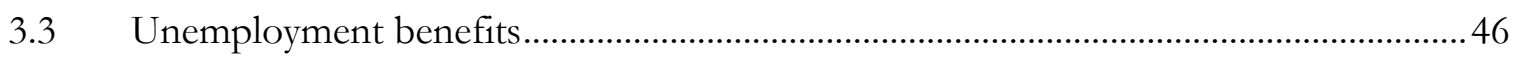

3.4 Services and Activating Labour Market Policies (ALMPs) .............................................. 46

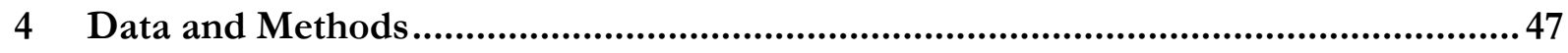

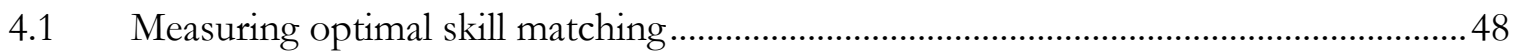

4.2 Measuring social policies............................................................................................... 50

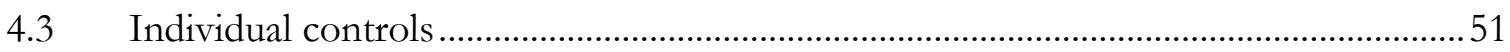


4.4 Analyses

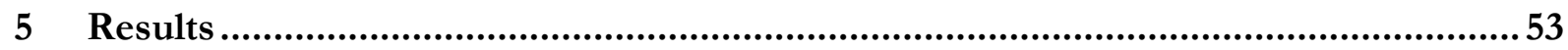

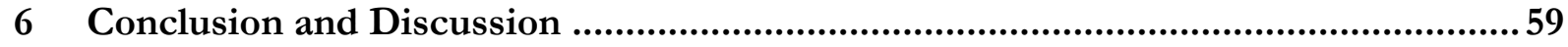

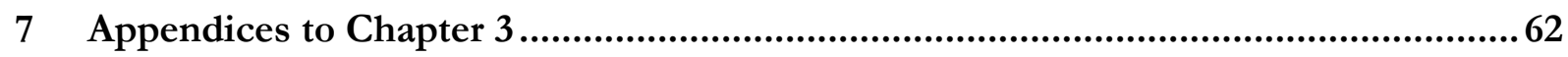

CHAPTER 4 MUCH ADO ABOUT NON-MONETARY OUTCOMES?

SKILLS, SKILL USE AND MISMATCHES AND THEIR RELATION

WITH JOB SATISFACTION AND POTENTIAL SOCIAL

OUTCOMES

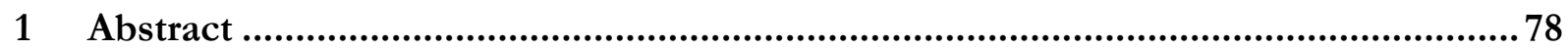

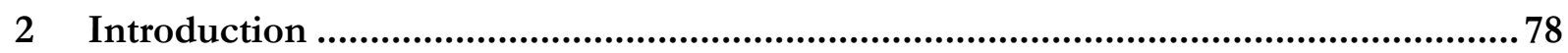

3 How do skills, skill use, and mismatches relate to non-monetary outcomes? ........... 80

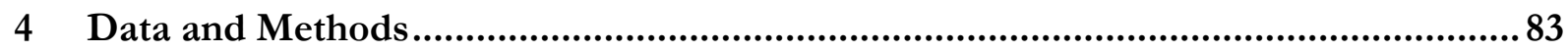

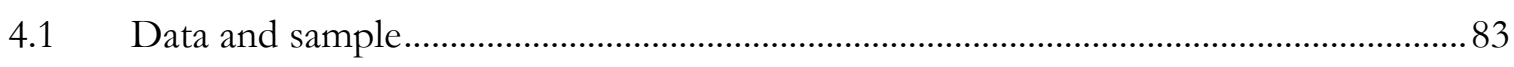

4.2 Skill mismatch, skill use and non-monetary outcomes....................................................... 84

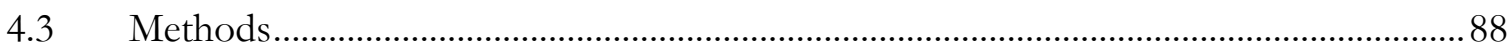

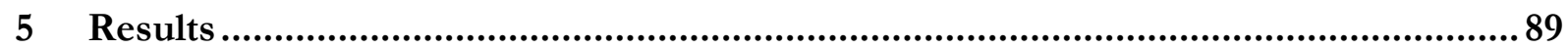

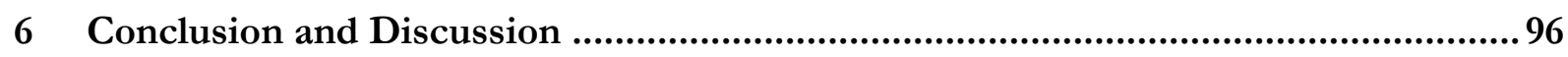

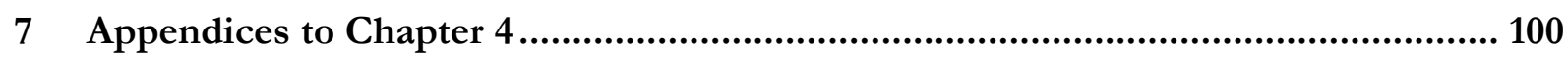

CHAPTER 5 THE FUTURE IS NOW

CROSS-COUNTRY EVIDENCE ON MISMATCHES IN DIGITAL PROBLEM-SOLVING SKILLS AND WAGE INEQUALITIES

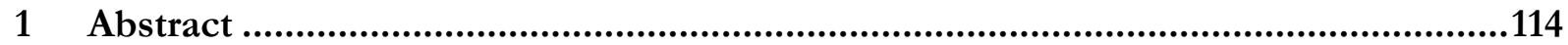

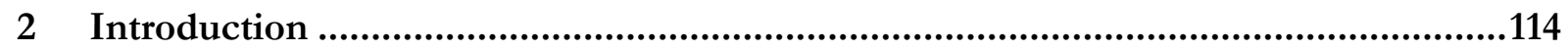

3 Theory: Mismatches in digital problem-solving skills and wages ...........................118

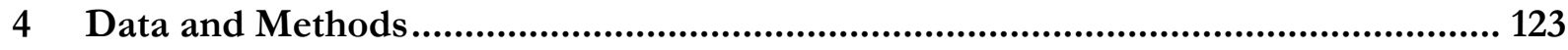

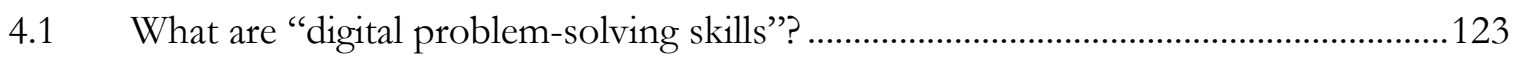

4.2 Measurement and operationalisation of theoretical concepts ......................................124

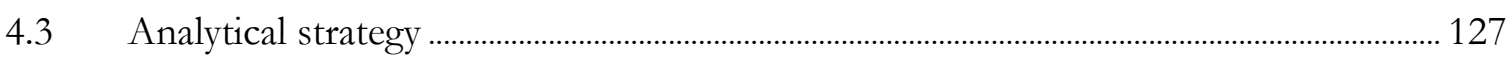




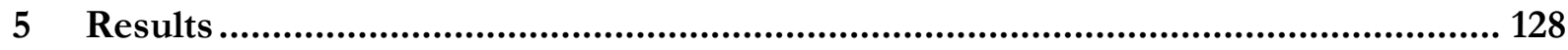

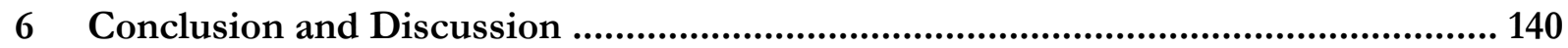

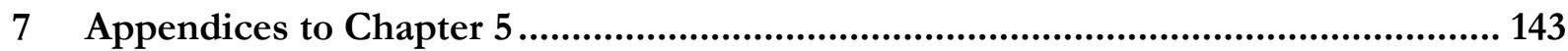

\section{CHAPTER 6 CONCLUSION AND DISCUSSION}

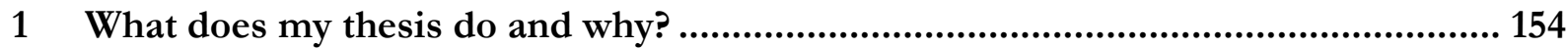

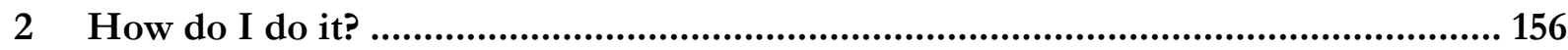

3 What does my research tell us that we did not know before?................................. 159

4 What are the value-added parts and main implications? .........................................161

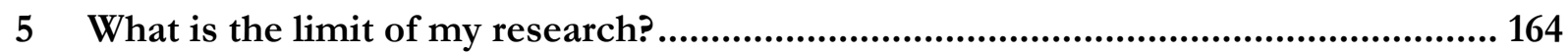

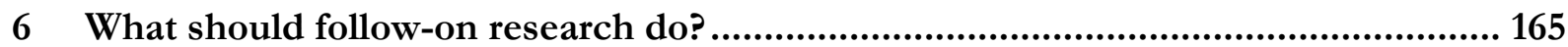

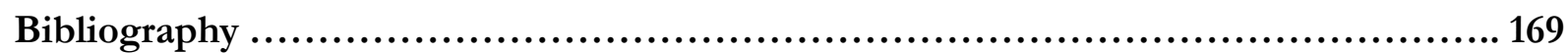

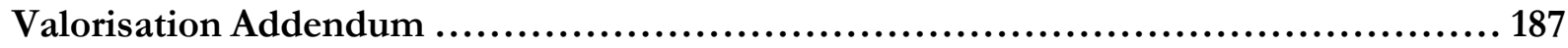

English Abstract ............................................................... 191

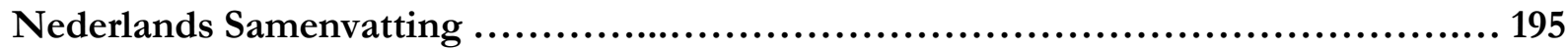

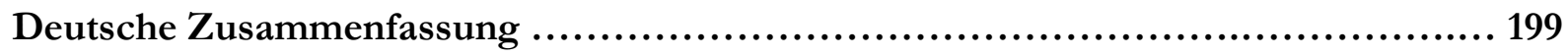

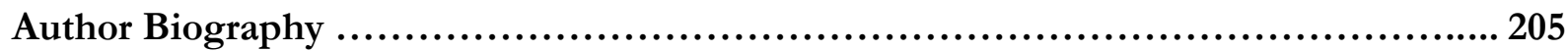

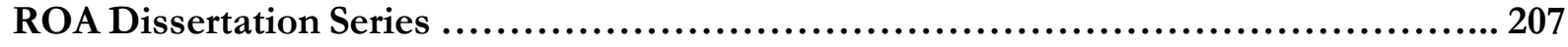




\section{Chapter 1}

The Skill Matching Challenge Introduction to the Dissertation 


\section{Analytical matters of skill matching}

The academic concern with skill has a long tradition. Across disciplines, researchers examined skills and related outcomes over the last decades. At the beginning of the $21^{\text {st }}$ century, skill formation and the idea of knowledge-based economies and societies was given priority ( $c f$. Buchanan, Finegold, Mayhew and Warhurst, 2017: 1). In recent years, research often addressed skill polarisation and the future of employment (e.g. Brynjolfsson and McAfee, 2014; Frey and Osborne, 2013; Holmes and Mayhew, 2012; Acemoglu and Autor, 2011; Goos and Manning, 2007). Against the background of technological developments and the mass-participation in higher education, the academic focus on skills tendentially shifted from skills formation to skills utilisation. To date, one of the major analytical concerns is the match between skills supply and changing labour market demands, that is: skill matching.

While automation has only had a moderate impact on the quantitative demand for work so far, it draws major consequences, profoundly and irreversibly transforming work and employment in a qualitative way (e.g. Gregory, Salomons and Zierahn, 2019; Frey and Osborne, 2017). However, that is not new. New technologies have always changed jobs. But with the implementation of artificial intelligence (AI), Robotic Process Automation (RPA) and industrial robots, the change in skill demands is enormous. Many jobs are affected, and the change is occurring fast. Some jobs disappear, new jobs we do not know yet will come into being, and many other jobs change (or will soon change) a lot. As a result, advanced market economies have generations of adults working, and their jobs are changing or demanding new or different skills. Structural changes in the economy in combination with organisational changes in production and service delivery processes induce a job specific skill obsolescence that is different from obsolescence stemming from actual ageing of skills and knowledge (Allen and van der Velden, 2002: 28). The physical and societal infrastructures of work and employment as well as education and training will have to change and adjust - but this has not sufficiently happened yet.

Against this background, skills utilisation and the match between skills supply and demand have become persistent matters of analytical concern (Buchanan et al., 2017: 11). However, the skill matching challenge is not a purely analytical matter. Governments across the world invest massively in supply-side policies to create more and better skilled workforces (Green, 2013: 4). The underlying idea is that firms benefit from higher-skilled (and thus more productive) workers, and so do industries and, in aggregate, economies and societies. For individuals, higher skills acquisitions provide higher incomes as well as a range of nonmonetary outcomes that are, in aggregate, also beneficial for societies (e.g. Grugulis, Holmes and Mayhew, 2017; McMahon, 2009). However, the potential to realise individual 
returns to skills has become a concern, as it can for example decline because the number of high-skilled individuals raises faster than the number of available jobs (e.g. Buchanan et al., 2017; Holmes and Mayhew, 2015). The concern is that workers are being upskilled with qualifications, while jobs are being deskilled through technology and management - or reskilled in terms of a new character of skills that are currently not (or too little) taught in education systems (Warhurst, Tilly and Gatta, 2017: 72; Braverman, 1974).

Although there is a large body of scientific literature, there is still a lot that we do not sufficiently understand about skill-to-job matching: How well are skills being deployed in paid work across countries? How can collective actors address the challenge of allocating the right people to the right jobs? And what if the individual skills supply does not meet the demands - how is skill mismatch related to labour market outcomes? Do skills, skill use, and mismatches have a broader impact on society, and are there potential social outcomes? And what about the technological changes that I outlined above - how do mismatches, and particularly shortages, in digital skills relate to individual labour market outcomes and how does this relation re-shape social inequalities? These major gaps remain in the understanding of basic questions surrounding skills, skill use, and the role of the individual agency as opposed to economic and structural forces (Green, 2013: 4). The challenges of the knowledge economy and changing demands for skills in times of digitalisation and automation require new insights into skill matching and outcomes in contemporary labour markets, and new cross-country evidence for the adult workforce (OECD, 2016a; Green, 2013). However, while these desiderata of knowledge are important to fill, linking theoretical concepts of skill-to-job matches to reliable and valid empirical indicators is still work in progress.

\section{What are the aims and relevance of this thesis?}

While research on skill formation and education-to-job matching has a longstanding tradition, academic interest in skill matching and skill utilisation is of more recent origin (Buchanan et al., 2017: 7; Green, 2013). This is, in part, based on the recognition that skills alone fail to deliver the anticipated economic and social improvements (Buchanan et al., 2017; Smith, 2017). Skills must be put to productive use (van der Velden and Bijlsma, 2018; Quintini, 2014). In Europe and beyond, the phenomenon of skill-to-job mismatch is found to be pervasive, widespread, and with significant consequences for individuals, labour markets and societies (Cedefop, 2018; Felstead, Gallie and Green, 2017; Livingstone, 2017; Green and Henseke, 2016; Flisi, Goglio, Meroni and Vera-Toscano, 2014; Levels, van der Velden and Allen, 2014b; Perry, Wiederhold and Ackermann-Piek, 2014; Allen, Levels and van der Velden, 2013; Green, 2013; Pellizzari and Fichen, 2013; Desjardins and Rubenson, 2011; 
Quintini, 2011; Cedefop, 2010; Allen and van der Velden, 2001 and others). Research has shown that with ever more breakthroughs in new technologies and further automation, the incidence of mismatch is more likely to increase than to improve (McKee-Ryan and Harvey, 2011: 963 cf. Livingstone, 2017: 295). The race between changing demands for, and supply of, skills provides a challenge when it comes to preventing increasing levels of social inequality in labour markets and in societies more generally (Green, 2013: 69). The academic interest in skills and mismatches rests, at least partly, upon the concern that skills are not only vital for the proper functioning of labour markets and economies, but also for societies and democracies (European Commission, 2016).

Against this background, my thesis seeks to contribute to a new and better understanding of theoretical explanations of worker-to-job matching processes. Moreover, I investigate the deployment of skills in advanced market economies and individual returns to skills. Based on empirical research, I provide explanations and cross-country evidence for both determinants and individual outcomes of skill-to-job (mis-)matches. Exploring the macromicro link between national social policies and individual matching processes, I give new insights concerning the relation between institutional characteristics of labour markets, social insurance schemes, education systems and optimal skill matching. To capture the impact of skills and mismatches, I furthermore investigate individual outcomes, taking into account non-monetary and social outcomes in addition to economic outcomes (Freeman, 1976; Green and Henseke, 2016; McMahon, 2009). Against the background of technologyinduced changes in work environments and skill demands, I furthermore examine the role of what I consider "future skills": digital problem-solving skills and their importance for wage inequalities. Using micro data for representative sample of the adult workforces of many countries, I investigate mismatches, and particularly shortages, in digital problemsolving skills and their relation with wage inequalities and group-specific returns to skills across countries.

\section{Dutline and main results}

The first part of my thesis is dedicated to the theoretical framework, providing details and background knowledge about all concepts, approaches, measures and arguments that are needed to conduct theory-based empirical research. The comprehensive theoretical framework is followed by a series of empirical chapters, the first one of which investigates macro-level determinants of optimal skill matching, whereas the other two explore individual labour market outcomes related to skill mismatches. My empirical research is based on high-quality micro data on objective assessments of individual skills and skill use 
at work for the adult workforces of 30 industrial countries ${ }^{1}$. Together, these countries represent around 75\% of the worldwide GDP (Falck, Heimisch and Wiederhold, 2016: 8). The data stem from the Adult Skill Survey from the OECD's Programme for the International Assessment of Adult Competencies (PIAAC; see OECD 2016a; 2016b), which was partly conducted in the years 2011/12 and partly in 2014/15. Using these data, my research covers representative samples of adults aged 16 to 65 years. I provide new cross-country evidence based on advanced statistical modelling. The following section provides a precise outline of my thesis, while Fig. 1 presents the overall story.

Figure l: Dutline of the thesis

\section{Chapter 2}

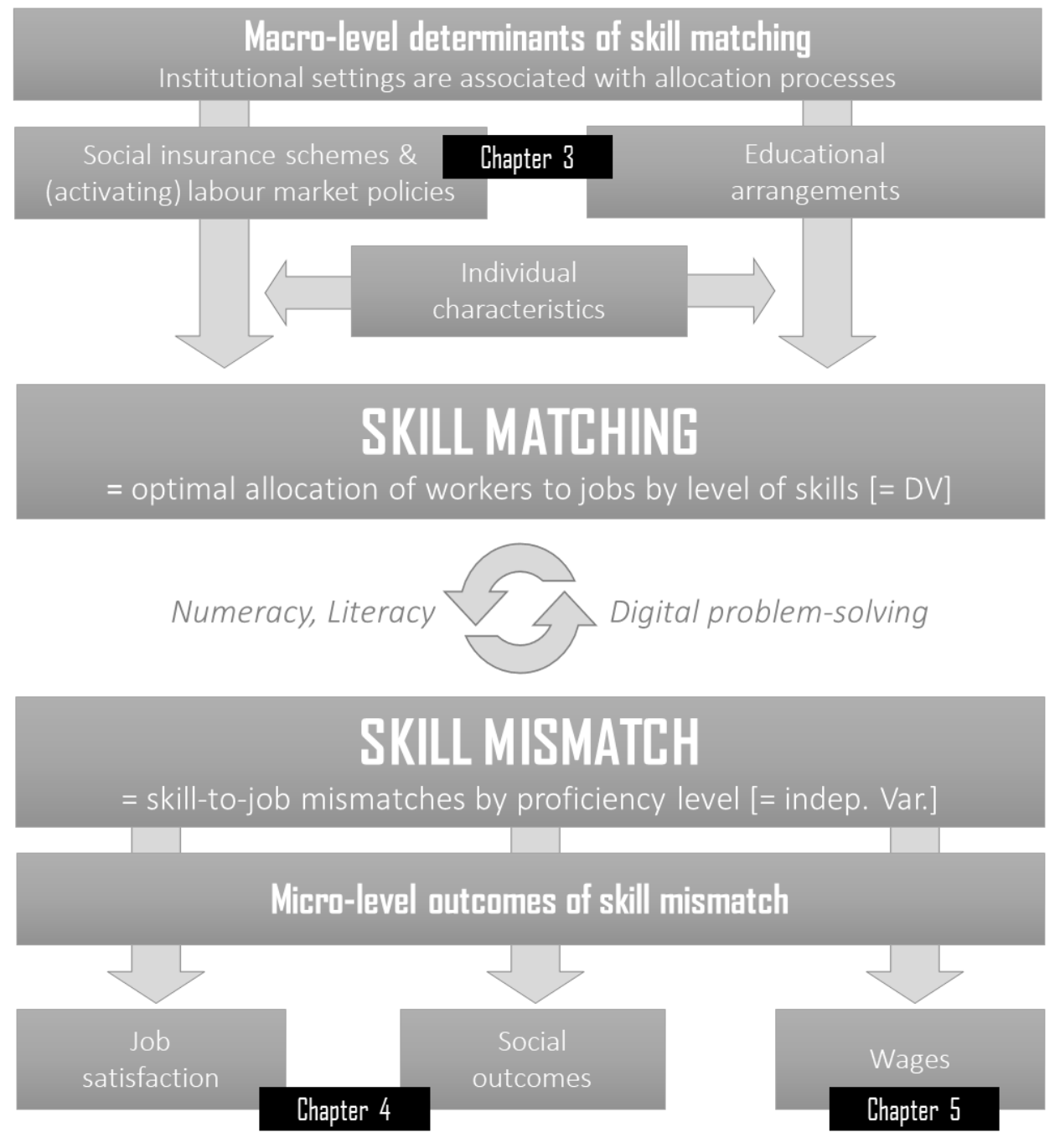

1 I use data from Austria, Belgium (Flanders), Canada, Chile, Cyprus, the Czech Republic, Denmark, Estonia, Finland, France, Germany, Greece, Ireland, Israel, Italy, Japan, South Korea, Lithuania, the Netherlands, New Zealand, Norway, Poland, Singapore, the Slovak Republic, Slovenia, Spain, Sweden, Turkey, the United Kingdom (England and Northern Ireland), and the United States. 
My research topic - 'skill matching' - is complex in its nature. The empirical research is complicated by a myriad of different conceptual approaches and measurement problems ("Measurement is always a troubling issue for skill analysts"; Green, 2013: 6). Therefore, I develop a broad and comprehensive theoretical framework, which I present in CHAPTER $\mathbf{Z}^{2}$. Here, I provide concepts, definitions and details on measurement. Moreover, I dig deeper into the political economy of skill utilisation as opposed to skill formation, developing theoretical explanations for potential determinants of individual skill-to-job matches and optimal matching. Thereafter, I outline theoretical notions about individual level outcomes related to skill mismatches, exploring both monetary and non-monetary outcomes. The three chapters that follow are based on (reviewed and revised) scientific articles.

CHAPTER 3 explores the relation between institutions and optimal skill matching, investigating social policies and the challenge of allocating the right people to the right jobs. With my co-authors, I investigate the extent to which job-worker matches are associated with vocational orientation and vocational specificity of school systems, employment protection legislation (EPL), unemployment benefits, and activating labour market policies. With a special focus on differences between labour market insiders and outsiders, I perform cross-country analyses for 28 industrial countries, merging microdata from the OECD's Programme for the Assessment of Adult Competencies (PIAAC) with appropriate macrolevel datasets. To operationalise the difference between enforcing and enabling activating policy measures, I make use of a unique composite policy indicator. There are two main findings: First, EPL is associated with more optimal matching. This is a strong finding that survived all robustness checks. A possible explanation is that the regulation of the firing process is also relevant when it comes to hiring. Second, my analyses show that the use of indicators other than those usually tested is enlightening: I provide cross-country evidence that strict enforcement does not lead countries into the right direction when it comes to optimal skill matching.

Concerning individual outcomes of skill mismatch, evidence merely exists for wages. But work characteristics such as occupational self-direction may also affect orientations and values, relating to social outcomes, even outside the work environment. Are the concerns about a broader impact of mismatches 'much ado about nothing'? CHAPTER 4 provides answers to this question, investigating skill use and mismatches and their relation with job satisfaction and social outcomes such as general trust in other people and the individual perception of one's own political efficacy. Applying a new conceptual approach to measure skill mismatch - the 'effective skill' concept as developed by van der Velden and Bijlsma

\footnotetext{
${ }^{2}$ This chapter is partly based on previous work (see Fregin, 2017).
} 
(2018) - I highlight the importance of skill use at work, disentangling skill use and skill proficiency, and shedding new light on old findings. The analyses show that, once I use objective indicators for the skill match (and I make use of all measures that are currently available), there is no relation between overskilling and job satisfaction. In fact, job satisfaction is driven by skill use, not by proficiency or mismatches. The second message that the analyses provide evidence for is that skill mismatch is associated with outcomes in civic life. Workers that fully exploit their skills are more likely to approve trust in others and to have a positive perception of political efficacy. Even outside the work environment, skill use and mismatches are "much ado about something".

CHAPTER $\mathbf{5}$ is dedicated to changing skills requirements of jobs and the recognition of the notion that digital problem-solving skills are key skills for everybody in the $21^{\text {st }}$ century. These skills ensure that workers remain both productive in labour markets and included in societies. While increasing automation is thought to further exacerbate the importance of digital problem-solving skills, evidence suggests that shortages in these skills are widespread. However, not much is known yet about individual skill-to-job matches, and particularly shortages, in digital problem-solving skills and their relation with wages and social inequalities. How does the digital skills divide translate into group-specific returns to skills? Will wage inequalities related to gender, age, migration background, socio-economic status (SES) and educational achievement be exacerbated or reduced? A thorough assessment of social inequalities related to digital problem-solving skills is the main gap in the literature. Systematically assessing skill-to-job matches and wage inequalities, I set out to narrow that gap. Drawing on PIAAC micro data for 26 countries, I build a skill matching model to show that skill-to-job matches in digital problem-solving skills matter for wages: shortages are damaging, while a skills surplus is profitable. However, digital problemsolving skills re-shape wage inequalities with the potential to serve as emancipatory lever, narrowing the divide between socio-economic status groups. These key skills may also help to reduce the gender wage gap, as high levels of digital problem-solving skills appear to pay off more for women than for men.

To sum up, CHAPTER $\mathbf{6}$ provides an overall conclusion and comprehensive discussion, highlighting the most relevant findings as well as their (policy) implications while evaluating limitations of my analyses and providing recommendations for further research. 


\section{Positioning of the thesis in the literature: What is my contribution?}

My thesis relates to different fields of study. In fact, the topical context and issues associated with studying determinants and outcomes of skill-to-job matches are of cross-disciplinary nature, combining research from sociology, economics, political economy and social psychology. Generally, there are three overarching questions in skill (mis-)match research:

(1) How can skill (mis-)match be explained?

(2) What are the outcomes?

(3) How can we adequately measure skill mismatch and related outcomes?

Providing new cross-country evidence, my thesis gives new insights concerning all three questions. Overall, my three empirical chapters address both, macro level determinants and individual outcomes.

\section{I Which gaps da / fill when it cames to explaining the likelihoud that warkers get a job that matches their skills?}

Social policies and their effects have been studied for a range of individual labour market outcomes (e.g. Barbieri, Cutuli and Passaretta, 2018; Ochsenfeld, 2018; Giesselmann, 2012; Noelke, 2011). CHAPTER $\mathbf{3}$ investigates how social policies relate to optimal skill matching, examining potential macro-level determinants of individual skill-to-job matches. This chapter is the first to empirically test the relation between institutional characteristics of labour markets and education systems, and skill matching at the individual level. My research advances the literature in three main ways: First, the analyses examine the extent to which cross-country variance in optimal matching can be explained by country characteristics. As such, my research is descriptively important, providing a solid basis for analyses of the causal impact of the various policies on worker-to-job skills matches. Second, using high-quality and internationally harmonised individual skills assessments, the focus on optimal skill matching seeks to advance the existing literature on education-to-job matches (see e.g. Levels et al., 2014b). Third, I test institutional features other than those usually tested by using composite indicators that capture enforcement and enablement (Knotz, 2012). Disentangling different shades of activating labour market policies that characterise todays' social policy mix of industrialised societies provides a deeper understanding of macro-micro links and underlying mechanisms. Furthermore, I take into account individual and job characteristics in all analyses, showing that the macro-micro link is important despite the relevance of micro-level determinants. Moreover, it is a comparative advantage to use micro data in research that is very much related to political 
economy. This has not been done often before, as political scientists usually make use of macro data. Exploring the macro-micro link in the context of policy analyses is in itself something special in this field.

\subsection{Which gaps da / fill when it cames to explaining individual labaur market autcames af skill mismatch?}

Concerning individual outcomes of skill-to-job matches, previous research (see e.g. van der Velden and Bijlsma, 2018; Hanushek, Schwerdt, Wiederhold, Woessmann, 2015b; Levels, van der Velden and Allen, 2014b; Perry, Wiederhold and Ackermann-Piek, 2014; Pellizzari and Fichen, 2013; Leuven, Oosterbeek and van Ophem, 2004; Allen and van der Velden, 2001; Groot and Maassen van den Brink, 2000; Hartog, 2000; Duncan and Hoffman, 1981) predominantly focussed on wages. Previous studies often used educational credentials instead of skills measures to proxy human capital and worker-to-job matches, and often did not seek to disentangle the effects of skill proficiency itself from skill use as dimension of working life. Previous research is also often based on a subjective evaluation of the skill-tojob match instead of objective measures of the skill match. Moreover, previous research largely ignored externalities and potential social outcomes; often focussed on numeracy and literacy skills; and merely lacks a systematic examination of inequalities between social groups. Within the different chapters of my thesis, I seek to address all these limitations.

CHAPTER 4 investigates non-monetary outcomes of skill-based worker-to-job matches, applying a new measure for the skill-to-job match. This chapter advances the literature with (1) new insights into old findings concerning job satisfaction, (2) with the creation of new knowledge concerning social outcomes and potential externalities of skill use and skill mismatch, and (3) with the adaption of a new skill mismatch measure - the 'effective skill' concept by van der Velden and Bijlsma (2018). This concept allows me and my co-authors to differentiate the effects of skill proficiency and skill use. In chapter 4, I deploy the 'effective skill' concept to show that skill mismatches are not related to job satisfaction. With this message, I contradict previous findings. There are two major reasons: First, former studies claiming that skill mismatches negatively affect job satisfaction, are usually not based on objective assessments of the skill match. As the Survey of Adult Skill from the OECD's Programme for the International Assessment of Adult Competencies (PIAAC; see OECD 2016a-c) is the only dataset that provides objective information about skill proficiency and skill use for many countries, previous studies often had to rely on worker self-assessments of the skill match. However, job satisfaction, too, is a subjective indicator, and subjective indicators always correlate. If I measure mismatches subjectively, I, too, find the same negative correlation. However, the correlation between different subjective indicators is endogenous. It does not tell us much about the effect of 'real', objective over- and 
underskilling. The second reason lies in the model specification: Generally, it is the combination of skill supply and demand that determines individual labour market outcomes. Evidence suggests that returns to education and skill-to-job (mis-)matches are therefore best explained by matching models (see e.g. van der Velden and Bijlsma, 2018; Groot and Maassen van den Brink, 2000; Hartog, 2000; Duncan and Hoffman, 1981). Previous studies often do not appropriately control for the use of skills in jobs and skill requirements of jobs. By contrast, my thesis deploys a theory-driven model specification. All models include a component of skill use and build on the logic of the classical Overeducation-Required education-Undereducation (ORU) model by Duncan and Hoffman (1981), which allows for an adequate assessment of returns to surplus skills and skill shortages.

Applying matching theories, chapter 4 furthermore shows that skill use and skill mismatch are related to non-monetary and potential social outcomes. Therewith, the chapter addresses a topic of public, academic and political concern that has been identified as missing in the discourse on skill mismatch. The link, however, is established in the literature. Research on the relation between work characteristics and values dates back to the seminal work of Kohn (1977), who shows that occupational experience and job characteristics, such as occupational self-direction, have a considerable impact upon worker's values and orientations (also see Warr and Inceoglu, 2018; Green and Henseke, 2016). Accordingly, occupational conditions conducive to the exercise of self-direction (as evident e.g. through an effective exploitation of skills) are empirically related to having orientations to self and to the outside world consonant with this value of self-direction (Kohn and Schooler, 1983: 54). My study is the first to pick up this classical line of theoretical reasoning. Combining theoretical notions with new data as provided by PIAAC, I show that both skill use and skill mismatch are related to social trust as well as to the individual perception of political efficacy.

CHAPTER 5 addresses recent challenges concerning technology-induced changes in job tasks and skills requirements of jobs. Recent breakthroughs in ever more advanced technologies are thought to further exacerbate changes in skill requirements and the importance of digital problem-solving skills at work and in daily life. But social groups are unequally equipped with the skills and knowledge needed to deal with those profound and irreversible changes. The concern is that mismatches, and particularly shortages, in digital problem-solving skills are exacerbating existing and generating new social inequalities. Most empirical studies on returns to computer skills have important limitations. Thereby, a thorough assessment of inequalities between social groups is the main gap in the literature. Systematically examining wage inequalities and their relation with digital problem-solving skills, this chapter narrows 
that gap. Merging PIAAC micro data with information on the importance of digital skills as provided by CEDEFOP's Occupational Skills Profiles (OSP) and O*NET, I develop a skill matching model to show that a lack of digital problem-solving skills has detrimental consequences for present wages. More precisely, I provide empirical evidence for differential returns to skills, showing how digital problem-solving skills can explain wage inequalities between social groups, even controlling for individual differences in skill proficiency. I advance the literature with the provision of cross-country evidence for representative samples of adult workforces of a large number of countries, and a thorough assessment of group-specific returns to skills.

Digital problem-solving skills provide a largely new field of study, particularly in inequality research. This chapter is the first to systematically assess social inequalities in returns to digital problem-solving skills and penalties related to shortages, systematically assessing differences between social groups across countries. I provide details concerning inequalities between men and women, younger and older workers, migrants and natives as well as socioeconomic status (SES) and educational attainment groups. The most important finding is that digital problem-solving skills seem to (re-)shape group-specific wage inequalities - with the potential to narrow e.g. the divide between SES groups. I find that an investment in high levels of digital problem-solving skills pays off more for workers with a lower SES than for the higher SES group, and for low and medium educated workers more than for graduates. This leads to the - tentative - conclusion that digital problem-solving skills could serve as potential emancipatory lever, narrowing wage gaps between SES groups. These key skills may also help to reduce the gender wage gap, as high levels of digital problem-solving skills appear to pay off more for women than for men. The ubiquitous availability of information and communication technology (ICT) induces specific forms of tasks that demand information-processing and digital problem-solving in multiple situations both at work and in social and civic life, leading to a situation in which digital problem-solving is considered a key skill for everybody (OECD, 2016d). My study contributes to a deeper understanding of the key skill that allows people to deal with those technology-induced changes and labour market outcomes. With my findings, I provide new knowledge that can be of high importance when it comes to developing policy measures, tackling social inequalities in changing labour market environments.

\subsection{Which gaps da / fill when it cames to measuring warker-job matches?}

My research is based on the Survey of Adult Skills from the OECD's Programme for the International Assessment of Adult Competencies (PIAAC). This is a unique dataset that provides high-quality micro data and objective measurements. PIAAC allows for an international comparison of representative samples of the adult workforces of a large 
number of countries. Moreover, PIAAC is the first dataset to assess digital problem-solving skills with objective skill use measure and in an internationally harmonised way. Using these data, my research provides two contributions to the state of the art, the first one of which is the application of a new skill mismatch measure. So far, the 'effective skill' concept by van der Velden and Bijlsma (2018) has only been applied to economic outcomes. Deploying the new theoretical perspective to assess non-monetary outcomes related to skill mismatches is very enlightening. Concerning job satisfaction, the adaption of the effective skill measure provided us with the out-of-the-box perspective that is necessary to understand the relation between skill matches (and skill use) and job satisfaction and to pinpoint the underlying mechanism. Comparing effective skill with alternative skill mismatch measures, I show that the van der Velden/Bijlsma-measure is theoretically sound, at least as good as previous skill mismatch measures, and furthermore valid for social outcomes. The second way in which this chapter advances the state of the art is the broader evidence of the importance of theory-driven model specifications, adapting renowned matching models to assess outcomes of skill mismatches. 


\section{Chapter 2}

\section{Skill-to-Jab Matches Conceptual Framework of an International Comparative Study ${ }^{3}$}

\footnotetext{
${ }^{3}$ This chapter is based on an article that was published in Schmid, J., Amos, K., Schrader, J., and Thiel, A. (eds.) (2017): Governance und Interdependen₹ von Bildung - Internationale Studien und Vergleiche [Governance and Interdependencies of Education - International Studies and Comparisons], Baden-Baden: Nomos. The text has been largely changed and updated to accommodate as chapter of the dissertation.
} 


\section{Introduction}

The increasing impact of computer-based technologies implies a measurable change in the composition of job tasks and in our everyday life (Autor and Price, 2013). The half-life of knowledge decreases and makes lifelong learning of new skills a necessity for workers of all education groups and in all fields. Economic and technological developments also bring the need for new skills. If skills are put to productive use, they can generate economic as well as non-monetary returns. However, if the individual skill supply does not match the skill demand of the workplace, i.e. if there is a skill mismatch, skills fail to produce the expected returns (Quintini, 2014). Reducing skill mismatch could, therefore, emerge as a new channel, through which effective policies could contribute to a higher productivity, reduce social and labour market inequalities, and enhance individual well-being at the same time (McGowan and Andrews, 2015b: 3; OECD, 2016a). Thus, the issue of skill mismatch has gained importance as a topic of scientific, but also political and social relevance. However, skill matching remains a major challenge - for collective agents as well as for individuals. From a macro-level perspective, skill mismatch may lead to a slower adaptation to the technological progress and thus decelerate economic progress (Perry et al., 2014). From a micro-level perspective, skill-to-job mismatches affect a range of economic and non-monetary outcomes. As skill mismatches may have a broad impact on outcomes both in work and daily life, the concern is that skill mismatches can exacerbate existing and generate new social inequalities.

Regarding the micro-level, existing evidence suggests that skill mismatch may cause a depreciation of skills and negatively affect earnings as well as job satisfaction (e.g. Hanushek and Woessmann, 2015; Salthouse, 2006; Allen and van der Velden, 2001). In addition to education certificates (Spence, 1973), skills turn out to be important as predictors of economic prosperity and individual economic success (Allmendinger and Leibfried, 2005: 52; Hanushek, Schwerdt, Wiederhold and Woessmann, 2015b). Therefore, putting the existing skills to effective use is a major challenge for today's and future economies. National governments need to develop policies that match the supply of skills to demand, also in the new context of rapidly changing demands. My thesis investigates how social policies that are in place already, shaping allocation processes, affect skill matching. I examine skill-to-job matches both as dependent and independent variable, using highquality proficiency and skill use measures to explain phenomena such as wage inequality, job satisfaction, social trust and the individual perception of one's political efficacy. Before I dig deeper into theoretical mechanisms, outlining explanations and considerations about individual outcomes, I should first clarify what I mean by 'skills' and 'skill mismatch'. 


\section{Skills and skill mismatch: Concepts, definitions, measurement}

In the context of manufacturing industries, 'skill' had a precise meaning (Martin, $2017 \mathrm{cf}$. Buchanan et al., 2017: 4). However, the meaning has widened massively since then. Firstly, due to the growth of the service economy, and secondly, due to changes in the character of competencies that are demanded in digitalised economies and so-called "new collar work". Trends like the increasing implementation of information and communication technology (ICT), increasing globalisation and uncertainty, changes of the economic structure, knowledge-based economies, and the increasing availability of high-performance workplaces changed the skills set that workers are expected to have (Humburg and van der Velden, 2017: 201; Allen and van der Velden, 2013). Accordingly, definitions of 'skill' widened to include soft skills and employability skills that were, at least partly, formerly thought of as personal characteristics (Buchanan et al., 2017: 4-5; Martin, 2017). Given the complexity of the topic, measurement has always been a troubling issue for skills analysts (Green, 2013: 6). Since the 1960s there have been a range of views in academic debates about how to define and measure skills (Smith, 2017: 491). Following human capital theory, it was (and still is) assumed that with schooling and work experience individuals will increase their ability to carry out particular activities. When deployed at work, this enhanced human capital makes workers more productive and hence increases the economy's output of goods and services (Livingstone, 2017).

In the early days of research on the education-earnings nexus, years of schooling were widely used to proxy human capital. Later, as more and better data became available, qualifications (i.e. formal certificates and educational credentials) became a more common metric (Buchanan et al., 2017: 6). As considerable variance exists between competencies of workers with the same educational level, formal qualifications are a partial and often poor indicator of workers' capabilities (Buchanan et al., 2017; Livingstone, 2017; Flisi, Goglio, Meroni et al., 2016; Heisig and Solga, 2014; Levels, van der Velden, Allen, 2014b). Therefore, large scale competency-assessments provide the best available data sources for analyses of skills and skill use. In the 1990s the release of International Adult Literacy Survey (IALS) and the Adult Literacy and Lifeskills Survey (ALL) paved the way for high-quality and direct measures of skills. The Survey of Adult Skills by the OECD's Programme for the International Assessment of Adult Competencies (PIAAC; see OECD 2016a; 2016b) provides detailed information on the actual skills of adult workers in many countries. The survey provides opportunities to measure and investigate both skills and mismatches in key information-processing skills required both at work and in daily life. Still, empirical research on the topic demands a clear and pragmatic definition of the term 'skill'. 


\section{I What types of skill do / investigate?}

Generally, skills are defined as "personal qualities that can produce value at work, are expandable, and are socially determined" (Green, 2013: 25). Following this definition, training and education can enhance skills with a focus on productive activity at work. The concept differentiates several skill domains, all related to thinking activities and managing information: literacy, numeracy, and high-level competencies such as problem-solving, decision making in information-rich settings or the use of ICT. Generally, any set of competencies deemed pertinent to the conduct of work could be identified as relevant skills: the use of internet; efficient use of time, performance under pressure, rapidly acquiring new knowledge, writing reports, solving problems, presenting to an audience, and analytical thinking mastery (Allen and van der Velden 2009: 56 ff. Livingstone 2017: 281).

In recent literature, skill is discussed both as a quality (what it is, how one develops or uses it) and a quantity (high-skilled versus low-skilled or calculations of the costs of skill acquisition or economic returns to skills; Bryson, 2017). A common characteristic of definitions is that skill is instrumental, shaped in the context of its use, and serving people in individual, social and economic life (e.g. Green, 2013; OECD, 2016a). However, the use of the term 'skill' is by no means universally shared. For the purpose of this thesis, I investigate information-processing skills, deploying the use-oriented, functional definition of skill (or competency ${ }^{4}$ ) that is provided by the OECD's Programme for the International Assessment of Adult Competencies (PIAAC; see OECD, 2016a-c; Rammstedt, 2013). For the Survey of Adult Skills, PIAAC defines skills as "the ability to apply knowledge and use know-how to complete tasks and solve problems" (OECD 2016a: 102). The survey measures a set of so-called 'key skills', i.e. skills that are considered to be crucial for a successful participation in the labour market as well as in civic life (OECD, 2016a: 96). More precisely, the skills assessed in PIAAC are perceived as "key information-processing competencies", defined as "general" skills in the sense of being relevant to the entire workforce as well as across all fields of adults' social and civic activities. The theoretical and empirical analyses performed for this thesis refer to such cognitive and technical skills, i.e. key skills as assessed in PIAAC. More precisely, I investigate numeracy, literacy, and digital problem-solving as key information-processing skills.

\footnotetext{
${ }^{4}$ In this thesis as well as more general in the context of the OECD Programme for the International Assessment of Adult Competencies (PIAAC), the terms 'skill' and 'competency' are used largely interchangeably: "Both terms refer to the ability or capacity of an agent to act appropriately in a given situation. Both involve the application of knowledge (explicit and/or tacit), the use of tools, cognitive and practical strategies and routines, and both imply beliefs, dispositions and values (e.g. attitudes)" (OECD, 2016a: 17, Box 1.1).
} 


\section{I.I Is it enough to look at key information-processing skills when examining skill-to-job matches and outcomes?}

The OECD Survey of Adult Skills (PIAAC) assesses the proficiency and skill use of adults in three information-processing skills that are crucial for the full participation in the knowledge-based economies and societies of the $21^{\text {st }}$ century: literacy, numeracy and problem solving in technology-rich environments, which I refer to as digital problemsolving skills ${ }^{5}$ (OECD, 2016a: 16). These skills are sometimes mistaken as basic, low-level competencies. However, "literacy" does not primarily measure the ability of adults to read or write but captures the derivation and processing of information; "numeracy" is more than the individual ability to conduct simple arithmetical operations; and "digital problemsolving" is more than routine computer skills as it involves workers' endowment of capabilities to use strategies (and develop the mindset) needed to interact with databases, navigate through digital interfaces, the use of networks to acquire or process information and perform practical tasks as well as digital communication (Acemoglu and Autor, 2011: 1045; PIAAC Expert Group, 2009).

It is exactly these types of skills that will become ever more important in changing labour markets and digital economies and societies. The skill domains measured in PIAAC capture the general cognitive ability to grasp meaning and relevant new information which the respondents did not have before (OECD, 2016a). This new information can be presented in words, sentences, different types of texts - or in numerical sense as in the case of numerical literacy (which is referred to as "numeracy"). The assessment domains in PIAAC capture "key skills" that can be deployed at all proficiency levels from very basic to very complex. However, what are "key skills"? To start with, skill (or competency, which is used interchangeably in the context of PIAAC) is the "capacity to generate appropriate performance: to marshal the resources (tools, knowledge, techniques) in a social context (which involves interacting with others, understanding expectations) to realise a goal that is appropriate to the context" (OECD, 2016a: 96). In short, skill is the application of knowledge and abilities in common life situation. Literacy, numeracy and digital problem-solving are considered "key skills", related to information-processing in all kinds of context.

\footnotetext{
${ }^{5}$ This shorthand contains the two components of the PIAAC framework for these types of skills: Technology-rich environments and problem-solving skills (PIAAC Expert Group, 2009).
} 
Key skills share several common features as they are:

- necessary for fully integrating and participating in the labour market, education and training, and social and civic life,

- highly transferable and relevant to multiple situations at work and in daily life,

- "general" in the sense that key skills are relevant to all individuals,

- "learnable" and, therefore, subject to the influence of policy (OECD, 2016a: 16 and 96).

Key skills are thinking skills related to managing information in all types of situations as opposed to specific skills that are of relevance in specific types of activities or certain occupations only. PIAAC, as well as most other key competency frameworks, puts the focus on generating performance that is appropriate to context (OECD, 2016a: 98). Given this, is it enough to "just" look at key skills when investigating skill matching and outcomes across countries? Yes. Numeracy and literacy are more than the school subjects language and maths but are key to process information that is presented in textual or numerical sense and needed to generate performance in multiple situations in work and civic life. The ubiquitous availability of IC technology leads to a situation, in which digital skills are thought to be key skills for everybody (OECD, 2016d). Key information-processing skills capture something close to fluid ability, which is also the reason why literacy and numeracy are highly correlated in PIAAC. Information processing is the base for many tasks that people encounter in multiple contexts at work and in daily life and forms the basis for all further development of mastery and, consequently, serve as measure of cognitive competencies needed for the $21^{\text {st }}$ century. It can serve as proxy for the general ability of an individual to acquire more specific skills. However, while the importance of "specific" skills is not denied, they are intentionally defined to be outside the scope of the competency framework that is deployed in PIAAC and in this thesis (OECD 2016a: 97). 


\subsubsection{Assessment damains in PIAAC: Defining numeracy, literacy, and digital problem- solving skills}

As this thesis makes use of all assessment domains in PIAAC, the following Table 1 provides detailed definitions of the three skill domains.

Table l: Definitions of the assessment domains in PIAAC

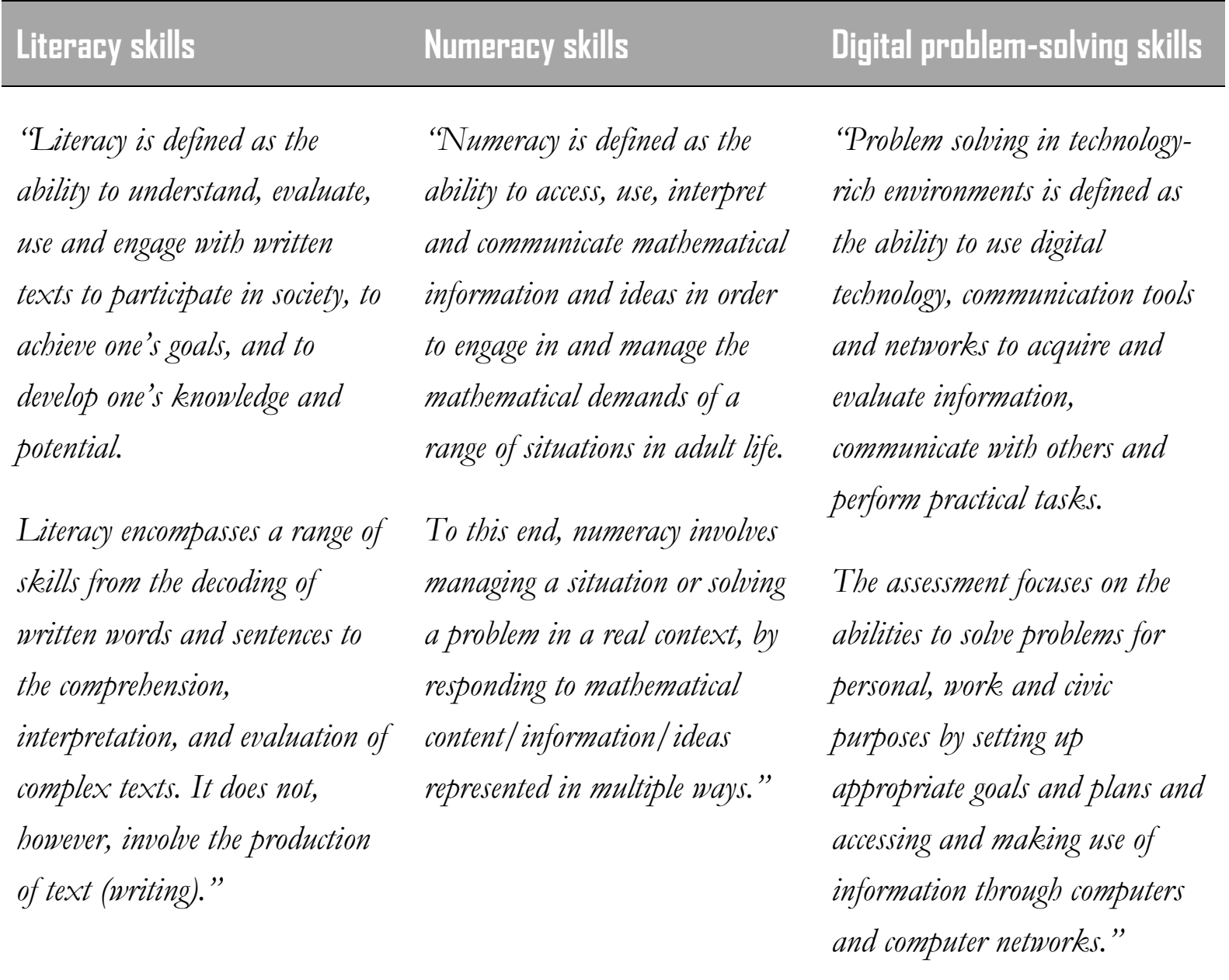

Source: OECD (2016a: 18) 


\subsection{What is 'skill mismatch'?}

Previous research has shown that while the above mentioned information-processing skills are key for a successful participation in contemporary labour markets as well as social inclusion, a significant discrepancy exists between workers' proficiency in these skills and the level required for their jobs (see e.g. Cedefop, 2018; van der Velden and Bijlsma, 2018; Felstead et al., 2017; Livingstone, 2017; Flisi et al., 2016; Allen, Levels and van der Velden, 2013; Green, 2013; Pellizzari and Fichen, 2013; Desjardins and Rubenson, 2011; Allen and van der Velden, 2001). This phenomenon is referred to as 'skill mismatch'. Generally, skillbased conceptions of the discrepancy between skills, education and knowledge that workers might bring to their job in comparison to what is needed for the job have many names. The phenomenon has been called under-utilisation (e.g. Allen et al., 2013), under-employment (e.g. Green and Henseke, 2016), over-qualification (e.g. Hartog, 2000) and several other terms. For a long time, education mismatch was the most common way to conceptualise skillto-job mismatches. Therefore, the next paragraph provides a brief excurse to education mismatch. Afterwards, I give details on the conceptualisation of the phenomenon of skill mismatch.

\subsection{Excurse: Education mismatch}

EDUCATION MISMATCH captures a situation in which workers have a formal educational attainment that is higher or lower than the level required by their job. If the formal qualification is higher, workers are defined as overqualified or overeducated; if the opposite is the case, workers are classified as underqualified or undereducated. The notion to measure education mismatch objectively was introduced by Freeman in the year 1976. Some years later, in 1981, Duncan and Hofmann specifically examined the "incidence and wage effects of overeducation", building a matching theory that, until today, is successfully applied to provide evidence on economic consequences of (mis-)matches. Building on the Duncan and Hofmann (1981) matching model, Oosterbeek (2000) was the first to present a measure for overqualification in a Mincer regression. Asking respondents directly, modern surveys such as PIAAC differentiate between the qualification that "if applying today, someone would usually need to get the job" and the required qualification level to "do the job satisfactorily" (see e.g. PIAAC Background Questionnaire). Educational credentials are often used as a proxy for individual's skills. Yet, there are serious doubts about the validity of this measure, as more education does not necessarily translate into more skills (e.g. Flisi et al., 2016). Although education mismatch and skill mismatch eventually overlap, they are, in fact, two distinct phenomena (Flisi et al., 2016: 3). In fact, previous research has shown that skills heterogeneity contributes considerably to the explanation of educational 
mismatch (Levels, van der Velden, and Allen, 2014b). Moreover, a considerable part of the effect of educational mismatches can be attributed to skills heterogeneity (ibid.). Direct and objective measurements of skills can take into account training and any form of informal education and learning. Compared to educational credentials, objective skills assessments are the broader and more dynamic picture of an individual's competencies and are considered the superior and more valid approach to measure individual competencies and qualifications (Flisi et al., 2016: 2). The academic debate thereby distinguishes two dimensions of skill-to-job mismatches: horizontal and vertical mismatches ${ }^{6}$.

\subsubsection{Two dimensions of skill mismatch}

HORIZONTAL SKILL MISMATCH is a horizontal form of misallocation that arises when workers are wellmatched in terms of level of education but employed in a job that requires different skills form those they have specialised. To assess this type of mismatch, analysts usually make use of a detailed list of occupations (e.g. at 3-digit ISCO classification level) to consider whether a workers' job is a good match (OECD, 2016b; Wolbers, 2003). By contrast, VERTICAL SKILL MISMATCH, refers to an upward or downward mismatch by level of skills. Such mismatches arise when workers have a significantly higher or lower skills proficiency than required by their jobs. Addressing the vertical dimension of skill-to-job matches by level in the empirical parts of this thesis, I consider workers that possess significantly more skills than actually needed at the workplace overskilled, whereas I regard workers with significantly fewer skills than required to be underskilled.

\subsubsection{Measuring skill mismatch by level: Conceptual approaches}

Every type of mismatch can be measured with several different approaches (for details see e.g. van der Velden and Bijlsma, 2018; Flisi et al., 2016; OECD, 2016c; Perry at al., 2014; Quintini, 2011). Although every approach has its advantages and problems, the measures partly measure qualitatively different things, which implies they are not interchangeable. This section outlines the most common (and one newly developed) conceptual approaches to measure skill mismatches by level.

Empirically, skill-to-job matching is measured by comparing a worker's individual skill proficiency to the skill level required for his or her job (e.g. Desjardins and Rubenson, 2011). This, however, poses challenges to sociological research and related academic disciplines, as no consensus exists on how to capture the mismatch phenomenon and what

\footnotetext{
${ }^{6}$ The horizontal form of education mismatch is called field-of-study mismatch (see e.g. Sellami, Verhaest, and van Trier, 2018; Verhaest, Sellami, and van der Velden, 2017). However, this concept is not relevant to the thesis and therefore not outlined further.
} 
constitutes an adequate indicator. Irrespective of the concrete operationalisation, every concept of skill mismatch requires measures of both skills possessed (available e.g. in surveys such as PIAAC) and skills required at the workplace. As the latter is not available in surveys that focus on the supply side rather than the demand side, several approaches have been developed to proxy skills requirements. Generally, surveys ask workers directly about their personal assessment of the skill match (subjective approach: worker self-assessment), compare a workers' skills to the country-specific average skill level in their occupation (statistical approacb: realised matches), take the relative use of skills at work as a proxy for the required skills proficiency (job requirement approach) or use task description to assess skill levels for each proficiency based on a systematic collection of expert opinions (job analyst method). The following section briefly introduces all four commonly used conceptual approaches.

\section{Worker Self-Assessment Approach (WSA)}

The 'Worker Self-Assessment' approach, asks workers directly whether their skills meet or exceed the required skills or whether they would need further training in order to cope with present duties. The subjective gap addresses the extent to which job holders' personal assessment of their skills exceed actual job requirements (Livingstone, 2017: 285). Although this approach is easy to implement in surveys, it bears several problems. The most pressing one being the lack of an objective anchor (see Allen and van der Velden, 2005). It is, therefore, prone to measurement error and the risk of social bias. In surveys such as PIAAC, the issue of "talking up one's own job" has been addressed by focusing on activities and using time frequency scales instead of importance or skill level. Still, neither problem has been solved completely. Despite its drawbacks, subjective matching research gained currency in the 1960s when fears were expressed that growing numbers of highly educated graduates who could not find commensurate employment would become increasingly dissatisfied and rebellious (Livingstone, 2017: 287). Subjective mismatch indicators display e.g. the feel of need for more training, which might cause stress, regardless of the objective match-situation. Therefore, we might expect that a substantial part of subjective indicators such as job satisfaction and general well-being can be explained by subjective mismatch indicators. There are, however, serious doubts about the validity of subjective measurements as proxy for 'real' mismatches (see Allen and van der Velden, 2005). Recent studies therefore often combine the subjective approach with either job analysts' estimates or worker self-assessments of education levels required for the job or additionally use a statistical method based on mean level of education held by workers in given occupations (van der Velden and Bijlsma, 2018; Livingstone, 2017). 


\section{Statistical approach (Realised Matches, RM)}

The 'Realised Matches' approach is a commonly used statistical skill mismatch measure that captures the deviation of the individual skill proficiency from the average proficiency in each occupation in each country (van der Velden and Bijlsma, 2018; Flisi et al., 2016; Perry, Wiederhold, and Ackermann-Piek, 2014; Pellizzari and Fichen, 2013). Usually, the mean or median skills proficiency level of each occupation (e.g. the International Standard Classification of Occupations (ISCO) two-or three-digit level) serves as a proxy for the required skills. A mismatch is perceived if the skill proficiency level of an individual lies significantly above or below the average skill level. The RM approach defines a worker as overskilled or underskilled if the worker has a skill proficiency level of-usually-one standard deviation above or below that occupation-specific level (e.g. Perry et al., 2014). The cut-off point of 1 standard deviation is usually used as it captures approximately the distance between two proficiency levels in PIAAC (OECD, 2016a; 2016b).

The RM approach was deployed in different versions (e.g. by Pellizzari and Fichen, 2013; Perry et al., 2014). Generally, with the RM approach, reference is always made to the average level of skills of other workers in the same occupation in the same country, which is why the use of this approach is not without problems. The main theoretical issue that arises is the forced equilibrium where, by definition, the 'average' worker is defined as well-matched, although this is questionable. A statistical problem derives from the fact that occupations are very heterogeneous, containing occupations that might differ substantially regarding their skill requirements. Some scholars regard the use of the RM as inferior to other methods (Leuven and Oosterbeek, 2011: 293). The main reason for this is that the realised match is the result of demand and supply forces and does not only reflect requirements. Moreover, like the method based on job analysis, it does not adequately capture variation in required schooling across different jobs within the same occupation.

\section{Jab requirement approach (JRA)}

The 'Job Requirement Approach' takes the relative use of skills at work as a proxy for the required skills proficiency. The major developmental work was done by Green and colleagues for the British Skills Survey and PIAAC (see e.g. Green, 2013). The JRA has been used and adapted e.g. by Allen, Levels and van der Velden (2013), whereby the relative use of skill is compared to the individual proficiency level, which serves as anchor - by contrast to the RM approach, the JRA captures more something like an "intra-worker" mismatch. Workers are classified as over-/under-using their skills if there is a significant discrepancy between their skill use (e.g. 50 scale points in PIAAC, which equals one skill level) than what would be predicted on the basis of the individuals' objective skill level. The approach uses and combines data gathered through survey questions such as "In your job 
bow often do you use a calculator - either hand-beld or computer based?" (see PIAAC Background Questionnaire). One problem with the JRA is that the use of skills is not necessarily a good predictor for skill requirements of jobs. Another problem arises with the assumption that proficiency and skill use are different forces. As skill use also reflects skill proficiency, it is not necessarily a good proxy for skill requirements of jobs. However, there is no simple way to address this problem, since we lack direct information on skill requirements from employers.

\section{Jab analyst method}

The job analyst method would provide a good way to address the outlined disadvantages of the mentioned skill mismatch approaches. The job analyst approach uses task descriptions to assess skill levels for each occupation, obtaining expert opinions on the required skill level in each three- or four-digit ISCO occupation category (Fleisher and Tsacoumis, 2018). For this method, job experts would need to assess required skill levels, using the same scale metric as the possessed skills are measured in. This would allow a directly comparison of the two. While the job analyst method is regarded as the gold standard, it has so far only been used for identifying educational mismatches (Hartog, 2000). One drawback of this method is that the assessment is sometimes not up to date and/or based on descriptions that date back. However, unfortunately neither the necessary information about task descriptions nor the respective expert assessment exists for the skill domains I am interested in for my thesis: numeracy, literacy and digital problem-solving.

\section{Skill mismatch research: Where did the literature start? Where are we naw?}

Starting in the 1960s with Gary S. Becker and Jacob Mincer, researchers analysed the relation between qualification and productivity based on human capital theory. Empirical studies usually conceptualise job-worker matching by measuring education-to-job matches (e.g. Boll, Leppin, Rossen and Wolf, 2016; Flisi et al., 2016; Verhaest and Verhofstadt, 2016; Vossemer and Schuck, 2016; Levels, van der Velden and di Stasio, 2014a; Gangl, 2004; Büchel, de Grip and Mertens, 2004; Sloane, 2003; Allen and van der Velden, 2001; Groot and Maassen van den Brink, 2000; Oosterbeek, 2000; Hartog, 2000). When it comes to measuring returns to mismatches, the study by Duncan and Hofmann (1981) is particularly important as the authors, for the first time, examined the "incidence and wage effects of overeducation" (Duncan and Hoffmann, 1981), building a matching theory that has since then been successfully replicated all over the world (Groot and Maassen van den Brink, 2000; Hartog, 2000 and multiple others; for details see empirical chapters 4 and 5). Until 
today, research on occupational mismatches makes use of the Duncan and Hoffman-logic to build skill matching models and measure labour market outcomes (e.g. van der Velden and Bijlsma, 2018; Levels, van der Velden and Allen, 2014b).

Research based on large scale competency-assessments can show that mismatches between the skills that workers possess and what is required by the workplace are increasing (e.g. Felstead, Gallie, and Green, 2017; European Commission, 2013; Green, 2013; Verhaest and van der Velden, 2013). Evidence suggests that the consequences may be increasing as well (Green and Zhu, 2010), particularly if workers are trapped in a job for which they are overqualified (Vossemer and Schuck, 2016). No less than $40 \%$ of all EU employers said in 2013 that they have difficulty finding workers with matching skills when recruiting (Cedefop, 2018: 5). Recent debates on work, education and inequality have brought greater attention to job skill requirements and skill matching than ever before (Handel, 2017: 92). Thereby, optimal skill utilisation is a general principle on which most collective and individual agents can agree: "Where skill potential is untapped there is a failure of fulfilment for workers and a failure of effective production for society as a whole" (Warhurst and Findlay, 2012). Investigating both macro-level determinants and micro-level outcomes related to skill-to-job matches, my thesis provides insights into the political economy of skill use, which I outline in the next section.

\section{I The political ecanomy of skill utilisation as apposed to skill formation}

The political economy of skill examines the range of institutions and collective agents of contemporary market economies (and particularly varieties of capitalism) in relation to skill formation, utilisation and value (Bryson, 2017: 20). Examining skill matching and skill use, my empirical research broadens that focus, acknowledging that institutional factors not only shape the type and level of skills that people acquire but also have an impact on the extent to which skills are being used productively in labour markets (hence "political economy of skill utilisation"). When employers and potential employees get together during allocation processes, matching is the result of economic processes of resource allocation but also socio-political processes (Green, 2013: 117; Gebel, 2017). Governments have wide effects on the demand and on the supply side (Green, 2013; Gangl, 2004). While education policies regulate skill acquisition, labour market policies influence the way in which employers reward and use skills (e.g. Hanushek et al., 2015b). However, the analytical discourse of skill mismatch (e.g. Perry et al., 2014; Allen et al., 2013) lacks explanation, especially regarding institutional and political factors. To fill this hiatus, the comparative empirical analyses in chapter 3, whose conceptual framework I present in this section, seek to follow a tradition of research on social inequality with a focus on institutional conditions set by the state as framework for individual life courses (Mayer and Müller, 1986). I address the relationship 
between central education and labour market policy measures and the incidence of skill mismatch (in its vertical dimension regarding over- and underskilling) in an international comparison of industrial countries. The empirical study follows the idea that heterogeneous national regimes differentiate the relationships between capital and labour, as a result of which divergences in economic and social outcomes persist - even in a world that is increasingly integrated by financial, trade and production relations (Green, 2013: 153). The general working hypothesis for this chapter is that differences in skill matching between countries relate to differences in political frameworks that affect allocation processes and occupational closure. As basis for the international comparison, I take into account the Varieties of Capitalism (VoC) approach by Hall and Soskice (2001), which is primarily a typology of different production regimes characterized by distinctive configurations of product market strategies and governance mechanisms, as well as skill (and skill formation) regimes. The basic distinction is between 'coordinated' and 'liberal' market economies. Thereby, coordinated market economies, like Germany, pursue a strategy of high quality and innovative production that relies heavily on workers' specific skills (e.g. Eichhorst and Marx, 2011). Under this regime, both employers and employees have strong incentives to establish long-lasting relationships. In liberal market economies like the US or Great Britain, by contrast, labour market turnover is higher due to production strategies that rely more on general skills, which are transferable between firms, occupations, and even industries. This makes a job loss less costly and goes along with lower levels of employment protection. Estévez-Abe, Iversen and Soskice (2001) draw on the VoC approach to explain country differences in social protection and their consequences for skill formation systems. Based on a political economy perspective on the nation state, the authors provide evidence that skill formation is closely linked to social protection (Estévez-Abe et al., 2001: 174). The authors explain differences between countries regarding the specificity of education systems by identifying distinct skill formation regimes, which they link to specific social policy measures and systems of social protection. The basic argument put forward is that social protection influences the propensity of individuals to invest in certain skills, which, in turn, determines the skills profile of an economy. The authors call this the "welfare-skill formation nexus" (Estévez-Abe et al., 2001: 147 et seq.). In chapter 3, I follow a similar approach, adapting the argumentation to skill utilisation rather than skill formation. Nevertheless, skill systems and modes of state involvement form a crucial part of the theoretical model. Following Green (2013: 151), I define a skill system as "a set of institutions for the production of skills and mechanisms for the articulation of the demand for and supplies of skilled labour". A skill system thereby comprises skill formation institutions (education systems and further vocational training) as well as institutions affecting allocation processes and the matching of the supply of skilled work with the 
demand (Green, 2013). This refers to institutions that, for example, influence the nature and supply of available qualifications (specific characteristics of education systems) or affect the incentives and opportunities for individuals to access education and professional training (e.g. activation measures). Furthermore, relevant institutions are those that intervene directly or indirectly in the process of matching workers with jobs (Gebel, 2017). These institutions complement each other's functions and can therefore be called a 'system' (Gebel, 2017: 152). As these skill systems belong to broader institutional regimes of capitalism, a 'welfare-skill system nexus' exists. However, is there also a 'welfare-skill match nexus'? Investigating determinants of a successful allocation of workers to jobs based on skills, the most demanding conceptual and empirical challenge is to understand the macromicro link of how environmental and individual factors interactively affect allocation processes (Allmendinger, 1989: 231).

\subsection{Challenges for social policy}

Changing demands for skills and skill mismatches pose major challenges for education policies and labour market policies. Education and employment policies provide incentives, restrictions and possibilities and therefore shape individual choices. While education policies shape educational attainment and individual skills, labour market policies address the interplay between supply of, and demand for, work. Welfare regimes (i.e. redistribution regimes) seek to support a good match between the supply of and the demand for skills and qualifications. However, while production systems change rapidly, redistribution regimes are path dependent and rather sluggish and therefore lag behind. Understanding skill mismatch as an inefficient allocation of workers to jobs, I assume that the deficit is not only based on market failure solely, but on a malfunction of welfare arrangements. Evidence suggests that cross-country differences in skill mismatch are associated with differences in the environment concerning labour market policies, social insurance schemes, and the institutional setup of education systems (Levels, van der Velden, and Di Stasio, 2014a; Levels, van der Velden, and Allen, 2014b; Green, 2013; van der Velden and Wolbers, 2003). Together, labour market policy and education policy provide the key infrastructure: labour market policies affect the allocation process, and different education regimes affect the kind of skills that are rewarded and used on the labour market (Schmid and Buhr, 2015; Schmid, 2010; Barbieri, 2009; Gangl, 2006; 2004; Estévez-Abe et al., 2001).

\section{What causes skill-to-job matches? Theoretical explanations}

In chapter 3, I put forward a theoretical model based on institutional differences in skill systems and deduce hypotheses that link the occurrence optimal matching (i.e. when the 
workers with the highest skills are allocated to the jobs with the highest skill requirements etc.; see chapter 3) with institutional divergences in skill systems. Beyond the literature on social stratification, I consider approaches on the effects of individual resources (based on human capital theory). Evidence suggests that skill matches (and mismatches) are shaped by two key factors: i) individual and job characteristics; and ii) policy variables that shape the allocation of workers to jobs. I focus on the relation between political factors and the incidence of optimal matching, controlling for individual and job characteristics.

\section{I State of the art: What da we knaw about determinants of skill mismatch? What not?}

Cross-country variation suggests that job-worker skills matches may also be related with institutional factors that shape the allocation of workers to job (Flisi et al., 2016; Levels, van der Velden, and di Stasio, 2014a; Levels, van der Velden, and Allen, 2014b; Green, 2013; van der Velden and Wolbers, 2003). The deployment of skills (and, thereby, the allocation of 'the right people to the right jobs') has increased the need to study the relation between social policies and skill utilisation as new outcome that, although not primarily targeted by social policies, can be affected. Theoretically, labour market policies (Gangl 2006; 2004) and educational arrangements (Levels et al., 2014a) seem to be particularly relevant. Against the background of changes in the economic structure and an increasing importance of lifelong learning, labour market arrangements (and especially unemployment benefit schemes) have been largely reconfigured during the last decades. This paradigm shift is referred to as 'activation turn' and was accompanied by deregulation and increasing flexibility (e.g. Eichhorst and Marx, 2011; Bonoli, 2010; Dingeldey, 2007; Gilbert, 2002). Activating labour market policies are crucial when it comes to countries' abilities to adjust to changes in economies, labour markets and skills demands. Nevertheless, the literature largely ignored skill utilisation and skill matching as potential outcome of policy changes. The same is true for social insurance schemes. Estévez-Abe, Iversen and Soskice (2001) draw on the varieties of capitalism approach to explain country differences in social protection and their consequences for skill formation systems. The impact on skill matching has not been investigated so far.

Generally, studies examining determinants of skill-to-job matches focus on individual and/or job characteristics. Previous research has for example shown that skill (mis-)match varies across age groups with young people being more likely to be overskilled in many countries (e.g. OECD 2016a; Allen, Levels, and van der Velden, 2013b). Skill mismatch was also shown to be more widespread among workers with a migration background (Perry, 2017; Seibert and Solga, 2005). Related to this, studies show that returns to skills are lower for migrants (e.g. Hanushek et al., 2015b). Last, the likelihood of having a job that matches the skills may also differ between educational levels (e.g. Heisig and Solga, 2017; Levels et 
al., 2014b). By contrast, not much is known about macro-micro links and the relevance of structural forces as opposed to individual characteristics (Green, 2013). In the section that follows, I point out some details on policy-related environmental factors before I extend the argument to individual characteristics.

\subsection{Palicy-related determinants of skill-to-jab matches}

I outlined the working hypothesis that differences in optimal skill matching between countries relate to differences in political frameworks that affect allocation processes and occupational closure. Taking into account that politico-institutional factors interact with structures of employment systems and therefore affect the relationship between individual resources and attainment (Gangl, 2004; Busemeyer and Thelen, 2015), my thesis considers theoretical notions of two policy fields: education policies and labour market policies. I use country-level indicators to operationalise two concepts that form the key elements of the theoretical framework: signalling and re-commodification. I first introduce characteristics of education systems that might affect the incidence of skill-to-job matches at the supply side of skills, and, thereafter, present considerations concerning the importance of labour market and employment policies.

\subsection{Education systems and signalling}

Educational attainment strongly determines individual labour market outcomes (Lavrijsen and Nicaise, 2012; Wolbers, 2003 and others). As educational attainment is shaped by the opportunities and restraints offered by the system, it cannot be treated as a purely individual characteristic (Allmendinger, 1989). Education systems for their part can be characterized by means of three key dimensions that address signalling (e.g. Bol and van de Werfhorst, 2012; Lavrijsen and Nicaise, 2012; Gross, 1998; Allmendinger, 1989):

(1) The degree of standardisation, which refers to the nation-wide conformity between qualifications, curricula etc.

(2) The degree of stratification (tracking), referring to the extent to which education takes place in distinct educational trajectories (Lavrijsen and Nicaise, 2012; Shavit and Müller, $1998)^{7}$

(3) The degree of vocational orientation, referring to the extent to which an education system provides vocational training programmes.

\footnotetext{
${ }^{7}$ Other authors, e.g. Gross (1998), seem to use the expressions 'stratification' and 'vertical differentiation' synonymously.
} 
The 'degree of standardisation' captures "the degree to which the quality of education meets the same standards nationwide" (Allmendinger, 1989: 233). Standardisation is achieved by institutions such as the use of central exams or uniform curricula. It is also related to the extent to which teachers get the same training or e.g. standardised budgets for all schools (Bol and van de Werfhorst, 2012: 7 et seq.). The 'degree of stratification', which is often also referred to as 'tracking' (e.g. Allmendinger, 1989) or 'level of external differentiation' (Bol and van de Werfhorst, 2012: 5). Indices of stratification are frequently used in larger- $\mathrm{N}$ comparative studies and inequality research. It captures the level of differentiation of students with different levels of scholastic ability, i.e. the existence of separate educational programmes at the same time point in an educational trajectory (Bol and van de Werfhorst, 2012: 5). For the topic of this thesis - skill matching - the 'degree of vocational orientation' is of particular relevance. Related to horizontal differentiation and skill-based worker-job matches, the socalled vocational orientation of an education system is a central characteristic, driving allocation processes. Vocational orientation captures the percentage of people enrolled in vocational training programmes (Bol and van de Werfhorst, 2012; also see Wolbers, 2003). The vocational segment of education systems is particularly relevant for allocation processes, as graduates with mainly general skills need more training on the job, whereas graduates from vocational programmes are directly productive once they take up a job (Verhaest, Lavrijsen, van Trier, Nicaise, and Omey, 2018). This makes allocating these students less risky for employers (Levels et al., 2014a; Wolbers, 2003). Within the vocational labour market, this argument holds even stronger for those who are trained in dual systems (captured by the term 'vocational specificity' of an education system), as dual systems directly create the demanded skills (Bol, Ciocca Eller, van de Werfhorst, and DiPrete, 2019; Bol and van de Werfhorst, 2012). The more supply there is that exactly fits the demands, the higher the match rate should be.

\subsubsection{Labour market activation and employment policies}

Welfare states as systems of social stratification try to reduce social inequality through different channels, the most important ones being (financial) transfers, services and regulation. With reference to globalisation and new demands for skills, social and labour market policies have fundamentally changed the institutional framework of employment during the last decades. Various welfare programs such as unemployment protection underwent major reforms in many advanced countries during recent decades (e.g. the combination of 'enablement' and 'enforcement', as evidenced, for example, in Germany with the Hartz IV reforms; see Giesselmann, 2012). While governments use cutbacks in financial transfers as straightforward way of improving the sustainability of social insurance schemes, preventive policies such as lifelong learning and enablement turn out to be a core 
area of reform programs in many countries. Regarding labour market reforms, the "activation" of the low-skilled, (long-term) unemployed, older workers and e.g. mothers are among the top priorities. National governments seek to pursue this goal through a combination of rights and responsibilities and a new balancing of enabling and enforcing measures in labour market policy (Dingeldey, 2011, 2007; Knotz, 2012; Eichhorst, 2007). Thereby, 'enforcing' reforms seek to tighten readiness-to-work requirements and suitability criteria. This comes along with cuts in the level of, access to, and duration of financial benefits (Knotz, 2012). On the other hand, 'enabling' reforms include the expansion of active labour market policies and services such as training measures, policies facilitating the compatibility of paid and care work, as well as wage subsidies. Based on a model of an active (or: activating) labour market policy, workers gain labour market security primarily through employability and life-long learning.

The policy framework of labour markets has changed towards a more liberal configuration (Gilbert, 2002), traditional welfare policies aiming at decommodification by means of financial transfers (Dingeldey, 2007). Several attempts of deregulation and increasing flexibility accompany this paradigm shift. At the heart of these developments is the activating labour market policy (ALMP): "It is understood to involve a mix of the enforcement of labour market participation, the conditioning of rights and growing obligations of the individual at one side, and an increase of services in order to promote employability and restore social equity at the other" (Dingeldey, 2007: 823). Universal legal entitlements to standardised social benefits are replaced by individualised services and transfers based on certain conditions to individual behaviour. I assume that activation measures and the degree of commodification force people to accept a job, even if it does not match their competencies and allow them to make the most of their potential. Thereby, activation and flexibilisation are entangled policy measures: At the macro level, flexibilisation measures (also referred to as deregulation) reconfigure the structures of job supply and adapt them to the needs of globalised markets and new production strategies. Due to the enforcement of labour market participation of the individual, activation measures force integration into the new structures. From a microlevel perspective, the conditioning of social rights and growing obligations increases the impact of market forces and reinforces economic self-reliance and risks (Giesselmann, 2012: 112). Furthermore, research has shown that these measures exert their effects particularly at the margins of the labour markets (Eichhorst and Marx, 2011). ALMPs and re-commodification measures seem to exacerbate rather than reduce mismatch and related labour market risks, which can be considered an unintended consequence of social investments. However, the extent to which workers are affected by social insurance schemes and related policies depends on country-specific macro characteristics 
(Giesselmann, 2012). Thereby, measures might be the same across countries, but they are implemented in different institutional settings at the national level.

Another element of employment policy, which relates to flexibilisation and has a major impact on labour market outcomes, is employment protection legislation (EPL) (e.g. Noelke, 2011; Wolbers, 2007). While EPL was relatively strict at the end of the 1980s, an easing of regulation has been taking place since then: "The overall strictness of EPL continues to vary widely between countries and the regulation of temporary employment remains the key element in explaining cross-country differences" (OECD, 2004: 63). There is a common understanding in the literature that employment protection policies favour insiders on the labour market, leading to a situation in which particularly young workers are confronted disproportionally with adverse labour market situations and related risks (Ochsenfeld, 2018; Giesselmann, 2012; De Vreyer et al., 2000; Lindbeck, and Snower, 1988). Particularly less restrictive EPL could also be associated with higher mismatch, not only amongst young entrants to the labour markets. The higher the protection against dismissal, the higher the firing costs for employer. The higher the costs, the more will employers ensure that their employees match their jobs, i.e. higher EPL is associated with lower skill mismatch (and, hence, more optimal matching). I assume that measures of re-commodification related to activation policies have a major impact on skill matching as they emphasize the impact of market forces. Furthermore, I hypothesize that unemployment protection relates to skill mismatch. Unemployment protection has two components: i) height of replacement ratio and ii) duration of benefits. A generous unemployment protection might allow workers to turn down a job that does not match their competencies. A longer benefit duration permits the unemployed enough time to find a job that matches their qualifications and skills. Therefore, I expect a low unemployment protection to rise skill mismatch and decelerate optimal matching.

\subsubsection{Individual and job characteristics}

There have been relatively few consistent findings on social background factors related to skill matching (Livingstone, 2017: 292). Previous research has shown that skill mismatch varies across age groups, with young people being more likely to be overskilled in many countries (e.g. OECD, 2016a; Allen, Levels, van der Velden, 2013b). As young workers lack experience and on-the-job-training, it is difficult for employers to judge their actual productivity (e.g. McGowan and Andrews, 2015b; 2015a; De Vreyer et al., 2000). Furthermore, young people are more likely to be in temporary employment where the skill demand could be lower, a fact that enhances their risk of being overskilled. On the other hand, older workers (and especially re-entrants to the labour markets) might possess skills that became obsolete due to the technological progress. This might lead to a higher skill 
mismatch for older workers as well - however, causes of mismatches as well as policies that address the necessities of older workers (e.g. early retirement programmes) are different from those for young people.

The incidence of skill mismatch relates to further socio-demographic factors. Women might be more prone to underskilling than men as they might be subject to statistical discrimination (Sesselmeier, Funk and Waas, 2010). Furthermore, if women obtain care duties that force them into atypical employment, skill mismatch might as well be more likely. Especially part-time work is associated with lower skill requirements (OECD, 2013). Skill mismatch may also be more widespread among workers with a migration background as employers may face difficulties to judge their qualifications and productivity adequately (Seibert and Solga, 2005). Last, the likelihood of having a job that matches the skills may also differ between educational levels (Levels et al., 2014b). To properly assess the correlation between institutional characteristics and the incidence of skill matches at the individual level, I will control for individual characteristics to assess whether the macromicro link is evident despite individual and job characteristics that are related to the skill match.

\section{Skill mismatch and individual outcomes: Explanations and evidence}

Skill mismatches can have serious consequences for individuals, firms, and economies. Untapped talents and the related performance gap might lead to a "squandered investment" (OECD, 2015b: 15) and a potential burden, not only for individuals and their personal fulfilment, but for societies and economies (Hanushek and Woessmann, 2015a; McGowan and Andrews, 2015a). This is even more the case as unused skills degrade over time ("useit-or-lose-it" hypothesis; Salthouse, 2006). Skill utilisation and the match between skill supply and demands - hence skill-to-job matches - have become an analytical concern, particularly because of their links to business strategies, managerial practices, innovative potential of firms, and work organisation (Buchanan et al., 2017). The skill-based misalignment of workers to jobs, especially in its vertical dimension of skill mismatch by level, can have negative consequences for individuals both in terms of pecuniary and nonpecuniary benefits as well as external spill overs (Felstead et al., 2017: 333; Green and Henseke, 2016 and multiple others). However, to have any effect, skills must be put to productive use (van der Velden and Bijlsma, 2018). To be deployed productively, skills must fit with the structure of contemporary labour markets. Skill-to-job matching, therefore, is a sine qua non (but not necessarily sufficient) condition for economic growth as well as for social equality (OECD, 2016a). As previous research has shown, this is especially true for 
employment prospects and related career and life chances. Nevertheless, the topic labour market outcomes related to skill mismatch in a cross-country comparison is not underpinned by a robust body of research (Buchanan et al., 2010).

\section{I State of the art: What da we know about individual labaur market autcames? What not?}

Skill mismatch literature often focuses either on income effects at the individual level, or on the macro-economic debate on skill-biased economic growth (Acemoglu, 2002). At the individual level, skill mismatch, and especially overskilling, might cause wage penalties, disillusion and a depreciation of skills (Heyes, Tomlinson and Witworth, 2017; Hanushek and Woessmann, 2015a; Green and Zhu, 2010; Salthouse, 2006; Allen and van der Velden, 2001). At the enterprise level, skill mismatch might reduce productivity and increase onthe-job search and turnover (Quintini, 2011; Green, 2010; Allen and Van der Velden, 2001). At the aggregate, macro-economic level, it might reduce GDP growth because existing human capital is not brought to productive use. Furthermore, the reduction in productivity might decelerate an economies' adaptation to technological developments (see Hanushek and Woessmann, 2015a; McGowan and Andrews, 2015a; Perry et al., 2014; Quintini, 2011).

\subsection{Ecanamic autcames}

Skill mismatch is considered a sub-optimal allocation of workers to jobs resulting in overor under-qualification (OECD, 2015a). Mismatches are associated with individual costs in terms of lower earnings and long-term financial risks. The literature indeed shows that skills are strongly related to wages (e.g. van der Velden and Bijlsma, 2018; Cedefop, 2018; OECD, 2017; Heyes, Tomlinson, and Whitworth, 2017; Hanushek et al., 2015b; Hanushek and Woessmann, 2015a; Perry et al., 2014; Allen and van der Velden, 2001; Groot and Maassen van den Brink, 2000; Hartog, 2000). Usually, the skill mismatch literature shows that returns to excess skills are less than returns to required skills (e.g. van der Velden and Bijlsma 2018; Hanushek et al. 2015b; Perry et al., 2014; Hartog, 2000). These studies mainly focus on literacy and numeracy skills. My thesis adds to this literature by examining the relation between digital problem-solving skills and wages, moreover, systematically assessing wage inequalities between social groups (see chapter 5).

While the evidence that mismatches in numeracy and literacy skills affect wages is very convincing, less is known about digital problem-solving skills, which provide a largely new field of study. The study of these skills (chapter 5) and their returns is an important contribution of this thesis. Previous empirical studies on returns to computer skills are less available, and if, they often rely on subjective measures of computer use (e.g. Borghans and 
Bas ter Weel, 2004). Skill shortages, however, are increasingly driven not solely by the widespread adoption of ICT but also by structural changes in the economy and a lack of synchronisation with developments of educational systems and access to lifelong learning (see e.g. Acemoglu and Autor, 2011). About $85 \%$ of all jobs currently available in the EU require at least a basic level in digital skills (Cedefop, 2018: 5). Besides, ICT skills are related to substantial economic returns (Falck, Heimisch and Wiederhold, 2016; Lane and Conlon, 2016; Hanushek et al., 2015b). Evidence exists that the use of computers at work is a key driver of wage inequalities (De La Rica and Gortazar, 2017). Thereby, ICT skills can compensate for lower levels of other marketable qualifications (Lane and Conlon, 2016). Overall, many previous studies ignore the importance of the match between digital skills possessed by worker and digital problem-solving that is required at workplaces, thereby missing information about (productive) use of skills and talent and inequalities concerning related consequences. There are serious concerns about rising levels of social inequality and technology-induced labour market risks. Nevertheless, a systematic assessment of mismatches, and particularly shortages, in digital problem-solving skills and differences between social groups is missing from the academic discourse. Mismatches in digital problem-solving skills and returns to shortages provide a largely new field of study. Besides, a systematic and thorough assessment of inequalities between social groups is the main gap in the literature.

\subsection{Non-monetary and potentia/ sacia/ outcumes}

One contribution of this thesis is that I also focus on non-monetary outcomes. Previous studies on qualifications addressed job satisfaction and mental well-being, suggesting that both are lower for overqualified workers (e.g. Heyes, Tomlinson, and Witworth, 2017; Green and Henseke, 2016; Verhaest and Verhofstadt, 2016; Allen, Levels, and van der Velden, 2013; Green and Zhu, 2010; Allen and van der Velden, 2001). There are strong indications that particularly overskilling, may have a negative effect on job satisfaction (e.g. Verhaest and Verhofstadt, 2016; Allen, Levels, and van der Velden, 2013; Allen and van der Velden, 2001). Less is known about undereducation/underskilling and the impact on job satisfaction. Some underskilling may indicate that people are working in a challenging job, which in general increases the job satisfaction (van der Velden and Verhaest, 2017; Judge and Bono, 2001; Judge, Bono and Locke, 2000). In the case of serious underskilling, people might feel stressed to meet the job's requirements (Warr, 2007, 2013). For skill use, the relation is also less straightforward. Given the lack of data on skills before the PIAAC survey was conducted, earlier studies are often based on subjective measures that capture the self-reported perception of the skill match. Less is known about the impact of objective, 'real' skill mismatches. 
Grugulis, Holmes and Mayhew (2017) examine wider returns to skills as well as nonmonetary returns to society, finding that higher educated people profit from a wide range of social, health, and other advantages such as stronger social connections et cetera. The authors also explore whether the benefits ascribed to education can also be attributed to skill. However, especially not much is known about the relationship of skill mismatch and non-monetary private benefits as well as external social benefits respectively costs. Both skill proficiency and skill use are central characteristics of the workplace, and strongly related to both education and occupational position. Research on the relation between work characteristics and values dates back to the seminal work of Kohn (1977), who shows that the adult occupational experience and job characteristics such as occupational self-direction have a considerable impact upon (male) worker's values and orientations (Green and Henseke, 2016; Warr and Inceoglu, 2018). This research has not been backed up yet with recent and high-quality data on objective skill proficiency, skill use at work and skill mismatches. A deeper examination of potential social outcomes of skill use and skill (mis)matches is largely missing in the present academic discourse (Green and Henseke, 2016). This gap is important to fill, particularly as well-being and non-monetary factors become ever more important as parts of contemporary policy debates: Against the background of recent re-commodification and flexibilisation reforms individuals are more self-responsible for improvement of subjective well-being. Concerning social outcomes, one can expect that people experiencing that they can fully exploit their skill and be efficacious at work might feel more in control of their lives in general. Therefore, well-matched people might evaluate their political efficacy higher. Self-esteem, efficacy, and satisfaction might in the first instance be a private benefit. Externality elements spill over to benefit other people, contributing to social cohesion and hence social capital (McMahon, 2009: 223).

\section{Dutlook}

Against the background of the rising demand for skills in the knowledge economy, skills are "widely regarded as a core object for policy interventions and analytical research" (Green, 2013: 9). Reforms of labour markets, education, and training programmes are high up on the political agenda in many countries. The aim is to better align labour market demands with the supply of skills. Nevertheless, the prevalence of mismatches is almost certainly growing (Green, 2013: 181). This makes research on the incidence of skill mismatch important. In my thesis, I face the skill matching challenge investigating both determinants and labour market outcomes, and providing new cross-country evidence based on high-quality micro data. Particularly, I provide the bigger picture related to the political economy of skill utilisation as largely new field of study. 
Over the years, skills research shifted from skill supply to demands to the match between the two. While research on skill formation based on human capital theory often focussed on whether a system can produce the relevant skills, recent studies acknowledge that having skills as such does not help individuals or lead to economic growth. Skills must be put to productive use at the labour markets, which makes skill-to-job matches a topic of increasing analytical importance. Thereby, imbalances exist. Welfare states have an impact on how skills formation is institutionalised, but also affect skill utilisation. Because of this, one can expect to find differences in skill use across countries. This chapter provides a comprehensive theoretical framework for an international comparative empirical study of skill-to-job matches. Starting with the political and academic relevance of the skill matching challenge, I provide background information about definitions, concepts and issues related to operationalisation and empirical measurement of skills and skill-based worker-job matches. Outlining explanations and potential relations, this framework serves as sound theoretical basis for the empirical research on macro-level determinants and micro-level outcomes of skill-to-job matches that is presented in the following chapters. 



\section{Chapter 3}

\section{Social Policy and the Challenge of Allocating the Right People to the Right Jabs}

\section{Evidence on the Relation between Institutions and Dptimal Skill Matching from 28 Industrial Countries ${ }^{8}$}

\footnotetext{
${ }^{8}$ This chapter is joint work with Mark Levels and Rolf van der Velden. We thank the participants of the Transitions in Youth $26^{\text {th }}$ Annual Workshop 2018 in Mannheim as well as Josef Schmid, Martin Gross and Paolo Barbieri for valuable comments and suggestions.
} 


\section{Abstract}

This chapter provides empirical evidence for the relation between institutional characteristics of labour markets, education systems and optimal skill matching at the individual level. More precisely, we investigate the extent to which skill-based job-worker matches are associated with vocational orientation and vocational specificity of education systems, employment protection legislation, unemployment benefits, and enforcing and enabling activating labour market policies. With a special focus on differences between labour market insiders and outsiders, we perform cross-country analyses for 28 industrial countries, merging microdata from the OECD's Programme for the Assessment of Adult Competencies (PIAAC) with appropriate macro-level datasets. Performing cross-country analyses, we show that a stricter employment protection legislation is associated with more skill matching. We also provide evidence that strict enforcement does not lead countries into the right direction concerning optimal matching as strict enforcement is related with lower shares of wellmatched workers.

Keywords: Skills, mismatch, allocation, education systems, social policy, labour market policy

\section{Introduction}

Against the background of technological developments and changing demands for skills, the allocation of the right people to the right jobs and a full usage of talent have become more important as an issue of political, societal and scientific concern. During the last decades many countries engaged in reforms of labour markets, education, and training programmes, aiming at a better alignment of labour market demands for skills and the supply of skills provided by education systems (Flisi et al., 2014; Green, 2013). Nevertheless, suboptimal matches between workers' skills and skill requirements of jobs seem to have increased in number over time (European Commission, 2013; Verhaest and van der Velden, 2013). This may be due to imbalances between supply and demand as well as to dynamics in the demand for skills: technological developments change job requirements so rapidly that education and training systems are unable to keep pace (Allen and van der Velden, 2002). Of course, education serves various functions such as preparing young people for citizenship et cetera. For the purpose of this thesis, however, we focus on labour market participation. Investigating the individual skills supply as compared to skill requirements of jobs, we focus on the optimal match between the two; from a different perspective, overqualification might be considered useful. 
Cross-country variation suggests that skill matching may also be related with institutional factors that shape the allocation of workers to jobs (Levels, van der Velden, and Di Stasio, 2014a; Levels, van der Velden, and Allen, 2014b; Green, 2013; van der Velden and Wolbers, 2003). Two institutional factors seem to be of particular theoretical relevance: labour market policies (Gangl, 2006; 2004) and educational arrangements (e.g. Levels et al., 2014a). Labour market policies may explain variation in allocation processes, and different education regimes may explain variation in the kind of skills that are rewarded on the labour market (Barbieri, 2009; Gangl, 2006; 2004; Estévez-Abe et al., 2001). In the literature, there is a common understanding that employment protection policies favour insiders on the labour market, leading to a situation in which outsiders, and particularly young workers, are confronted disproportionally with adverse labour market situations and related risks (Ochsenfeld, 2018; Fregin, 2013; Giesselmann, 2012; Lindbeck and Snower, 1988; De Vreyer et al., 2000). Labour market arrangements (and especially unemployment benefit schemes) have been reconfigured during the last decades and especially during the 'activation turn' in labour market policy, a paradigm shift that was accompanied by deregulation and increasing flexibility (Bonoli, 2010). Activating labour market policies involve a combination of measures that enforce labour market participation, and services that promote employability and enable individuals to find their way into employment (Dingeldey, 2007: 823; Gilbert, 2002; also see Buhr et al., 2016). The consequences of this 'activation turn' are not fully understood yet. This chapter empirically tests the relation between institutional characteristics of labour markets and education systems, and optimal skill matching. We pose the following research question: To what extent can the likelihood that workers find a job for which they have the right skills be explained by characteristics of labour market arrangements and education systems?

To answer this question, we analyse data from the OECD's Programme for the International Assessment of Adult Competencies (PIAAC). PIAAC is an international comparative assessment of cognitive and workplace skills of adults aged 16 to 65. Our analyses rely on objective skills measurements for workers in 28 industrialised countries. We enrich the PIAAC micro data with measures of social policies at the country level, more specifically, the degree of employment protection (EPL), unemployment benefits, and activating labour market policy (ALMPs), and the vocational orientation and vocational specificity as central characteristics of education systems. While we base our analyses on statistical models for workers of all ages, we put a specific focus on the situation of young workers, which we here define as labour markets outsiders, comparing their situation to labour market insiders (Ochsenfeld, 2018; Fregin, 2017; 2013; Palier and Thelen, 2012; Giesselmann, 2012; Wolbers, 2007; Lindbeck and Snower, 1988). We do so because young workers form a specific group of outsiders (de Vreyer et al. 2000), since particularly young entrants to the 
labour markets have to compete for available jobs with those who have already gained experience with work and employment.

This chapter advances the literature in two main ways. First, the analyses are the first to explain the extent to which cross-country variance in optimal skill matching is related to country characteristics. As such, the chapter is descriptively important. It provides a solid basis for future analyses of the causal impact of various policies on worker-to-job skills matches. Second, our focus on optimal skill matching particularly seeks to advance the literature on educational matches. In previous research, the match between workers and jobs has often been conceptualised by measuring education-to-job matches (e.g. Gangl, 2004). Indicators that are based on detailed information about skills instead of education certificates provide a better and more dynamic picture of an individual's human capital and job-worker matches (e.g. Levels et al., 2014b). To contribute to the literature, we examine the relation between optimal matching and institutional characteristics. We also test institutional features other than those usually tested by using composite indicators that capture enforcing and enabling activating labour market policies (Knotz, 2012).

\section{How is social policy related to optimal skill matching? Theory and hypotheses}

Previous studies exploring the relation between labour market policies and individual outcomes seldom look at skill-to-job matches (McGowan and Andrews, 2015b) but focus e.g. on employment chances, school-to-work transitions, youth unemployment rates, wages or types of contract (e.g. Barbieri, Cutuli and Passaretta, 2018; Ochsenfeld, 2018; van der Velden and Wolbers, 2003). Studies that investigate the relation between institutional contexts and labour market matching mainly focus on education-to-job matches instead of skill matches (e.g. Levels et al., 2014a; 2014b). Besides, this line of research mainly addresses the impact of education system characteristics, often ignoring labour market policies (e.g. Heisig and Solga, 2014).

This chapter is about 'optimal skill matching'. Treating both workers and jobs as a given, this term captures the optimal allocation of workers to jobs on the basis of the skill level, i.e. a situation, in which, in a country, the workers with the highest skills are allocated to the jobs with the highest skill requirements, and the workers with the lowest skills are allocated to the jobs with the lowest skill requirements. From a societal point of view, this would be the most optimal way of matching skills to jobs. Any disturbance in this order leads to suboptimal matching, where workers are over- or underskilled for their jobs. This prevents countries from the optimal allocation of the right worker to the right job, leading to a 
situation in which the available skills of the available workforce are not put to optimal use. Hereby, more disturbance means more suboptimal matching (i.e. more skill mismatches) and hence less optimal matching. To illustrate this, think of the following example. Suppose we can rank all workers in a country on the basis of their skill levels from high to low. And we can also rank all jobs on the basis of their skill requirements from high to low. Ranking both workers and jobs in this one-dimensional order, the following graph illustrates the idea of 'optimal matching' (for more information see methods section).

Figure 2. Illustration of the idea of optimal skill matching as compared to suboptimal matching

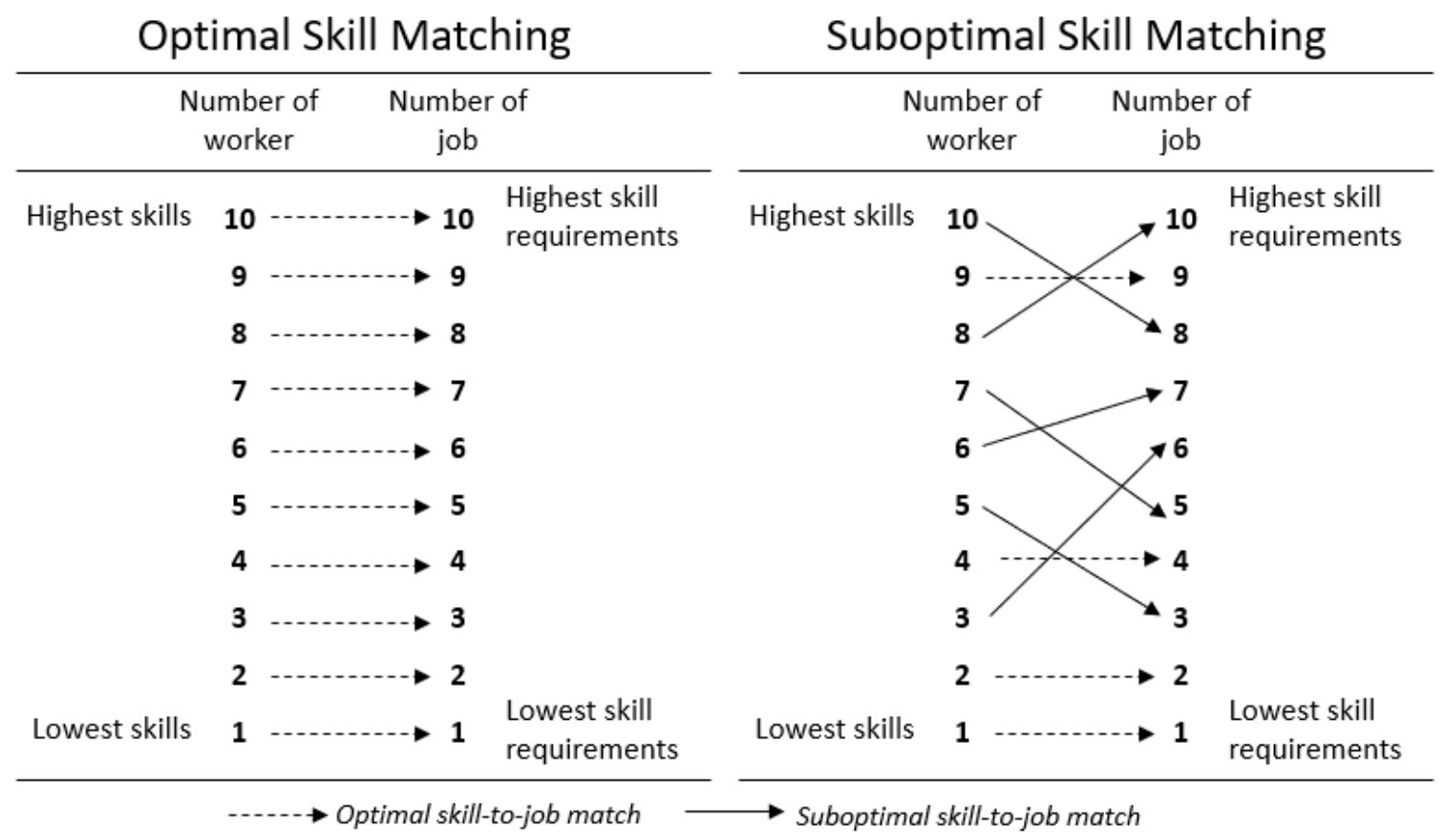

Source: own graph

From a societal point of view, social policies should have a role in making sure that countries have an optimal matching situation, seeking to ensure an optimal social outcome. We, therefore, explore how optimal skill matching relates to institutional and political factors at the national level. Education policies explain cross-national variation in skill acquisition. In turn, labour market policies explain the way in which these skills are allocated to jobs. Thereby, various aspects of welfare states are important for explaining optimal skill matching, the most important ones being (i.) regulation, (ii.) financial transfers such as unemployment benefits, and (iii.) non-financial services (Schmid, 2010). We investigate aspects of all three dimensions. 


\subsection{Vocationa/ orientation and vacationa/ specificity of education systems}

A core element of education systems is to what extent they offer vocational training programmes that prepare specifically for certain occupations (Shavit and Müller, 1998). A central characteristic driving allocation processes is the so-called vocational orientation of an education system, capturing the percentage of people enrolled in vocational training programmes (Bol and van de Werfhorst, 2012). Whereas graduates with mainly general skills need more training on the job, graduates from vocational programmes are more likely to be directly productive once they take up a job, which makes allocating these graduates less risky for employers (Levels et al., 2014a; Wolbers, 2007). We, therefore, hypothesise that:

H1. The higher the vocational orientation of education systems, the more likely it is that workers are allocated to jobs that match their skill level, i.e. the higher the share of optimal skill matching.

Within the vocational labour market, the argument outlined above holds even stronger for those who are trained in dual systems, as these systems directly create the demanded skills (Bol and van de Werfhorst, 2012; Wolbers, 2007). The more supply there is that exactly fits the demands, the higher the optimal matching rate should be. This should be specifically true for specific skills, but we would also expect this to be true for the kind of key information-processing workplace skills measured in PIAAC, as key skills are likely to be highly correlated with specific skills. Capturing the institutional setup of vocational training systems, the so-called vocational specificity of education systems is particularly important when it comes to skill-centred allocation strategies that are evident in vocational labour markets. $V$ ocational specificity refers to the extent to which, in vocational programs, students are trained in an apprenticeship (dual system) rather than a school-based system. The dual system is effective in establishing so-called institutional linkages (Bol and van de Werfhorst, 2012). This refers to the fact that students enrolled in dual systems establish relations with employers, as part of the education takes place in firms. These linkages make it easier for employers to observe the actual skills of prospective workers, thus leading to a better matching process. In addition to hypothesis 1, we phrase the following hypothesis 1a to further specify our theoretical argument for vocational labour markets:

H1a. The higher the vocational specificity of education systems, the more likely it is that vocationally educated workers are allocated to jobs that match their skill level, i.e. the higher the share of optimal skill matching. 


\subsection{Regulation}

The degree of regulation (or deregulation respectively) has a major impact on individual labour market outcomes (Giesselmann, 2012; Barbieri et al., 2018). This is especially true for employment protection legislation (EPL), i.e. legal schemes of procedures and costs involved in worker dismissals. The "Overall strictness of EPL continues to vary widely between countries and $[\ldots]$ remains the key element in explaining cross-country differences" (OECD, 2004: 63). The higher the protection against dismissal, the higher the firing costs even with workers that are mismatched and not optimally productive. One could therefore hypothesise that the harder it is to fire someone the more likely it is that mismatched workers remain in their jobs. However, the regulation of the firing process also changes hiring processes. Job security provisions such as EPL increase hiring risks on the side of the employer. During the allocation process, employers have to anticipate paying dismissal costs, assessing how likely it is that these risks arise in practice, for example because a worker turns out to be less productive than initially expected (Noelke, 2011: 4). Dismissal costs would lower the expected returns and, therefore, diminish the utility of hiring. Generally, employers tend to be rather risk averse, seeking to realise expected returns. The higher the costs for dismissals, the more employers will ensure that their workers match their jobs, which, at the aggregate level, makes a positive relation between stricter EPL and optimal matching more likely than a negative relation. In countries with a high EPL, we therefore expect that employers try either to find persons that match their jobs or invest in training measures for workers that they already hired, as EPL makes reallocation costlier for employers. Based on this reasoning, we hypothesise that:

H2. The stricter the degree of employment protection legislation is, the more likely it is that workers are allocated to jobs that match their skill level, i.e. the higher the share of optimal skill matching.

As outlined in the introductory section of this paper, deregulating reforms did not explain outcomes of all groups of workers in the same way. By contrast, it is held in the literature that deregulation took part selectively and was directly targeted at labour market entrants (Ochsenfeld, 2018). We therefore further specify our argument for young workers, developing additional hypothesis 2a. Restricting our argument to young workers, we capture the moderation of regulation through the introduction of a cross-level interaction between EPL and temporary contracts, hypothesising that:

H2a. The stricter the degree of employment protection legislation is, the more likely it is that particularly young entrants to the labour market are allocated to jobs that match their skill level. 


\subsection{Unemployment benefits}

With reference to globalisation and new demands for skills, social and labour market policies have changed the institutional framework of employment towards a more liberal configuration (Dingeldey, 2011; 2007; Gilbert, 2002). From a micro-level perspective, the conditioning of social rights reinforced economic self-reliance and risks (Fregin, 2013; Giesselmann, 2012: 11). De-commodification is defined as welfare state generosity regarding financial transfers such as unemployment benefits. More generous unemployment benefits are theoretically thought to allow workers to turn down a job, permitting the unemployed enough time to find a job that optimally matches their skills (Estévez-Abe et al., 2001). We, therefore, hypothesise:

H3. The more generous unemployment benefits are, the more likely it is that workers are allocated to jobs that match their skill level, i.e. the higher the share of optimal skill matching.

\subsection{Services and Activating Labour Market Palicies (ALMPs)}

While governments use cutbacks in unemployment benefits as a straightforward way to improve the sustainability of social insurance schemes, preventive and enabling services such as lifelong training and enablement turn out to be a core area of reform programs in many countries. These services should increase the likelihood of optimal skill matching, as e.g. unemployed adults are purposefully (re-)trained to acquire skills that fit labour market demands. A country's overall effort in ALMPs finds expression in the amount of public spending for these policy measures. We test the overall effort in active labour market policies across countries (OECD, 2013), hypothesising:

H4. The more countries invest in Active Labour Market Policies, the more likely it is that workers are allocated to jobs that match their skills, i.e. the higher the share of optimal skill matching.

The term ALMP includes a diverse pool of policy measures, ranging from re-skilling and lifelong training to the promotion of atypical, and sometimes even precarious, forms of employment. We expect that diverse measures relate to optimal skill matching in different ways; some of them enhancing the chances of optimal matches, others, by contrast, increasing labour market risks. We therefore take a closer look at the combination of enabling and enforcing ALMPs, whereby the latter seek to tighten readiness-to-work requirements and suitability criteria, which usually comes along with cuts in the access to unemployment benefits (Estévez-Abe et al., 2001). As persons are forced into employment irrespective of the match between the job and the worker, we expect that:

H5a. The more enforcing ALMP's are in place, the less likely it is that workers are allocated to jobs that match their skills, i.e. less optimal matching. 
The outlined enforcing policies are usually accompanied by services to assist people on their way into the labour market. These so-called 'enabling' policies include the expansion of training and upskilling measures, but also policies facilitating the compatibility of paid and care work as well as, for example, job counselling. As enabling policies are designed to support people to find a job that matches their skills, we hypothesise:

H5b. The more enabling ALMP's are in place, more likely it is that workers are allocated to jobs that match their skills, i.e. more optimal matching.

\section{Data and Methads}

We use data of the Survey of Adult Skill from the OECD's Programme for the International Assessment of Adult Competencies (PIAAC; see OECD 2016a; 2016b). For PIAAC, representative samples of the adult workforce aged 16-65 were tested in key skills related to information processing at work and in daily life. The survey conducted computer-based assessments in different skill domains such as literacy and numeracy and was conducted in more than 30 industrial countries. PIAAC provides unique possibilities to investigate optimal skill matching as it contains individual level data about cognitive and workplace skills as well as a large amount of background information?. For our analyses, we take numeracy skills as proxy for key information-processing skills that can be deployed at the workplace. Key skills such as numeracy are crucial for the full participation in the knowledge-based economies and societies and can be deployed at all proficiency levels from very basic to very complex. The PIAAC numeracy domain captures the general cognitive ability to grasp meaning and relevant new information which is presented in numerical sense (OECD, 2016a). Numeracy is therefore more than the individual ability to conduct simple arithmetical operations. It is defined as the "ability to access, use, interpret and communicate mathematical information and ideas in order to engage in and manage the mathematical demands of a range of situations in adult life" (OECD, 2016a: 18). PIAAC deploys a use-oriented, functional skills framework that involves managing a situation or solving a problem in a real context. During the scenario-based competency assessment, PIAAC respondents had to respond to mathematical content/information/ideas represented in multiple ways. Previous research has shown that numeracy is the single most important skill that workers need to have when explaining returns to skills (Levels et al., 2014b).

For our analyses, we draw the following sample selection: As allocation processes and labour market engagement may be different for part-time workers, we restrict our working sample to fulltime workers (which we define as working 30 hours or more per week). We

\footnotetext{
${ }^{9}$ For more detailed information about the PIAAC dataset and technical issues see OECD (2016b).
} 
furthermore restrict our sample to men as the labour market activity of women, especially of older generations, is much different from that of men. However, we conduct analyses for female workers as a robustness check. We exclude self-employed, members of the armed forces, unpaid family workers and students/interns as for these workers the allocation process is different from employees. We further exclude four countries either because data are missing for the country level variables (Singapore and Cyprus), data confidentiality issues (Australia) or data quality issues (Russian Federation). As the Canadian sample is much bigger than the other countries' samples, we select a random sample of Canada's respondents to avoid overrepresentation in our dataset. Our analyses are thus based on a dataset that contains representative samples of male fulltime workers for 28 industrial countries based on microdata for 39,041 individuals (for sample statistics see Appendix, Tables A1, A2, A3).

\section{I Measuring aptimal skill matching}

Focussing on optimal skill matching in the domain of numeracy, we use an indicator that captures individual skill match as micro level dependent variable that we deploy in all analyses. In the literature, there is no agreement on how to measure skill matching ${ }^{10}$. As PIAAC measures general skill proficiency levels, we focus on the vertical dimension, i.e. optimal matching at the level of skills, which is different from horizontal field of study matches, capturing a misfit in type of skills (for more information see chapter 2). We treat both workers' skills and job skill requirements as a given and define "optimal matching" (that is optimal allocation) as a situation, in which the workers with the highest skill levels are allocated to the jobs with the highest skill requirements and vice versa (see the Figure in the introduction to this chapter). An optimal allocation would then be defined as the situation in which both rank orders correlate perfectly, and the match is thus $100 \%$. However, this is seldom the case as there are disturbances in the allocation process, which we here refer to as suboptimal matching. We expect this amount of misallocation to differ between countries as a result of differences in institutional factors that may disturb the optimal allocation.

In practice, an optimal allocation cannot be directly observed as we do not have direct information on the skill requirements of all individual jobs. Instead we will proxy the optimal allocation by using the so-called Realised Matches Approach (RMA) (van der Velden and Bijlsma, 2018; Flisi et al., 2016; Perry, Wiederhold, and Ackermann-Piek, 2014). Generally, the RMA assumes that every occupation has a typically required skill level,

\footnotetext{
${ }^{10}$ We include a description of the debate and the commonly used measures in Appendix A in the online supplementary material; for more information also see chapter 2.
} 
defined as the average skill level in a certain occupation in a certain country. The RMA defines a worker as wellmatched if the worker has a skill proficiency level of - usually-not more than one standard deviation above or below that occupation-specific level (e.g. Perry et al., 2014). Thereby, the cut-off point of one standard deviation is also chosen as it captures approximately the distance between two proficiency levels in PIAAC (OECD, 2016a; 2016b). We follow this approach, defining a corridor between one standard deviation above and below the robust required skill level of each occupation-country-cell to identify well-matched workers. If the skill level of a worker lies outside that corridor, we classify the respective worker as mismatched, i.e. misallocated by level of skill ${ }^{11}$. This approach has the attractive feature that the average worker in an occupation is defined as well-matched, just like we assume this in the optimal allocation model.

Our skill match measure is based on the actual skill distribution and the required skill levels for each ISCO 2-digit occupation in each country. To estimate robust average skill proficiency levels for each of these occupations, we make use of the calculations performed by Allen and Bijlsma (forthcoming) ${ }^{12}$. This is necessary because several ISCO groups at the 2-digit level in PIAAC are very small ${ }^{13}$. Allen and Bijlsma (forthcoming) effectively tackle this problem by computing robust estimates of the average skill level in each occupationcountry-cell. These robust estimates are partly based on information from other countries than the reference country. This procedure might introduce some bias, as countries differ regarding the occupational and sectoral structure of their labour markets. We effectively control for this bias by introducing occupational structure (using the 1-digit ISCO classification) and sector of industry (1-digit ISIC classification) of each country as controls in all statistical models. We introduce relevant micro-level predictors in our models to assess the robustness of the country-level results. Due to the special model specification required, our hypothesis $2 \mathrm{a}$ is tested for vocationally educated only. Assessing the robustness of findings, we also re-run our main models leaving out one country at a time. We furthermore perform additional analyses, computing our main models separately for workers in the public vs. private sector, for natives, and for fulltime working women.

\footnotetext{
${ }^{11}$ We compute the standard deviation of the 10 plausible values (PVs) of the individual PS-TRE scores in PIAAC, pooling over ISCO 2-digit categories. We use the repest-command in Stata 15 to properly take into account the PIAAC replicate weights.

${ }^{12}$ Van der Velden and Bijlsma (2018) show that the total explained variance does not change if they use 3-digit instead of 2-digit ISCO categories.

${ }^{13}$ We could have simply computed the simple mean per country but then we would have lost many occupations (see Pellizzari and Fichen, 2013). Instead, we decided to just exclude the very small occupation-country-cells with less than 25 observations.
} 


\subsection{Measuring social policies}

We merge institutional characteristics collected in appropriate macro-datasets on the country level with PIAAC micro data. This combined, hierarchical dataset enables us to model the macro- and micro-variables simultaneously, testing the hypotheses in multilevel models (Snijders and Bosker, 2012). The information on the macro level originates from different sources. Most macro level indicators that we use describe the situation in the year in which the PIAAC survey was conducted in the respective country. PIAAC ran from 2011-2014. For each country, we use macro data from the year in which PIAAC was conducted in the respective country. Only the indicators for enforcement and enablement (Knotz, 2012) display the situation in the mid-2000s, as this is the only point in time available. The indicators for vocational orientation and vocational specificity are provided by Bol and van de Werfhorst $(2012 ; 2014)$. Vocational orientation is defined as the proportion of students in upper-secondary education who are enrolled in any kind of vocational training (ibid., 2012). The original authors standardised this variable and it is available for 26 PIAAC countries. It has a range from -1.8 to 1.7 , a mean on 0.25 and a standard deviation of 0.9 . The second variable that captures institutional characteristics of education systems is vocational specificity, defined as the percentage of students in upper secondary education that are educated in dual systems (OECD, 2007 cf. Bol and van de Werfhorst, 2012). This variable runs from $0 \%$ to $47 \%$, with a mean of $14 \%$ and a standard deviation of 16 and is also available for 26 countries. To capture labour market policies, we make use of several indicators that are commonly used in this type of research. We use an index for employment protection legislation (EPL) for permanent contracts as proxy for the degree of regulation (OECD, 2018). This indicator as provided by the OECD (2018) is the weighted sum of sub-indicators concerning the regulations for individual dismissals (weight of 5/7) and additional provisions for collective dismissals (2/7). It incorporates 13 detailed data items. The indicator is available for all 28 countries in our analyses, and has a range from 1 to 3 , with a mean of 2.3 and a standard deviation of 0.5 .

To operationalise unemployment benefits we use the state-of-the-art indicator for average net replacement rates during the first five years of unemployment as percentage of previous net income (OECD, 2013c). The indicator captures the average net replacement rate over 60 months following unemployment for a one earner couple with two children, where the earner previously earned the average wage (OECD, 2013c). This indicator is available for all our 28 countries. It has a range from 9 to 83 , a mean of 57, and a standard deviation of 18. The information on public spending on active labour market policies is also provided by the 
OECD (2013a). It captures the total amount of public spending as percentage of GDP14. For this indicator, the latest data is available for 2011, which is why we use these data also for PIAAC round II countries. It is only available for 23 countries. The indicator has a range of 0 to 2.3 , a mean of 0.7 , and a standard deviation of 0.6 .

The indicators that we use to operationalise enforcement and enablement stem from Knotz (2012). Inspired by Esping-Andersen's decommodification index (Esping-Andersen, 1990; 2006), Knotz (2012) provides composite indicators that quantify the mix of enforcing and enabling measures that characterises ALMP schemes in an international comparison. Based on a so-called 'Activation toolbox' (Knotz, 2012: 14), the author constructs two composite indices, quantifying the strengths of enabling versus enforcing policies across countries (for details see Knotz, 2012). The data display the situation in 17 PIAAC-countries. The unique composite indicators quantify activation strategies, which are defined as configurations of ALMPs, passive benefit systems, and all related policies (e.g. family and tax policies). The author combines financial and non-financial policy measures for both enforcement and enablement and combines them into composite indicators, quantifying ALMPs that are designed to activate unemployed and inactive persons to search for and take up employment (Knotz, 2012: 12 et seq.). Enforcement has a min of 0.5 and a max of 0.8, with a mean of 0.6 (std. dev. 0.01). Enablement has a slightly smaller range of 0.2 to 0.65 , with a mean of 0.4 , and a standard deviation of 0.1 . We use the indicators provided by Knotz (2012) in addition to the above mentioned, commonly used measures, as they allow us to capture a more detailed picture of ALMP schemes across countries. ${ }^{15}$

\subsection{Individual cantrals}

Previous research has shown that skill-to-job matches, and the incidence of mismatches, vary across age groups with young people being more likely to be overskilled in many countries (e.g. OECD, 2016c; Allen, Levels, van der Velden, 2013). In this chapter, we make use of a metric age variable, controlling for age and age squared. In our working sample, the average age is 40.3 years, with a range from 15 to 65 . Skill mismatch may also be more widespread among workers with a migration background as employers may face difficulties to judge their qualifications and productivity adequately (Seibert and Solga, 2005). We make use of a binary indicator, comparing first- and second-generation migrants with natives. $12 \%$ of the workers in our sample have a migration background. Last, the likelihood of

\footnotetext{
${ }^{14}$ As a robustness check, we make use of another indicator that captures the total spending on ALMP per unemployed workers as percentage of GDP per capita as provided by the OECD Employment and Labour Market Statistics database 2016.

${ }^{15}$ Country scores on all macro-level indicators are displayed in the supplemental materials (Table A1 in the appendices to this chapter).
} 
having a job that matches the skills may also differ between educational levels (Levels et al., 2014b). The indicator that we use defines three levels of educational attainment (measured based on educational credentials) and differentiates between compulsory education (16\% of the sample), secondary education/apprenticeship (59\% of the sample) and tertiary education ( $25 \%$ of the sample). We include age, age squared, migration background, and highest level of education in our statistical models to test for such compositional differences (for descriptive statistics see Appendix Table A2 and A3). Testing our hypothesis 2a, we furthermore resort to information on type of contract, using a dummy variable.

\subsection{Analyses}

We start our analyses with descriptive results on the cross-country univariate distribution of skill matching. Thereafter, we perform the above outlined multilevel analyses to explore the relation between social policy indicators and skill matches at the individual level. Next, we provide the results of several robustness checks, including analyses for different subgroups of workers. We estimate multilevel mixed-effects logit regression models (using the melogit-command in Stata 15). Defining $\pi_{i j}=\operatorname{Pr}\left(\operatorname{match}_{i j}=1\right)$, we use the following equation [1]:

$\operatorname{logit}\left(\pi_{i j}\right)=A_{j} \beta+B_{i j} \gamma+X_{i j} \delta+u_{j}+\epsilon_{i j}$

for $j=1 ; \ldots ; 28$ countries, with $i=1 ; \ldots ; n_{j}$ fulltime working men in countries $j . A_{j}$ is a vector that contains country-level variables, i.e. the characteristics of education systems and labour market policies that we described in the theoretical section. The vector $B_{i j}$ contains a constant as well as ISCO-1 digit and ISIC-sector dummies, which we use as basic controls on the individual level in all our statistical models. $X_{i j}$ is the vector containing our microlevel characteristics. If not stated differently in the tables, it includes age, age squared, educational attainment, and migration background. All our main analyses are based on Equation [1]. Only for the analysis referring to hypothesis $2 a$ we extend $X_{i j}$ adding a fixed component of temporary contract as dummy variable, a cross-level interaction with EPL, and a random slope on the country level. The errors $\epsilon_{i j}$ are assumed to be distributed as logistic with mean 0 and variance $\pi^{2} / 3$ and are assumed to be independent of country random effects $u_{j}$. All analyses are weighted using a 'rescaling to cluster size' approach, with which we account for different sample-sizes between countries by adjusting the overall sample weight in PIAAC. To evaluate the goodness of fit of our statistical models, we conduct deviance tests (Snijders and Bosker, 2012: 97). 


\section{Results}

We start our empirical analyses assessing the amount of skill matching vs. skill mismatches across countries. As outlined above, we restrict our main analyses to male fulltime workers. Figure 2 displays the proportions workers in our sample who have skills that match their jobs across countries compared to the percentages of over- and underskilling.

Figure 2. Proportion of skill-to-job matching and mismatches over countries (Male fulltime workers)

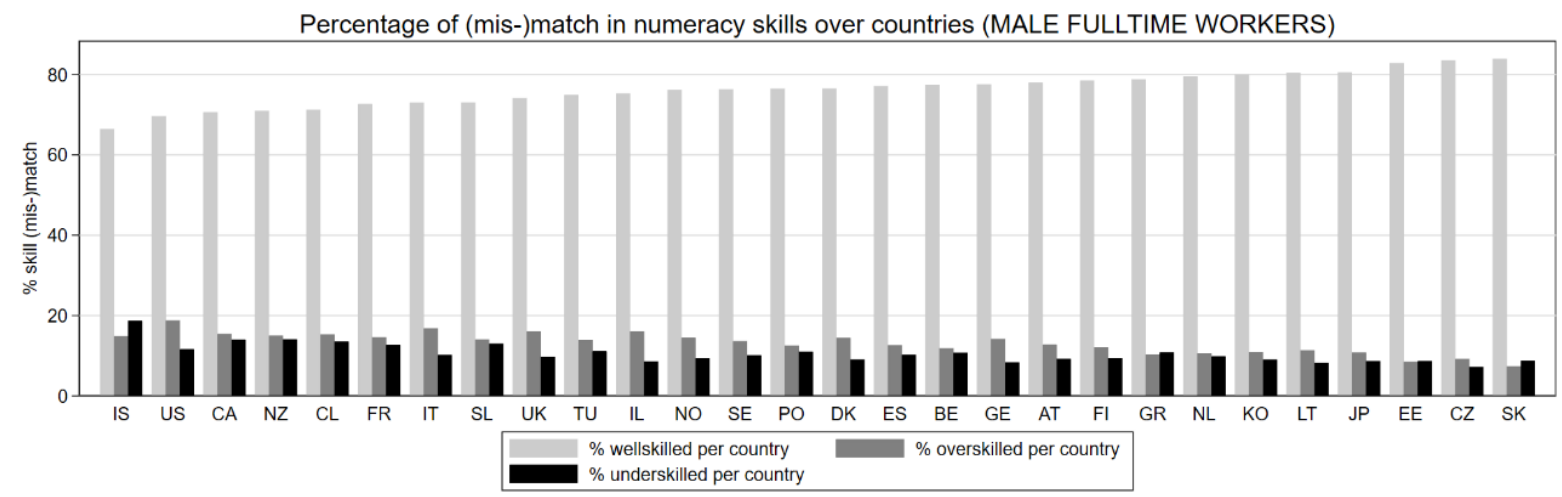

Source: Pooled PIAAC data; own calculation

The proportion of skill-to-job matches varies between 67 percent (in Israel) and 85 percent (Slovak Republic). On average, around 76 percent of the male fulltime workers are wellmatched on the basis of their skills, although considerable differences exist between countries. Furthermore, we find considerable amounts of suboptimal matching, with around 11 percent of our working sample being underskilled, and around 13 percent being overskilled. We now turn to the multilevel analyses, starting with results for the whole sample of male fulltime workers before restricting our analyses to young workers, comparing the results with adult workers. For each model, skill matching at the micro-level is the dependent variable under study. If not stated differently, all tables display average marginal effects (AMEs). Note that ISCO1 and ISIC1 are included as controls in all models. 


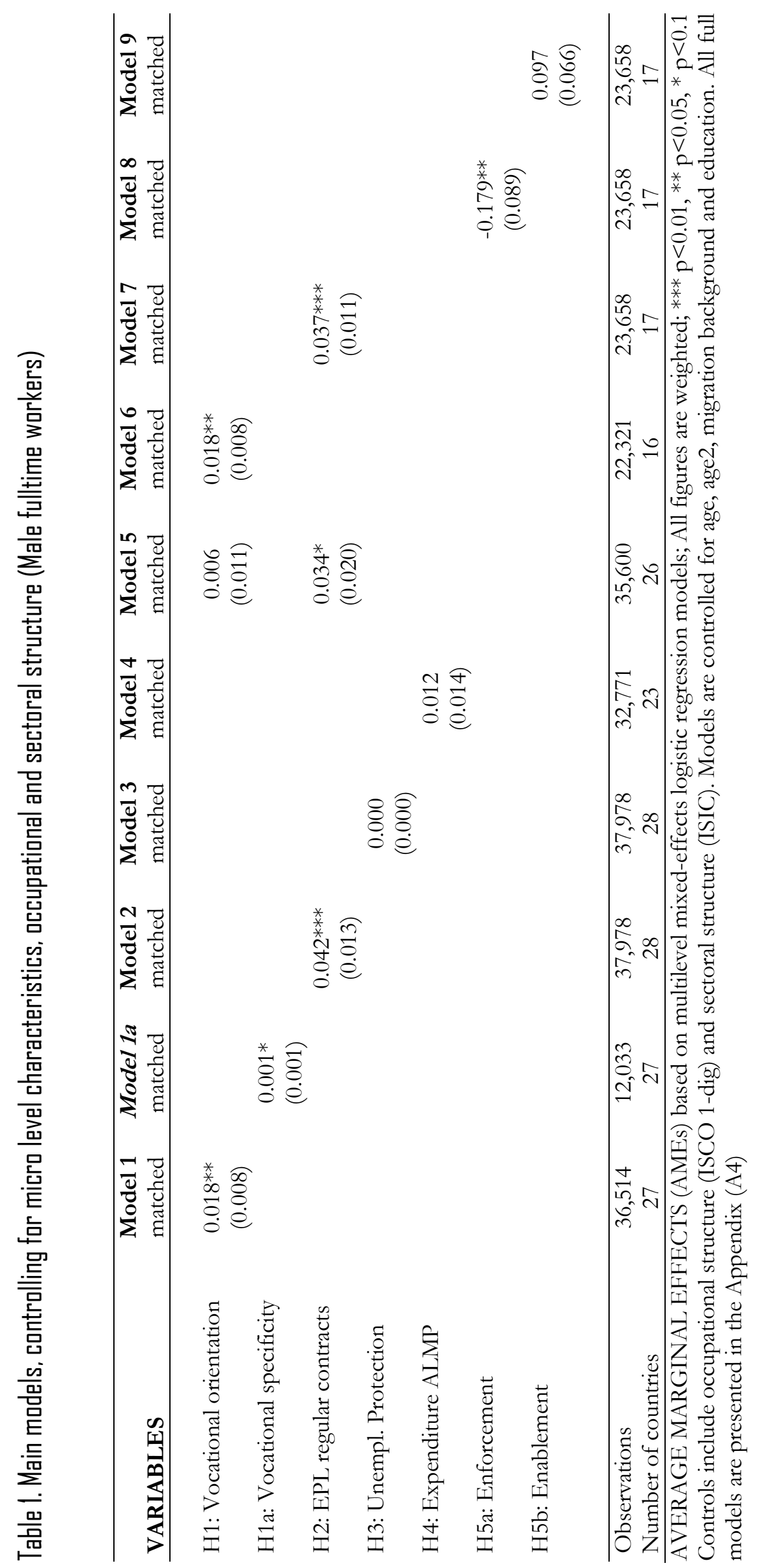


Table 1 displays our findings regarding the relation between social policies and optimal skill matching for the whole sample of male fulltime workers, controlling for individual characteristics, occupational and sectoral structure. We present coefficients for the relevant coefficients only for reasons of brevity; full models and fit statistics are presented in the Appendix (A3). Model 1 displays the results for vocational orientation and provides support for hypothesis 1: The correlation between vocational orientation and skill matching is positive and statistically significant at the $5 \%$ level, which means that the higher the vocational orientation of an education system, the more likely it is that workers get allocated to jobs that match their skills, i.e. the more optimal skill matching. Model 1a specifies the theoretical argument further for vocational specificity as provided by dual systems, testing hypothesis 1a. We find support for this hypothesis, but the coefficient is very small. Note that this may also have to do with the reduced sample size, as this analysis has to be restricted to respondents with vocational education. The displayed average marginal effect, however, indicates that the association goes in the same direction.

Model 2 estimates the relation between EPL for regular contracts and the likelihood of skill-to-job-matches at the individual level. The AME is positive, which means that the stricter the degree of employment protection legislation is, the more likely it is that workers have jobs that match their skills. This is exactly what we expected based on theoretical arguing in hypothesis 2. Models 3 and 4 shows the results with regard to unemployment benefits (hypothesis 3) and public spending on active labour market policy (hypothesis 4). However, we do not find empirical support for these hypotheses as the obtained AMEs are close to 0 (or even 0 in the case of unemployment protection) and statistically not significant ${ }^{16}$. The first intermediate conclusion is that particularly two institutional characteristics are related to skill matching: vocational orientation and EPL. To scrutinise this result, we take the two macro level variables both up in a joint model with 26 countries, finding that the relation between the vocational orientation of the education system and skill matching nearly disappears while the AME of EPL is reduced in size, but stays slightly significant (Model 5). It is likely that EPL and vocational orientation are correlated, which could explain the changing statistical significance. However, we find that EPL is still significant, even if we control for educational systems' vocational orientation.

As outlined in the theoretical section, we use special composite indicators measuring the combination of enforcement and enablement (Knotz, 2012). As shown in Table 1, these indicators are only available for 17 countries. We do not want our estimates to be different

\footnotetext{
${ }^{16}$ As a robustness check, we re-ran Model 4 using an alternative indicator for public spending per unemployed worker as percentage of GDP per capita (OECD, 2016). This indicator, too, does give AMEs close to 0 that are statistically not significant. Results are available upon request.
} 
just because we have to rely on a different sample of countries when we test our hypotheses $5 \mathrm{a}$ and $5 \mathrm{~b}$. We therefore test both vocational orientation and EPL on the limited sample of countries for which the indicators provided by Knotz (2012) are available. Models 6 and 7 show that our results are still valid. Based on the reduced sample of 17 countries, Models 8 and 9 test the policy indicators for enforcement and enablement provided by Knotz (2012). For Hypotheses $5 \mathrm{a}$ (enforcement) we find what the theory predicts: strict enforcement of labour market participation shows a quite considerable negative association with skill matches. However, testing hypothesis $5 \mathrm{~b}$ based on Model 9 we do not find support for our theoretical argument that enabling policies are associated with more skill matching. In all models we included age, age squared, migration background and two dummies for highest education obtained. We did so to adjust the macro-micro associations between (contextual) social policies and individuals' skill matching for compositional differences on the most relevant micro-level characteristics ${ }^{17}$. Concerning the individual characteristics (full results are provided in Table A4), we find that while age has almost no association, the likelihood of skill-to-job match is significantly smaller for workers with a migration background than for natives in all models. Compared to low educated respondents, male fulltime workers with secondary education or apprenticeships have better chances to experience a skill-tojob match, whereas the dummy indicating tertiary education has no significant effect. Assessing the goodness of fit of our (logit) models using likelihood ratio tests, we conclude that the decrease in deviance is statistically highly significant for all models.

In Table 2, we test our hypothesis 2a, assessing insider-outsider differences for EPL. Note that, for this special analysis, we modify our model specification, additionally including a dummy for temporary contract, a cross-level interaction with EPL, and a random slope on the country level. For this analysis, the working sample is restricted to young workers (age<35). The results show that EPL explains variation in skill matching for both insiders and outsiders (conceptualised as young workers) in the same way. The interaction term is not statistically significant. We also tested a random slope on the country level which only has a small effect. Migration background and tertiary education both display negative associations.

\footnotetext{
${ }^{17}$ We repeat these analyses for women, obtaining overall comparable results (see Table A1 in the online Appendix A).
} 
Table 2. Testing hypothesis Za: Is the relation between EPL and skill matching different for insiders and outsiders to the labour market?

Male fulltime workers; full model | Young workers (age<35) only

\begin{tabular}{lc}
\hline VARIABLES & Model 1 \\
wellskilled
\end{tabular}

\section{GOODNESS OF FIT of the models}

Likelihood ratio test

$\log$ likelihood

Deviance $^{2}\left(\mathrm{D}_{\mathrm{i}}\right)$

Deviance decrease $\left(\mathrm{D}_{0}-\mathrm{D}_{\mathrm{i}}\right)^{3}$

Degrees of freedom

Chi-squared value

LOG ODDS based on multilevel mixed-effects logistic regression models; Figures are weighted; *** $\mathrm{p}<0.01,{ }^{* *} \mathrm{p}<0.05,{ }^{*} \mathrm{p}<0.1$; Robust standard errors in parentheses; Controls include occupational structure (ISCO1) and sectoral structure (ISIC1)

${ }^{1}$ We tested a random slope on the country level, which only has an insignificantly small effect.

${ }^{2}$ Deviance $=-2 *(\log$ likelihood), see Snijders and Bosker, 2012: 97 et seq.

${ }^{3}$ The decrease in deviance is computed based on the specific intercept of each model $\left(\mathrm{D}_{0}\right)$.

\section{Model 1}

12976

$(\mathrm{df}=3)$

\section{$(\mathrm{de}=3)$}




\section{Rabustness}

As a first robustness check, we compute our main models for female fulltime workers, obtaining the overall same results (see Table A5 in Appendix A). The main difference that we find between men and women is that characteristics of education systems seem to play a larger role for women than for men. Moreover, both unemployment benefits and public spending on ALMPs show a statistically significant and small, but positive correlation with skill-to-job matches for women, whereas the coefficient is not significant for men. The indicator capturing enablement is here also significant, but only at the $10 \%$ level. We also find nonlinear age-effects and more pronounced results for the dummies capturing education for women than for men.

Going back to our working sample of male fulltime workers, we furthermore address differences between the public and private sector, running the above outlined models separately for male fulltime workers in the public sector and in the private sector (Tables A6 and A7 in the online Appendix A). We find that all results hold for the private sector, but not for the public sector for which we hardly find any significant correlations that can explain variance. This is an interesting result in itself, and in line with theoretical reasoning: We would expect social policies like EPL to explain more variation in the private sector than in the public sector, as public sectors are highly regulated in all countries and therefore more similar across countries than private sectors.

For our working sample of male fulltime workers, we furthermore repeat the analyses excluding migrants (see Table A8). The main difference between this Table A8 and the results displayed in Table 2 is that the estimate of EPL is even bigger, and the indicator capturing enablement is significant at the $5 \%$ level. However, these results point in the same direction, providing further support for our theoretical reasoning.

To take into account the fact that institutions may not explain variation in outcomes of all groups of workers in the same way, we repeat these analyses for young (age $<35)$ and older (age $>=35$ ) male fulltime workers separately. Results are displayed in Table A9a and A9b. While, overall, the results point in the same direction, we find for young workers that vocational orientation is not significant, although, based on the stronger statistical significance, vocational specificity seems to be more important. The indicator for EPL does not change much in size, but slightly loses statistical significance. We find that - for this reduced sample - the estimates for both Knotz-indicators for enforcement and enablement disappear. This could also be due to the large reduction both in number of countries and number of individuals. We repeat these analyses for adult workers (age $>=35$ ). Here, the results are more pronounced. The main differences between adult and young workers is that for adults, vocational specificity does not seem to be relevant, whereas enablement 
here is (slightly) significant. However, the association is weak. The results for EPL are robust also if we only look at adult workers. As a further robustness check, we analyse whether our results are driven by single countries, re-running Models 1, 1a, 2 and 8 repeatedly with $\mathrm{n}-1$ countries. We find that the correlation between vocational specificity (Model 1a), EPL (Model 2) and optimal skill matching is robust and valid for all countries. However, we find that the US are an exception to the rule when it comes to the estimate of EPL. Our findings show that the association decreases a little if we re-run the model without the US-American data (see Table A10 in the appendices to this chapter). The US have a lower amount of skill matching combined with a low EPL that allows employers to fire workers that are not optimally productive. We conclude that EPL can work in two ways: through the hiring and the firing process. Repeating this robustness check for vocational orientation (Model 1) and enforcement (Model 8), we find that the observed associations here are driven by the outliers Canada and the United States. These two countries score high on enforcement and have relatively low share of optimal matching at the same time. We conclude that the negative relation between enforcing policies and optimal skill matching that we reported earlier is only evident for very high values of enforcement. Generally, this robustness check still supports our theoretical arguing outlined in hypothesis $5 \mathrm{a}$ : If high levels of strict enforcing ALMPs are in place, the likelihood that workers are allocated to jobs that do match their skills is reduced. Full results are available upon request. Our final robustness check is concerned with model specification. Heisig, Schaeffer and Giesecke (2017) argue that multilevel models should generally include random effects of the control variables at the lower levels, since the assumption of cluster invariance is often not realistic. In Table A11, we present estimates for our main models with random effects for the lower level variables. This test shows that the estimates for EPL and enforcement are not sensitive to this model specification. The estimates for vocational orientation of the system, however, is. We conclude that the theoretical reasoning concerning EPL is largely supported while the argument for vocational orientation is more sensible toward model specification.

\section{Conclusion and Discussion}

According to recent studies, skill mismatches are a 'pervasive' (Cedefop, 2010) and 'persistent' phenomenon, implying that the incidence is also related to labour market structures (Flisi et al., 2016: 2). Against this background, the issue of optimal job-worker matching has gained importance as a topic of scientific, but also political and social relevance. Our analyses contribute to fill in a gap in existing literature by providing empirical evidence for the association between social policies and optimal skill matching, and by 
disentangling different shades of activating labour market policies that characterise todays' social policy mix of industrialised societies, examining their relation with optimal skill matching. We seek to outline the most important policy implications of our findings:

First and foremost, we provide empirical evidence that a higher EPL is associated with higher shares of optimal matching: The stricter the degree of employment protection legislation is, the more likely it is that workers are allocated to jobs that match their skill level. This is a strong and very robust finding that holds even if we control for vocational orientation, on a reduced sample of countries, or look at subgroups of workers. Furthermore, we find that EPL does not only explain variation in optimal matching for young entrants to the labour market but both adults and young workers in the same way. One possible explanation may be that a stricter EPL increases employer's awareness that skills must fit with requirements, particularly for workers in permanent contracts. The underlying mechanism of the association that we find is either in a more careful selection of workers into jobs or in lifelong learning: Keeping workers' skills matched with jobs over the years is related to providing opportunities for learning on the job. Our results provide first indications that employers may be more selective in the process of hiring, but this could go hand in hand with more emphasis on training on the job. The robustness check also suggests that the lack of EPL also explains variation through the firing decisions. The US is a country that combines a low level of skill matching combined with a low EPL, allowing employers to fire workers that are not optimally productive. The results open a promising research area that should be further explore in future studies.

Second, our findings initially seem to suggest that vocational education, especially but not only if it takes place in dual systems, is correlated with a higher likelihood of optimal matching: The higher the vocational orientation and vocational specificity of education systems, the more likely it is that workers are allocated to jobs that match their skill level, i.e. the higher the share of optimal matching. Based on micro data for 16-65-year-old fulltime workers, our findings seem to indicate that education systems with higher shares of enrolment in vocational education provide more than an "entry ticket" to the labour market for young people, as a high vocational orientation is associated with better matching over the working life course than in general education systems. Vocational specificity as provided by dual systems thereby seem mostly relevant for young workers. However, we further research is needed here, since we also find compelling evidence that this finding is sensitive to the specification of the multilevel model and thus may be an artefact.

Third, concerning activating labour market policies (ALMPs), we show that expenditures are not related to skill matching in that way. Using indicators that capture the qualitative mix of enforcing and enabling policy measures, we find a negative and highly significant 
correlation between enforcement and skill matching at the individual level: The more enforcing ALMP's are in place in a country, the less likely it is that workers are allocated to jobs that match their skills. However, this association is driven by extreme cases. Nevertheless, our findings provide first hints that strict enforcement does not lead countries in the right direction when it comes to facing the challenge of allocating the right people to the right jobs. The analyses that we conduct for women as robustness check provide more pronounced results than the analyses for men. Especially ALMPs have been particularly designed to activate social groups that have formerly been largely inactive (such as women and especially mothers). This paper provides first indications that this is also relevant for optimal matching. However, the empirical evidence that we are able to provide concerning adverse effect for labour market outsiders is limited as we cannot identify causal effects using these data. Further research is necessary, i.e. to shed more light on the particularly interesting issue of selective policy effects. Our analyses are a first step towards a thorough investigation of the causal effect of policies that can help policy makers when facing the challenge of allocating the right people to the right jobs. 


\section{Appendices to Chapter 3}

\section{Description Al - Measuring Skill (Mis-)Match: Conceptual Approaches}

In the literature, there is an ongoing debate on how to capture the phenomenon of skill-tojob matching and what constitutes an adequate indicator of the mismatch. Irrespective of the concrete operationalisation, every concept of skill-to-job matches, or mismatch respectively, requires measures of both skills possessed (available e.g. in PIAAC) and skills required at the workplace. As the PIAAC survey only provides information on the skills possessed by workers, a direct and objective measure of skill matching based on a systematic evaluation of job requirements does not exist. By now, three different approaches have been developed to proxy skill requirements: (1) The worker selfassessment (WSA), for which workers are asked directly about the required level of skills. Although this approach is easy to implement in survey, it bears several problems, the most pressing one being the lack of an objective anchor (see Allen and van der Velden, 2005) and the risk of social bias ("talking up one's own job"). Approach (2) is the job requirement approach (JRA), capturing (mis-)matches between the skills that workers possess and the (frequency of) skill use at the job (see Green et al., 2013). One theoretical problem here is that skill use is not necessarily a good proxy for skill requirements, and that skill proficiency and skill use are closely interlinked and can therefore not be treated as two different forces. The third approach (3) is the so-called Realised Matches Approach (RMA), which is a commonly used statistical skill mismatch measure that captures the deviation of the individual skill proficiency from the mean proficiency in each occupation in each country (van der Velden and Bijlsma, 2018; Flisi et al., 2016; Perry, Wiederhold, and AckermannPiek, 2014; Pellizzari and Fichen, 2013). The main theoretical problem that arises with this approach is the forced equilibrium where, by definition, the 'average' worker is defined as well-matched (more detailed information is provided in chapter 2).

For the purpose of the analyses presented in chapter 3, this drawback of the RMA is not a problem. Note that we take an optimal matching approach. That means that we assume that the best skilled worker is allocated to the job that requires the highest skills level, the next best skilled worker is allocated to the job with the next highest skill requirements etc. This is perfectly in line with the RMA assumption that the average skilled worker is wellmatched if he/she is employed in a job with average skill requirements. In other words, as we look at relative matching rather than absolute matching, the RMA approach is perfectly suitable for our analyses. 


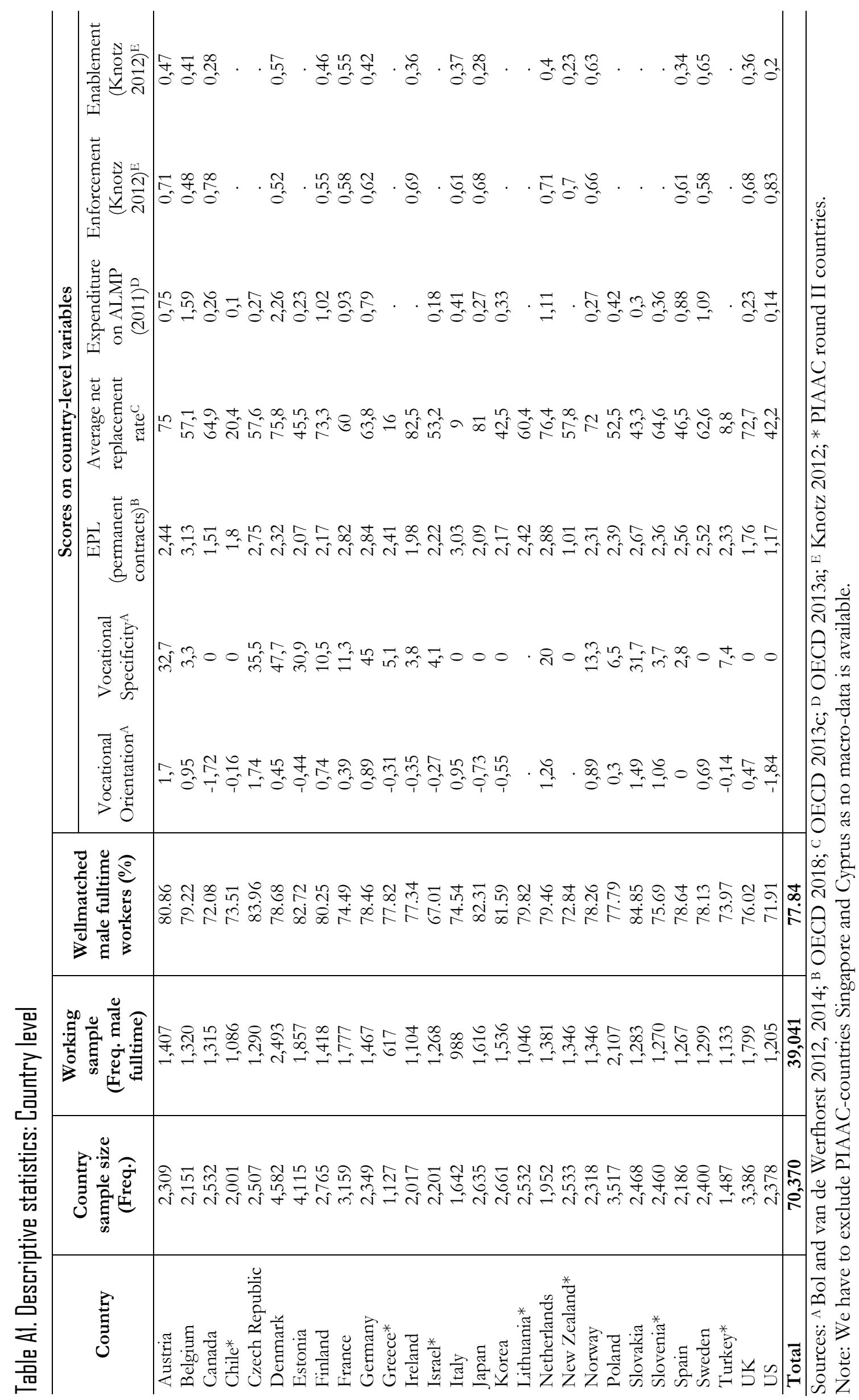



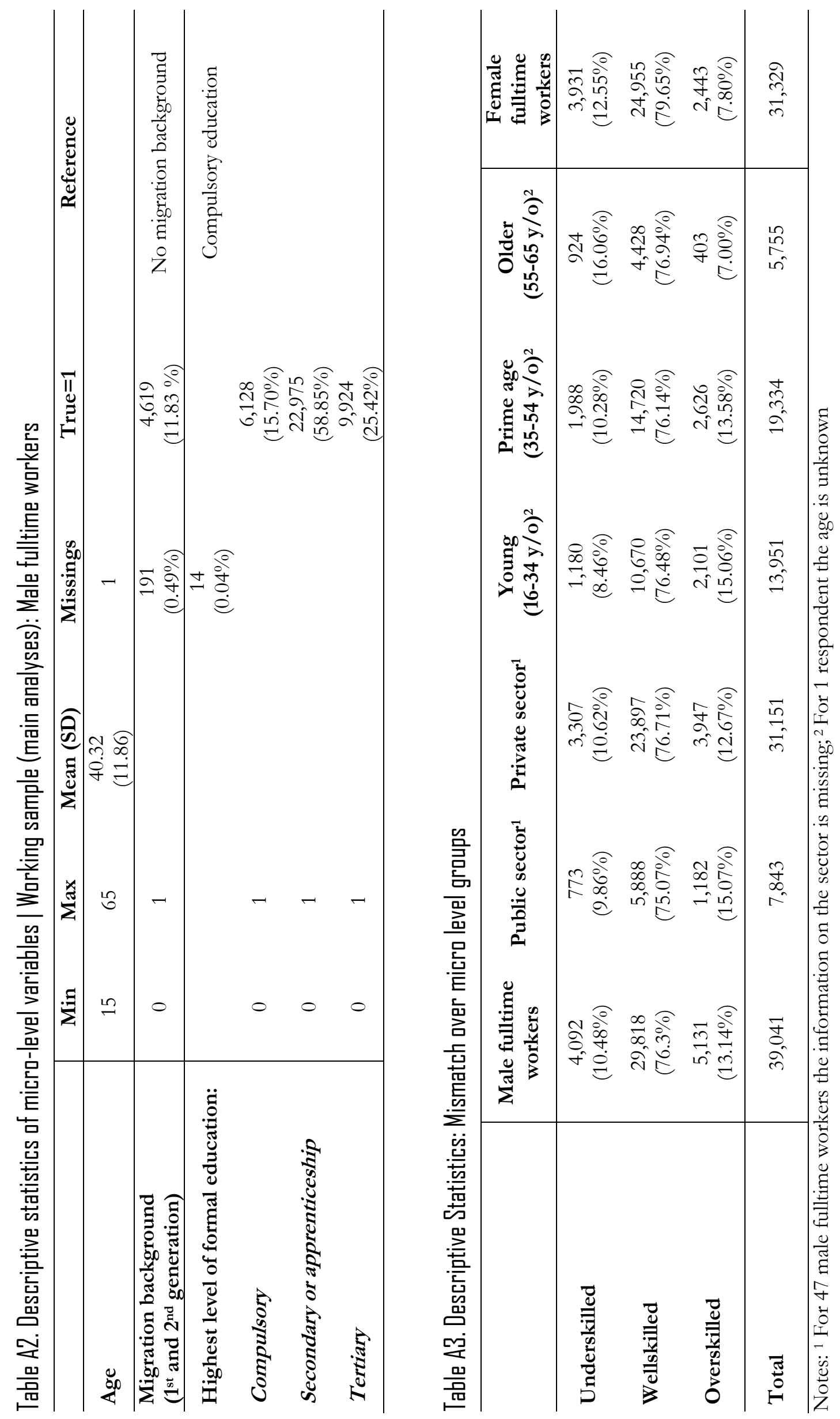


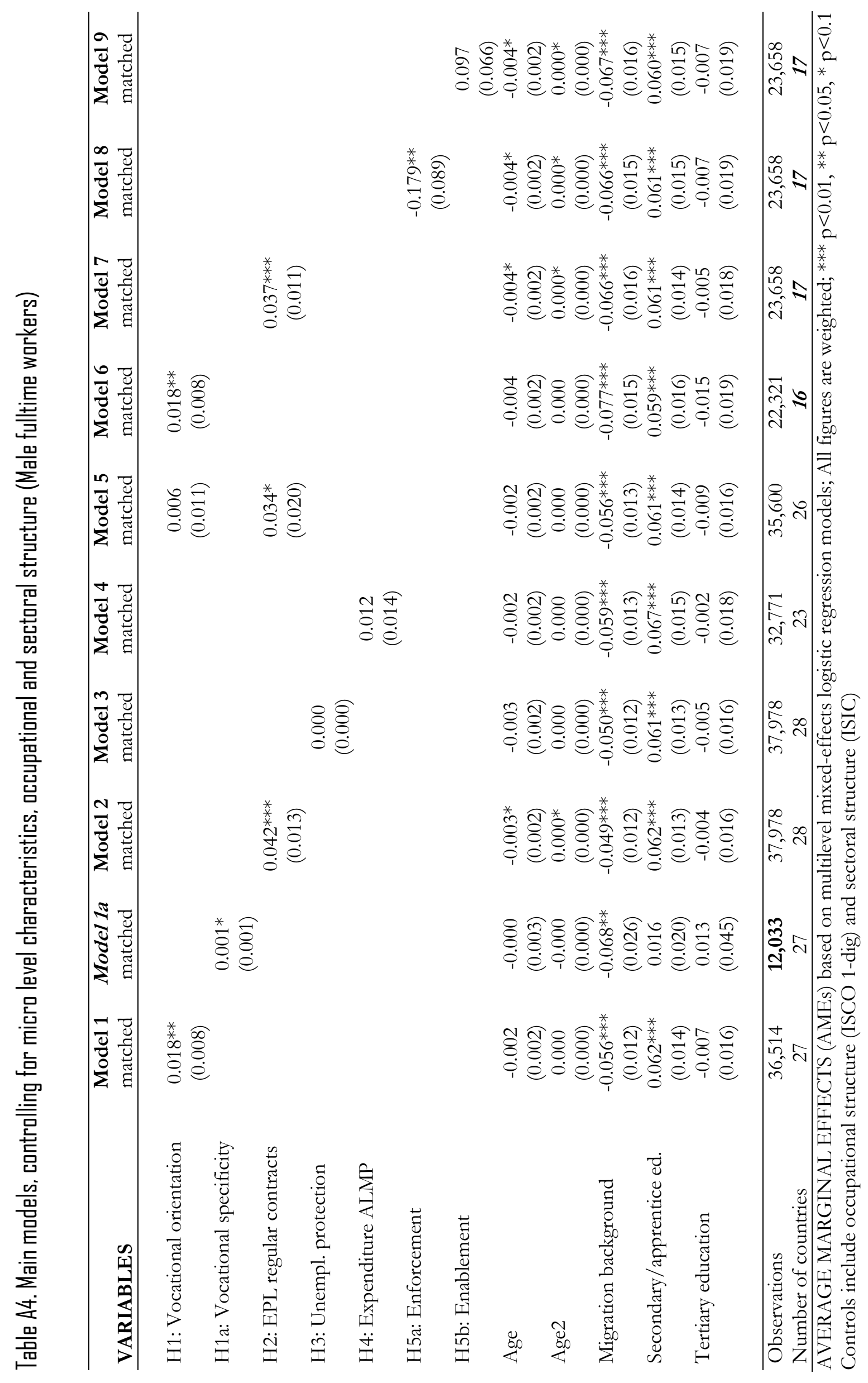




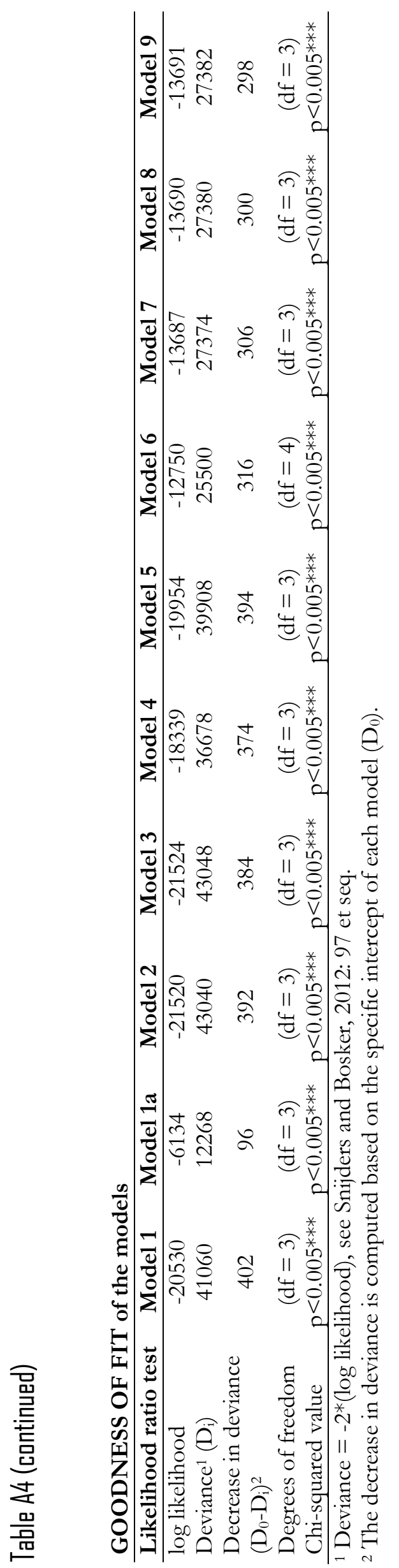

66 


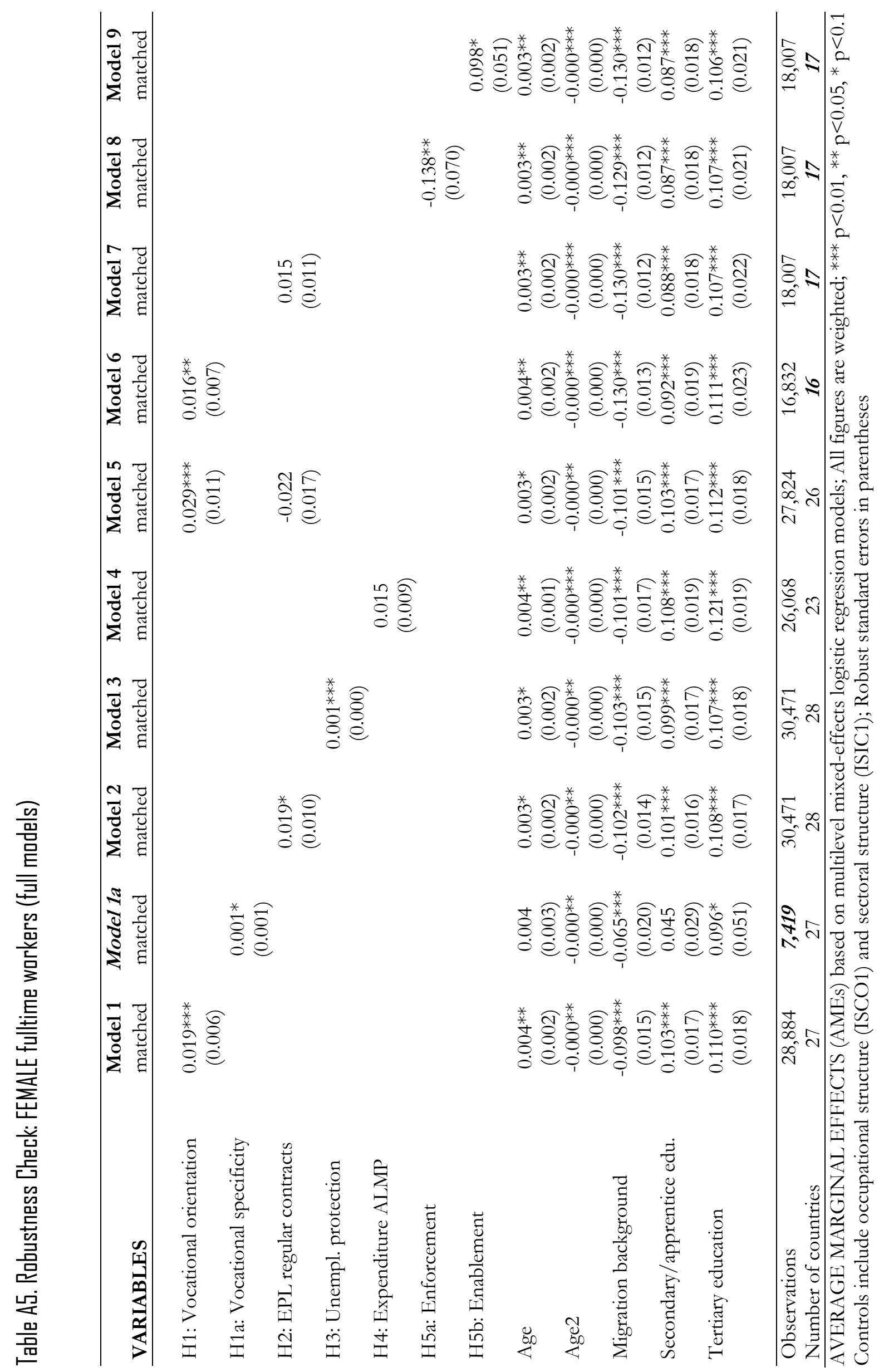




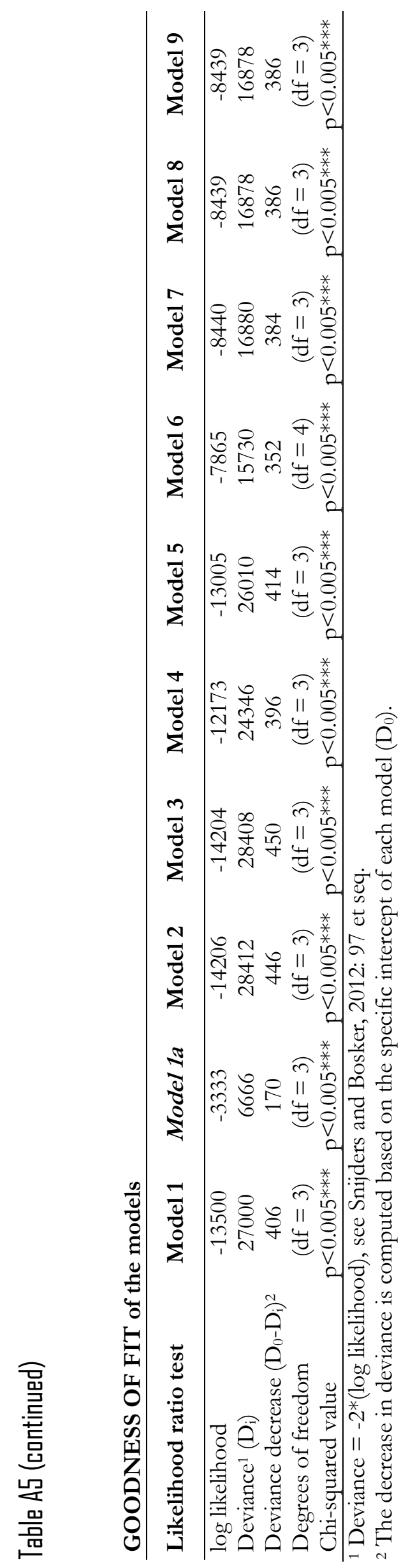

68 


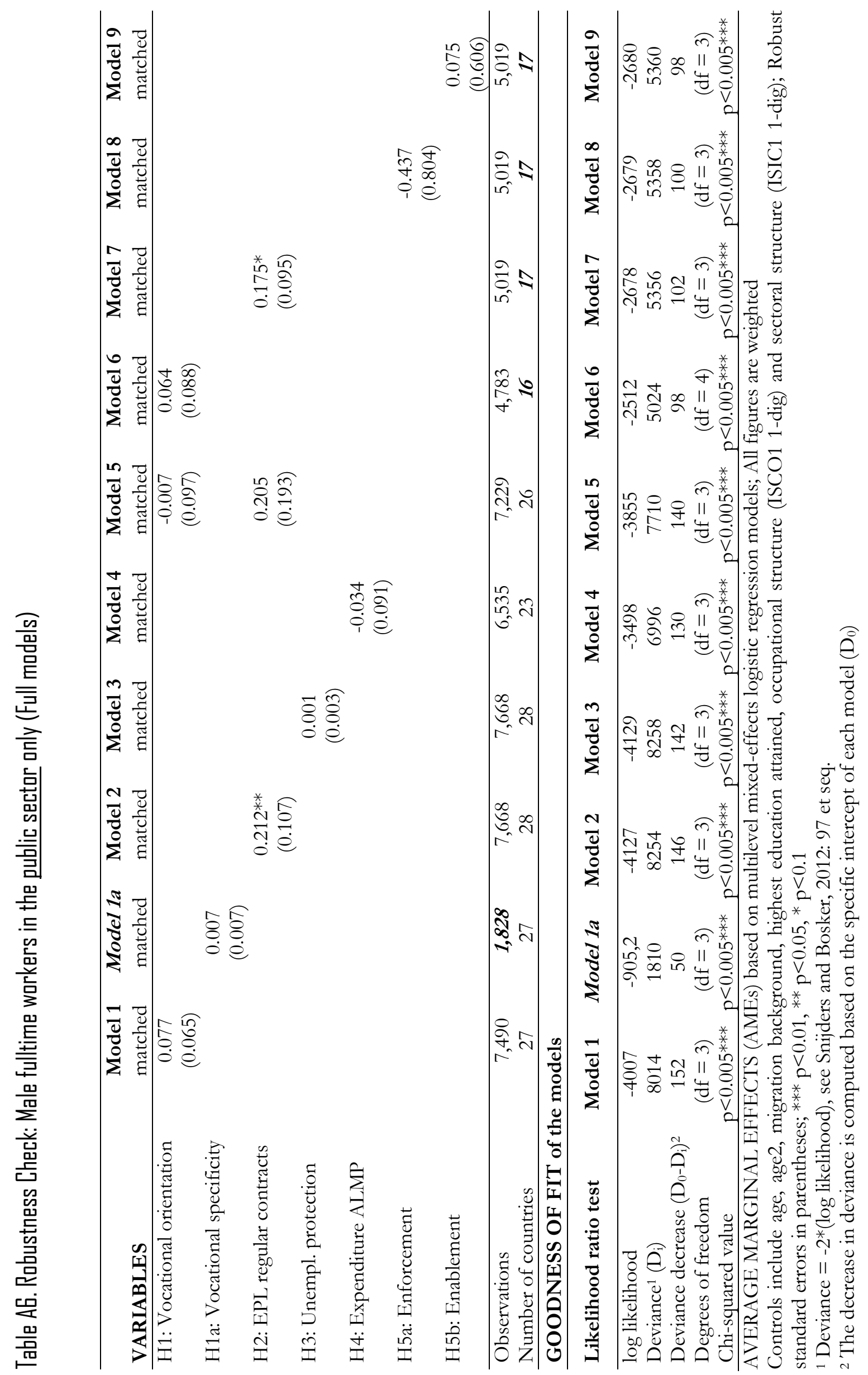




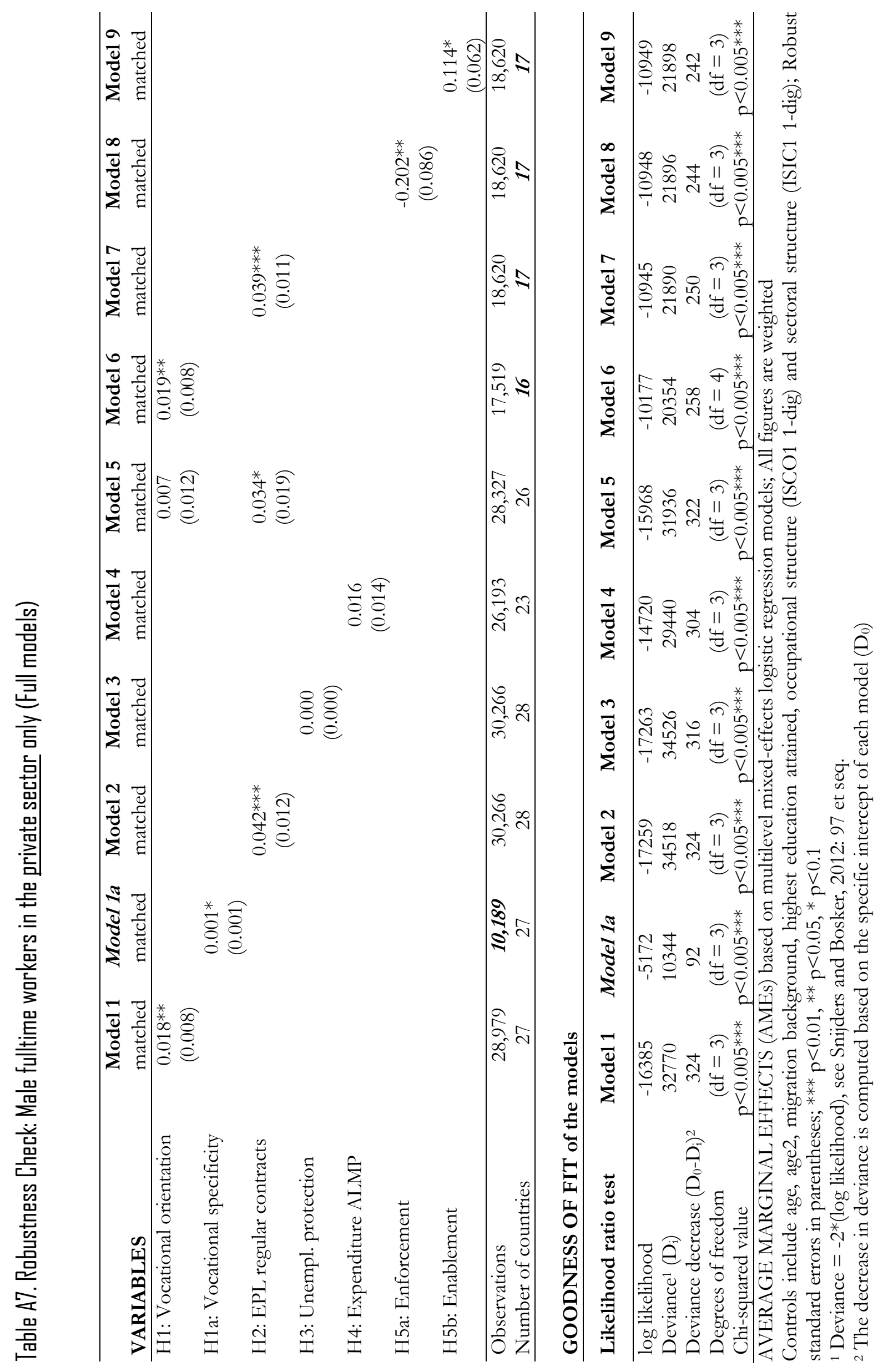




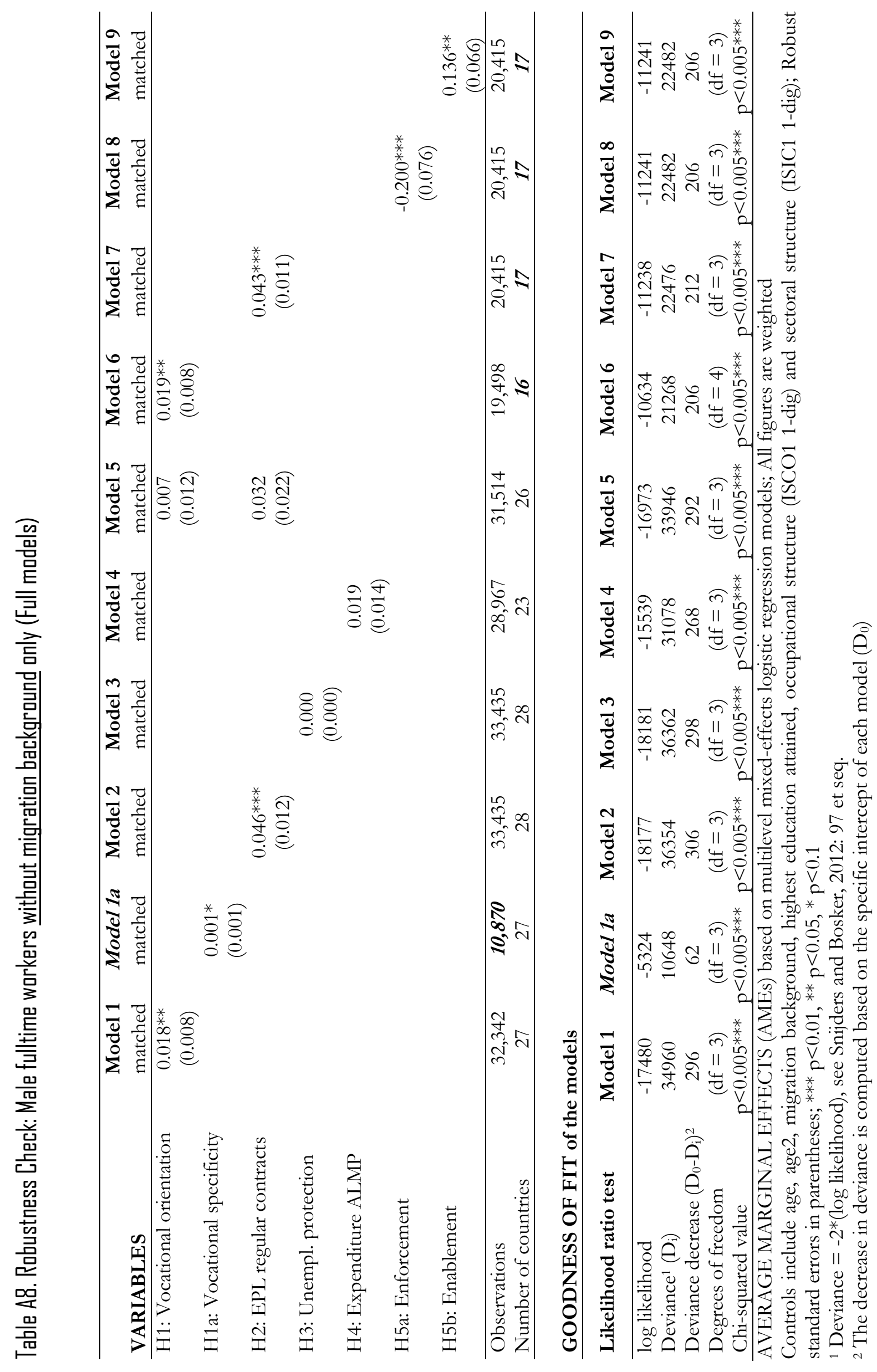




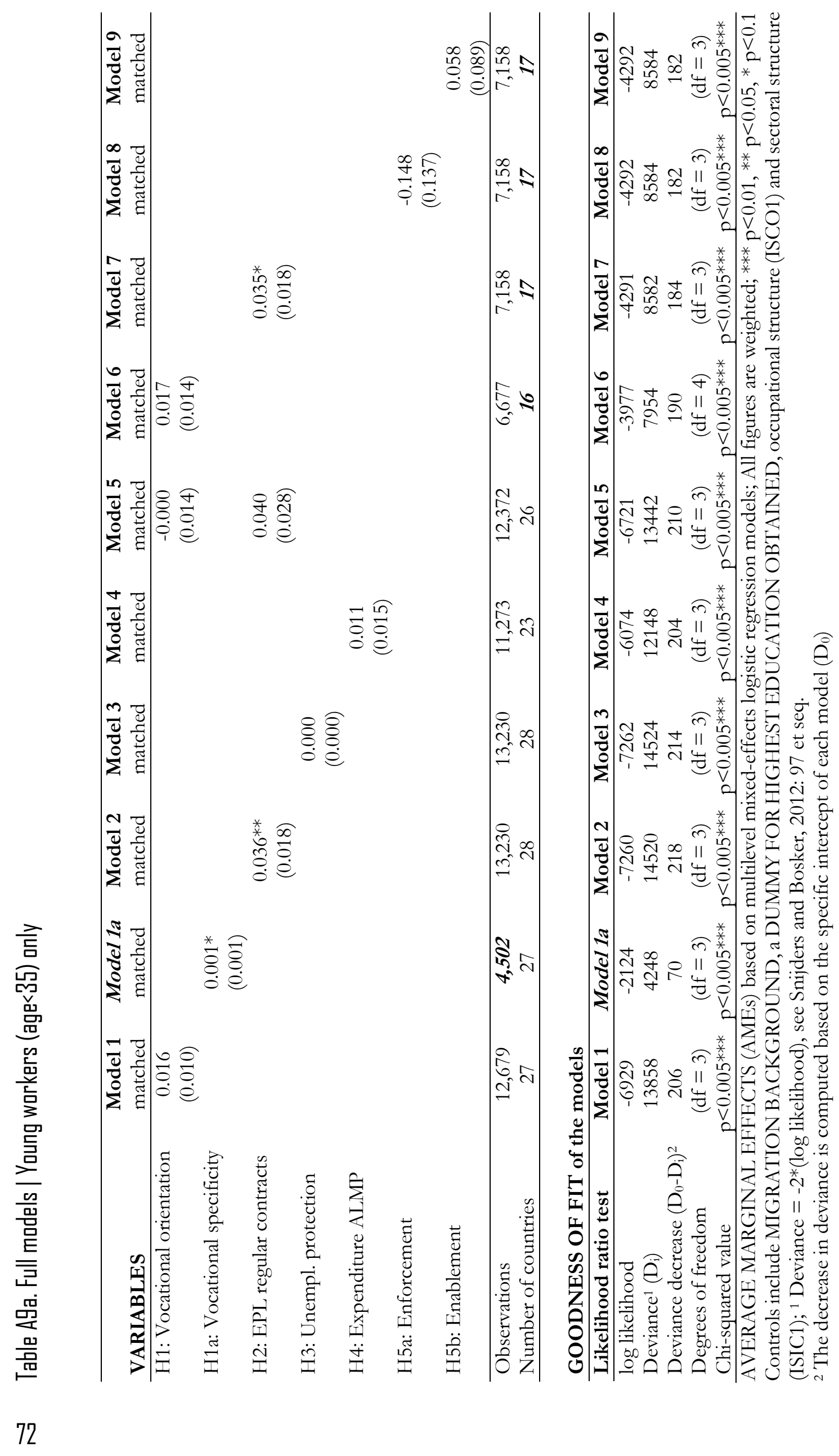




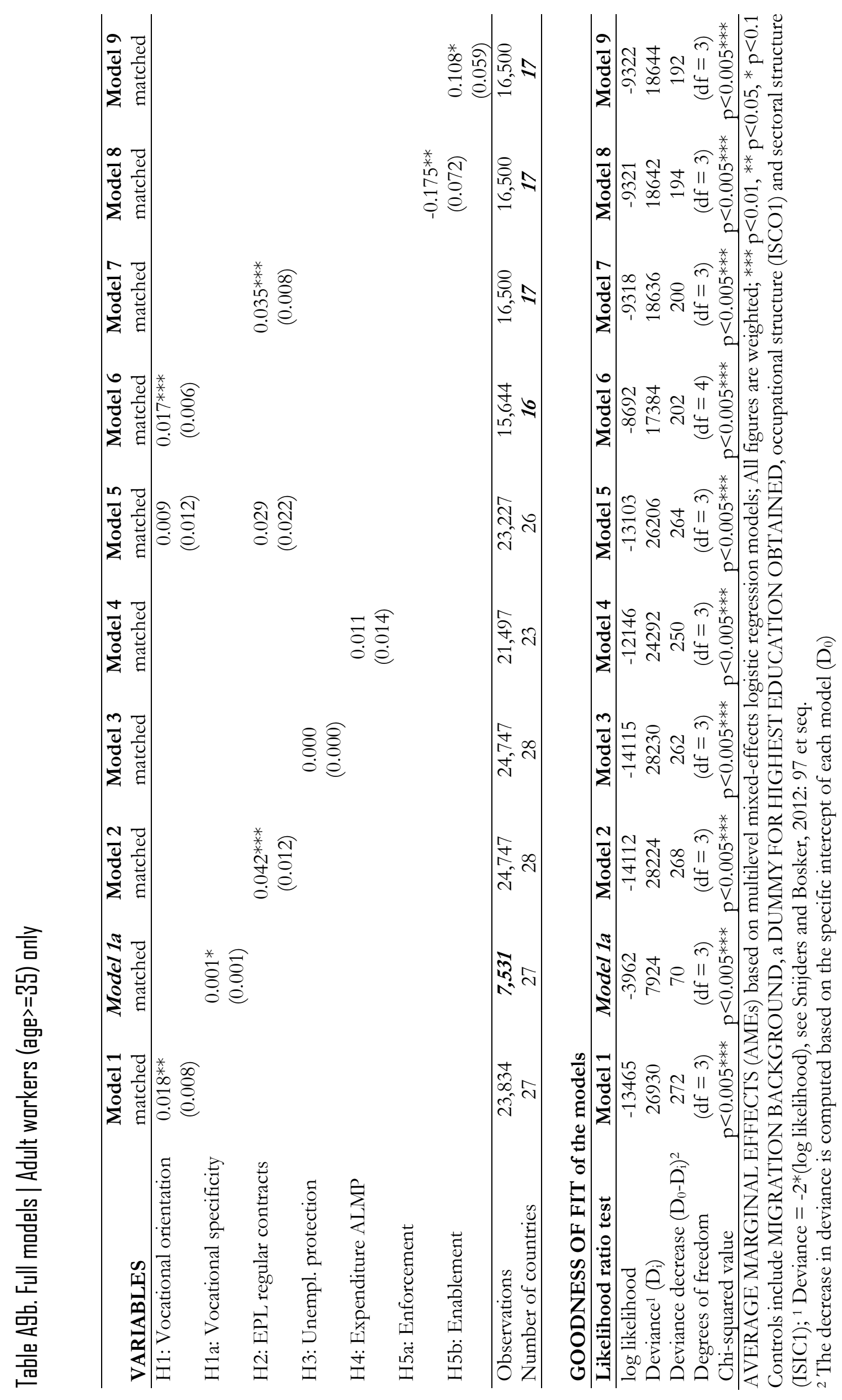




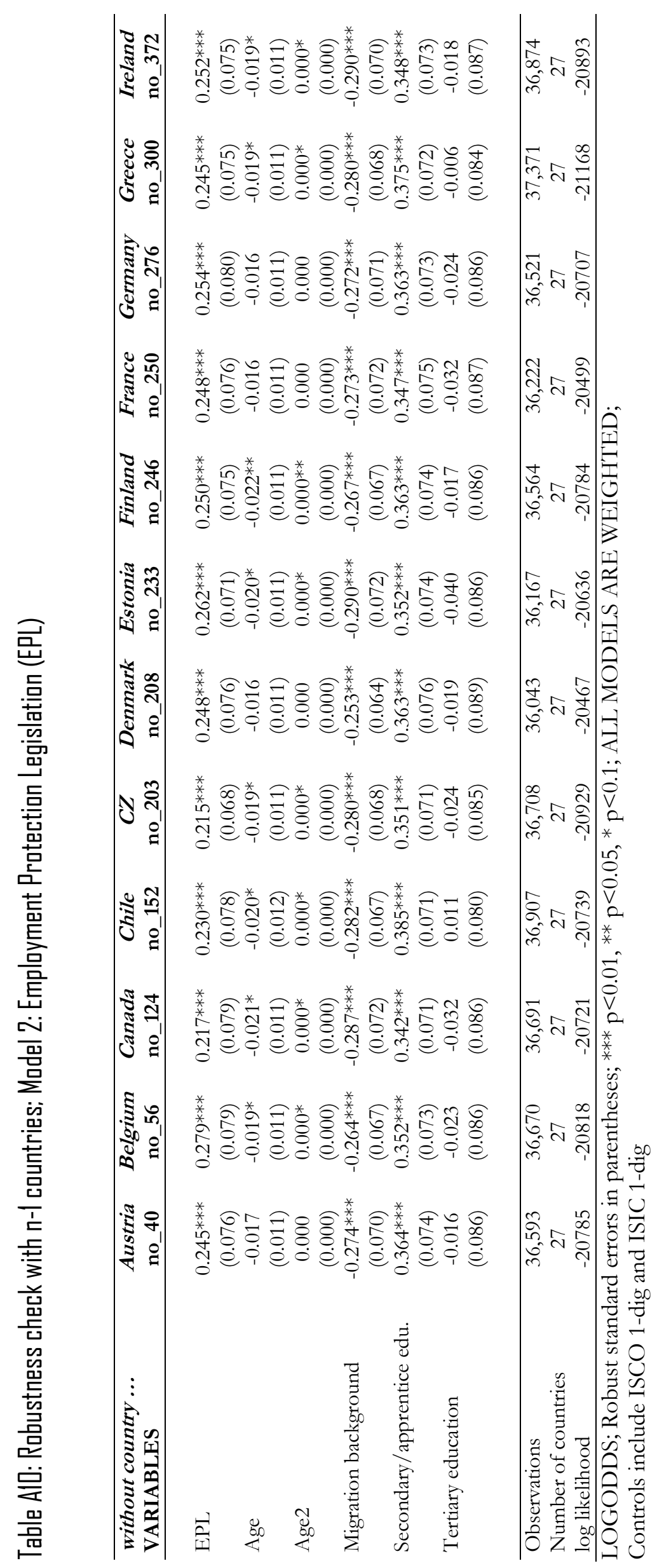




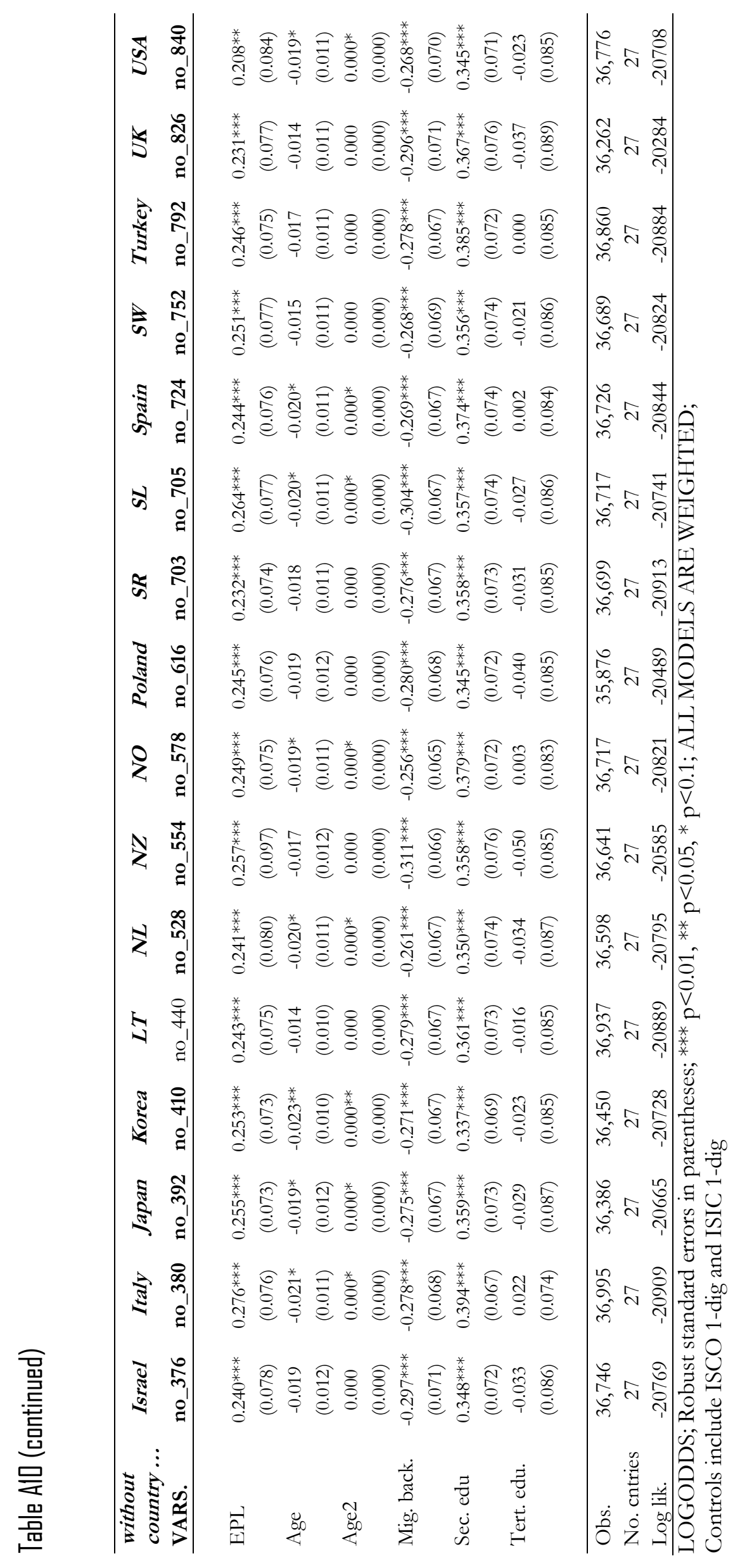


Table All: Models including randam slopes far lower level controls

\begin{tabular}{|c|c|c|c|c|}
\hline & Model 1 & Model 2 & Model 3 & Model 4 \\
\hline Vocational orientation & $\begin{array}{c}0.071 \\
(0.055)\end{array}$ & & & \\
\hline EPL & & $\begin{array}{c}0.218^{* * *} \\
(0.055)\end{array}$ & & \\
\hline Enablement & & & $\begin{array}{c}0.555 \\
(0.371)\end{array}$ & \\
\hline Enforcement & & & & $\begin{array}{c}-1.024 * * \\
(0.501)\end{array}$ \\
\hline Age & $\begin{array}{l}-0.008 \\
(0.011)\end{array}$ & $\begin{array}{l}-0.017 \\
(0.011)\end{array}$ & $\begin{array}{c}-0.023^{*} \\
(0.013)\end{array}$ & $\begin{array}{c}-0.023^{*} \\
(0.013)\end{array}$ \\
\hline Age2 & $\begin{array}{c}0.000 \\
(0.000)\end{array}$ & $\begin{array}{c}0.000 \\
(0.000)\end{array}$ & $\begin{array}{l}0.000^{*} \\
(0.000)\end{array}$ & $\begin{array}{l}0.000^{*} \\
(0.000)\end{array}$ \\
\hline Migration background & $\begin{array}{c}-0.371 * * * \\
(0.069)\end{array}$ & $\begin{array}{c}-0.321 * * * \\
(0.072)\end{array}$ & $\begin{array}{c}-0.360 * * * \\
(0.080)\end{array}$ & $\begin{array}{c}-0.358 * * * \\
(0.079)\end{array}$ \\
\hline Secondary of apprenticeship education & $\begin{array}{c}0.391 * * * \\
(0.066)\end{array}$ & $\begin{array}{c}0.382^{* * *} \\
(0.063)\end{array}$ & $\begin{array}{c}0.342^{* * *} \\
(0.079)\end{array}$ & $\begin{array}{c}0.343 * * * \\
(0.078)\end{array}$ \\
\hline Tertiary education & $\begin{array}{c}0.042 \\
(0.070)\end{array}$ & $\begin{array}{c}0.053 \\
(0.071)\end{array}$ & $\begin{array}{l}-0.036 \\
(0.098)\end{array}$ & $\begin{array}{l}-0.034 \\
(0.097)\end{array}$ \\
\hline Observations & 36,514 & 37,978 & 23,658 & 23,658 \\
\hline $\begin{array}{l}\text { Number of groups } \\
\text { log likelihood }\end{array}$ & $\begin{array}{c}27 \\
-48534\end{array}$ & $\begin{array}{c}28 \\
-50342\end{array}$ & $\begin{array}{c}17 \\
-13691\end{array}$ & $\begin{array}{c}17 \\
-13690\end{array}$ \\
\hline
\end{tabular}

ODDS RATIOS, obtained using a random slope at the country level; Robust standard errors in parentheses; All figures are weighted; ${ }^{* * *} \mathrm{p}<0.01,{ }^{* *} \mathrm{p}<0.05,{ }^{*} \mathrm{p}<0.1$; Controls include age, age 2 , migration background, highest education, ISCO 1-digit and ISIC 1-digit 


\section{Chapter 4}

\section{Much Ado About}

\section{Non-Monetary Dutcomes?}

\section{Skills, Skill Use and Mismatches and their Relation with Jab Satisfaction and Potential Social Dutcomes ${ }^{18}$}

\footnotetext{
${ }^{18}$ This chapter is joint work with Ineke Bijlsma, and Rolf van der Velden. We thank the participants of the Workshop "Educational policies, processes and social inequalities" by Herman van de Werfhorst at the University of Tuebingen (October 2017), the audience of the $4^{\text {th }}$ OECD PIAAC Conference in Singapore (November 2017) as well as of the CNAM-CEET Summer School 'Advanced Measurement of Quality of Working Life' in Paris (June 2018).
} 


\section{Abstract}

Skills and skill mismatches are claimed to have major consequences for individuals and societies, although convincing evidence mainly exists for wages. This chapter examines the association between skills, skill use, mismatches and job satisfaction as well as potential social outcomes, such as political efficacy and social trust. Drawing on data from the OECD Programme for the International Assessment of Adult Competencies (PIAAC), we contribute to sociological research by disentangling effects of skill use and proficiency, examining how they affect outcomes jointly or not jointly. We highlight the importance of skill use at work, comparing different skill mismatch measures, including the newly developed 'effective skill' concept. Our analyses provide evidence for two important messages: First, we find that once we use objective indicators for the skill-to-job match, there is no association with job satisfaction. In fact, skill use drives job satisfaction, not proficiency or mismatches. Second, we show that skill use and mismatches are associated with outcomes in social life. Even outside the work environment, skill use and mismatches are "much ado about something".

Keywords: Skill use, Skill Mismatch, Effective skill, Job Satisfaction, Social Outcomes

\section{Introduction}

Job-worker mismatches are claimed to be persistent and pervasive (Cedefop, 2018; Green, 2013). The significance of the literature on skill mismatch is driven by the fact that technological developments and the mass participation in higher education have changed both skills requirements of jobs, and the workforce of industrial societies, often resulting in a mismatch between supply and demand (Büchel, de Grip, and Mertens, 2003). In line with that, the proportion of job-to-worker mismatches increased over time (Verhaest and van der Velden, 2013). Evidence suggests that the consequences may be increasing as well (Green and Zhu, 2010), particularly if workers are trapped in a job for which they are overqualified (Vossemer and Schuck, 2016). The political and academic interest in skills and mismatches rests upon the concern that skills are not only important for the individual wellbeing but are also vital for the proper functioning of labour markets, democracies, and societies (European Commission, 2016). Nevertheless, convincing evidence mainly exists for individual wages (van der Velden and Bijlsma, 2018; Heyes, Tomlinson, and Whitworth, 2017; Hanushek and Woessmann, 2015a; Korpi and Tåhlin, 2009; Allen and van der Velden, 2001). However, if workers are in a situation in which their jobs require more (or 
fewer) skills than they can provide, it is not only about money. There are strong indications that skill mismatches, and particularly overskilling, may have a negative effect on job satisfaction (e.g. Verhaest and Verhofstadt, 2016; Allen, Levels, and van der Velden, 2013; Allen and van der Velden, 2001). Furthermore, characteristics of the work environment may affect orientations and values. Therefore, they relate to outcomes outside work such as the perception of the own efficacy in all kinds of settings, and general trust in other people (Kohn and Schooler, 1983). To capture the full impact of skills and mismatches, we must consider non-monetary and social outcomes in addition to monetary outcomes (Green and Henseke, 2016; McMahon, 2009; Freeman, 1976). We, thereby, define 'social outcomes' as individual outcomes with social effects and potential externalities for social groups, communities or societies. Restricting all our analyses to the micro level, we understand that outcomes such as the perception of political efficacy or social trust may contribute to social outcomes such as level of social cohesion.

In his seminal article, Peter Sloane raised the question about social outcomes, asking: Is overeducation "Much Ado About Nothing?" (Sloane, 2003). At the time, however, good mismatch indicators were lacking, and the empirical evidence was mainly based on workers' self-assessment of the skill match. The empirical evidence for social returns to skills has not been backed up yet by research based on objective indicators. To date, the OECD Programme for the International Assessment of Adult Competencies (PIAAC) provides detailed information on the actual skills of workers. PIAAC gives new and better opportunities for the investigation of returns to skills and the development of mismatch indicators that are based on objective rather than subjective data. Nevertheless, skill mismatch still poses challenges to sociological research and related academic disciplines, as no consensus exists on how to capture the phenomenon and what constitutes an adequate indicator.

The objective of this chapter is twofold: First, building on the discussion that skills have a broader impact, we seek to shed new light on the relation between skills, mismatches, and non-monetary outcomes inside and outside the work environment. Second, we seek to contribute to sociological research by applying the new 'effective skill' concept that has been developed by van der Velden and Bijlsma (2018). Previous skill mismatch measures typically focus on required skills and skill proficiency and the difference between the two. 'Effective skill', by contrast, offers a new theoretical perspective. Explicitly tackling the importance of skill use, the concept combines skill proficiency and skill use into a multiplicative function. Van der Velden and Bijlsma (2018) show that this concept is theoretically and empirically sound and even superior to alternative skill mismatch indicators in explaining wages. In this chapter, we apply the effective skill concept to explain non-monetary outcomes, thereby disentangling the effects of skill use and proficiency. 
Using PIAAC micro data, our analyses rely on objective skills measurements for male fulltime workers in 30 industrialised countries ${ }^{19}$. We provide evidence for two important messages: First, we show that there is no relation between skill mismatches and job satisfaction once we use objective measures for the skill match. Job satisfaction is in fact driven by skill use, not by overskilling or proficiency. The second message is that skills, skill use, and mismatches relate to social outcomes outside the work environment: The degree to which people use their skills effectively in their work is associated with their general values and orientations, for example, when it comes to the perception of political efficacy and social trust.

This chapter begins with a brief review of the state of the art concerning skills, workplace characteristics and returns to mismatches. Thereafter, we describe our dataset and analytical methods. We then investigate non-monetary outcomes related to skill mismatches, concluding with a discussion of our results.

\section{How do skills, skill use, and mismatches relate to non- monetary outcomes?}

Before we outline our theoretical considerations, we should first clarify what the subject of our study is: Skill mismatch. In its vertical dimension, the concept refers to a working situation in which the skills possessed by workers do not meet or exceed the skill requirements of their jobs. For example, we define workers as overskilled if they have more skills than required by the workplace, and hence do not have the chance to fully exploit their talent. Underskilled workers, by contrast, have fewer skills than required by their jobs. The scientific debate on skill mismatch is longstanding, and there has been a large amount of research during the past decades. Usually, the literature focuses on wages, showing that returns to excess skills are less than returns to required skills (e.g. Hanushek, Schwerdt, Wiederhold, Woessmann, 2015b; Levels, van der Velden and Allen, 2014b; Perry, Wiederhold and Ackermann-Piek, 2014; Leuven, Oosterbeek and van Ophem, 2004). Previous studies also addressed job satisfaction and mental well-being, finding that both are lower for overqualified workers (e.g. Heyes, Tomlinson, and Witworth, 2017; Green and Henseke, 2016; Verhaest and Verhofstadt, 2016; Allen, Levels, and van der Velden, 2013; Green and Zhu, 2010; Allen and van der Velden, 2001). However, given the lack of data on skills before the PIAAC survey was conducted, earlier studies merely rely on subjective measures, capturing the self-reported perception of the skill match instead of objective over- or underskilling. Against the background of previous findings, skills and

\footnotetext{
${ }^{19}$ A full list of these countries is presented in chapter 1, footnote 1, p. 5.
} 
mismatches are considered to have a broad impact, also affecting aspects of private and social life outside work (OECD, 2017; Desjardins and Schuller, 2006). Nevertheless, a deeper examination is largely missing in the present discourse (Green and Henseke, 2016). Starting in the 1970s with Kohn (1977), there is a literature on how workers' job characteristics relate to non-monetary and potential social outcomes. Our paper is the first to pick up this classical line of theoretical reasoning, combining it with new data on both skill use and objective skills assessments as provided by PIAAC. Investigating the broader impact of skill mismatch, we dig deeper into a topic of current academic, political and societal interest.

\section{Skills, skill use, mismatches and non-monetary outcomes}

We start with the question how skills, skill use, and mismatches relate to non-monetary outcomes. For job satisfaction, the relation with mismatches is straightforward. In general, satisfaction strongly relates to meeting expectations. People with certain skills expect that these skills are actually used in their work. And typically, their reference group is people who work in jobs that require these skills. Therefore, the expectation is that overskilling is negatively related to job satisfaction (e.g. van der Velden and Verhaest, 2017). For underskilling this relation is less straightforward. Some underskilling may indicate that people are working in challenging jobs, which in general increases satisfaction (van der Velden and Verhaest, 2017; Judge, Bono and Locke, 2000). However, in the case of serious underskilling, people might feel stressed to meet the job's requirements (Warr, 2013; 2007).

Job satisfaction, as a key determinant of general well-being, bridges the worlds of work and social life (Warr, 2013). Skills relate to generalised trust in other people, which we here refer to as 'social trust'. Skills also relate to the perception of the own (political) efficacy. Both social trust and political efficacy - require individuals to have the cognitive and analytical competency that is needed to "develop, maintain, and (perhaps) restore" trust (Borgonovi and Burns, 2015: 10; also see Schleicher and Thorn, 2016; McMahon, 2009). Research on the relation between work characteristics and values dates back to the seminal work of Kohn (1977), who shows that occupational experience and job characteristics, such as occupational self-direction, have a considerable impact upon (male) worker's values and orientations (also see Warr and Inceoglu, 2018; Green and Henseke, 2016). Kohn and Schooler (1983) show that the association between job characteristics and psychological functioning is driven by experiences: The more a worker experiences that he can be efficacious, the more likely it is that the same worker will believe in self-direction and efficacy. The authors show that occupational conditions conducive to the exercise of selfdirection (as evident e.g. through an effective exploitation of skills) are empirically related to having orientations to self and to the outside world consonant with this value of selfdirection (Kohn and Schooler, 1983: 54). We, therefore, would expect that the experience 
of an effective use of one's own skills contributes to an orientation that allows the worker to see society as so constituted that individual efficacy is both possible and useful. As work, society and self are distinct but entangled aspects of reality, we would expect spill over effects to all kinds of contexts: If people experience self-efficacy (e.g. at work), we would expect that they will be more likely to believe that they can be efficacious also in other domains of life such as the political system. Self-direction, efficacy, and an internal locus of control (Judge and Bono, 2001; Bandura, 1977) may also contribute to an open and flexible orientation towards others, forming the basis for social trust. An individual's positive attitude towards social trust and political efficacy has externalities that benefit other people, contributing to social cohesion and hence social capital (McMahon, 2009: 223; also see European Commission, 2016). Therefore, we refer to political efficacy and social trust as potential social outcomes.

We set out to test the following theoretical notions. We expect that job satisfaction relates positively to requirements in the job as challenging jobs may increase job satisfaction (van der Velden and Verhaest, 2017). In line with previous studies, we argue that any surplus of skills will negatively affect job satisfaction. The reason is that workers will compare themselves either with workers in the same job that deploy a lower level of skill or compare themselves with similarly skilled workers in jobs that require a higher level of skill. In both cases, they will find themselves in a situation that is disadvantageous, leading to lower levels of job satisfaction. The relation of underskilling to job satisfaction is less clear. As argued above, a small skill shortage may be positive for the worker. However, if the shortage is too big, it may lead to stress and reduced levels of satisfaction (van der Velden and Verhaest, 2017). We refrain from formulating a specific hypothesis on the effect of underskilling.

Concerning the social outcomes under study, we argue as follows. The perception of individuals about the own potential to exert influence on political issues is deeply rooted in individual experiences and based on cognitive and analytical capacities that are needed to develop and maintain an adequate perception of the own efficacy (Borgonovi and Burns, 2015). A high skill proficiency level combined with the experience of task-related efficacy at work due to a productive use of one's skills may serve as an empowering combination, increasing both engagement and effort in other domains of life (Kohn and Schooler, 1983). People who feel that they are in control of their work may also feel more efficacious when it comes to other contexts. We would also expect a positive relation with social trust, which is known to be related to skill proficiency and education, but which may also be underpinned by the experience of an efficacious exploitation of one's own skills and talents. We sum up these theoretical expectations as follows. 
If job satisfaction, political efficacy, and social trust are related to skill use, job requirements, and skill-to-job matches, we would expect to find support for following three hypotheses:

H1. Both skill proficiency and skill use in accordance with what is required at the workplace are positively related to job satisfaction, political efficacy and social trust.

H2. Being overskilled is negatively related to job satisfaction.

H3. Being overskilled is positively related to political efficacy and social trust as additional skills pay off, whereas the relation between being underskilled and these outcomes is negative.

\section{Data and Methads}

\section{I Data and sample}

To empirically test our hypotheses, we use the Survey of Adult Skills from the OECD's Programme for the International Assessment of Adult Competencies (PIAAC; see OECD 2016a; 2016b; 2016c). In this survey, adults aged 16-65 have been tested in key skills related to information processing at work and in daily life. For our analyses, we take numeracy and literacy skills as proxy for key information-processing skills deployed at the workplace. These skills capture the cognitive ability of individuals to grasp meaning and relevant new information which the respondents did not have before (OECD, 2016a). This new information can be presented in words, sentences, different types of texts - or in numerical sense as in the case of numerical literacy (numeracy). As such, information processing is the base for many tasks that people encounter in multiple contexts at work and in daily life, forming the basis for all further development of mastery and specific skill sets. Informationprocessing is a key skill needed for the full participation in knowledge-based economies and societies and can be deployed at all proficiency levels from very basic to very complex. PIAAC deploys a use-oriented, functional skills framework that involves managing a situation or solving a problem in a real context. Numeracy is therefore more than the individual ability to conduct simple arithmetical operations. It is defined as the "ability to access, use, interpret and communicate mathematical information and ideas in order to engage in and manage the mathematical demands of a range of situations in adult life" (OECD, 2016a: 18). Literacy is defined as "the ability to understand, evaluate, use and engage with written texts to participate in society, to achieve one's goals, and to develop one's knowledge and potential" (OECD; 2016a: 18). It is exactly these types of skills that will become ever more important in changing labour markets and digital economies and societies. Our main analyses use numeracy skills, whereas we provide additional analyses for literacy. 
We use data for 30 countries that participated in PIAAC ${ }^{20}$. We exclude Russia and Australia due to issues regarding data reliability and data protection legislation. From the Canadian sample, we take a random sample of about 20 percent to avoid overrepresentation in the dataset. For this chapter, we decided to homogenise our sample instead of modelling differences. We, therefore, restrict our analyses to male fulltime workers because labour market engagement, especially of older generations, is different for women. Moreover, the mechanisms that drive job satisfaction and the other outcomes under study may also be different for men and women. We exclude part-time workers because the indicators in PIAAC assessing the frequency of skill use are more adequately designed for fulltime workers. We furthermore exclude self-employed, members of the armed forces, unpaid family workers and students/interns as for these workers the allocation process is different from employees. Our main analyses rely on representative samples of male fulltime workers in 30 industrial countries based on a single analytical sample containing micro data for 38,901 respondents.

\subsection{Skill mismatch, skill use and nan-manetary autcames}

The theoretical reasoning that we outlined above suggests that it is important to look at skill use when explaining psychological outcomes and personal orientations that are relevant to multiple aspects of social and civic life. As argued above, job satisfaction is related to whether or not workers can actually use the skills they have. If workers cannot deploy the skills they have, to realise their full potential, this may lead to dissatisfaction. Similarly, self-direction in work and the experience of one's own efficacy is strongly related to what workers can actually do. Using skills is an important indicator for this. We, therefore, introduce skill use as separate component next to skill proficiency in our empirical analyses, and furthermore include job requirements in all skill mismatch measures that we use. In the literature, no consensus exists about how to measure skill-to-job matches and about what constitutes an adequate indicator. Skill mismatch measures typically focus on required skills and skill proficiency, capturing the differences between the two (e.g. Pellizzari and Fichen, 2013). Only two approaches exist that explicitly link skill proficiency and skill use. Allen, Levels and van der Velden (2013) compare skill use and proficiency and use this comparison to operationalise mismatches. The basic idea here is that workers use skills to a higher level than their proficiency permits and vice versa. By contrast, van der Velden and Bijlsma (2018) combine skill use and proficiency, integrating both into the effective skill model. Firmly based on efficacy theory (Bandura, 1977) and use-it-or-lose-it

\footnotetext{
${ }^{20}$ In most participating countries, the PIAAC survey was conducted in 2011/12 while some countries ran the survey in 2014/15.
} 
theories (Salthouse, 2006), the intuitive understanding of effective skill is that skills can have no effect if they are not put to productive use - and, vice versa, using skills can only have a small effect if proficiency is low.

Evidence suggests that the association between mismatches and outcomes are best explained by matching models, assuming that the combination of supply and demand determines outcomes (e.g. Hartog, 2002; Groot and Maassen van den Brink, 2000; Duncan and Hoffman, 1981). Following the logic of Duncan and Hoffmann (1981), skill matching models, such as the van der Velden/Bijlsma (2018) effective skill model, identify three underlying components: the typically required skills in an occupation (indicating skills requirements of jobs), and the individual overskilling or underskilling. In the effective skill model, "overperformance" refers to a situation in which the skills deployed by a worker are considerably higher than the skills required by the job, whereas "underperformance" is defined as the opposite. The Duncan and Hoffman (1981) matching model has been successfully replicated in studies all over the world (Groot and Maassen van den Brink, 2000; Hartog, 2000). We, therefore, apply the same underlying logic to test skill matching models on non-monetary outcomes, differentiating between over- and underskilling and controlling for the required skill level and skill use.

\section{Independent variables}

Irrespective of the concrete operationalisation, every concept of skill mismatch requires measures of both skills possessed by the worker (available in PIAAC) and skill requirements of the workers' workplace. However, in surveys like PIAAC, information is only available about the skills that workers possess, while a direct and objective measure of skill requirements of jobs is not available. Various approaches have been developed to proxy skill requirements, combining both skill proficiency and skill use into indicators of the skillto-job match. We make use of four of the most commonly used methods.

The first one is the effective skill matching model as developed by van der Velden and Bijlsma (2018). This model makes use of a so-called Realised Matches (RM) approach (for details see e.g. Hartog, 2000). The RM approach assumes that every occupation has a unique required skill proficiency level. To obtain robust estimates of the average skill proficiency for each country-specific ISCO 2-digit occupation category, we resort to calculations performed by Allen and Bijlsma (forthcoming) ${ }^{21}$. To identify well-matched vs. mismatched workers, we resort to the same cut-off point that has been used by van der Velden and Bijlsma (2018) in their paper on effective skill and wages. We proceed as follows: If the

\footnotetext{
${ }^{21}$ Van der Velden and Bijlsma (2018) show that the total explained variance does not change if they use 3-digit instead of 2-digit ISCO categories.
} 
effective skill of a certain worker lies more than 0.5 standard deviations above the required level in that occupation, the person is classified as overperforming/overskilled. If a worker's effective skill lies more than 0.5 standard deviation below the required level, this person is classified as working below the required effective skill level (underperforming/underskilled) (see van der Velden and Bijlsma, 2018). We compute dummies for over- and underperformance to be included in our statistical models alongside the continuous variable capturing required effective skill.

The second model is the one developed by Allen et al. (2013). As outlined before, the authors compare the individual skill use to the individual skill proficiency, capturing the relative skill use and the amount of over- and underutilisation of skills. They standardise both variables (skill use and skill proficiency) and look at the difference between the scores. If that difference is more than 1.5 standard deviation, they define the workers as overutilised (if the difference is negative) or underutilised (if the difference is positive). All other workers are defined as well-matched.

The third method we use is developed by Pellizzari and Fichen (2013). They assess the range of skill proficiency of all workers who identify themselves as well-matched. Every respondent with a skill proficiency level above $95 \%$ of the proficiency range of the wellmatched, is defined as overskilled, whereas every respondent below the $5 \%$ level is considered as underskilled (Pellizzari and Fichen, 2013).

Finally, we include a subjective measure which is based on worker's self-assessment (WSA) of the skill match. This is based on questions directly posed to the respondents in PIAAC. We define workers as underskilled if they answer "yes" to the question 'Do you feel that you need further training in order to cope well with your present duties?" and "no" to the question 'Do you feel that you have the skills to cope with more demanding duties than those you are required to perform in your current job?'. By contrast, we define workers as overskilled if they answer the opposite to both questions. Following the WSA approach developed by the OECD (2016a), self-reported well-matched people are respondents who answer "no" to both questions. We use this category as a reference. Many people reported that they are both underskilled and overskilled, a combination that is not interpretable. We include this mixed category in our models for the sake of completeness but do not interpret the results. Based on the self-assessment, the category "well-matched" is very small, containing only around 8 percent of all male fulltime workers. ${ }^{22}$

\footnotetext{
${ }^{22}$ This is problematic when it comes to giving a good description of the distribution of self-assessed skill mismatches in the different countries. However, in our case we are more interested in the effect of subjective overskilling or underskilling. These results are probably less biased.
} 


\section{Dependent variables}

We have three dependent variables: job satisfaction, political efficacy, and social trust. We decided to dichotomise all three. The first outcome under study - job satisfaction - is not normally distributed. Besides, factors that make worker satisfied may differ from those that make workers dissatisfied. We therefore predict satisfaction as opposed to no satisfaction. In PIAAC, the original variable that captures political efficacy is based on a 5-point scale ranging from "disagreement" to "agreement" with the statement 'People like me don't have any say about what the government does'. The category "neither agree nor disagree" does not seem to represent the indifferent middle in a continuum but rather should be interpreted as "don't know". We therefore predict disagreement with the statement vs. the rest. Social trust is based on the sum score of two five-level Likert items on the perception of general trustworthiness of people. We dichotomise this variable, distinguishing between high social trust (sum scores $>5$ ) and low social trust (sum scores $<=5$ ). For sample statistics, see Table 1.

\section{Measuring skill proficiency, skill use and skill requirements}

In PIAAC, skill use is based on an indicator that rates the frequency of skill use at the workplace with a six-item battery (each of the items conveys a 5-point scale, ranging from “never" to "every day"). Following van der Velden and Bijlsma (2018), we compute a simple average of the six items indicating the use of numeracy skills at work. For the proficiency scores, we use the average of the ten plausible values (PVs) for each skill domain that are drawn from the proficiency distribution and provided in the PIAAC dataset (OECD, 2016a; 2016b). We leave out the $1^{\text {st }}$ and $99^{\text {th }}$ percentile of the distribution to avoid outliers. Note that we standardise both skill proficiency and skill use with mean of 10 and a standard deviation of 123 . Our dataset contains individuals nested in sampling clusters (characterised by a specific weighting procedure) nested in countries. To properly consider country-level errors, we estimate multilevel mixed-effects logit regression models (using the melogit command in Stata 15) ${ }^{24}$. Computing multilevel models, we cannot make use of the replicate weights that are implemented in PIAAC. All analyses are therefore weighted using a 'rescaling to cluster size' approach with which we adjust the overall sample weight to

\footnotetext{
${ }^{23}$ We use a mean of 10 to avoid negative and zero values. Van der Velden and Bijlsma (2018) show that the results are not sensitive to which positive value is used, if it is large enough to avoid negative values or zero.

${ }^{24}$ Our multilevel logit model has the recommended 30 observations on the level 2-variable that are required for a proper estimation of the country effects according to the rule of thumb given by Bryan and Jenkins (2015). However, our main interest lies in the robust estimation of the individual level predictors. According to Bryan and Jenkins (2015), these would be unaffected even by a model specification with a smaller number of countries.
} 
account for different sizes of the country samples. We assign a random effect on the cluster level as well as on the country level (for detailed information about the dataset and technical issues see OECD, 2016a; 2016b). We conduct deviance tests to evaluate the correct fit of our statistical models (Snijders and Bosker, 2012).

\subsection{Methads}

As numeracy and literacy proficiency levels are highly correlated $(\mathrm{r}=0.89)$, we run the main analyses with numeracy and check the results for literacy (see Appendices to this chapter). In our main analyses, we first test job satisfaction as dependent variable before we move on to political efficacy and social trust. For each dependent variable under study, we proceed as follows. We begin with a basic model, testing the effects of skill use and skill proficiency as separate components (see Model 0 in all regression tables). After this, we estimate matching models to investigate the relation between skill mismatch and social outcomes. The effective skill matching model (Model 1 in all regression tables) is based on the following equation [1]

$Y_{i c}=\alpha_{c}+\beta_{1} R_{E S} S_{i c}+\beta_{2} \mathrm{OES}_{i c}+\beta_{3} U_{E S} S_{i c}+\beta_{4} C_{i c}+v_{i c}+\omega_{c}$

or

$Y_{i c}=\alpha_{c}+\beta_{1} E_{S M} M_{i c}+\beta_{2} C_{i c}+v_{i c}+\omega_{c}$

where $Y_{\text {ic }}$ is the outcome under study of individual $i$ in country $c ; \alpha_{c}$ is the country-specific constant; $\mathrm{ESM}_{\mathrm{ic}}$ is a vector of the three effective skill match variables: Required Effective Skill RES $\mathrm{ic}_{\text {c }}$ Overperformance in Effective Skill OES $\mathrm{S}_{\mathrm{ic}}$, and Underperformance in Effective skill $\mathrm{UES}_{\mathrm{i}}$; $\mathrm{C}_{\mathrm{ic}}$ is a vector of control variables (containing age and age squared) ${ }^{25}$. The idiosyncratic error term at the individual level is represented by $v_{i c}$ whereas $\omega_{\mathrm{c}}$ refers to the country-level error term.

As indicated above, we compare the effective skill matching model with alternative skill mismatch models as suggested by Allen, Levels and van der Velden (2013), and by Pellizzari and Fichen (2013) as well as the subjective WSA model. Results are displayed in Models 2, 3 and 4 in each regression table. Following the logic of the classical Duncan and Hoffmann

\footnotetext{
${ }^{25}$ Controlling for age and age squared, we make sure that the natural driven effect of the cognitive decline in skills over the life span does not bias our findings. In Appendix A we present the results for several robustness check, including one with educational attainment and wages as possible confounders. These results show that our main findings are robust and not driven by these micro confounders, although the effect sizes change as we would have expected (see Tables A6a-c). We furthermore run additional model specifications with different sets of microlevel confounders, using both worker and job characteristics, as well as a robustness checks for young workers only (see Appendix A).
} 
(1981) approach, we turn all mismatch models into standard matching models containing three components that indicate required skills and dummies for overskilling and underskilling. While the effective skill matching model contains all three components, Allen et al. (2013) and Pellizzari/Fichen (2013) only identify underutilisation/overskilling and overutilisation/underskilling. We complement these models, and the subjective WSA model, with skill use to proxy skill requirements of jobs (cf. Green et al., 2013). We estimate the following equation [2]

$\mathrm{Y}_{\mathrm{ic}}=\alpha_{\mathrm{c}}+\beta_{1} \mathrm{SU}_{\mathrm{ic}}+\beta_{2} \mathrm{OS}_{\mathrm{ic}}+\beta_{3} \mathrm{US}_{\mathrm{ic}}+\beta_{4} \mathrm{C}_{\mathrm{ic}}+\mathrm{vic}_{\mathrm{ic}}+\omega_{\mathrm{c}}$

Here, $\mathrm{SU}_{\mathrm{ic}}$ is the individual skill use score, and $\mathrm{OS}_{\mathrm{ic}}$, and $\mathrm{US}_{\mathrm{ic}}$ indicate overskilling and underskilling respectively. For the subjective skill mismatch measure, we additionally control for the mixed category (respondents who indicate that they need further training, and at the same time feel that they can cope with more demanding tasks).

\section{Results}

Testing the hypotheses that we outlined before, we compute matching models to examine the relation between skill mismatches and (1) job satisfaction, (2) political efficacy, and (3) social trust as dependent variables. We start the analyses with our basic Model 0 , assessing if and how numeracy proficiency and use affect the outcome. All tables display average marginal effects, reflecting the average change in the probability of being in category 1 (vs. 0) for an additional unit of the independent variable (Mood, 2010). To achieve a better comparison of the models, we standardise the continuous independent variables such as required effective skill. Note that to compare the results both numeracy proficiency and skill use have the same scale with mean of 10 and a standard deviation of 1 in each table. All mismatch indicators are dummy variables. For job satisfaction, Table 2 displays the main results. 


\section{TABLE 2 - Comparison of mismatch indicators; DV: Jab Satisfaction}

Average marginal effects based on multilevel mixed-effects logistic regression models, standard errors in parentheses; Parameters are multiplied by 100

\begin{tabular}{|c|c|c|c|c|c|}
\hline & \multirow[b]{2}{*}{ Model 0} & \multicolumn{4}{|c|}{ SKILL MISMATCH MODELS } \\
\hline & & Model 1 & Model 2 & Model 3 & Model 4 \\
\hline VARIABLES & $\begin{array}{l}\text { Skill prof. } \\
\text { \& skill use }\end{array}$ & $\begin{array}{c}\text { van der } \\
\text { Velden \& } \\
\text { Bijlsma } \\
(2018) \\
\end{array}$ & $\begin{array}{l}\text { Allen et } \\
\text { al. }(2013)\end{array}$ & $\begin{array}{c}\text { Pellizzari } \\
\text { \& Fichen } \\
\quad(2013)\end{array}$ & $\begin{array}{l}\text { Subjective } \\
\text { measure } \\
\text { (WSA) }\end{array}$ \\
\hline Skill proficiency (std.) & $\begin{array}{c}0.1470 \\
(0.4220)\end{array}$ & & & & \\
\hline Skill use (std.) & $\begin{array}{c}2.8273^{* * *} \\
(0.2845)\end{array}$ & & $\begin{array}{c}3.0535^{* * *} \\
(0.4201)\end{array}$ & $\begin{array}{c}2.9042 * * * \\
(0.3309)\end{array}$ & $\begin{array}{c}2.7694^{* * *} \\
(0.3409)\end{array}$ \\
\hline Required Effective Skill Level (std.) & & $\begin{array}{c}3.7751^{* * *} \\
(0.5469)\end{array}$ & & & \\
\hline Overskilled (Van der Velden/Bijlsma) (Dummy) & & $\begin{array}{l}-1.5601 \\
(1.4951)\end{array}$ & & & \\
\hline Underskilled (Van der Velden/Bijlsma) (Dummy) & & $\begin{array}{l}-2.5836^{*} \\
(1.5682)\end{array}$ & & & \\
\hline Overskilled (Allen et al.) (Dummy) & & & $\begin{array}{l}-0.6991 \\
(0.9423)\end{array}$ & & \\
\hline Underskilled (Allen et al.) (Dummy) & & & $\begin{array}{c}-2.7151 * * * \\
(0.9600)\end{array}$ & & \\
\hline Overskilled (Pellizzari/Fichen) (Dummy) & & & & $\begin{array}{l}-0.2185 \\
(0.9437)\end{array}$ & \\
\hline Underskilled (Pellizzari/Fichen) (Dummy) & & & & $\begin{array}{l}1.7561 * \\
(0.9069)\end{array}$ & \\
\hline Overskilled (WSA) (Dummy) & & & & & $\begin{array}{l}-4.7010^{* * *} \\
(1.1006)\end{array}$ \\
\hline Underskilled (WSA) (Dummy) & & & & & $\begin{array}{l}-2.7639 * * \\
(1.2743)\end{array}$ \\
\hline Mixed (WSA) (Dummy) & & & & & $\begin{array}{l}-1.3741 \\
(1.1233)\end{array}$ \\
\hline $\mathrm{N}_{\text {individuals }}$ & 38,901 & 38,901 & 38,901 & 38,901 & 38,901 \\
\hline $\mathrm{N}_{\text {countries }}$ & 30 & 30 & 30 & 30 & 30 \\
\hline Likelihood ratio test & Model 0 & Model 1 & Model 2 & Model 3 & Model 4 \\
\hline log likelihood & -19055 & -19017 & -19050 & -19053 & -19021 \\
\hline Deviance $^{1}\left(\mathrm{D}_{\mathrm{i}}\right)$ & 38110 & 38034 & 38100 & 38106 & 38042 \\
\hline $\begin{array}{l}\text { Decrease in deviance compared to Intercept } \\
\text { model }\left(\mathrm{D}_{0}-\mathrm{D}_{\mathrm{i}}\right)^{2}\end{array}$ & 188 & 264 & 198 & 192 & 256 \\
\hline Degrees of freedom & $(\mathrm{df}=2)$ & $(\mathrm{df}=3)$ & $(\mathrm{df}=3)$ & $(\mathrm{df}=3)$ & $(\mathrm{df}=4)$ \\
\hline Chi-squared value & $\begin{array}{c}\mathrm{p}<0.005 \\
* * *\end{array}$ & $\begin{array}{c}\mathrm{p}<0.005 \\
* * *\end{array}$ & $\begin{array}{c}\mathrm{p}<0.00 \\
5 * * *\end{array}$ & $\begin{array}{c}\mathrm{p}<0.005 \\
* * *\end{array}$ & $\begin{array}{c}\mathrm{p}<0.005 \\
* * *\end{array}$ \\
\hline
\end{tabular}

Parameters are multiplied times 100; All figures are weighted; Controls include age, age2;

${ }^{* * *} \mathrm{p}<0.01,{ }^{* *} \mathrm{p}<0.05,{ }^{*} \mathrm{p}<0.1 ;{ }^{1}$ Deviance $=-2 *(\log$ likelihood), see Snijders and Bosker, 2012: 97ff.

${ }^{2}$ The decrease in deviance is computed based on the specific intercept model of each mismatch approach 
The basic Model 0 in Table 2 confirms what we expected based on theoretical reasoning: Skill use is statistically highly significant and has a quite considerable positive relation with job satisfaction. Overall, workers are more satisfied with their jobs if they can make use of their skills. Skill proficiency, however, is not associated with job satisfaction, at least not once we control for skill requirements of jobs (proxied by skill use) - which is an unexpected finding. It seems like the two independent variables do not relate to the outcome jointly - skill use drives job satisfaction, not proficiency. Given this, we refute hypothesis 1 for job satisfaction. Nevertheless, we want to see whether skill mismatches matter for job satisfaction, which we test with Models 1 to 4 . In line with previous studies, we expected to find that being overskilled relates negatively to job satisfaction (hypothesis 2). Looking at the likelihood ratio test, the effective skill matching model (Model 1) performs clearly better than the alternative skill mismatch Models 2 and 3 . However, given what we find in our basic Model 0, we must be cautious with the interpretation of the results. The findings based on the effective skill model indicate the following: There is a relative strong and highly significant correlation between the level of required effective skill and job satisfaction: workers in jobs that require more effective skill are also more satisfied with their jobs. However, being overskilled is not associated with a decrease in the satisfaction level, as the average marginal effect is statistically not significant. Underperformance is slightly significant at the $10 \%$ level, indicating a negative relation with job satisfaction. For the alternative skill mismatch measures by Allen et al. (2013) and Pellizzari/Fichen (2013) in Models 2 and 3, we find positive and significant associations of skill use and job satisfaction. Although the empirical evidence is relatively weak, we do find negative associations between underskilling and job satisfaction in all models, except the Pellizzari/Fichen-model. By contrast, we do not find any support for decreasing job satisfaction in the case of overskilling. Against this background, we must refute hypothesis 2. Being overskilled does not relate to job satisfaction ${ }^{26}$.

These are important findings. No matter which objective measure we use - the Allen et al. (2013) measure, Pellizzari/Fichen (2013) or the van der Velden/Bijlsma (2018) effective skill matching model - we do not find a correlation between being overskilled and job

\footnotetext{
${ }^{26}$ This finding is contrary to the results of the study by Allen et al. (2013), as the authors found that mismatched, and especially underutilised (meaning: overskilled) workers are less satisfied. The difference between the article at hand and the Allen et al.-study lies in the model specification: Allen et al. control for proficiency, whereas we control for skill use, following the classical Duncan and Hoffman (1981) specification. We also computed the model controlling for skill proficiency instead of skill use and obtained the same negative effect of skill mismatches on job satisfaction that Allen et al. found. The authors agreed that the results related to the negative effect of skill mismatches were entirely driven by skill use.
} 
satisfaction. This is contrary to what other studies have shown before, but that is because these previous findings were based on subjective measures of skill mismatch. If we look at the self-assessed, subjective measure of skill mismatch available in PIAAC (Model 4 in Table 2), we also find the expected negative effect of being overskilled. It thus seems that previous results on the relation between overskilling and job satisfaction, are only true when we measure skill mismatch in a subjective way. In other words, workers seem to become dissatisfied when they think that they can handle more complex jobs. However, based on this observation one cannot make any claim about the effect of real skill mismatch based on objective indicators.

To scrutinise these findings, we run several robustness checks and additional analyses, which can be found in Appendix A. First, we repeat the analyses for young entrants to the labour markets only, because here the expectations are clearer as young graduates will compare themselves with other graduates that did find a matching job. Even then, there is no association between objectively measured overskilling and job satisfaction, while skill use displays an even bigger and statistically highly significant average marginal effect (see Table A1). Second, we run the same analyses controlling for wages, as one could hypothesise that wages may affect the relation between skill-to-job matches and job satisfaction. We find that this is not the case (see Table A2). Third, we include various worker and job characteristics in our models (see Table A3). Controlling for task discretion (as proxy for worker autonomy), the possibility to exert influence at the workplace, highest education attained, migration background, temporary contract, public sector, firm size, occupation categories (ISCO 1-digit), age, and age squared, we obtain slightly different results: Skill use is no longer significant. In the Allen et al. model, we now find a negative effect of overskilling that is significant at the $5 \%$ level. Besides those changes, the results are overall comparable to what we have shown before. Another robustness checks including wages and educational attainment as to major micro level confounders (see Table A6a), however, underlines our findings. We conclude that the results displayed in Table 2 are largely robust: Even if we re-run our analyses for young workers only or include different sets of controls - we do not find any convincing support for hypothesis 2. Lastly, to check whether our results hold when controlling for self-selection into the labour market, we compute a sample selection logit regression model (see Table A5, Model 1). Although our conclusions are, of course, based on the fact that respondents are selected into employment, we find that all our findings are valid. We now look at the results for political efficacy, displayed in Table 3. 


\section{TABLE 3 - Comparison of mismatch indicators; DV: Political Efficacy}

Average marginal effects based on multilevel mixed-effects logistic regression models, standard errors in parentheses; Parameters are multiplied by 100

\begin{tabular}{|c|c|c|c|c|c|}
\hline & \multirow[b]{2}{*}{ Model 0} & \multicolumn{4}{|c|}{ SKILL MISMATCH MODELS } \\
\hline & & Model 1 & Model 2 & Model 3 & Model 4 \\
\hline VARIABLES & $\begin{array}{c}\text { Skill prof. } \\
\& \text { skill } \\
\text { use }\end{array}$ & $\begin{array}{c}\text { van der } \\
\text { Velden } \\
\& \\
\text { Bijlsma } \\
(2018) \\
\end{array}$ & $\begin{array}{l}\text { Allen et al. } \\
\qquad(2013)\end{array}$ & $\begin{array}{c}\text { Pellizzari } \\
\text { \& Fichen } \\
\quad \text { (2013) }\end{array}$ & $\begin{array}{c}\text { Subjective } \\
\text { measure } \\
\text { (WSA) }\end{array}$ \\
\hline Skill proficiency (std.) & $\begin{array}{c}6.0509 * * * \\
(0.5282)\end{array}$ & & & & \\
\hline Skill use (std.) & $\begin{array}{l}3.9578^{* * *} \\
(0.4176)\end{array}$ & & $\begin{array}{c}7.7619 * * * \\
(0.5889)\end{array}$ & $\begin{array}{c}6.0577 * * * \\
(0.5020)\end{array}$ & $\begin{array}{c}6.0358 * * * \\
(0.4727)\end{array}$ \\
\hline Required Effective Skill Level (std.) & & $\begin{array}{l}8.9159 * * * \\
(0.6968)\end{array}$ & & & \\
\hline Overskilled (Van der Velden/Bijlsma) (Dummy) & & $\begin{array}{l}2.8995^{* *} \\
(1.4149)\end{array}$ & & & \\
\hline Underskilled (Van der Velden/Bijlsma) (Dummy) & & $\begin{array}{l}-3.9495^{* * *} \\
(1.3047)\end{array}$ & & & \\
\hline Overskilled (Allen et al.) (Dummy) & & & $\begin{array}{c}8.5516 * * * \\
(1.4907)\end{array}$ & & \\
\hline Underskilled (Allen et al.) (Dummy) & & & $\begin{array}{c}-11.4615^{* * *} \\
(1.2187)\end{array}$ & & \\
\hline Overskilled (Pellizzari/Fichen) (Dummy) & & & & $\begin{array}{c}5.0533 * * * \\
(0.9760)\end{array}$ & \\
\hline Underskilled (Pellizzari/Fichen) (Dummy) & & & & $\begin{array}{l}-1.0170 \\
(1.0605)\end{array}$ & \\
\hline Overskilled (WSA) (Dummy) & & & & & $\begin{array}{c}1.6665 \\
(1.0533)\end{array}$ \\
\hline Underskilled (WSA) (Dummy) & & & & & $\begin{array}{l}3.3377 * * \\
(1.3305)\end{array}$ \\
\hline Mixed (WSA) (Dummy) & & & & & $\begin{array}{c}4.8103 * * * \\
(1.5117)\end{array}$ \\
\hline $\mathrm{N}_{\text {individuals }}$ & 38,901 & 38,901 & 38,901 & 38,901 & 38,901 \\
\hline $\mathrm{N}_{\text {countries }}$ & 30 & 30 & 30 & 30 & 30 \\
\hline Likelihood ratio test & Model 0 & Model 1 & Model 2 & Model 3 & Model 4 \\
\hline log likelihood & -24234 & -24274 & -24357 & -24450 & -24456 \\
\hline Deviance $^{1}\left(\mathrm{D}_{\mathrm{i}}\right)$ & 48468 & 48548 & 48714 & 48900 & 48912 \\
\hline $\begin{array}{l}\text { Decrease in deviance compared to Intercept } \\
\text { model }\left(\mathrm{D}_{0}-\mathrm{D}_{\mathrm{i}}\right)^{2}\end{array}$ & 1194 & 1114 & 948 & 762 & 750 \\
\hline Degrees of freedom & $(\mathrm{df}=2)$ & $(\mathrm{df}=3)$ & $(\mathrm{df}=3)$ & $(\mathrm{df}=3)$ & $(\mathrm{df}=4)$ \\
\hline Chi-squared value & $\begin{array}{c}\mathrm{p}<0.005 \\
* * *\end{array}$ & $\begin{array}{c}\mathrm{p}<0.005 \\
* * *\end{array}$ & $\begin{array}{c}\mathrm{p}<0.005 \\
* * *\end{array}$ & $\begin{array}{c}\mathrm{p}<0.005 \\
* * *\end{array}$ & $\begin{array}{c}\mathrm{p}<0.005 \\
* * *\end{array}$ \\
\hline
\end{tabular}

Parameters are multiplied times 100; All figures are weighted; Controls include age, age2;

${ }^{* * *} \mathrm{p}<0.01,{ }^{* *} \mathrm{p}<0.05,{ }^{*} \mathrm{p}<0.1 ;{ }^{1}$ Deviance $=-2 *(\log$ likelihood $)$, see Snijders and Bosker, 2012: $97 \mathrm{ff}$.

2 The decrease in deviance is computed based on the specific intercept model of each mismatch approach 
In Table 3, the basic Model 0 displays results that are in line with what we would have expected based on previous results: Both skill use and skill proficiency relate positively to political efficacy, although the effect of the latter is almost twice the size of that of skill use. Moving on to the skill mismatch models, we find that Model 1 - the effective skill model - has a better likelihood ratio test than the alternative skill mismatch models.

The effective skill model confirms both Hypotheses 1 and 3, indicating that the level of required effective skill is indeed highly associated with political efficacy. Regarding being overskilled, our theoretical considerations are also supported as excess performance pays off. In line with our expectations, being underskilled is negatively related to political efficacy, although the effects of both mismatch variables are considerably smaller than for required effective skill. The alternative objective skill mismatch models by Allen et al. (2013) and Pellizzari/Fichen (2013) show similar results although we note that the effect sizes in the Allen et al. model are considerably larger and the coefficient for underskilling is not significant in the Pellizzari/Fichen-model. Comparing the results for over- and underskilling, we find that overskilling relates positively to political efficacy, whereas underskilling shows a negative relation. In both models, skill use has a strong and positive relation to perceived political efficacy. The last Model 4 displays the results obtained using the subjective mismatch indicator. We find no effect for the perception of being overskilled and a positive instead of the expected negative effect for subjective underskilling, significant at 5\% level. As a robustness check, we again re-run these models using wages and educational attainment as important micro level confounders (see Tables A6b), finding that our main results are robust. We furthermore compute a sample selection logit regression model, finding that our conclusions are valid (see Appendix A, Table A5, Model 2). We now move on to the results for social trust, displayed in Table 4. 


\section{TABLE 4 - Comparison of mismatch indicators; DV: Social Trust}

Average marginal effects based on multilevel mixed-effects logistic regression models, standard errors in parentheses; Parameters are multiplied by 100

\begin{tabular}{|c|c|c|c|c|c|}
\hline & \multirow[b]{2}{*}{ Model 0} & \multicolumn{4}{|c|}{ SKILL MISMATCH MODELS } \\
\hline & & Model 1 & Model 2 & Model 3 & Model 4 \\
\hline VARIABLES & $\begin{array}{l}\text { Skill prof. } \\
\text { \& skill use }\end{array}$ & $\begin{array}{c}\text { van der } \\
\text { Velden } \\
\text { \& Bijlsma } \\
(2018) \\
\end{array}$ & $\begin{array}{l}\text { Allen et } \\
\text { al. (2013) }\end{array}$ & $\begin{array}{c}\text { Pellizzari } \\
\text { \& Fichen } \\
\quad(2013)\end{array}$ & $\begin{array}{c}\text { Subjective } \\
\text { measure } \\
\text { (WSA) }\end{array}$ \\
\hline Skill proficiency (std.) & $\begin{array}{c}5.2446^{* * *} \\
(0.6367)\end{array}$ & & & & \\
\hline Skill use (std.) & $\begin{array}{c}2.8581 * * * \\
(0.3057)\end{array}$ & & $\begin{array}{c}6.0220^{* * *} \\
(0.5491)\end{array}$ & $\begin{array}{c}4.6969 * * * \\
(0.4350)\end{array}$ & $\begin{array}{c}4.7310^{* * *} \\
(0.4293)\end{array}$ \\
\hline Required Effective Skill Level (std.) & & $\begin{array}{c}8.0049 * * * \\
(0.7201)\end{array}$ & & & \\
\hline Overskilled (Van der Velden/Bijlsma) (Dummy) & & $\begin{array}{c}1.4218 \\
(1.5605)\end{array}$ & & & \\
\hline Underskilled (Van der Velden/Bijlsma) (Dummy) & & $\begin{array}{l}-3.0281^{*} \\
(1.5567)\end{array}$ & & & \\
\hline Overskilled (Allen et al.) (Dummy) & & & $\begin{array}{l}8.0908 * * * \\
(1.5533)\end{array}$ & & \\
\hline Underskilled (Allen et al.) (Dummy) & & & $\begin{array}{l}-8.3096^{* * *} \\
(1.3598)\end{array}$ & & \\
\hline Overskilled (Pellizzari/Fichen) (Dummy) & & & & $\begin{array}{c}2.2277 * * * \\
(0.6881)\end{array}$ & \\
\hline Underskilled (Pellizzari/Fichen) (Dummy) & & & & $\begin{array}{l}-0.0359 \\
(0.8658)\end{array}$ & \\
\hline Overskilled (WSA) (Dummy) & & & & & $\begin{array}{l}-1.7020 \\
(1.0579)\end{array}$ \\
\hline Underskilled (WSA) (Dummy) & & & & & $\begin{array}{c}0.3737 \\
(1.2375)\end{array}$ \\
\hline Mixed (WSA) (Dummy) & & & & & $\begin{array}{l}-0.2090 \\
(1.0369)\end{array}$ \\
\hline $\mathrm{N}_{\text {individuals }}$ & 38,901 & 38,901 & 38,901 & 38,901 & 38,901 \\
\hline $\mathrm{N}_{\text {countries }}$ & 30 & 30 & 30 & 30 & 30 \\
\hline Likelihood ratio test & Model 0 & Model 1 & Model 2 & Model 3 & Model 4 \\
\hline log likelihood & -21080 & -20999 & -21194 & -21278 & -21278 \\
\hline Deviance $^{1}\left(\mathrm{D}_{\mathrm{i}}\right)$ & 42160 & 41998 & 42388 & 42556 & 42556 \\
\hline $\begin{array}{l}\text { Decrease in deviance compared to Intercept } \\
\text { model }\left(\mathrm{D}_{0}-\mathrm{D}_{\mathrm{i}}\right)^{2}\end{array}$ & 898 & 1060 & 670 & 502 & 502 \\
\hline Degrees of freedom & $(\mathrm{df}=2)$ & $(\mathrm{df}=3)$ & $(\mathrm{df}=3)$ & $(\mathrm{df}=3)$ & $(\mathrm{df}=4)$ \\
\hline Chi-squared value & $\begin{array}{c}\mathrm{p}<0.005 \\
* * *\end{array}$ & $\begin{array}{c}\mathrm{p}<0.005 \\
* * *\end{array}$ & $\begin{array}{c}\mathrm{p}<0.005 \\
* * *\end{array}$ & $\begin{array}{c}\mathrm{p}<0.005 \\
* * *\end{array}$ & 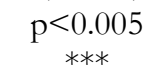 \\
\hline
\end{tabular}

Parameters are multiplied times 100; All figures are weighted; Controls include age, age2;

${ }^{* * *} \mathrm{p}<0.01,{ }^{* *} \mathrm{p}<0.05,{ }^{*} \mathrm{p}<0.1 ;{ }^{1}$ Deviance $=-2 *(\log$ likelihood), see Snijders and Bosker, 2012: 97ff.

${ }^{2}$ The decrease in deviance is computed based on the specific intercept model of each mismatch approach. 
In Table 4, we start again with an analysis whether skill proficiency and skill use explain variance in social trust as dependent variable. Model 0 displays what we would have expected: Both variables are highly significant and positively related to social trust, although the effect of proficiency is much bigger than the effect of skill use. This, too, is in line with what we know from previous studies.

The skill mismatch models support our hypothesis 1 for social trust: In all models, skill use displays quite considerable and statistically highly significant correlations. However, hypothesis 3 is only partly supported for social trust. The effective skill matching model (Model 1) shows a strong and positive relation between required effective skill and social trust. However, being overskilled is not significant, and being underskilled displays only a slightly significant negative correlation. Model 2 based on the Allen et al. (2013) skill mismatch model gives more pronounced results, supporting both Hypotheses 1 and 3 . The Pellizzari/Fichen model (2013), only gives a positive effect of skill use and overskilling, while there is no significant relation with underskilling. Among the alternative objective skill mismatch models, the effective skill matching model - again - shows the strongest likelihood ratio test. The results of Model 4 based on the subjective indicator show no effect of skill mismatches. We conclude that social trust, although primarily related to proficiency, is increased by the positive (and potentially empowering) experience caused by the utilisation of one's skills and talent. The robustness check with wages and educational attainment as micro confounders provides additional support for our findings (see Table Ac). Also, the sample selection logit regression model shows that our conclusions are valid (see Appendix A, Table A5, Model 3).

As outlined above, we re-ran our basic model and the effective skill matching model for all three dependent variables using the skill domain of literacy instead of numeracy (see Appendix A, Table A4). We find that our results are robust and largely consistent over the different skill domains, which is also in line with what we have expected based on the underlying proximity of these two, key information-processing skills. Compared to numeracy, the relation between literacy and political efficacy and social trust is stronger, e.g. underskilling displays the expected significant negative average marginal effect.

\section{Conclusion and Discussion}

Skill mismatch is claimed to have major consequences for societies and individuals, although convincing evidence mainly exists for individual wages (e.g. OECD, 2017). However, it is not only about money: Previous studies have shown that mismatches may lead to dissatisfaction, and that both skills and mismatches may explain variance in job satisfaction and other aspects of private and social life, as they are associated, for example, 
with ideas about one's impact on political processes as well as general trust in other people. This relation between proficiency, skill use and the mentioned social outcomes is established in the literature (Kohn and Schooler, 1983; McMahon, 2009).

Non-monetary outcomes such as job satisfaction, political efficacy, and social trust are not only important for individual well-being, but, in aggregate, also for the way in which labour markets and societies function. Investigating job satisfaction and potential social outcomes, our article addresses a topic of public, academic and political concern that has been identified as missing in the discourse on skill mismatch. We furthermore contribute to sociological research by applying a new approach to measure skill mismatch: the 'effective skill' concept, developed by van der Velden and Bijlsma (2018). In the article at hand, we relate this new measure to non-monetary outcomes, comparing the results with alternative indicators that are established in the literature. We draw on PIAAC data, the first study to provide detailed data on workers' actual skills, and skill utilisation for representative samples of the work force of a large number of countries. Our analyses are based on objective skills measurements for representative samples of some 39,000 male fulltime workers in 30 industrial countries.

We provide empirical evidence for two important messages, the first of which is that skill mismatch is not related to job satisfaction. Previous studies find negative effects of mismatches, and especially overeducation/overskilling, on job satisfaction. We show that based on objective indicators - making use of all alternative objective measures that we currently have - skill mismatch does not have an impact, as job satisfaction is in fact driven by skill use (also see Warr, 2013; 2007). People feel satisfied if they $d o$ things, especially if they do things, they are good at (Benz and Frey, 2008; Warr and Inceoglu, 2018). We deploy the unprecedented opportunities of the PIAAC data, and the newly developed theoretical perspective as provided by the effective skill model to show: There is no relation between objectively measured overskilling and job satisfaction - not even if we look at young entrants to the labour market only or when we include wages and different sets of other relevant job and worker characteristics. With this message, we contradict previous findings. Why? There are two major reasons for that: The main reason is the operationalisation of skill (mis-)match. The claim that former studies make regarding negative associations of skill mismatches with job satisfaction, is often based on subjective assessments of the skill match. To measure skill mismatch, both detailed information about a worker's real skill proficiency and skill requirements of jobs is needed. As PIAAC is the only dataset that provides this information for many countries, previous studies often could not assess objective skill mismatch measures. However, objective information about worker's real skill proficiency should always be the basis for an investigation of real skill-to-job matches. Drawing on such measurements as provided by PIAAC, our findings indicate that the claim 
that earlier studies made regarding the negative correlation between overskilling and job satisfaction is an artefact because the mismatch measures do not use reliable and objective proficiency indicators. However, job satisfaction is a subjective indicator and, therefore, influenced by the subjective evaluation of one's own situation compared to what a worker expected for himself compared to others. Our analyses show that if we measure mismatches subjectively, we find the same negative effects. Of course, subjective effects are also real effects. When workers feel mismatched, they are less satisfied. However, the correlation between different subjective measures is endogenous. The second reason lies in the model specification: Previous studies often do not appropriately control for skill requirements of jobs. E.g. Allen et al. (2013) found a negative effect of being overskilled, but they did not control for the level of required skills. We replicated their findings and found a negative effect, but once we control for skill use in the job (as a proxy for skill requirements) this negative effect of overskilling disappears.

The second message that we provide empirical evidence for is that both effective skill and skill (mis-)matches relate to potential social outcomes, such as political efficacy and social trust. We provide new support for the classical theoretical arguing that characteristics of the work environment affect orientations and values, and therefore relate to social outcomes outside work such as the perception of one's own efficacy in all kinds of settings, and general trust in other people. Kohn and Schooler (1983) have shown empirically that the experience e.g. of an effective use of one's own skills contributes to an orientation that allows the worker to see society as so constituted that individual efficacy is both possible and useful. As work, society and self are distinct but entangled aspects of reality, spill over effects can be expected, shaping the perception of the own efficacy also in other domains of life such as the political system. The experience of self-direction and -efficacy at work may also contribute to an open and flexible orientation towards others, forming the basis for social trust. Here, skill use (i.e. the experience of self-efficacy due to a full use of the own skills and talent) is of particular importance. Our paper is the first to pick this classical theoretical link between skill use, self-direction and social outcomes. Our analyses show that a surplus in skills or effective skill positively relates to social outcomes in most of the currently used skill mismatch models. Correspondingly, skill shortages and underperformance entail penalties for most models.

Further research is necessary to examine the relation between skills, skill use, mismatches, and outcomes and the relation with different dimensions of satisfaction and well-being. Thereby, it is important to make an informed choice about which mismatch indicator should be used. The effective skill model, for example, was developed to explore productivity in the job, hence the underlying assumption that skills in themselves can only be productive if deployed at work. The model proofed superior in explaining wages (van 
der Velden and Bijlsma, 2018). However, our results, particularly for job satisfaction, show no evidence that effective skill is also the best indicator here. For non-monetary outcomes, the Allen et al. (2013) model proofs to be most robust, giving stronger results than the other models. The Allen et al. model looks at individual experiences at work, capturing the intraindividual mismatch when a worker over- or underuses the own skill set. As our theoretical model based on Kohn and Schooler (1983) also addresses individual experiences, the Allen et al. model fits better with the theoretical mechanism at stake and proofs to be the better model when explaining social outcomes. We conclude that the dependent variable in combination with the underlying theoretical mechanism determines which mismatch measure should be used. Further research should assess whether this holds also for other social outcomes that assumedly relate to the same theoretical mechanisms, such as voluntary work or mental health.

What we observe leads us to the speculation that high proficiency combined with high skill use may serve as an empowering combination, creating a stronger feeling of efficacy. Taskrelated efficacy may potentially increase perceived efficacy in other domains of life (Bandura, 1977; Kohn and Schooler, 1983; Warr and Inceoglu, 2018). However, we cannot directly test these speculations empirically, which is an important limitation of our paper that further research should address. Moreover, the empirical analyses that we present here, are of limited scope. We decided to focus on male fulltime workers, homogenising our sample instead of modelling differences. Further research should model differences across social groups, including the gender comparison, and furthermore analyse differences across countries, thereby seeking to establish causal effects. Against the background of our findings, we are inclined to explore the potential of the PIAAC survey regarding social outcomes of skills and mismatches further. We hope that the second cycle of PIAAC will widen the possibilities for in-depth research on the outlined topics. Particularly, we seek to investigate how the increasing implementation of information and communication technologies at workplaces affects skill use at work and how this relate to different outcomes. Digital technologies change production and service delivery processes fundamentally, thereby affecting both skill use at work and skill requirements of jobs. Therefore, we would expect effects on non-monetary and potential social outcomes that should best be investigated through an identification of causality. However, this is a puzzle for further research to address. Our findings clearly indicate that, when it comes to social outcomes, skills, skill use and skill mismatch are "much ado about something". 


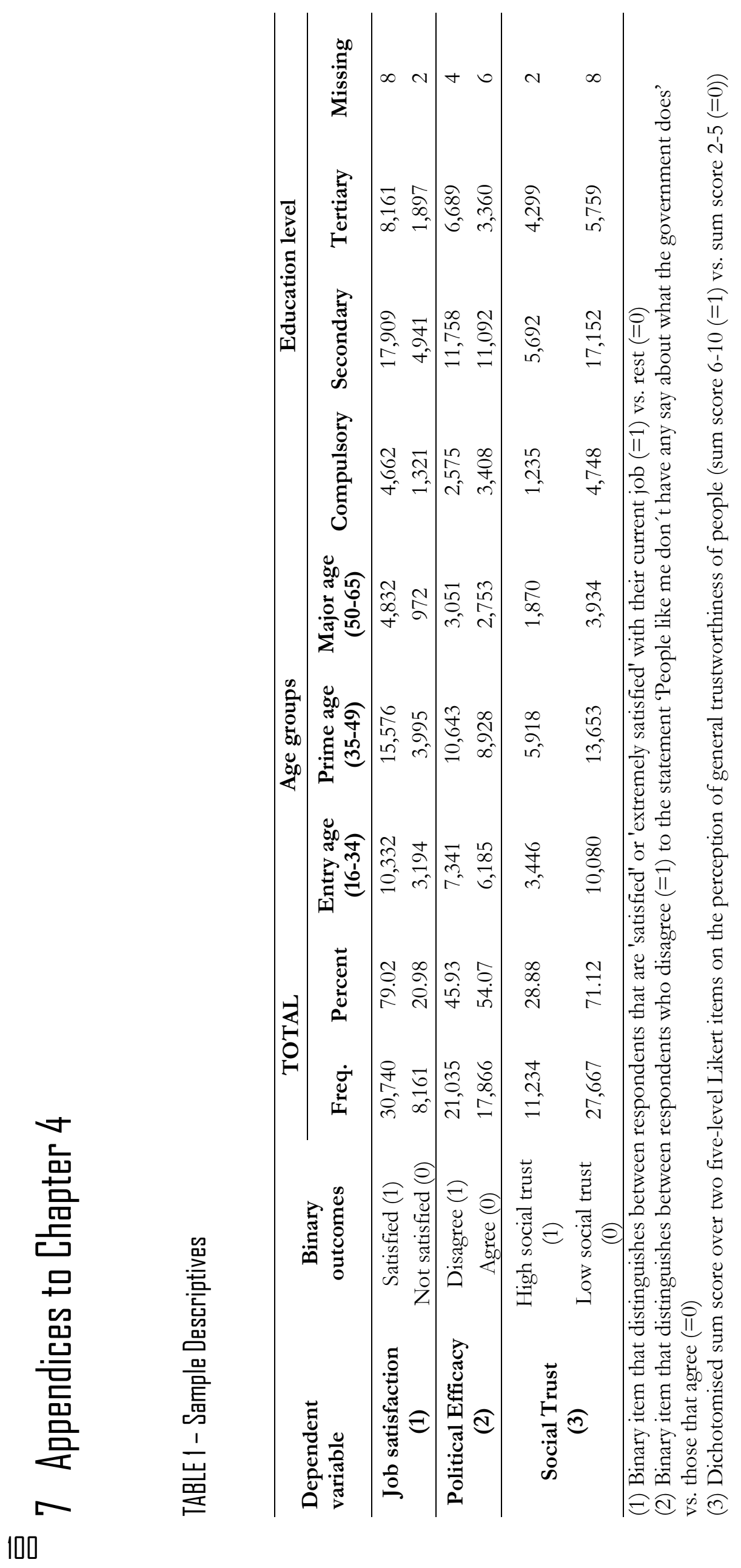




\section{Material AD - Additional backgraund infarmation on the 'Effective Skill' concept by van der Velden and Bijlsma (2018)}

The 'effective skill' concept is a new conceptual approach to measure skill mismatch. We use this appendix to provide the reader with details about the theoretical and empirical model, going beyond the information that we provide in the main text.

Integrating skill proficiency and skill use into a multiplicative function called 'effective skill', van der Velden and Bijlsma (2018) developed a new perspective on how skills and mismatches affect worker's outcomes. The intuitive understanding of the effective skill concept is that skills can have no effect if they are not put to productive use - and, vice versa, using skills can only have a small effect if proficiency is low (van der Velden and Bijlsma, 2018: 2). The authors apply this theoretical reasoning to develop their 'effective skill' concept, captured by the following equation [A1]:

$\mathrm{W}_{\mathrm{i}}=\alpha+\beta \mathrm{S}_{\mathrm{i}} * \mathrm{U}_{\mathrm{i}}+\mathrm{v}_{\mathrm{i}}=\alpha+\beta \mathrm{ES}_{\mathrm{i}}+\mathrm{v}_{\mathrm{i}}$

Here, $\mathrm{W}_{\mathrm{i}}=\log$ hourly wage of individual $\mathrm{i} ; \mathrm{S}_{\mathrm{i}}=$ skill proficiency, and $\mathrm{U}_{\mathrm{i}}=$ skill use of individual $\mathrm{i} ; \mathrm{ES}_{\mathrm{i}}=$ effective skill of $\mathrm{i} ; \mathrm{v}_{\mathrm{i}}=$ idiosyncratic error term (van der Velden and Bijlsma, 2018: 2).

To assess the impact of skill mismatches, the authors turn the effective skill concept into a standard matching model. Thereby, they follow the logic of the classical OvereducationRequired education-Undereducation (ORU) model by Duncan and Hoffman (1981). The ORU model breaks down the individual educational attainment into three components (years of education required for the job, years of overeducation, and years of undereducation). Results based on this model have been replicated in many studies all over the world (e.g. Groot and Maassen van den Brink, 2000; Hartog, 2000). Note that the ORU model uses years of education required on the job as crucial control proxying job requirements.

In their paper, van der Velden and Bijlsma use the ORU approach to identify three underlying components of the effective skill matching model: the typically required effective skill in an occupation (indicating skills requirements of jobs), and the individual overperformance or underperformance. Hereby, "overperformance" refers to a situation in which the effective skill deployed by a worker is considerably higher than the effective skill required by the job, whereas "underperformance" is defined as the opposite. To define mismatched individuals, the authors apply a so-called Realised Matches (RM) approach (e.g. Perry, 2017; Hartog, 2000). A person is classified as overperforming if his or her effective skill lies more than 0.5 standard deviation above the required level in that occupation. If a 
worker's effective skill lies more than 0.5 standard deviations below the required level, this person is classified as working below the required effective skill level (underperforming). Applying the ORU logic, and standardising both $S_{i}$ and $U_{i}$ with a mean of 10 and a standard deviation of one, equation [A1] can be written as in the following matching model [A2]:

$\mathrm{W}_{\mathrm{i}}=\alpha+\beta 1 * \mathrm{RES}_{\mathrm{i}}+\beta 2 * \mathrm{OES}_{\mathrm{i}}+\beta 3 * \mathrm{UES}_{\mathrm{i}}+\mathrm{vi}_{\mathrm{i}}$

Here, $\operatorname{RES}_{\mathrm{i}}=$ mean $\mathrm{ES}_{\mathrm{ij}}=$ typically required effective skill of individual in in occupation $\mathrm{j}$; $\mathrm{OES}_{\mathrm{i}}=$ individual overperformance, and $\mathrm{UES}_{\mathrm{i}}=$ individual underperformance.

Using the OECD PIAAC Survey, van der Velden and Bijlsma show that the effective skill assumption is theoretically and empirically sound as there is no effect of numeracy skill on wages, other than through using it (van der Velden and Bijlsma, 2018: 10). In this chapter, we extend the analyses to include job satisfaction and potential social outcomes. To test whether the association between the two components of effective skill and the outcomes under study is the same over the entire distribution, we perform additional analyses with quantile independent variables. For job satisfaction, the graphical representation of these regression results shows job satisfaction does not vary with numeracy skill proficiency. By contrast, the graphs for political efficacy and social trust show relatively smooth surfaces, clearly displaying a multiplicative effective skill effect.

\section{Figures: Regressions with quantile independent variables}

DV: Job satisfaction

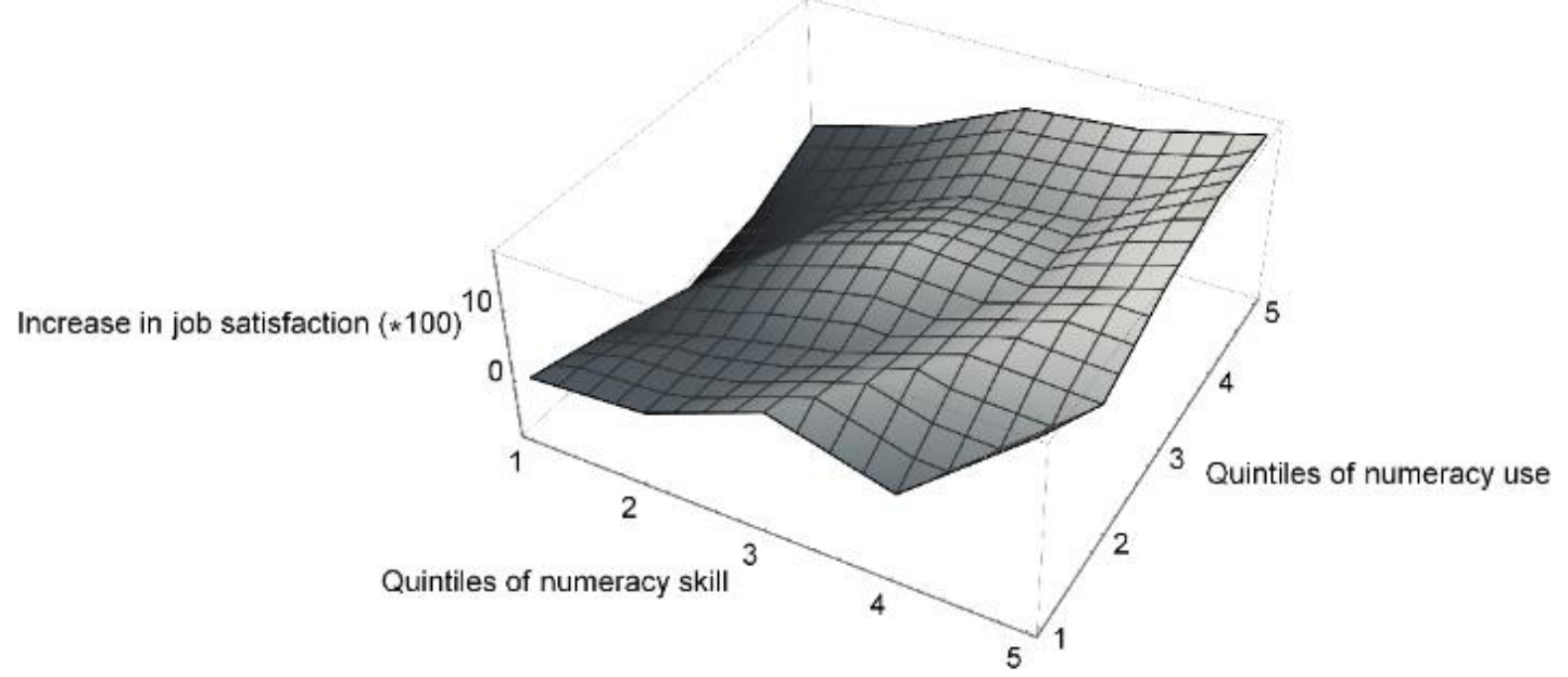


DV: Political Efficacy

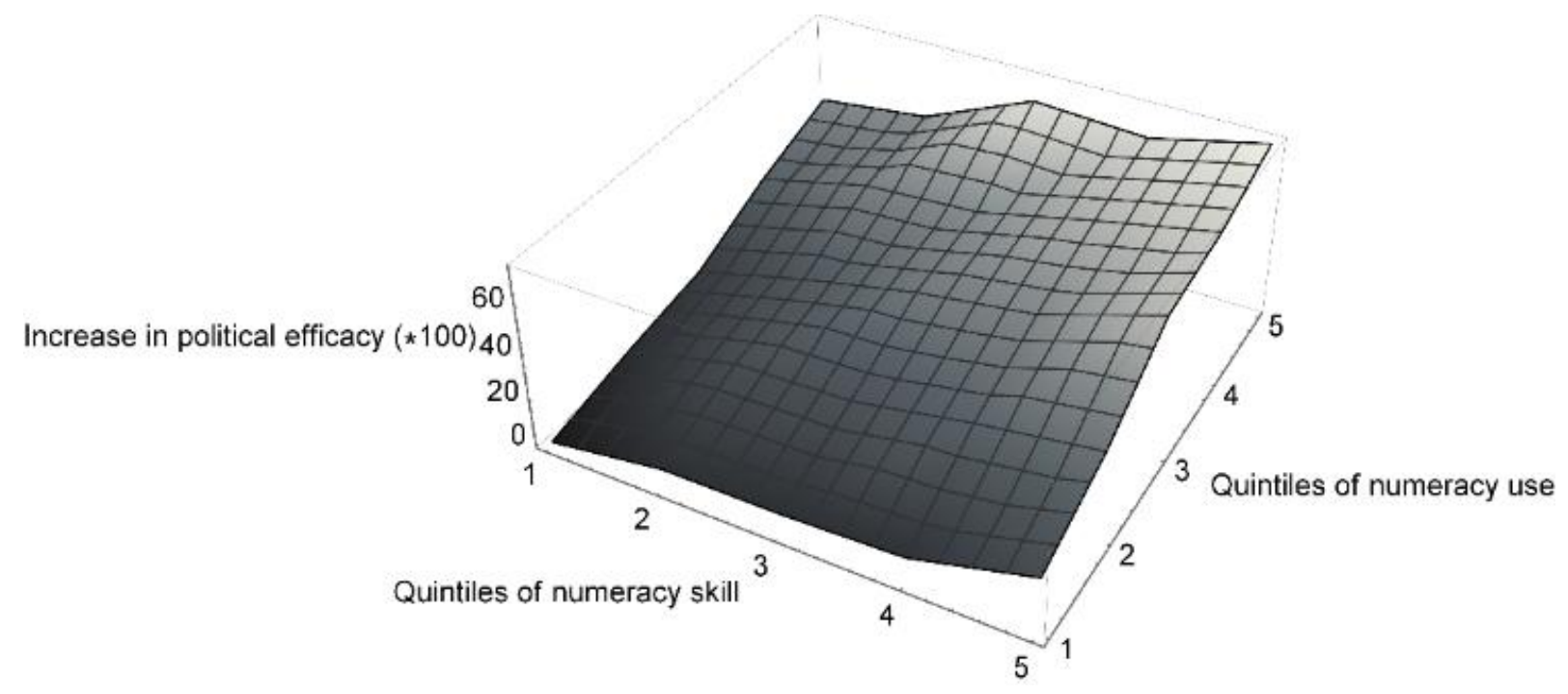

DV: Social Trust

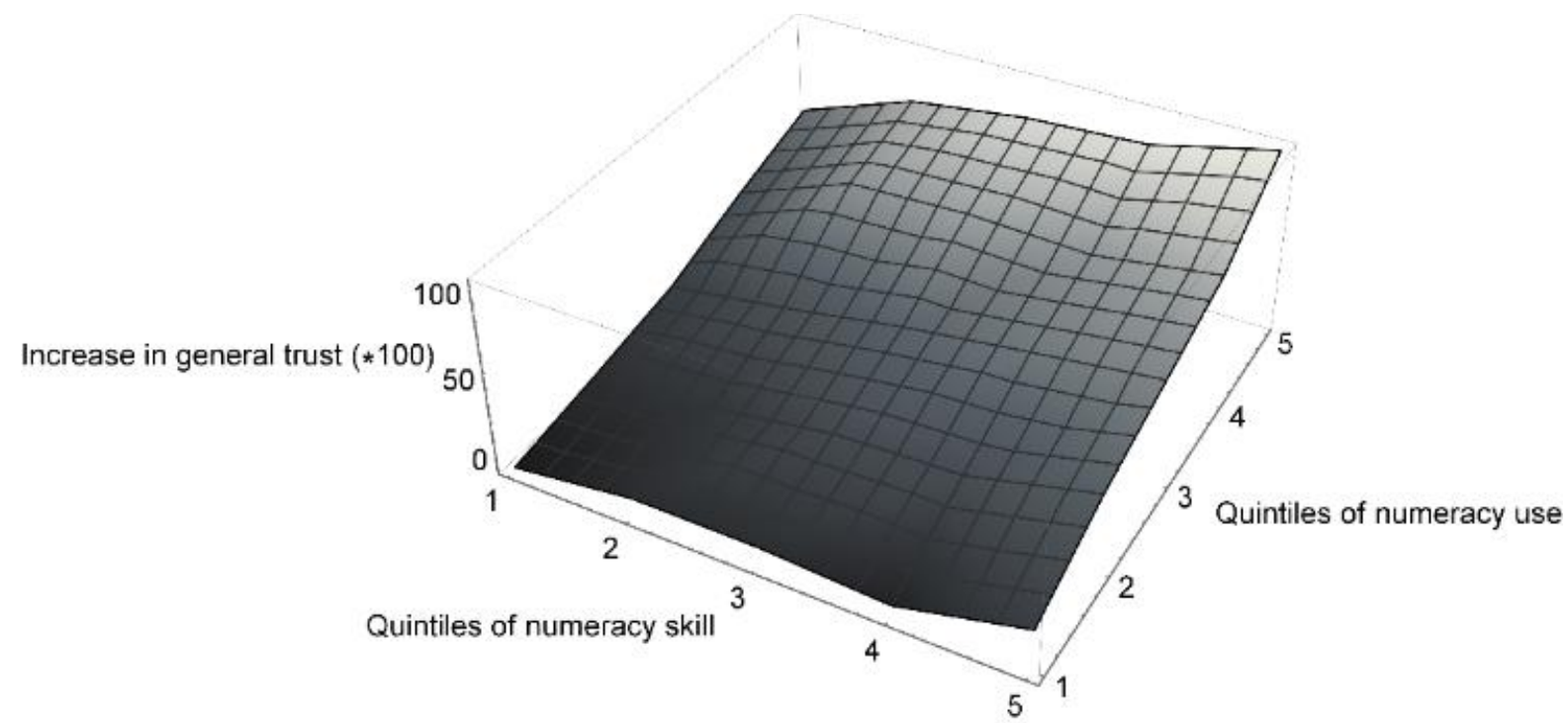


TABLE AI - Comparison of mismatch indicators; DV: Jab satisfaction - Young warkers (aged 35) anly Average marginal effects based on multilevel mixed-effects logistic regression models, standard errors in parentheses; Parameters are multiplied by 100

\begin{tabular}{|c|c|c|c|c|c|}
\hline & \multirow[b]{2}{*}{ Model 0} & \multicolumn{4}{|c|}{ SKILL MISMATCH MODELS } \\
\hline & & Model 1 & Model 2 & Model 3 & Model 4 \\
\hline VARIABLES & $\begin{array}{c}\text { Skill } \\
\text { prof. \& } \\
\text { skill use }\end{array}$ & $\begin{array}{c}\text { van der } \\
\text { Velden } \\
\& \\
\text { Bijlsma } \\
(2018) \\
\end{array}$ & $\begin{array}{l}\text { Allen et al. } \\
\quad(2013)\end{array}$ & $\begin{array}{c}\text { Pellizzari } \\
\text { \& Fichen } \\
\text { (2013) }\end{array}$ & $\begin{array}{c}\text { Subjective } \\
\text { measure } \\
\text { (WSA) }\end{array}$ \\
\hline Skill proficiency (std.) & $\begin{array}{l}-0.5931 \\
(0.6665)\end{array}$ & & & & \\
\hline Skill use (std.) & $\begin{array}{c}3.1427 * * * \\
(0.5512)\end{array}$ & & $\begin{array}{c}3.0304 * * * \\
(0.4945)\end{array}$ & $\begin{array}{l}3.0126 * * * \\
(0.4916)\end{array}$ & $\begin{array}{c}2.8498^{* * *} \\
(0.5038)\end{array}$ \\
\hline Required Effective Skill Level (std.) & & $\begin{array}{c}3.7557 * * * \\
(0.5614)\end{array}$ & & & \\
\hline Overskilled (Van der Velden/Bijlsma) (Dummy) & & $\begin{array}{l}-2.4636 \\
(2.5671)\end{array}$ & & & \\
\hline Underskilled (Van der Velden/Bijlsma) (Dummy) & & $\begin{array}{l}-2.5052 \\
(2.5113)\end{array}$ & & & \\
\hline Overskilled (Allen et al.) (Dummy) & & & $\begin{array}{l}-1.7703 \\
(1.7461)\end{array}$ & & \\
\hline Underskilled (Allen et al.) (Dummy) & & & $\begin{array}{l}-2.7868^{*} \\
(1.6751)\end{array}$ & & \\
\hline Overskilled (Pellizzari/Fichen) (Dummy) & & & & $\begin{array}{l}-1.5491 \\
(1.3372)\end{array}$ & \\
\hline Underskilled (Pellizzari/Fichen) (Dummy) & & & & $\begin{array}{l}-0.4351 \\
(1.6520)\end{array}$ & \\
\hline Overskilled (WSA) (Dummy) & & & & & $\begin{array}{l}-8.4617 * * * \\
(2.0391)\end{array}$ \\
\hline Underskilled (WSA) (Dummy) & & & & & $\begin{array}{c}-6.1811 * * * \\
(2.3086)\end{array}$ \\
\hline Mixed (WSA) (Dummy) & & & & & $\begin{array}{c}-4.3521 * * \\
(2.1701)\end{array}$ \\
\hline $\mathrm{N}_{\text {individuals }}$ & 13,526 & 13,526 & 13,526 & 13,526 & 13,526 \\
\hline $\mathrm{N}_{\text {countries }}$ & 30 & 30 & 30 & 30 & 30 \\
\hline Likelihood ratio test & Model 0 & Model 1 & Model 2 & Model 3 & Model 4 \\
\hline log likelihood & -6851 & -6842 & -6850 & -6851 & -6831 \\
\hline Deviance $^{1}\left(\mathrm{D}_{\mathrm{i}}\right)$ & 13702 & 13684 & 13700 & 13702 & 13662 \\
\hline $\begin{array}{l}\text { Decrease in deviance compared to Intercept } \\
\text { model }\left(\mathrm{D}_{0}-\mathrm{D}_{\mathrm{i}}\right)^{2}\end{array}$ & 66 & 84 & 68 & 66 & 106 \\
\hline Degrees of freedom & $(\mathrm{df}=2)$ & $(\mathrm{df}=3)$ & $(\mathrm{df}=3)$ & $(\mathrm{df}=3)$ & $(\mathrm{df}=4)$ \\
\hline Chi-squared value & $\begin{array}{c}\mathrm{p}<0.005 \\
* * *\end{array}$ & $\begin{array}{c}\mathrm{p}<0.005 \\
* * *\end{array}$ & $\begin{array}{c}\mathrm{p}<0.005 \\
* * *\end{array}$ & $\begin{array}{c}\mathrm{p}<0.005 \\
* * *\end{array}$ & $\begin{array}{c}\mathrm{p}<0.005 \\
* * *\end{array}$ \\
\hline
\end{tabular}

Parameters are multiplied times 100; All figures are weighted; Controls include age, age2;

${ }^{* * *} \mathrm{p}<0.01,{ }^{* *} \mathrm{p}<0.05,{ }^{*} \mathrm{p}<0.1 ;{ }^{1}$ Deviance $=-2 *(\log$ likelihood$)$, see Snijders and Bosker, 2012: 97 et seq.

${ }^{2}$ The decrease in deviance is computed based on the specific intercept model of each mismatch-approach 
TABLE AZ - Robustness check: Comparison of mismatch indicators, controlling for log hourly wage;

\section{DV: Jab satisfaction}

Average marginal effects based on multilevel mixed-effects logistic regression models, standard errors in parentheses; Parameters are multiplied by 100

\begin{tabular}{|c|c|c|c|c|c|}
\hline & \multirow[b]{2}{*}{ Model 0} & \multicolumn{4}{|c|}{ SKILL MISMATCH MODELS } \\
\hline & & Model 1 & Model 2 & Model 3 & Model 4 \\
\hline VARIABLES & $\begin{array}{c}\text { Skill } \\
\text { prof. \& } \\
\text { skill use }\end{array}$ & $\begin{array}{c}\text { van der } \\
\text { Velden } \\
\& \\
\text { Bijlsma } \\
(2018) \\
\end{array}$ & $\begin{array}{l}\text { Allen et al. } \\
\qquad(2013)\end{array}$ & $\begin{array}{c}\text { Pellizzari } \\
\text { \& Fichen } \\
\quad(2013)\end{array}$ & $\begin{array}{c}\text { Subjective } \\
\text { measure } \\
\text { (WSA) }\end{array}$ \\
\hline Skill proficiency (std.) & $\begin{array}{c}0.0977 \\
(0.4288)\end{array}$ & & & & \\
\hline Skill use (std.) & $\begin{array}{c}2.8584 * * * \\
(0.2752)\end{array}$ & & $\begin{array}{c}3.0517 * * * \\
(0.4157)\end{array}$ & $\begin{array}{c}2.9258 * * * \\
(0.3256)\end{array}$ & $\begin{array}{c}2.8012^{* * *} \\
(0.3340)\end{array}$ \\
\hline Required Effective Skill Level (std.) & & $\begin{array}{c}3.7197 * * * \\
(0.5459)\end{array}$ & & & \\
\hline Overskilled (Van der Velden/Bijlsma) (Dummy) & & $\begin{array}{l}-1.0753 \\
(1.5923)\end{array}$ & & & \\
\hline Underskilled (Van der Velden/Bijlsma) (Dummy) & & $\begin{array}{l}-2.1526 \\
(1.6896)\end{array}$ & & & \\
\hline Overskilled (Allen et al.) (Dummy) & & & $\begin{array}{l}-0.8230 \\
(0.9624)\end{array}$ & & \\
\hline Underskilled (Allen et al.) (Dummy) & & & $\begin{array}{c}-2.7093 * * * \\
(1.0513)\end{array}$ & & \\
\hline Overskilled (Pellizzari/Fichen) (Dummy) & & & & $\begin{array}{l}-0.4843 \\
(0.9229)\end{array}$ & \\
\hline Underskilled (Pellizzari/Fichen) (Dummy) & & & & $\begin{array}{l}1.6161 * \\
(0.8710)\end{array}$ & \\
\hline Overskilled (WSA) (Dummy) & & & & & $\begin{array}{l}-4.8710^{* * *} \\
(1.1507)\end{array}$ \\
\hline Underskilled (WSA) (Dummy) & & & & & $\begin{array}{c}-3.4209 * * * \\
(1.3193)\end{array}$ \\
\hline Mixed (WSA) (Dummy) & & & & & $\begin{array}{l}-1.8317 \\
(1.1392)\end{array}$ \\
\hline Log hourly wage & $\begin{array}{l}0.1177 \\
(0.1002) \\
\end{array}$ & $\begin{array}{l}0.1029 \\
(0.0972) \\
\end{array}$ & $\begin{array}{l}0.1156 \\
(0.1002) \\
\end{array}$ & $\begin{array}{l}0.1186 \\
(0.1008) \\
\end{array}$ & $\begin{array}{l}0.1178 \\
(0.1013) \\
\end{array}$ \\
\hline $\mathrm{N}_{\text {individuals }}$ & 36,904 & 36,904 & 36,904 & 36,904 & 36,904 \\
\hline $\mathrm{N}_{\text {countries }}$ & 30 & 30 & 30 & 30 & 30 \\
\hline Likelihood ratio test & Model 0 & Model 1 & Model 2 & Model 3 & Model 4 \\
\hline log likelihood & -18082 & -18051 & -18077 & -18080 & -18052 \\
\hline Deviance $^{1}\left(\mathrm{D}_{\mathrm{i}}\right)$ & 36164 & 36102 & 36154 & 36160 & 36104 \\
\hline $\begin{array}{l}\text { Decrease in deviance compared to Intercept } \\
\text { model }\left(\mathrm{D}_{0}-\mathrm{D}_{\mathrm{i}}\right)^{2}\end{array}$ & 184 & 246 & 194 & 188 & 244 \\
\hline Degrees of freedom & $(\mathrm{df}=2)$ & $(\mathrm{df}=3)$ & $(\mathrm{df}=3)$ & $(\mathrm{df}=3)$ & $(\mathrm{df}=4)$ \\
\hline Chi-squared value & $\begin{array}{c}\mathrm{p}<0.005 \\
* * *\end{array}$ & $\begin{array}{c}\mathrm{p}<0.005 \\
* * *\end{array}$ & $\begin{array}{c}\mathrm{p}<0.005 \\
* * *\end{array}$ & $\begin{array}{c}\mathrm{p}<0.005 \\
* * *\end{array}$ & $\begin{array}{c}\mathrm{p}<0.005 \\
* * *\end{array}$ \\
\hline
\end{tabular}

Parameters are multiplied times 100; All figures are weighted; Controls include age, age2;

${ }^{* * *} \mathrm{p}<0.01,{ }^{* *} \mathrm{p}<0.05, * \mathrm{p}<0.1 ; 1$ Deviance $=-2 *(\log$ likelihood $)$, see Snijders and Bosker, $2012: 97$ et seq. 2 The decrease in deviance is computed based on the specific intercept model of each mismatch-approach 
TABLE A3 - Robustness check: Comparison of mismatch indicators, controlling for worker and job characteristics; DV: Job satisfaction

Average marginal effects based on multilevel mixed-effects logistic regression models, standard errors in parentheses; Parameters are multiplied by 100

\begin{tabular}{|c|c|c|c|c|c|}
\hline & \multirow[b]{2}{*}{ Model 0} & \multicolumn{4}{|c|}{ SKILL MISMATCH MODELS } \\
\hline & & Model 1 & Model 2 & Model 3 & Model 4 \\
\hline VARIABLES & $\begin{array}{l}\text { Skill prof. } \\
\text { \& skill use }\end{array}$ & $\begin{array}{c}\text { van der } \\
\text { Velden \& } \\
\text { Bijlsma } \\
\text { (2018) }\end{array}$ & $\begin{array}{l}\text { Allen et } \\
\text { al. (2013) }\end{array}$ & $\begin{array}{c}\text { Pellizzari } \\
\text { \& Fichen } \\
\quad(2013)\end{array}$ & $\begin{array}{c}\text { Subjective } \\
\text { measure } \\
\text { (WSA) }\end{array}$ \\
\hline Skill proficiency (std.) & $\begin{array}{l}-0.6658^{*} \\
(0.3838)\end{array}$ & & & & \\
\hline Skill use (std.) & $\begin{array}{c}0.1973 \\
(0.3381)\end{array}$ & & $\begin{array}{c}0.1043 \\
(0.3858)\end{array}$ & $\begin{array}{c}0.0561 \\
(0.3362)\end{array}$ & $\begin{array}{c}0.0665 \\
(0.3313)\end{array}$ \\
\hline Required Effective Skill Level (std.) & & $\begin{array}{c}-1.3777 * \\
(0.7512)\end{array}$ & & & \\
\hline Overskilled (Van der Velden/Bijlsma) (Dummy) & & $\begin{array}{l}-1.9102 \\
(1.8862)\end{array}$ & & & \\
\hline Underskilled (Van der Velden/Bijlsma) (Dummy) & & $\begin{array}{l}-1.9106 \\
(1.9681)\end{array}$ & & & \\
\hline Overskilled (Allen et al.) (Dummy) & & & $\begin{array}{c}-1.7990 * * \\
(0.8961)\end{array}$ & & \\
\hline Underskilled (Allen et al.) (Dummy) & & & $\begin{array}{l}-1.9054^{*} \\
(1.1128)\end{array}$ & & \\
\hline Overskilled (Pellizzari/Fichen) (Dummy) & & & & $\begin{array}{c}0.3148 \\
(0.8251)\end{array}$ & \\
\hline Underskilled (Pellizzari/Fichen) (Dummy) & & & & $\begin{array}{l}-0.8018 \\
(0.8177)\end{array}$ & \\
\hline Overskilled (WSA) (Dummy) & & & & & $\begin{array}{c}-4.1268^{* * *} \\
(1.1173)\end{array}$ \\
\hline Underskilled (WSA) (Dummy) & & & & & $\begin{array}{l}-4.2828^{* * *} \\
(1.6595)\end{array}$ \\
\hline Mixed (WSA) (Dummy) & & & & & $\begin{array}{l}-2.4845^{* *} \\
(1.2126)\end{array}$ \\
\hline Controls & yes & yes & yes & yes & yes \\
\hline $\mathrm{N}_{\text {individuals }}$ & 33,522 & 33,522 & 33,522 & 33,522 & 33,522 \\
\hline $\mathrm{N}_{\text {countries }}$ & 30 & 30 & 30 & 30 & 30 \\
\hline Likelihood ratio test & Model 0 & Model 1 & Model 2 & Model 3 & Model 4 \\
\hline log likelihood & -15653 & -15651 & -15651 & -15655 & -15641 \\
\hline Deviance $^{1}\left(\mathrm{D}_{\mathrm{i}}\right)$ & 31306 & 31302 & 31302 & 31310 & 31282 \\
\hline $\begin{array}{l}\text { Decrease in deviance compared to Intercept } \\
\text { model }\left(\mathrm{D}_{0}-\mathrm{D}_{\mathrm{i}}\right)^{2}\end{array}$ & 672 & 676 & 676 & 668 & 696 \\
\hline Degrees of freedom & $(\mathrm{df}=2)$ & $(\mathrm{df}=3)$ & $(\mathrm{df}=3)$ & $(\mathrm{df}=3)$ & $(\mathrm{df}=4)$ \\
\hline Chi-squared value & $\begin{array}{c}\mathrm{p}<0.005 \\
* * *\end{array}$ & $\begin{array}{c}\mathrm{p}<0.005 \\
* * *\end{array}$ & $\begin{array}{c}\mathrm{p}<0.005 \\
* * *\end{array}$ & $\begin{array}{c}\mathrm{p}<0.005 \\
* * *\end{array}$ & $\begin{array}{c}\mathrm{p}<0.005 \\
* * *\end{array}$ \\
\hline
\end{tabular}

Parameters multiplied times 100; All figures are weighted; *** $\mathrm{p}<0.01,{ }^{* *} \mathrm{p}<0.05,{ }^{*} \mathrm{p}<0.1$

Controls include age, age2, task discretion (worker autonomy), influence, dummies for highest education, migration background, temporary contract, public sector, firm size, ISCO 1-digit

${ }^{1}$ Deviance $=-2 *(\log$ likelihood), see Snijders and Bosker, 2012: 97 et seq.

${ }^{2}$ The decrease in deviance is computed based on the specific intercept model of each mismatch-approach. 


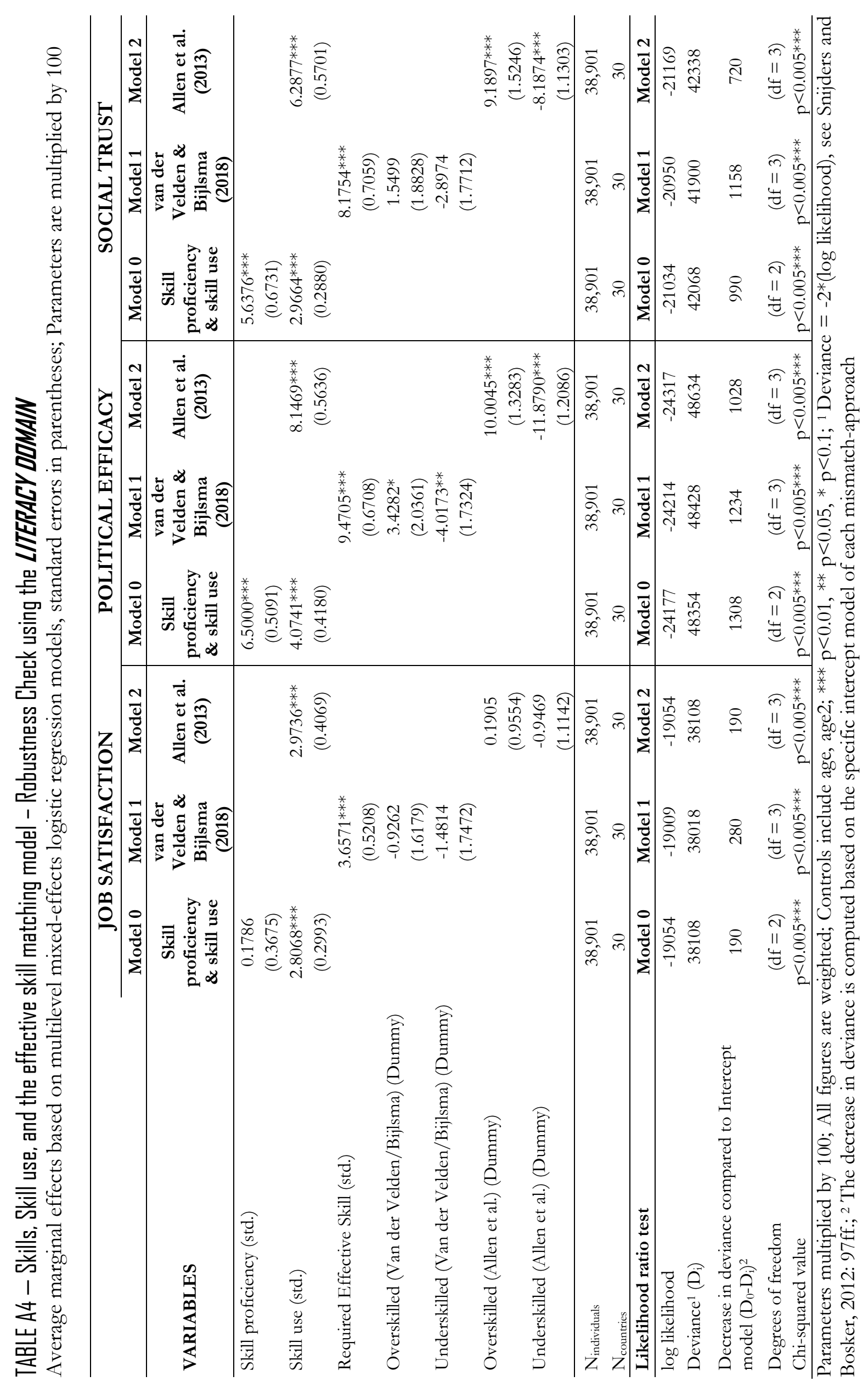




\section{TABLE A5 - Robustness check: Sample Selection Logit Regression}

Average marginal effects based on multilevel mixed-effects logistic regression models, standard errors in parentheses; Parameters are multiplied by 100

\begin{tabular}{|c|c|c|c|}
\hline & $\begin{array}{c}\text { Model } 1 \\
\text { JOB } \\
\text { SATISFACTION } \\
\end{array}$ & $\begin{array}{c}\text { Model } 2 \\
\text { POLITICAL } \\
\text { EFFICACY }\end{array}$ & $\begin{array}{c}\text { Model } 3 \\
\text { SOCIA } \\
L \\
\text { TRUST } \\
\end{array}$ \\
\hline Required Effective Skill Level (std.) & $\begin{array}{c}0.139 * * * \\
(0.009)\end{array}$ & $\begin{array}{c}0.028^{* * *} \\
(0.008)\end{array}$ & $\begin{array}{c}0.250^{* * *} \\
(0.008)\end{array}$ \\
\hline Overskilled (Van der Velden/Bijlsma) (Dummy) & $\begin{array}{l}-0.041 \\
(0.044)\end{array}$ & $\begin{array}{l}0.073^{* *} \\
(0.036)\end{array}$ & $\begin{array}{c}0.018 \\
(0.041)\end{array}$ \\
\hline $\begin{array}{l}\text { Underskilled (Van der Velden/Bijlsma) } \\
\text { (Dummy) }\end{array}$ & $\begin{array}{c}-0.075^{*} \\
(0.044)\end{array}$ & $\begin{array}{c}-0.135^{* * *} \\
(0.036)\end{array}$ & $\begin{array}{c}- \\
0.129 * * * \\
(0.041) \\
-\end{array}$ \\
\hline _cons & $\begin{array}{l}-0.097 \\
(0.128)\end{array}$ & $\begin{array}{c}-2.859 * * * \\
(0.107)\end{array}$ & $\begin{array}{c}3.081 * * * \\
(0.119)\end{array}$ \\
\hline Selection model & & & \\
\hline age & $\begin{array}{c}-0.065^{* * *} \\
(0.004)\end{array}$ & $\begin{array}{c}-0.065^{* * *} \\
(0.004)\end{array}$ & $\begin{array}{c}0.065^{* * *} \\
(0.004)\end{array}$ \\
\hline age2 & $\begin{array}{c}0.001 * * * \\
(0.000)\end{array}$ & $\begin{array}{c}0.001^{* * *} \\
(0.000)\end{array}$ & $\begin{array}{c}0.001 * * * \\
(0.000)\end{array}$ \\
\hline low education & $\begin{array}{c}-0.147^{* * *} \\
(0.019)\end{array}$ & $\begin{array}{c}-0.146^{* * *} \\
(0.019)\end{array}$ & $\begin{array}{c}0.146^{* * *} \\
(0.019)\end{array}$ \\
\hline tertiary education & $\begin{array}{c}0.076^{* * *} \\
(0.017)\end{array}$ & $\begin{array}{c}0.074 * * * \\
(0.017)\end{array}$ & $\begin{array}{c}0.071 * * * \\
(0.017)\end{array}$ \\
\hline _cons & $\begin{array}{c}2.661 * * * \\
(0.089)\end{array}$ & $\begin{array}{c}2.658^{* * *} \\
(0.089)\end{array}$ & $\begin{array}{c}2.658^{* * *} \\
(0.089)\end{array}$ \\
\hline rho & $\begin{array}{c}-0.034 * * * \\
(0.010)\end{array}$ & $\begin{array}{l}0.013 \\
(0.008)\end{array}$ & $\begin{array}{l}0.029 * * * \\
(0.0069)\end{array}$ \\
\hline $\mathrm{N}_{\text {individuals }}$ & 47,932 & 47,932 & 47,932 \\
\hline
\end{tabular}

Note: Likelihood ratio test for rho (Model 1-3) $=0: \operatorname{chi} 2(1)=0.00$ Prob $>=$ chi2 $=1.000$; link function: logit; Controls include age, age2, and 29 country dummies (Reference $=$ Austria) 
TABLE A6a - Robustness check with wage and education as micro confounders; DV: Jab Satisfaction

Average marginal effects based on multilevel mixed-effects logistic regression models, standard errors in parentheses; Parameters multiplied by 100

\begin{tabular}{|c|c|c|c|c|c|}
\hline & \multirow[b]{2}{*}{ Model 0} & \multicolumn{4}{|c|}{ SKILL MISMATCH MODELS } \\
\hline & & Model 1 & Model 2 & Model 3 & Model 4 \\
\hline VARIABLES & $\begin{array}{c}\text { Skill } \\
\text { prof. \& } \\
\text { skill use }\end{array}$ & $\begin{array}{c}\text { van der } \\
\text { Velden } \\
\& \\
\text { Bijlsma } \\
(2018) \\
\end{array}$ & $\begin{array}{l}\text { Allen et } \\
\text { al. (2013) }\end{array}$ & $\begin{array}{c}\text { Pellizzari } \\
\& \\
\text { Fichen } \\
\text { (2013) }\end{array}$ & $\begin{array}{l}\text { Subjec- } \\
\text { tive } \\
\text { measure } \\
\text { (WSA) }\end{array}$ \\
\hline Skill proficiency (std.) & $\begin{array}{l}-0.0263 \\
(0.4176)\end{array}$ & & & & \\
\hline Skill use (std.) & $\begin{array}{l}2.75^{* * *} \\
(0.2971)\end{array}$ & & $\begin{array}{c}2.9108^{* * *} \\
(0.4105)\end{array}$ & $\begin{array}{c}2.7678^{* * *} \\
(0.3262)\end{array}$ & $\begin{array}{c}2.6517 * * * \\
(0.3285)\end{array}$ \\
\hline Required Effective Skill (std.) & & $\begin{array}{c}4.0343^{* * *} \\
(0.5487)\end{array}$ & & & \\
\hline Overskilled (Van der Velden/Bijlsma) (Dummy) & & $\begin{array}{l}-0.9432 \\
(1.5741)\end{array}$ & & & \\
\hline Underskilled (Van der Velden/Bijlsma) (Dummy) & & $\begin{array}{l}-2.2784 \\
(1.6763)\end{array}$ & & & \\
\hline Overskilled (Allen et al.) (Dummy) & & & $\begin{array}{l}-0.9466 \\
(0.9101)\end{array}$ & & \\
\hline Underskilled (Allen et al.) (Dummy) & & & $\begin{array}{l}-2.5659 * * \\
(1.0354)\end{array}$ & & \\
\hline Overskilled (Pellizzari/Fichen) (Dummy) & & & & $\begin{array}{l}-0.5639 \\
(0.8909)\end{array}$ & \\
\hline Underskilled (Pellizzari/Fichen) (Dummy) & & & & $\begin{array}{l}1.5167^{*} \\
(0.8703)\end{array}$ & \\
\hline Overskilled (WSA) (Dummy) & & & & & $\begin{array}{l}-4.8492 * * * \\
(1.1481)\end{array}$ \\
\hline Underskilled (WSA) (Dummy) & & & & & $\begin{array}{c}-3.4316^{* * *} \\
(1.3209)\end{array}$ \\
\hline Mixed (WSA) (Dummy) & & & & & $\begin{array}{l}-1.8532 \\
(1.1450)\end{array}$ \\
\hline $\mathrm{N}_{\text {individuals }}$ & 36,896 & 36,896 & 36,896 & 36,896 & 36,896 \\
\hline $\mathrm{N}_{\text {countries }}$ & 30 & 30 & 30 & 30 & 30 \\
\hline Likelihood ratio test & Model 0 & Model 1 & Model 2 & Model 3 & Model 4 \\
\hline log likelihood & -18073 & -18042 & -18068 & -18070 & -18043 \\
\hline Deviance $^{1}\left(\mathrm{D}_{\mathrm{i}}\right)$ & 36146 & 36084 & 36136 & 36140 & 36086 \\
\hline $\begin{array}{l}\text { Decrease in deviance compared to Intercept } \\
\text { model }\left(\mathrm{D}_{0}-\mathrm{D}_{\mathrm{i}}\right)^{2}\end{array}$ & 194 & 256 & 204 & 200 & 254 \\
\hline Degrees of freedom & & $(\mathrm{df}=3)$ & $(\mathrm{df}=3)$ & $(\mathrm{df}=3)$ & $(\mathrm{df}=4)$ \\
\hline Chi-squared value & & $\begin{array}{c}\mathrm{p}<0.005 \\
* * *\end{array}$ & $\begin{array}{c}\mathrm{p}<0.005 \\
* * *\end{array}$ & $\begin{array}{c}\mathrm{p}<0.005 \\
* * *\end{array}$ & $\mathrm{p}_{* * *}<0.005$ \\
\hline
\end{tabular}

Parameters multiplied by 100; All figures are weighted; Controls include age, age2, log hourly wage and dummies indicating highest educational attainment, ${ }^{* *} \mathrm{p}<0.01,{ }^{* *} \mathrm{p}<0.05, * \mathrm{p}<0.1$;

${ }^{1}$ Deviance $=-2 *(\log$ likelihood), see Snijders (2003), p. 12;

${ }^{2}$ The decrease in deviance is computed based on the specific intercept model of each mismatch approach 
TABLE A6b - Robustness check with wage and education as micro confounders; DV: Political Efficacy

Average marginal effects based on multilevel mixed-effects logistic regression models, standard errors in parentheses; Parameters multiplied by 100

\begin{tabular}{|c|c|c|c|c|c|}
\hline & \multirow[b]{2}{*}{ Model 0} & \multicolumn{4}{|c|}{ SKILL MISMATCH MODELS } \\
\hline & & Model 1 & Model 2 & Model 3 & Model 4 \\
\hline VARIABLES & $\begin{array}{l}\text { Skill prof. } \\
\text { \& skill } \\
\text { use }\end{array}$ & $\begin{array}{c}\text { van der } \\
\text { Velden \& } \\
\text { Bijlsma } \\
\text { (2018) }\end{array}$ & $\begin{array}{l}\text { Allen et al. } \\
\qquad(2013)\end{array}$ & $\begin{array}{l}\text { Pellizzari } \\
\text { \& Fichen } \\
\quad(2013)\end{array}$ & $\begin{array}{c}\text { Subjective } \\
\text { measure } \\
\text { (WSA) }\end{array}$ \\
\hline Skill proficiency (std.) & $\begin{array}{l}4.5311^{* * *} \\
(0.5596)\end{array}$ & & & & \\
\hline Skill use (std.) & $\begin{array}{l}3.1386^{* * *} \\
(0.3614)\end{array}$ & & $\begin{array}{c}5.5786^{* * *} \\
(0.5348)\end{array}$ & $\begin{array}{c}4.1712^{* * *} \\
(0.4145)\end{array}$ & $\begin{array}{c}4.1192 * * * \\
(0.4037)\end{array}$ \\
\hline Required Effective Skill (std.) & & $\begin{array}{c}6.4792^{* * *} \\
(0.6315)\end{array}$ & & & \\
\hline $\begin{array}{l}\text { Overskilled (Van der Velden/Bijlsma) } \\
\text { (Dummy) }\end{array}$ & & $\begin{array}{l}2.0070 \\
(1.6119)\end{array}$ & & & \\
\hline $\begin{array}{l}\text { Underskilled (Van der Velden/Bijlsma) } \\
\text { (Dummy) }\end{array}$ & & $\begin{array}{l}-3.0914 * * \\
(1.5179)\end{array}$ & & & \\
\hline Overskilled (Allen et al.) (Dummy) & & & $\begin{array}{c}5.3004 * * * \\
(1.5018)\end{array}$ & & \\
\hline Underskilled (Allen et al.) (Dummy) & & & $\begin{array}{c}-8.6895^{* * *} \\
(1.3596)\end{array}$ & & \\
\hline Overskilled (Pellizzari/Fichen) (Dummy) & & & & $\begin{array}{c}3.8126^{* * *} \\
(1.0028)\end{array}$ & \\
\hline Underskilled (Pellizzari/Fichen) (Dummy) & & & & $\begin{array}{l}-0.3716 \\
(1.0939)\end{array}$ & \\
\hline Overskilled (WSA) (Dummy) & & & & & $\begin{array}{c}1.2115 \\
(1.0788)\end{array}$ \\
\hline Underskilled (WSA) (Dummy) & & & & & $\begin{array}{l}3.2199 * * \\
(1.4154)\end{array}$ \\
\hline Mixed (WSA) (Dummy) & & & & & $\begin{array}{c}3.7503 * * * \\
(1.4558)\end{array}$ \\
\hline $\mathrm{N}_{\text {individuals }}$ & 36,896 & 36,896 & 36,896 & 36,896 & 36,896 \\
\hline $\mathrm{N}_{\text {countries }}$ & 30 & 30 & 30 & 30 & 30 \\
\hline Likelihood ratio test & Model 0 & Model 1 & Model 2 & Model 3 & Model 4 \\
\hline log likelihood & -22913 & -22959 & -22968 & -23008 & -23009 \\
\hline Deviance $^{1}\left(\mathrm{D}_{\mathrm{i}}\right)$ & 45826 & 45918 & 45936 & 46016 & 46018 \\
\hline $\begin{array}{l}\text { Decrease in deviance compared to } \\
\text { Intercept model }\left(\mathrm{D}_{0}-\mathrm{D}_{\mathrm{i}}\right)^{2}\end{array}$ & 1314 & 1222 & 1204 & 1124 & 1122 \\
\hline Degrees of freedom & & $(\mathrm{df}=3)$ & $(\mathrm{df}=3)$ & $(\mathrm{df}=3)$ & $(\mathrm{df}=4)$ \\
\hline Chi-squared value & & $\mathrm{p}<0.005^{* * *}$ & $\mathrm{p}<0.005^{* * *}$ & $\mathrm{p}<0.005^{* * *}$ & $\mathrm{p}<0.005^{* * *}$ \\
\hline
\end{tabular}

Parameters multiplied by 100; All figures are weighted; Controls include age, age2, log hourly wage and dummies indicating highest educational attainment; ${ }^{* * *} \mathrm{p}<0.01,{ }^{* *} \mathrm{p}<0.05,{ }^{*} \mathrm{p}<0.1$;

${ }^{1}$ Deviance $=-2 *(\log$ likelihood $)$, see Snijders (2003), p. 12;

${ }^{2}$ The decrease in deviance is computed based on the specific intercept model of each mismatch-approach 
TABLE A6c - Robustness check with wage and education as micro confounders; DV: Sacial Trust

Average marginal effects based on multilevel mixed-effects logistic regression models, standard errors in parentheses; Parameters multiplied by 100

\begin{tabular}{|c|c|c|c|c|c|}
\hline & \multirow[b]{2}{*}{ Model 0} & \multicolumn{4}{|c|}{ SKILL MISMATCH MODELS } \\
\hline & & Model 1 & Model 2 & Model 3 & Model 4 \\
\hline VARIABLES & $\begin{array}{l}\text { Skill prof. } \\
\text { \& skill } \\
\text { use }\end{array}$ & $\begin{array}{c}\text { van der } \\
\text { Velden \& } \\
\text { Bijlsma } \\
(\mathbf{2 0 1 8 )} \\
\end{array}$ & $\begin{array}{l}\text { Allen et al. } \\
\quad(2013)\end{array}$ & $\begin{array}{l}\text { Pellizzari } \\
\text { \& Fichen } \\
\quad(2013)\end{array}$ & $\begin{array}{c}\text { Subjective } \\
\text { measure } \\
\text { (WSA) }\end{array}$ \\
\hline Skill proficiency (std.) & $\begin{array}{c}3.1916 * * * \\
(0.6418)\end{array}$ & & & & \\
\hline Skill use (std.) & $\begin{array}{c}1.8458^{* * *} \\
(0.2944)\end{array}$ & & $\begin{array}{c}3.4742 * * * \\
(0.4793)\end{array}$ & $\begin{array}{c}2.6016^{* * *} \\
(0.3598)\end{array}$ & $\begin{array}{c}2.5861 * * * \\
(0.3530)\end{array}$ \\
\hline Required Effective Skill (std.) & & $\begin{array}{c}5.2083^{* * *} \\
(0.7208)\end{array}$ & & & \\
\hline $\begin{array}{l}\text { Overskilled (Van der Velden/Bijlsma) } \\
\text { (Dummy) }\end{array}$ & & $\begin{array}{c}1.3859 \\
(1.7582)\end{array}$ & & & \\
\hline $\begin{array}{l}\text { Underskilled (Van der Velden/Bijlsma) } \\
\text { (Dummy) }\end{array}$ & & $\begin{array}{l}-1.4104 \\
(1.7577)\end{array}$ & & & \\
\hline Overskilled (Allen et al.) (Dummy) & & & $\begin{array}{l}4.3568^{* * *} \\
(1.4557)\end{array}$ & & \\
\hline Underskilled (Allen et al.) (Dummy) & & & $\begin{array}{c}-4.8244 * * * \\
(1.4127)\end{array}$ & & \\
\hline Overskilled (Pellizzari/Fichen) (Dummy) & & & & $\begin{array}{c}0.8682 \\
(0.6678)\end{array}$ & \\
\hline Underskilled (Pellizzari/Fichen) (Dummy) & & & & $\begin{array}{c}0.2938 \\
(0.8690)\end{array}$ & \\
\hline Overskilled (WSA) (Dummy) & & & & & $\begin{array}{l}-2.2359 * * \\
(1.0659)\end{array}$ \\
\hline Underskilled (WSA) (Dummy) & & & & & $\begin{array}{c}0.1627 \\
(1.2582)\end{array}$ \\
\hline Mixed (WSA) (Dummy) & & & & & $\begin{array}{l}-1.0228 \\
(1.0244)\end{array}$ \\
\hline $\mathrm{N}_{\text {individuals }}$ & 36,896 & 36,896 & 36,896 & 36,896 & 36,896 \\
\hline $\mathrm{N}_{\text {countries }}$ & 30 & 30 & 30 & 30 & 30 \\
\hline Likelihood ratio test & Model 0 & Model 1 & Model 2 & Model 3 & Model 4 \\
\hline log likelihood & -19911 & -19878 & -19946 & -19971 & -19965 \\
\hline Deviance $^{1}\left(\mathrm{D}_{\mathrm{i}}\right)$ & 39822 & 39756 & 39892 & 39942 & 39930 \\
\hline $\begin{array}{l}\text { Decrease in deviance compared to } \\
\text { Intercept model }\left(\mathrm{D}_{0}-\mathrm{D}_{\mathrm{i}}\right)^{2}\end{array}$ & 1330 & 1396 & 1260 & 1210 & 1222 \\
\hline Degrees of freedom & & $(\mathrm{df}=3)$ & $(\mathrm{df}=3)$ & $(\mathrm{df}=3)$ & $(\mathrm{df}=4)$ \\
\hline Chi-squared value & & $\mathrm{p}<0.005^{* * *}$ & $\mathrm{p}<0.005^{* * *}$ & $\mathrm{p}<0.005^{* * *}$ & $\mathrm{p}<0.005^{* * *}$ \\
\hline
\end{tabular}

Parameters multiplied by 100; All figures are weighted; Controls include age, age2, log hourly wage and dummies indicating highest educational attainment; ${ }^{* * *} \mathrm{p}<0.01,{ }^{* *} \mathrm{p}<0.05,{ }^{*} \mathrm{p}<0.1$;

${ }_{1}$ Deviance $=-2 *(\log$ likelihood), see Snijders (2003), p. 12;

${ }^{2}$ The decrease in deviance is computed based on the specific intercept model of each mismatch approach 



\section{Chapter 5}

\section{The Future is Now}

\section{Cross-Country Evidence on Mismatches in Digital Problem-Solving Skills and Wage Inequality ${ }^{27}$}

This chapter is joint work with Mark Levels and Rolf van der Velden. We thank Jan Koucky for the provision of indices for the importance of digital skills based on O*NET data, and Ineke Bijlsma for support with the analyses. 


\section{Abstract}

In all industrialised countries, automation leads to a profound and persistent transformation of work and skill requirements of jobs. Thereby, digital problem-solving skills are becoming increasingly important for workers' productivity and performance. However, not much is known yet about individual skill-to-job matches, and particularly shortages, in these skills and their relation with wages and social inequalities. How does the digital skills divide translate into group-specific returns to skills? Will existing wage inequalities (e.g. related to gender, age, migration background or socio-economic status) be exacerbated or reduced? A thorough assessment of social inequalities is the main gap in the literature. Systematically assessing skill-to-job matches and wage inequalities, this chapter sets out to narrow that gap. Drawing on data from the OECD's Programme for the International Assessment of Adult Competencies (PIAAC), our research is based on objective skills measurements for representative samples of workers in 26 industrial countries. We build a skill matching model to show that skill-to-job matches in digital problem-solving skills matter for wages: shortages are damaging, while a skills surplus is profitable. However, digital problemsolving skills re-shape wage inequalities with the potential to serve as emancipatory lever, narrowing the divide between socio-economic status groups. These skills may also help to reduce the gender wage gap, as high levels of digital problem-solving skills appear to pay off more for women than for men.

Keywords: PIAAC, digital skills, skill mismatch, wages, social inequality, gender

\section{Introduction}

Automation is not only changing the way we work, but also affects social inequalities. In industrial countries, labour automation only had a moderate impact on the quantitative demand for labour so far. Nevertheless, it is pervasively and irreversibly transforming work in a qualitative way (Frey and Osborne, 2017; Brynjolfsson and McAfee, 2014; Autor and Dorn, 2013; Acemoglu and Autor, 2011). This is not new. The adaptation of digital technologies has led to fundamental changes in the demand for skills since the mid-1990s (e.g. Elliot, 2017; Gross, 2015; Green, 2013; Levy, 2010; Acemoglu, 2002). The latest technological breakthroughs, however, seem to be less and less biased toward transforming and replacing labour in routine-activities but may very well transform work throughout the entire occupational system, also highly affecting skilled jobs of professionals and other 
experts (Autor and Salomons, 2018; Susskind and Susskind, 2017; OECD, 2016d; Goos, Manning and Salomons, 2014). The ubiquitous availability of information and communication technology (ICT) leads to a situation, in which digital skills are thought to be key skills for everybody (OECD, 2016d; 2016f; 2016e). The demand for such ICT generic skills increased in a majority of industrialised countries between 2011 and 2014 (OECD, 2016g). As automation not only infuses into work but also everyday life, digital skills are not only key to ensure that workers remain productive and employable in labour markets but also included in societies (OECD, 2013b). Artificial Intelligence (AI) and Robotic Process Automation (RPA) are thought to further exacerbate that trend. However, social groups are unequally equipped to deal with these changes.

The increasing impact of computer-based technologies implies a measurable change in the composition of job tasks both at work and in everyday life (Autor and Dorn, 2013). The key to understanding this is the assumption that the use of ICT induces specific forms of tasks that demand information-processing and digital problem-solving (Brynjolfsson and McAfee, 2014; Acemoglu and Autor, 2011; Levy, 2010; Autor, Levy, and Murnane, 2002). Digital problem-solving is considered a key skill, capturing the general capability of adults to generate appropriate performance in all kinds of technology-rich environments (OECD, 2016a: 96). Key skills are highly transferrable and can be used as a measure of cognitive competencies needed for the 21 st century and "general" information-processing skills that allow adults to fully participate in labour markets and multiple situations in social and civic life (OECD, 2016a: 16). As they allow adults to adapt to and perform adequately in changing environments, digital problem-solving skills capture the fluid ability that is assumed to be ever more important in the increasingly digitised labour markets of the near future (OECD, 2016g; 2016f; 2016e). However, these skills are already important for a successful participation in present labour markets. About $85 \%$ of all jobs currently available in the EU require at least a basic level in digital skills (Cedefop, 2018: 5), and ICT skills are substantially rewarded at the labour market (Falck, Heimisch and Wiederhold, 2016; Lane and Conlon, 2016; Hanushek, Schwerdt, Wiederhold, and Woessmann, 2015b). In the more automated labour markets of the future these skills will most likely become even more important to ensure employability and social inclusion. However, social groups are unequally equipped with those skills and the knowledge needed to deal with the profound and irreversible changes.

Can labour markets adjust to changing skill demands? And how do these changing skill demands affect social inequalities? Previous research on the topic suggests that the rapid developments are increasing the incidence of mismatches between the skills that workers possess and what is required by the workplace (Felstead, Gallie, and Green, 2017; Holmes and Mayhew, 2015; Green, 2013; Verhaest and van der Velden, 2013). In a 2013 survey, no 
less than $40 \%$ of all EU employers said that they have difficulty finding workers with the right skills when recruiting (Cedefop, 2018: 5). The concern is that mismatches, and particularly shortages, in what we think of as "future skills" are exacerbating existing and generating new social inequalities (e.g. Goldin and Katz, 2010). Mismatches in digital skills may have a broad impact on outcomes both in work and daily life.

A large body of literature suggests that income inequalities are to a large extent related to skills differences (e.g. Bol, Ciocca Eller, van de Werfhorst, and DiPrete, 2019; van der Velden and Bijlsma, 2018; Cedefop, 2018; Holmes, 2017; OECD, 2017; 2013b; Mayhew, 2016; Hanushek and Woessmann, 2015a; Hanushek et al., 2015b; Levels, van der Velden, and Allen, 2014b; Perry, Wiederhold, and Ackermann-Piek, 2014; Quintini, 2014; Leuven, Oosterbeek and van Ophem, 2004; Allen and van der Velden, 2001; Groot and Maassen van den Brink, 2000; Hartog, 2000). Most studies merely focus on general cognitive skills such as literacy and numeracy. The few available empirical studies on returns to computer skills have important limitations. For example, most rely on subjective measures of computer use (e.g. Borghans and ter Weel, 2004). Worker self-assessment bears several problems for analyses, the most pressing one being the lack of an objective anchor (Allen and van der Velden, 2005) and the risk of social bias ("talking up the job"). Objective measures give a better and more valid picture of the 'real' skills and their relation with outcomes, but only very few studies use such measures. The most important findings are that, first, ICT skills are substantially rewarded at the labour market, with the highest returns in occupations that heavily rely on the use of these skills (Falck, Heimisch, and Wiederhold, 2016). Second, the use of computers is a key driver of wage inequalities (De La Rica and Gortazar, 2017). And third, significantly higher returns to increasing levels of ICT skills can compensate for lower levels of other marketable qualifications (Lane and Conlon, 2016). However, a skilled population is not enough to achieve growth and inclusive digital societies: skills need to be put into productive use ( $c f$. Quintini, 2014).

Many studies ignore the importance of the match between worker's digital problem-solving skills and the level of skills that is required at the workplace. This leads to a lack of information about the (productive) use of skills and talent and related social inequalities in labour market outcomes. There is a digital skill divide between social groups, e.g. between age groups, workers with different educational attainment, socio-economic status groups, natives and migrants and gender (European Commission, 2018a; 2018b; 2015; OECD, 2016c; 2016f; Nanos and Schluter, 2014). However, not much is known about how this digital skill divide translates into group-specific returns to skills and whether wage inequalities will be exacerbated or reduced if digital problem-solving skills get ever more important in the future. 
When it comes, for example, to gender, it is a longstanding finding that women are consistently underpaid relative to men, even when they are equally skilled and educated (Lauder, Brown and Ashton, 2017: 418; see also Amado, Santos and São José 2018; Holmes, 2017; Becker, 1957). Moreover, the relation between skill and wage is stronger for men than for women (e.g. Hanushek et al., 2015b). However, only few studies examine digital skills and the gender pay gap (European Commission, 2018b; Kupfer, 2014). Another study investigates returns to digital skills and mismatches by focussing on migrants (Perry, 2017). Overall, however, the research on social inequalities and skill mismatches is scarce. In fact, a systematic and thorough assessment of inequalities between social groups is the main gap in the literature.

This hiatus in knowledge is important to fill. Skill shortages are increasingly driven not solely by the widespread adoption of ICT but also by structural changes in the economy and a lack of synchronization with developments of educational systems and opportunities for lifelong learning (Acemoglu and Autor, 2011). Access to workplace training and related wage premia may also differ between social groups, e.g. men and women (Holmes, 2017: 367). At the same time, organisational changes in production and service delivery processes lead to a technology-induced and job specific skill obsolescence that is different from obsolescence stemming from actual ageing of skills and knowledge (Allen and van der Velden, 2002: 28). The need for reskilling makes continuous learning a necessity for workers of all educational levels and in all fields. Against the background of recent breakthroughs in ever more advanced technologies, the incidence of mismatch is likely to increase (McKee-Ryan and Harvey, 2011: 963 cf. Livingstone, 2017: 295). Skill-to-job matching has become a matter of analytical concern as well as a persistent problem for advanced market economies (Buchanan, Finegold, Mayhew and Warhurst, 2017: 11). Incongruencies between changing demands for, and supply of, digital skills also provide a challenge when it comes to preventing increasing levels of inequality in societies more generally (Green, 2013: 69; also see Goldin and Katz, 2010; Bills, 2003; 2004). Against this background, we need to know which social groups will be affected most and how. We address the following research questions:

(1) To what extent do mismatches in digital problem-solving skills matter for wages?

(2) Do mismatches in digital problem-solving skills affect all workers in the same way - or are there (new) inequalities between social groups?

Addressing our research questions demands comprehensive and high-quality information on requirements of jobs concerning ICT skills as well as digital problem-solving skills. There is only one dataset that provides objective, valid and internationally harmonised assessments of these skills: The Adult Skill Survey from the OECD's Programme for the 
International Assessment of Adult Competencies (PIAAC). This survey provides micro data for representative samples of workers in more than 30 countries. We use these data to measure digital skill levels of workers and the match with the skill requirements of their respective jobs (skill-to-job matches). To identify technology-driven occupations, we enrich PIAAC micro data with information on occupational skills profiles. We use measurements of skills requirements of jobs in terms of ICT and problem-solving skills that are based on O*NET data and provided by Cedefop (2015). Our results show that skill-to-job matching in digital problem-solving skills matters for wages: shortages are damaging, while a skills surplus is profitable. We furthermore provide empirical evidence that the digital divide translates into groups-specific wage inequalities. At the same time, however, our analyses show that digital problem-solving could serve as an emancipatory skill, with the potential to narrow the divide between socio-economic status groups. These types of skills may also help to tackle the gender pay gap as high levels of digital problem-solving skills pay off more for women than for men.

\section{Theory: Mismatches in digital problem-solving skills and wages}

Starting in the 1960s with Gary S. Becker and Jacob Mincer, researchers have analysed the relation between schooling and productivity based on human capital theory (Mincer, 1974; Becker, 1962). The central idea is that skills and knowledge have economic value, which can be realised if skills are put to (productive) use on the labour market (Cedefop, 2018; van der Velden and Bijlsma, 2018; OECD, 2017, 2013b; Hanushek and Woessmann, 2015a; Hanushek et al., 2015b; Levels, van der Velden and Allen, 2014b; Quintini, 2014; Leuven et al., 2004; Groot and Maassen van den Brink, 2000; Hartog, 2000; Duncan and Hoffman, 1981). However, one downside of the human capital theory is the fixation on the supply side, largely ignoring the importance of the demand side of labour. Concerning the (productive) use of human capital, the match between skills possessed by a worker and the skills requirements of his or her job is crucial for a productive use of talent (e.g. Quintini, 2014). As the combination of supply and demand determines outcomes, evidence suggests that returns to education and skill (mis-)matches are best explained by matching models (Groot and Maassen van den Brink, 2000; Hartog, 2000). To examine of the relation between over- and underskilling and wages, we therefore build on the logic of the classical Overeducation-Required education-Undereducation (ORU) model by Duncan and Hoffman (1981). The ORU model breaks down the individual educational attainment into three components (years of education required for the job, years of overeducation, and years of undereducation). The model assumes positive returns to required years of 
schooling, a wage premium for overeducation, and a wage penalty for undereducation. These results have been replicated numerous times and for many different countries (e.g. van der Velden and Bijlsma, 2018; Levels et al., 2014b; Allen, Levels, and van der Velden, 2013; Groot and Maassen van den Brink, 2000; Hartog, 2000).

We make use of the ORU-logic to develop a matching model for skill-to-job matches with which we assess economic outcomes related to surpluses and shortages in digital problemsolving skills. These skills are key information-processing skills that allow workers to be productive and to generate adequate performance in contemporary labour markets. We make use of digital problem-solving skills, as it is exactly these types of key skills that become more important because work is increasingly digitised while the required skills are still not fully taught in education systems (OECD, 2016a; 2016g). Against the background of technology-induced changes in the task composition of workplaces, digital problemsolving is increasingly important for productivity in most occupations (Cedefop, 2018). These key skills should, therefore, also relate to wages. However, digitalisation at the workplace is not new. With our analyses we seek to capture the current situation, asking: Is the relation with future skills already evident for present wages?

Using the logic of the Duncan and Hoffman (1981) ORU-model, we address the mechanism that relates mismatches in digital problem-solving skills to differential wage effects. The underlying idea of the ORU-model is that more skills generally lead to higher wages. Based on the ORU-logic, we assume that every occupation has a typically required level of skills. However, depending on skill requirements of their job, workers can have significantly too much or too little skills. In its vertical dimension, the concept of skill mismatch refers to a working situation in which the skills possessed by workers do not meet or exceed the skill requirements of their jobs. We consider workers that possess significantly more skills than needed at the workplace overskilled, whereas we regard workers with significant shortages to be underskilled. This over- or underskilling is related to wages. In the case of underskilling, workers lack required skills, which entails wage penalties. By contrast, overskilled workers make more money than well-matched co-workers in the same job, but not as much as they could earn in a job that requires their own (higher) level of skills. Studies on numeracy and literacy skill mismatches show that economic returns to required skills are positive and bigger than returns to excess skills, which, in turn, are bigger than the (absolute value of) the penalties that are related to skills shortages (e.g. van der Velden and Bijlsma, 2018; Levels et al., 2014b). We expect to find that (mis-)matches in digital problem-solving skills are generally related to economic outcomes in the same way in which numeracy and literacy skills are associated with wages (see e.g. Perry, 2017; Hanushek et al., 2015b). Under the assumptions that digital problem-solving skills are key to generating productivity in all kinds of occupations, and that returns to digital problem- 
solving skills are variable and dependent on the match with what is required at the workplace, we expect to find support for the following hypotheses:

H1a. The bigher the required level of digital problem-solving skills in an occupation, the bigher the returns.

H1b. Underskilling in digital problem-solving entails wage penalties, while overskilling in digital problemsolving is positively related to wages as surplus skills pay off.

Looking at skill-to-job matches of the employed workforce we cannot assume that a wage penalty is entirely driven by the fact that workers lack the skills required by their job. Because why then would they (still) be employed in their job? There are two possible explanations: (1) underskilled workers will soon leave their jobs, or (2) they compensate shortages in one skill domain with a higher proficiency in other skills that we do not observe, for example management skills. It is known from the literature that this holds for certain groups of workers more than for others. However, wage inequalities can only partly be explained by the individual differences in skill proficiency.

Human capital theory assumes that employers reward workers for their productivity, i.e. for skills used at work (Becker, 1962). The underlying assumption is that a higher productivity leads to higher wages. Educational attainment and age (displaying experience), for example, are thought to serve as valuable market signals to proxy acquired human capital. Accordingly, highly educated and older workers are expected to be more productive than low educated or young entrants to the labour markets (Bills, 2004; Becker, 1962). However, human capital theory cannot explain differential wage effects for equally productive workers. Therefore, the economic theory of discrimination is of particular importance here (see e.g. Sesselmeier et al., 2010; Becker, 1971) next to job market signalling theory (Bills, 2004; 2003; Spence, 1971). The argument is that the market value of productivity is not exclusively based on the actual productivity but also affected (1) by the performance as perceived by the wage-setter, and (2) by potentially differential value judgments about the extent to which performance should be rewarded. This subjective evaluation of performance implies that the rewards for productivity may be systematically affected by value judgements about perceived personal indices and characteristics of the worker - such as gender, migration background or socio-economic status. When it comes to digital problem-solving skills and labour market outcomes, personal characteristics could even be more important than for numeracy or literacy skills as digital problem-solving is usually not taught and certificated at schools.

Concerning the market value of personal characteristics, the gender pay gap is long standing finding. Women are consistently found to be underpaid relative to men, even when they are equally skilled and educated (Lauder, Brown and Ashton, 2017: 418; Holmes 2017; Kupfer, 2014; OECD, 2012; Blau and Kahn, 2003; Goldin, 1986; Becker, 1971). Although 
the actual gender differences in digital problem-solving skills are rather small (OECD, 2016c), the relation between skill and wage is known to be stronger for men than for women (e.g. Hanushek et al., 2015b). Results based on PISA 2015 show that this does not start at labour market entry but is evident also for pre-market situations at young ages: "Genderrelated differences in science engagement and career expectations appear more related to disparities in what boys and girls think they are good at and is good for them, than to differences in what they actually can do" (OECD, 2016h: 18). Prejudice can lead to affirmative action and effective discrimination (Becker, 1971)28. Gender stereotypes, such as the one that women are less capable than men when it comes to maths or handling ICT and solving problems in technology-rich environments (see e.g. PISA 2015 results as provided by OECD, 2016h) can lead to unequal labour market outcomes. This hold irrespective of the fact that actual gender differences in skill proficiency are small, which is evident for digital problem-solving skills of adults across countries (OECD, 2016c: 83). As the salary of women is partly driven by discrimination and the relation between skill and wages is stronger for men, we expect to find:

H2. While a small part of the wage gap between male and female workers is explained by differences in digital problem-solving skill proficiency, the wage penalty for a shortage in digital problem-solving skills is higher for females, and the wage premium for overskilling is higher for male workers.

Previous studies also find that returns to cognitive skills such as numeracy are higher for natives than for migrants (e.g. Hanushek et al., 2015b). Natives also tend to be more often wellskilled for their jobs, with lower levels of skill mismatches than migrants (Perry, 2017; OECD 2016c ${ }^{29}$. As digital problem-solving skills are often merely trained on the job, the type of technology used in the home country could affect proficiency, particularly for firstgeneration migrants (Sanromá, Ramos, and Simón, 2015; Chiswick and Miller, 2008; 2009). Besides, differential wage returns could go back to the above outlined discriminatory mechanism: Migrants could be perceived less capable as they might have language difficulties or lack cultural codes. Ethnicity as personal characteristic can modify the market value of (excess) skills, leading to lower returns and aggravated penalties for migrants as compared to natives (Hanushek et al., 2015b; Oreopoulos, 2009; Seibert and Solga, 2005).

\footnotetext{
${ }^{28}$ Another study finds that normative contexts in which individuals are raised can explain gender differences in educational attainment, both over time and across countries (van Hek, Kraaykamp, and Wolbers, 2016).

${ }^{29}$ Reasons for higher shares of skill mismatch among migrants may be an imperfect transferability and signalling of skills (Chiswick and Miller, 2009), a lower language proficiency and citizenship issues could also be important (Dustmann and van Soest, 2002).
} 
Measuring returns to skill-to-job mismatches, we expect to find:

H3. While part of the wage gap between natives and migrants is explained by differences in skill proficiency, the wage penalty for a shortage in digital problem-solving skills is higher for migrants, and the wage premium for overskilling is higher for native workers.

While technological developments of the past mainly affected routine jobs, recent breakthroughs in AI and business process automation also affect high skilled jobs and human experts (Susskind and Susskind, 2017). Accordingly, a lack of digital skills should be detrimental for workers throughout the labour market. However, we would expect that certain social groups, such as higher socio-economic status (SES), have more means to compensate skill shortages in one domain with higher levels of other skills. Socio-economic status forms a classic predictor for wage inequalities, and e.g. Hanushek et al. (2015b) show that returns to numeracy skills are higher for workers with high parental education. Besides, non-cognitive skills, better means to express oneself, higher negotiating skills, or more cultural capital could all lead to a positive discrimination for higher SES groups as compared to lower SES groups. Against this background, we expect to find:

H4. While part of the wage gap between workers with higher and lower socio-economic status is explained by differences in skill proficiency, the wage penalty for a shortage in digital problem-solving skills is higher for workers from lower socio-economic status, and the wage premium for overskilling is higher for workers from higher socio-economic status.

Educational attainment serves as proxy for acquired human capital, having a strong and independent effect on labour market outcomes (Bills, 2004; 2003; Spence, 1973; Becker, 1962). Even returns to skills depend on formal qualifications (Heisig and Solga, 2017). Even if no certificate exists that covers digital problem-solving skills, we would expect that the signalling effect of formal qualifications serves as such powerful screening device when assessing productivity that the effect of 'real' digital problem-solving skills is played off. Accordingly, for lower educated workers, the effect of surplus skills should be superimposed by the signal of lower education. We phrase the following hypothesis:

H5. While part of the wage gap between higher and lower educated workers is explained by differences in skill proficiency, the wage penalty for a shortage in digital problem-solving skills is higher for workers with medium or low education, and the wage premium for overskilling is higher for high educated workers.

Next to educational credentials, age also serves as proxy for acquired human capital, generating higher wage premia e.g. for more experienced (and therefore older) workers as compared to younger workers. Older workers are paid more on the basis of skills, less on credentials (van der Velden and Bijlsma, 2018; Altonji and Pierret, 2001). As skills matter 
more for older than for younger workers, we would expect to find that mismatches also matter more. As employers tend to valuate particularly long-lasting and high-trust relations to experienced workers, we would expect that high levels of skills and overskilling pay off more for older than for younger workers, while shortages are more penalised (e.g. van der Velden and Bijlsma, 2018; Hanushek et al., 2015b). Comparing age groups, we would expect to find:

H6. While part of the wage gap between older and younger workers is explained by differences in skill proficiency, the wage penalty for a shortage in digital problem-solving skills is higher for older workers, and the wage premium for overskilling is also higher for older workers.

\section{Data and Methads}

We test our hypotheses using micro data from the OECD Programme of the International Assessment of Adult Competencies (PIAAC; see OECD, 2016a; 2016b). For PIAAC, representative samples of the working age population (ages 16-65) in more than 30 countries were tested in key skills related to information processing at work and in daily life ${ }^{30}$. The survey conducted assessments in three different skill domains: literacy, numeracy and problem solving in technology-rich environments. The survey addressed key demographic and socioeconomic characteristics, also gathering information about the workplace. In most cases, the assessment was computer-based. Adaptive testing and item response techniques were implemented to derive 10 plausible values (PVs) of the competency level of each respondent. Taken together, these PVs provide unbiased estimates of the 'real' competency scores (OECD, 2016b). Providing internationally comparable skills measurements for many countries, the objective and high-quality PIAAC micro data are a unique opportunity to investigate digital skills and related outcomes across countries. For the study at hand, we make use of the problem solving in technology-rich environments (PS-TRE) skill domain in PIAAC, which we here refer to as "digital problemsolving skills". This shorthand contains the two components of the PS-TRE framework: Technology-rich environments and problem-solving skills.

\section{I What are "digita/ problem-sa/ving skills"?}

In PIAAC, digital problem-solving skills are defined as "using digital technology, communication tools and networks to acquire and evaluate information, communicate with others and perform practical tasks" (PIAAC Expert Group, 2009: 9). The problem solving

\footnotetext{
${ }^{30}$ In the majority of participating countries, the PIAAC survey was conducted in the years $2011 / 12$, while some countries tested in 2014/15.
} 
in technology-rich environments domain is a scenario-based assessment, entailing nine response items that cover specific problems that people encounter when using computerbased artefacts at the workplace or in daily life. The core feature of problem-solving is that the tasks are designed in a way that prevents the respondents to reach the goal using simple routine actions (PIAAC Expert Group, 2009: 7). Therefore, digital problem-solving is more than basic or routine computer skills. By contrast, it involves active strategies to set goals and the workers' endowment of capabilities to use strategies (and develop the mindset) needed to interact with databases. It also involves the capabilities to navigate online and through digital interfaces, tools and folders as well as documents as well as the use of networks to acquire or process information and perform practical tasks and digital communication (Acemoglu and Autor, 2011: 1045; PIAAC Expert Group, 2009). Completing the PIAAC-tasks requires skills from basic digital navigation to advanced knowledge to conduct and interpret searches, interact within databases, and make decisions about competing information in order to solve so-called information-rich problems. The problem-solving scale has a range from zero to 500, with an OECD international average of 278 (OECD, 2016b).

\subsection{Measurement and aperationalisation of theoretical concepts}

\section{Measuring mismatches in digital problem-sa/ving skills}

The concept of skill mismatch requires measures of both skills possessed (available in PIAAC) and skills required at the workplace. As the survey focuses on the supply side instead of the demand side of the labour market, information on the latter is not available in PIAAC. Addressing the vertical dimension of mismatches (i.e. mismatch by level of skills), we use a Realised Matches Approach (RMA). This is a commonly used statistical measure, capturing the deviation of the individual skill proficiency from the mean skill level in each occupation in each country (e.g. van der Velden and Bijlsma, 2018; Perry, Wiederhold, and Ackermann-Piek, 2014). Generally, the RMA assumes that every occupation has a typically required skill level that differs between countries. The RMA defines a worker as overskilled or underskilled if the worker has a skill proficiency level of - usually_one standard deviation above or below that occupation-specific level (e.g. Perry et al., 2014). The cut-off point of one standard deviation is chosen as it captures approximately the distance between two proficiency levels in PIAAC (OECD, 2016a; 2016b). We follow this approach, defining a corridor between one standard deviation above and below the robust required skill level of each occupation-country-cell to identify wellmatched workers. If the skill level of a worker lies outside that corridor, we classify the 
respective worker as mismatched, i.e. misallocated by level of skill ${ }^{31}$. We exclude observations from ISCO 2-digit-country-cells that contain less than 25 observations. For all cells with the necessary number of observations, we estimate robust required skill levels, making use of calculations performed by Allen and Bijlsma (forthcoming) ${ }^{32}$.

Not all countries that participated in PIAAC tested for digital problem-solving skills ${ }^{33}$. We use data for those 26 countries that participated in PIAAC and took part in the assessment of digital problem-solving skills. We exclude Russia and Australia due to respectively data quality issues and administrative restrictions. As the Canadian sample is much bigger than the other countries' samples, we select a random sample of Canada's respondents to avoid overrepresentation in our dataset. For our main analyses, we restrict the sample to fulltime workers. This was done to avoid that different wage-setting regimes for part-time workers affect our analyses. We exclude self-employed workers as the relation between skills and earnings for such workers is quite different from that of workers. We also exclude members of the armed forces, (unpaid) family workers and students/interns as for these workers wage setting is different from other employees. Our dependent variable is log hourly wages that we trimmed per country, omitting the first and 99th percentile of the respondents in each country. Our main analyses rely on a working sample of 58,761 male and female fulltime workers from 26 countries. The additional analyses, in which we include part-time workers, rely on micro level data for 72,004 workers.

\section{How do we treat respondents who did not take the problem-salving test?}

PIAAC used computer-based testing. However, about $18 \%$ of the fulltime workers did not take the test (OECD, 2016c: 54). Test scores are missing for three groups of adults: (1) adults lacking computer experience, (2) respondents who failed the "ICT core" test implemented in PIAAC and thus lack the computer skills needed for computer-based competency testing, and (3) people who would have had the required skills but refused to use a computer for testing (OECD 2016c: 54 et seq.). While gender differences are rather small, non-respondents are a selective group that contains more migrants than natives, and that is, on average, older than the respondents who took the computer-based assessment, has lower levels of education and more often belongs to middle or lower socio-economic

\footnotetext{
${ }^{31}$ We compute the standard deviation of the 10 PVs of the individual PS-TRE scores in PIAAC, pooling over ISCO 2-digit categories. We use the repest-command in Stata 15 to properly take into account the PIAAC replicate weights.

${ }^{32}$ Van der Velden and Bijlsma (2018) show that the total explained variance does not change if they use 3-digit instead of 2-digit ISCO categories.

${ }^{33}$ Cyprus, France, Italy, Indonesia (Jakarta), and Spain did not offer the PS-TRE tests. A list of all countries under study is provided in Table A1 (Appendix A).
} 
status groups as compared to higher socio-economic status (Table 1 and Figure A1 in Appendix A; also see OECD, 2016c: 56). Although it is valid to assume that these respondents should be at the lower end of the proficiency scale, not all of them can per se be classified as underskilled. If they are in a job that requires very little or no digital problemsolving skills, they could also be wellskilled. We deal with this by using a special imputation procedure to assign match/mismatch for the respondents with missing test scores in digital problem-solving skills. For each ISCO 2-digit-country-cell, we compare the posterior mean with the empirically observed proficiency levels for the problem-solving scale in PIAAC (OECD, 2016b: p. 13; also see Additional Material 1, Appendix A).

\section{Dperationalisation: Sacial groups and importance of skills}

For each social group under study, we compute a dummy variable. First, we compare male vs. female fulltime workers, whereby $45 \%$ of our sample are women and $55 \%$ men. Second, we compare migrants and native workers, whereby migration background equals 1 for first and second-generation migrants. In our sample, we have 13\% migrants and $87 \%$ natives (that is workers who were born in the country in which they now reside, and this holds also for their parents). Third, we identify workers with high vs. lower socio-economic status (SES). SES is operationalised using information on the educational background of parents as provided in PIAAC (at least one parent with tertiary education vs. no parent with tertiary education). Our sample consists of $25 \%$ workers of high SES backgrounds and $71 \%$ workers of lower SES backgrounds (information is missing for $4 \%$ of the full sample). Fourth, we compare tertiary educated vs. low and medium educated workers. Educational level is assessed on the basis of the highest educational attainment, with $30 \%$ tertiary educated workers and $70 \%$ with medium or low education. Last, we compare younger (aged $<45)$ vs. older workers (aged $>=45$ ). The age of 45 is used as a cut-off for younger vs. older workers as this age marks the half of what is usually captured as "prime age" in terms of careers. Workers of 45 are clearly older than entry ages while still clearly younger than exit ages. In our sample, we have 39\% older and 61\% younger workers (for a detailed description of the social groups see Table 1a).

To control for the occupation-specific importance of digital problem-solving skills, we resort to detailed information on occupational skills profiles (OSPs) as provided by Cedefop (2015). These data summarise essential characteristics required for each job at ISCO 2-digit level (Cedefop, 2015: 7). We make use of six OSP scales that - together capture something qualitatively very close to the digital problem-solving domain in PIAAC, covering the relevant aspects of both ICT skills and problem-solving skills. We perform orthogonal factor analyses to obtain the first unrotated factor that we use to identify scores on the importance of digital problem-solving skills for each occupation. We introduce these 
scores in our statistical models as micro level control, explaining wage returns (for details see Additional Material 2 in Appendix A).

\subsection{Analytical strategy}

First, we provide sample statistics, describing the prevalence of the mismatch phenomenon among social groups and countries. We then estimate economic returns to mismatches in digital problem-solving skills using multilevel mixed-effects models. In our main model, we compute the individual-level wage regression with trimmed log hourly wages as dependent variable.

The model is based on the following Equation [1]:

$\mathrm{W}_{\mathrm{ic}}=\alpha_{\mathrm{c}}+\beta_{1} \mathrm{RS}_{\mathrm{c}}+\beta_{2} \mathrm{US}_{\mathrm{ic}}+\beta_{3} \mathrm{OS}_{\mathrm{ic}}+\beta_{4} \mathrm{I}_{\mathrm{c}}+\beta_{5} \mathrm{C}_{\mathrm{ic}}+v_{\mathrm{ic}}+\omega_{\mathrm{c}}$

where, for each individual $\mathrm{i}$ in country $\mathrm{c}$; $\mathrm{W}_{\text {ic }}$ is the natural logarithm of the hourly wages; $\alpha_{c}$ captures the country-specific constant; and $\mathrm{RS}_{\mathrm{c}}$ is the estimate of the required skill level in each ISCO 2-digit occupation-country-cell. $\mathrm{US}_{\mathrm{ic}}$ and $\mathrm{OS}_{\mathrm{ic}}$ are dummies that indicate individual under- or overskilling. $I_{c}$ is the factor that measures importance of ICT and problem-solving skills in the occupation. $\mathrm{C}_{\text {ic }}$ is a vector of control variables, including a dummy for missing test scores in digital problem-solving skills, age and age squared. Last, $\nu_{i c}$ and $\omega_{c}$ are error terms at the individual and country levels, respectively.

As outlined in the theoretical section, the focus of this paper is to examine inequalities between social groups in returns to mismatches in digital problem-solving skills. For each social group that we outlined in the theoretical section, we compute a series of nested models, answering the question: to what extent is the wage gap between social groups (Model 1) explained by the individual skill proficiency (Model 2) and skill matching (Model 3), and how can mismatches in problem-solving skills explain wage inequalities between social groups (Model 4)?

The analyses are based on following Equations [2-5]:

$$
\begin{aligned}
\mathrm{W}_{\mathrm{ic}}= & \alpha_{\mathrm{c}}+\beta_{1} \mathrm{SG}_{\mathrm{ic}}+\beta_{2} \mathrm{I}_{\mathrm{c}}+\beta_{3} \mathrm{C}_{\mathrm{ic}}+\mathrm{u}_{\mathrm{ic}}+\omega_{\mathrm{c}} \\
\mathrm{W}_{\mathrm{ic}}= & \alpha_{\mathrm{c}}+\beta_{1} \mathrm{SG}_{\mathrm{ic}}+\beta_{2} \mathrm{I}_{\mathrm{c}}+\beta_{3} S \mathrm{SP}_{\mathrm{ic}}+\beta_{4} \mathrm{C}_{\mathrm{ic}}+\mathrm{v}_{\mathrm{ic}}+\omega_{\mathrm{c}} \\
\mathrm{W}_{\mathrm{ic}}= & \alpha_{\mathrm{c}}+\beta_{1} \mathrm{SG}_{\mathrm{ic}}+\beta_{2} \mathrm{I}_{\mathrm{c}}+\beta_{3} \mathrm{RS}_{\mathrm{c}}+\beta_{4} \mathrm{US}_{\mathrm{ic}}+\beta_{5} \mathrm{OS}_{\mathrm{ic}}+\beta_{6} \mathrm{C}_{\mathrm{ic}}+\mathrm{vic}_{\mathrm{ic}}+\omega_{\mathrm{c}} \\
\mathrm{W}_{\mathrm{ic}}= & \alpha_{\mathrm{c}}+\beta_{1} \mathrm{SG}_{\mathrm{ic}}+\beta_{2} \mathrm{I}_{\mathrm{c}}+\beta_{3} \mathrm{RS}_{\mathrm{c}}+\beta_{4} \mathrm{US}_{\mathrm{ic}}+\beta_{5} \mathrm{OS}_{\mathrm{ic}} \\
& +\beta_{6} \mathrm{SG}_{\mathrm{ic}} * \mathrm{RS}_{\mathrm{c}}+\beta_{7} \mathrm{SG}_{\mathrm{ic}} * \mathrm{US}_{\mathrm{ic}}+\beta_{8} \mathrm{SG}_{\mathrm{ic}} * \mathrm{OS}_{\mathrm{ic}}+\beta_{9} \mathrm{C}_{\mathrm{ic}}+\mathrm{v}_{\mathrm{ic}}+\omega_{\mathrm{c}}
\end{aligned}
$$


In addition to the legend above, $\mathrm{SG}_{\text {ic }}$ is a binary variable capturing social group index, $\mathrm{SP}_{\text {ic }}$ is the individual skill proficiency in digital problem-solving, and the two multiplicative terms in [5] capture interactions between social group and the skill (mis-)match indicators. Note that we control for age and age squared in all analyses, except the comparison of age groups.

We run a series of robustness checks and additional analyses. We repeat our main model based on Equation [1] four times: First, excluding the respondents with missing test scores; second, only for the countries with less than $20 \%$ missing test scores in digital problemsolving skills; third, to assess whether our results change if we include micro level characteristics other than age and age squared, we repeat our main model, controlling for worker- and job-related characteristics; and fourth, we leave out one country at a time to assess whether single countries drive our main results. To furthermore assess differences between new and old skills, we repeat the series of nested models based on Equations [2] to [5] for socio-economic status using literacy skills instead of digital problem-solving skills. Our dataset contains individuals nested in sampling clusters (characterised by a specific weighting procedure) nested in countries. To properly take into account macro level errors, we estimate multilevel mixed-effects regression models (using the 'mixed' command in Stata 15) ${ }^{34}$. Computing multilevel models, we cannot use the replicate weights implemented in PIAAC. All analyses are weighted using a 'rescaling to cluster size' approach with which we adjust the overall sample weight to account for different sizes of the country samples (for detailed information about the dataset and technical issues, see OECD 2016a; 2016b). To assess the goodness of fit of our models, we calculate the amount of explained variance (Snijders and Bosker, 2012).

\section{Results}

\section{Descriptive results}

Table $1 \mathrm{~b}$ gives descriptive statistics for all groups of individuals under study. We find that, over all 26 countries, $78 \%$ of the fulltime workers are wellmatched in terms of digital problem-solving skills. By contrast, $10 \%$ are classified as overskilled, whereas $12 \%$ have shortages in these skills. While gender differences are comparably small, we still find that overskilling is more prevalent among male workers and native workers. Besides, overskilling

\footnotetext{
${ }^{34}$ Our multilevel logit models have 26 observations on the level 2 -variable. The main interest of the analyses that we provide here lies in the robust estimation of the fixed parameters on individuallevel predictors. According to Bryan and Jenkins (2015: 18), these estimates are unaffected by a small number of countries and calculated without bias and with the correct SEs with multilevel models.
} 
is clearly more prevalent for workers with a high socio-economic status, workers with tertiary education, and younger workers. Underskilling, by contrast, is more widespread among female fulltime workers, migrants, workers from lower socio-economic status, workers with secondary or compulsory education and older workers. Table $1 \mathrm{~b}$ also provides an overview of the percentages of respondents that could or would not take the computerbased problem solving-test (i.e. missing test scores). Here, too, we find large differences between social groups. The percentage of non-respondents in our analytical sample is more than twice as big among older workers compared to younger workers (27\% vs. $13 \%)$. The share of non-respondents is also bigger among migrants ( $24 \%$ vs. $17 \%$ for natives), workers from lower socio-economic status ( $21 \%$ vs. $8 \%$ for the higher SES), middle or low educated workers ( $23 \%$ vs. $6 \%$ for tertiary graduates), while, again, gender differences are rather small $(22 \% \text { men vs. } 17 \% \text { females })^{35}$. The percentage of wellskilled workers ranges from $70 \%$ in Japan to $86 \%$ in Slovakia.

\footnotetext{
${ }^{35}$ In addition to Table 1b, Figure A1 (Appendix A) gives an overview of missings over ISCO 2digit categories and importance levels. Across countries, we find considerable differences in the amount of skill mismatch (Figure 1, also see Table A1 in Appendix A).
} 


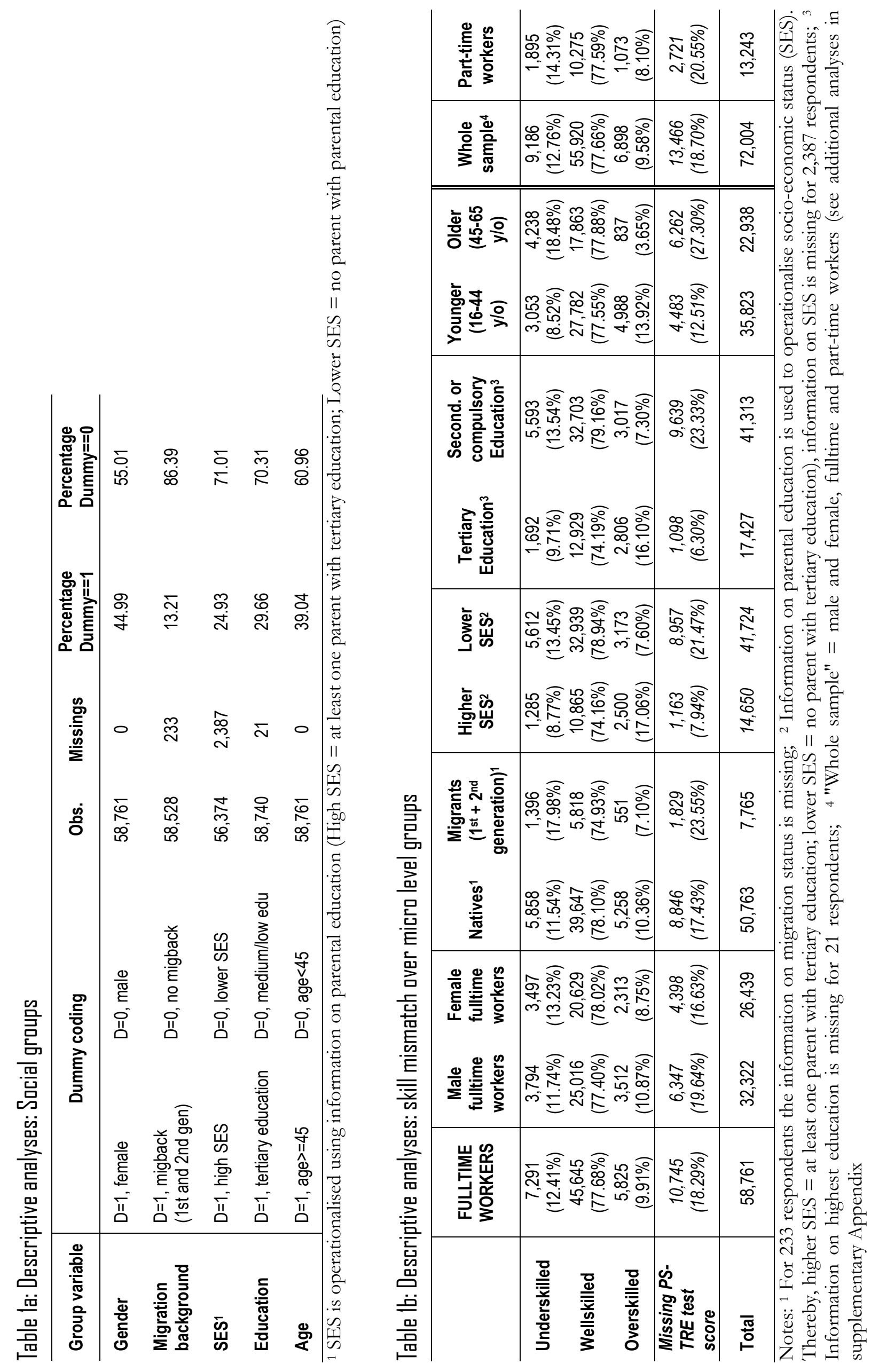




\section{Multileve/ analyses}

We now move on to our regression analyses, referring to our main model for fulltime workers (Table 2). Our first finding is that digital problem-solving skills matter for wages: the higher the required skill level in digital problem-solving in an occupation, the higher the returns. An increase of one standard deviation in required digital problem-solving skills is associated with a wage return of around $8 \%$, which supports hypothesis $1 \mathrm{a}$. The coefficient capturing the occupation-specific importance of digital problem-solving also displays a positive and statistically highly significant association with wages. Both mismatch indicators are statistically highly significant and supporting hypothesis $1 \mathrm{~b}$. Surplus skills pay off with a considerable wage premium of $12 \%$. The premium for overskilling is thereby bigger than the (absolute value) of the penalty for underskilling, with around $-10 \%$, which is in line with other analyses on returns to mismatches in numeracy skills using the same data (e.g. van der Velden and Bijlsma, 2018). As in all following analyses, we find that the wage premium increases with the importance of digital problem-solving skills in the respective job. Our main model can explain 31\% of the total variance. Moving on to the social group analyses, we explore the extent to which returns to skill mismatches are different for different groups of workers. We compute the above outlined series of nested models, starting with an examination of digital problem-solving skills and the gender wage gap (Table 3).

Are returns to digital problem-solving skills different for men and women? Model 1 shows that wage returns are around 17\% lower for women than for men, even controlled for the occupation-specific importance of digital problem-solving skills ${ }^{36}$. Model 2 shows that only a small part of around 1 percentage points of the gender pay gap can be explained by differences in skill proficiency, controlled for the importance of digital problem-solving in the job. The skill matching Model 3 shows that a higher level of required skills pays off with around 10\% higher earnings, while shortages are penalised, and surplus skills are additionally rewarded. Concerning differential wage returns, Model 4 shows that an investment in digital problem-solving skills pays off for women, as they receive higher wages than men if they make it into jobs that require a higher level of these skills. Surprisingly, Model 4 counteracts our theoretical considerations and leads to a rejection of hypothesis H2: Overskilling pays more off for women than for men, although the coefficient is rather small (4\%). The average marginal effect of underskilling, by contrast, is no longer significant. We find that Model 4 can explain 36\% of the total variance.

\footnotetext{
${ }^{36}$ Note that we restrict our analyses to fulltime workers to avoid different wage setting regimes for part-time workers. We include part-time workers as additional analysis, finding that the gender gap stays the same while part-time work correlates with slightly higher earnings (Table A4 in Appendix A).
} 
Table Z: MAIN MDDEL - Fulltime workers

Mixed model; DV: Trimmed ln hourly wage

Model 1

VARIABLES

Fulltime

Required skill level (standardised)

$0.076^{* * *}$

$(0.026)$

Underskilled in digital PS-skills (Dummy)

$-0.096^{* * *}$

Overskilled in digital PS-skills (Dummy)

$0.121^{* * *}$

$(0.011)$

Importance of digital skills (std. $)^{1}$

$0.148^{* * \star}$

(0.015)

\begin{tabular}{lcc}
\hline Observations & 58,761 & 58,761 \\
Number of groups & 26 & 26 \\
BIC & 74441 & 57208.3 \\
\hline
\end{tabular}

\begin{tabular}{lcc}
\hline VARIANCE COMPONENTS & Int. Model & Model 1 \\
\hline Between Variance & 0.182 & 0.127 \\
Within Variance & 0.0107 & 0.00586 \\
Total Variance & 0.1927 & 0.13286 \\
\hline \% EXPLAINED VARIANCE & & Model 1 \\
\hline \% Explained Between Variance & & 30.22 \\
\% Explained Within Variance & & 45.23 \\
\% Explained Total Variance & & 31.05 \\
\hline
\end{tabular}

Robust standard errors in parentheses; *** $\mathrm{p}<0.01, * * \mathrm{p}<0.05, * \mathrm{p}<0.1$;

std. = standardised; D. = Dummy; MODELS ARE WEIGHTED; Controls include age, age2, and a dummy for missing test scores

1 Note that this variable displays the first unrotated factor of a PCA, which is standardised by definition 
Table 3: Female vs. male fulltime workers

Sample: Fulltime workers; Mixed model; DV: Trimmed ln hourly wage

\begin{tabular}{|c|c|c|c|c|c|c|c|c|}
\hline VARIABLES & & $\begin{array}{c}\text { Model } 1 \\
\text { Fulltime }\end{array}$ & & $\begin{array}{c}\text { Model } 2 \\
\text { Fulltime } \\
\end{array}$ & & $\begin{array}{c}\text { Model } 3 \\
\text { Fulltime } \\
\end{array}$ & & $\begin{array}{c}\text { Model } 4 \\
\text { Fulltime }\end{array}$ \\
\hline Gender Dummy (D. $=1$, female) & & $-0.167^{* * *}$ & & $-0.156^{\star * *}$ & & $-0.173^{* * *}$ & & $-0.176^{* * *}$ \\
\hline & & $(0.020)$ & & $(0.020)$ & & $(0.020)$ & & $(0.019)$ \\
\hline Importance of dig. skills (std.) & & $0.202^{* * *}$ & & $0.161^{* * *}$ & & $0.132^{* * *}$ & & $0.130^{\star * *}$ \\
\hline & & $(0.012)$ & & $(0.009)$ & & $(0.014)$ & & $(0.014)$ \\
\hline Proficiency dig. PS-skills (std.) & & & & $0.096^{* * *}$ & & & & \\
\hline & & & & $(0.007)$ & & & & \\
\hline Required skill level (std.) & & & & & & $0.098^{* * *}$ & & $0.084^{* * *}$ \\
\hline & & & & & & $(0.025)$ & & $(0.025)$ \\
\hline Underskilled in dig. P-S (D.) & & & & & & $-0.093^{* * *}$ & & $-0.083^{* * *}$ \\
\hline & & & & & & $(0.010)$ & & $(0.015)$ \\
\hline Overskilled in dig. P-S (D.) & & & & & & $0.109^{* * *}$ & & $0.096^{* * *}$ \\
\hline & & & & & & $(0.011)$ & & $(0.013)$ \\
\hline Req. skills*Female $(D .=1)$ & & & & & & & & $0.047^{* * *}$ \\
\hline & & & & & & & & $(0.011)$ \\
\hline UnderskilledFemale (D. $=1)$ & & & & & & & & -0.024 \\
\hline & & & & & & & & $(0.019)$ \\
\hline OverskilledFemale $(D .=1)$ & & & & & & & & $0.038^{* * *}$ \\
\hline & & & & & & & & $(0.014)$ \\
\hline Constant & & $1.653^{* * *}$ & & $1.564^{* * *}$ & & $1.633^{* * *}$ & & $1.622^{* * *}$ \\
\hline & & $(0.074)$ & & $(0.076)$ & & $(0.068)$ & & $(0.070)$ \\
\hline Observations & & 58,761 & & 48,016 & & 58,761 & & 58,761 \\
\hline Number of groups & & 26 & & 26 & & 26 & & 26 \\
\hline $\mathrm{BIC}$ & & 55867.1 & & 41613.5 & & 54401 & & 54205.7 \\
\hline VARIANCE COMPONENTS & Int. & Model 1 & Int. & Model 2 & Int. & Model 3 & Int. & Model 4 \\
\hline Between Variance & 0.185 & 0.147 & 0.169 & 0.128 & 0.185 & 0.12 & 0.185 & 0.119 \\
\hline Within Variance & 0.011 & 0.00613 & 0.011 & 0.00606 & 0.011 & 0.0058 & 0.011 & 0.00586 \\
\hline Total Variance & 0.196 & 0.15313 & 0.18 & 0.13406 & 0.196 & 0.1258 & 0.196 & 0.12486 \\
\hline$\%$ EXPLAINED VARIANCE & Int. & Model 1 & Int. & Model 2 & Int. & Model 3 & Int. & Model 4 \\
\hline \% Exp. Between Var. & & 20.54 & & 24.26 & & 35.14 & & 35.68 \\
\hline$\%$ Exp. Within Var. & & 43.76 & & 43.89 & & 46.79 & & 46.24 \\
\hline \% Exp. Total Var. & & 21.83 & & 25.44 & & 35.78 & & 36.26 \\
\hline
\end{tabular}

Robust standard errors in parentheses; $* * * \mathrm{p}<0.01,{ }^{* *} \mathrm{p}<0.05,{ }^{*} \mathrm{p}<0.1 ;$ std. $=$ standardised; D. $=$ Dummy ALL MODELS ARE WEIGHTED; Controls include age, age2, and a dummy for missing test scores 
Results of the analyses for migrants as compared to natives are displayed in Table 4. Based on the academic discourse on discrimination, we expected to find that (excess) skills pay off less for migrants due to the discriminatory context in which a migration background depreciates the market signal provided by a productive use of skills in the job (Spence, 1973; Becker, 1971; also see Seibert and Solga, 2005; Perry, 2017). However, we find that the relatively small wage gap that we find in Model 1 can be fully explained by a lack of skills when we include skill proficiency and the skill matching model in Models 2 and 3. Model 4 shows that migrants in our sample get even higher wage premia than natives if they work in occupations that require a higher level of digital problem-solving skills (this could be e.g. IT specialists from abroad, who are really paid based of required skills). Returns to skill mismatches do not differ between natives and migrants, which does not support hypothesis H3.

Table 5 shows a wage premium of around 8\% related to a higher socio-economic status (SES), controlling for importance of digital problem-solving in the job (Model 1). The premium is reduced to $5 \%$ but persistent, even when we control for skills proficiency as well as the importance of digital problem-solving skills in the job (Model 2). Model 3 give the expected results for the skill matching model: overskilling pays off, while underskilling entails penalties. Model 4, however, bears surprising results. First, the wage penalty related to both required skills and underskilling is the same for upper and lower SES groups - there is no additional social status premium when working in a job that requires a higher level of digital problem-solving. Second, there is a general wage premium for the SES, but the interaction between overskilling and SES is negative and significant at the 5\% level. An investment in high levels of digital problem-solving skills pays off specifically for workers from a low SES background, but not for workers from a high SES background - which leads us to a rejection of hypothesis $\mathrm{H} 4$. This finding is unexpected and potentially highly important: it suggests that digital problem-solving skills could potentially work as a social emancipation lever, narrowing the divide between socio-economic status groups when it comes to wage inequalities. The wage premium that workers from higher SES groups receive is not based on additional returns to higher levels of required skills or excess digital skills, but on other criteria. This finding is unexpected and requires additional analyses.

Digital problem-solving skills are generally less related to SES. By contrast, literacy is typically more related to SES. To provide further evidence that helps us to assess the potential of digital problem-solving skills as emancipatory lever, we repeat our series of nested models using literacy skills instead of digital problem-solving skills (Table A2 in the appendix). We run these additional analyses with the exact same sample selection that we have in Table 5 to ensure comparability. The results are interesting: For literacy skills, we find that none of the interactions between literacy skills and SES is significant, while the 
general SES premium is persistent. There is a general SES premium, but literacy does pay off to the same extent for both SES groups and does therefore not narrow the wage gap between low and high SES workers. The fact that we do not find the same result for literacy does underline our assumption that digital problem-solving can serve as an emancipatory lever as these skills are less related to SES than literacy and more open for all classes.

Table 6 shows a substantial wage premium of 20\% for tertiary education (Model 1), only part of which is explained by individual skill proficiency (Model 2). The wage premium for graduates is not just for digital problem-solving skills. Model 3 shows that mismatches do explain differences in returns. Model 4, however, shows that there is no additional bonus for tertiary educated workers in jobs that requires a high level of digital problem-solving skills, while underskilling even relates to positive returns. The most important finding, however, is the interaction between tertiary education and overskilling, which is - as in the case of socio-economic status - negative while statistically highly significant. Surprisingly, we find that an investment in high levels of digital problem-solving skills pays off specifically for lower educational levels. Similar to high SES workers, workers with tertiary education seem to get their premium not for digital problem-solving skills but for other skills, be it job specific skills or other cognitive or non-cognitive key competencies. These findings do not support hypothesis $\mathrm{H} 5$.

Based on theoretical reasoning, we argued that, next to educational credentials, age can serve as a proxy for acquired human capital. Model 1 in Table 7 shows that workers aged 45 or older earn around $11 \%$ more than younger workers, while this wage gap is larger than can be expected on the basis of skills proficiency (Model 2). In the other social group analyses, the wage gaps that we found were narrowed or even closed when we controlled for skill proficiency. But this is not the case for age. Older workers really receive a higher wage premium which is not based on their proficiency in digital problem-solving skills. There is a large digital (skill) divide between older and younger workers and skill shortages are clearly more widespread among older workers (see Table 1). However, younger workers do not get an extra premium for surplus expertise while older workers do. Age might indeed serve as proxy for acquired skills. But the premium for older workers is clearly not defined on proficiency in digital problem-solving. Other analyses show that this holds for numeracy and literacy skills as well (see e.g. van der Velden and Bijlsma, 2018). While we find that skills are more important for older workers, there is no additional penalty related to underskilling for older workers. These finding partly support Hypothesis H6. 
Table 4: Migrants vs. native workers

Sample: Fulltime workers; Mixed model; DV: Trimmed ln hourly wage

\begin{tabular}{|c|c|c|c|c|c|c|c|c|}
\hline VARIABLES & & $\begin{array}{l}\text { Model } 1 \\
\text { Fulltime }\end{array}$ & & $\begin{array}{l}\text { Model } 2 \\
\text { Fulltime }\end{array}$ & & $\begin{array}{l}\text { Model } 3 \\
\text { Fulltime }\end{array}$ & & $\begin{array}{c}\text { Model } 4 \\
\text { Fulltime }\end{array}$ \\
\hline $\begin{array}{l}\text { Migr. background } \\
(D .=1, \text { migback })\end{array}$ & & $\begin{array}{l}-0.038^{*} \\
(0.020)\end{array}$ & & $\begin{array}{l}-0.009 \\
(0.022)\end{array}$ & & $\begin{array}{l}-0.026 \\
(0.020)\end{array}$ & & $\begin{array}{l}-0.024 \\
(0.019)\end{array}$ \\
\hline Importance dig. skills (std.) & & $0.202^{\star \star *}$ & & $0.160^{\star \star *}$ & & $0.148^{\star \star \star}$ & & $0.149^{* \star *}$ \\
\hline Proficiency dig. PS-skills (std.) & & $(0.012)$ & & $\begin{array}{l}(0.009) \\
0.099^{* * *}\end{array}$ & & $(0.015)$ & & $(0.015)$ \\
\hline & & & & $(0.007)$ & & & & \\
\hline Required skill level (std.) & & & & & & $0.076^{\star \star \star}$ & & $0.069^{* \star *}$ \\
\hline Underskilled in dig. P-S (D.) & & & & & & $\begin{array}{c}(0.027) \\
-0.094^{\star \star \star}\end{array}$ & & $\begin{array}{c}(0.024) \\
-0.092^{* * *}\end{array}$ \\
\hline Overskilled in dig. P-S (D.) & & & & & & $\begin{array}{l}(0.009) \\
0.120^{\star \star \star}\end{array}$ & & $\begin{array}{l}(0.011) \\
0.120^{* * *}\end{array}$ \\
\hline & & & & & & $(0.011)$ & & $(0.011)$ \\
\hline Req. skills * Migback (D. $=1$ ) & & & & & & & & $0.035^{\star *}$ \\
\hline Underskilled * Migback (D. $=1$ ) & & & & & & & & $\begin{array}{c}(0.016) \\
-0.014 \\
(0.015)\end{array}$ \\
\hline Overskilled ${ }^{*}$ Migback $(D .=1)$ & & & & & & & & $\begin{array}{c}0.002 \\
(0.029)\end{array}$ \\
\hline Constant & & $\begin{array}{l}1.594^{* * *} \\
(0.077)\end{array}$ & & $\begin{array}{l}1.498^{* * *} \\
(0.080)\end{array}$ & & $\begin{array}{l}1.570^{\star * *} \\
(0.074)\end{array}$ & & $\begin{array}{l}1.557^{* * *} \\
(0.076)\end{array}$ \\
\hline Observations & & 58,528 & & 47,853 & & 58,528 & & 58,528 \\
\hline Number of groups & & 26 & & 26 & & 26 & & 26 \\
\hline $\mathrm{BIC}$ & & 58146.3 & & 43422.6 & & 56917 & & 56891.2 \\
\hline VARIANCE COMPONENTS & Int. & Model 1 & Int. & Model 2 & Int. & Model 3 & Int. & Model 4 \\
\hline Between Variance & 0.185 & 0.15 & 0.169 & 0.129 & 0.185 & 0.128 & 0.185 & 0.129 \\
\hline Within Variance & 0.011 & 0.006 & 0.011 & 0.006 & 0.011 & 0.007 & 0.011 & 0.006 \\
\hline Total Variance & 0.196 & 0.156 & 0.18 & 0.135 & 0.196 & 0.134 & 0.196 & 0.135 \\
\hline \% EXPLAINED VARIANCE & Int. & Model 1 & Int. & Model 2 & Int. & Model 3 & Int. & Model 4 \\
\hline \% Exp. Between Var. & & 18.92 & & 23.67 & & 30.81 & & 30.27 \\
\hline \% Exp. Within Var. & & 43.39 & & 42.31 & & 46.06 & & 45.32 \\
\hline \% Exp. Total Var. & & 20.28 & & 24.79 & & 31.66 & & 31.11 \\
\hline
\end{tabular}


Table 5: Higher vs. lower sacio-econamic status (SES)

Sample: Fulltime workers; Mixed model; DV: Trimmed ln hourly wage

\begin{tabular}{|c|c|c|c|c|c|c|c|c|}
\hline VARIABLES & & $\begin{array}{l}\text { Model } 1 \\
\text { Fulltime }\end{array}$ & & $\begin{array}{l}\text { Model } 2 \\
\text { Fulltime }\end{array}$ & & $\begin{array}{l}\text { Model } 3 \\
\text { Fulltime }\end{array}$ & & $\begin{array}{l}\text { Model } 4 \\
\text { Fulltime }\end{array}$ \\
\hline SES (D.=1, high SES) & & $\begin{array}{c}0.075^{* * *} \\
(0.009)\end{array}$ & & $\begin{array}{l}0.049^{* * *} \\
(0.007)\end{array}$ & & $\begin{array}{l}0.058^{* * *} \\
(0.008)\end{array}$ & & $\begin{array}{l}0.066^{* * *} \\
(0.008)\end{array}$ \\
\hline $\begin{array}{l}\text { Importance of digital skills } \\
\text { (std.) }\end{array}$ & & $0.196^{* * *}$ & & $0.156^{\star * *}$ & & $0.145^{\star * *}$ & & $0.146^{* * *}$ \\
\hline $\begin{array}{l}\text { Proficiency dig. PS-skills } \\
\text { (std.) }\end{array}$ & & $(0.012)$ & & $\begin{array}{c}(0.009) \\
0.095^{\star * *}\end{array}$ & & $(0.015)$ & & $(0.015)$ \\
\hline Required skill level (std.) & & & & $(0.007)$ & & $\begin{array}{l}0.073^{\star * *} \\
(0.028)\end{array}$ & & $\begin{array}{l}0.077^{\star * *} \\
(0.028)\end{array}$ \\
\hline $\begin{array}{l}\text { Underskilled in dig. P-S } \\
\text { (D.) }\end{array}$ & & & & & & $-0.089^{* * *}$ & & $-0.093^{* * *}$ \\
\hline Overskilled in dig. P-S (D.) & & & & & & $\begin{array}{c}(0.009) \\
0.115^{\star * *}\end{array}$ & & $\begin{array}{l}(0.008) \\
0.131^{* * *}\end{array}$ \\
\hline & & & & & & $(0.010)$ & & $(0.010)$ \\
\hline Req. skills * SES (D.=1) & & & & & & & & -0.017 \\
\hline & & & & & & & & $(0.012)$ \\
\hline Underskilled * SES (D.=1) & & & & & & & & $\begin{array}{l}0.016 \\
(0.022)\end{array}$ \\
\hline Overskilled * SES (D.=1) & & & & & & & & $\begin{array}{l}-0.036^{\star *} \\
(0.015)\end{array}$ \\
\hline Constant & & $\begin{array}{l}1.546^{* * *} \\
(0.079)\end{array}$ & & $\begin{array}{l}1.468^{* * *} \\
(0.081)\end{array}$ & & $\begin{array}{l}1.533^{\star * *} \\
(0.075)\end{array}$ & & $\begin{array}{l}1.529 * * * \\
(0.075)\end{array}$ \\
\hline Observations & & 56,374 & & 46,254 & & 56,374 & & 56,374 \\
\hline Number of groups & & 26 & & 26 & & 26 & & 26 \\
\hline $\mathrm{BIC}$ & & 55905.8 & & 41953.2 & & 54845.6 & & 54847.8 \\
\hline $\begin{array}{l}\text { VARIANCE } \\
\text { COMPONENTS }\end{array}$ & Int. & Model 1 & Int. & Model 2 & Int. & Model 3 & Int. & Model 4 \\
\hline Between Variance & 0.186 & 0.147 & 0.171 & 0.129 & 0.19 & 0.127 & 0.19 & 0.127 \\
\hline Within Variance & 0.011 & 0.006 & 0.0112 & 0.006 & 0.01 & 0.006 & 0.01 & 0.01 \\
\hline Total Variance & 0.197 & 0.153 & 0.182 & 0.135 & 0.19 & 0.133 & 0.2 & 0.13 \\
\hline $\begin{array}{l}\% \text { EXPLAINED } \\
\text { VARIANCE }\end{array}$ & Int. & Model 1 & Int. & Model 2 & Int. & Model 3 & Int. & Model 4 \\
\hline \% Exp. Between Var. & & 20.97 & & 24.56 & & 31.72 & & 31.72 \\
\hline \% Exp. Within Var. & & 44.55 & & 43.04 & & 46.43 & & 46.52 \\
\hline$\%$ Exp. Total Var. & & 22.31 & & 25.70 & & 32.56 & & 32.56 \\
\hline
\end{tabular}


Table 6: Tertiary education vs. secondary/ compulsary education

Sample: Fulltime workers; Mixed model; DV: Trimmed ln hourly wage

\begin{tabular}{|c|c|c|c|c|}
\hline VARIABLES & $\begin{array}{l}\text { Model } 1 \\
\text { Fulltime }\end{array}$ & $\begin{array}{l}\text { Model } 2 \\
\text { Fulltime }\end{array}$ & $\begin{array}{c}\text { Model } 3 \\
\text { Fulltime }\end{array}$ & $\begin{array}{c}\text { Model } 4 \\
\text { Fulltime }\end{array}$ \\
\hline Tertiary education ( $D .=1$, tert. edu) & $\begin{array}{c}0.199^{* * *} \\
(0.020)\end{array}$ & $\begin{array}{c}0.163^{* * *} \\
(0.018)\end{array}$ & $\begin{array}{c}0.177^{* * *} \\
(0.017)\end{array}$ & $\begin{array}{c}0.175^{\star * *} \\
(0.022)\end{array}$ \\
\hline Importance of digital skills (std.) & $0.165^{* * *}$ & $0.133^{* * *}$ & $0.131^{* * *}$ & $0.131^{* * *}$ \\
\hline Proficiency dig. PS-skills (std.) & $(0.009)$ & $\begin{array}{c}(0.007) \\
0.082^{* * *}\end{array}$ & $(0.015)$ & $(0.015)$ \\
\hline & & $(0.006)$ & & \\
\hline Required skill level (std.) & & & $0.053^{* *}$ & $0.052^{* *}$ \\
\hline Underskilled in dig. P-S (D.) & & & $\begin{array}{c}(0.025) \\
-0.080^{\star * *}\end{array}$ & $\begin{array}{c}(0.026) \\
-0.089^{* * *}\end{array}$ \\
\hline Overskilled in dig. P-S (D.) & & & $\begin{array}{c}(0.009) \\
0.094^{* * *}\end{array}$ & $\begin{array}{c}(0.008) \\
0.113^{* * *}\end{array}$ \\
\hline & & & $(0.010)$ & $(0.011)$ \\
\hline Req. skills * Tertiary edu (D. $=1)$ & & & & 0.005 \\
\hline & & & & $(0.023)$ \\
\hline Underskilled * Tertiary edu (D.=1) & & & & $\begin{array}{l}0.043^{\star *} \\
(0.020)\end{array}$ \\
\hline Overskilled * Tertiary edu (D. $=1)$ & & & & $\begin{array}{c}-0.039^{* * *} \\
(0.011)\end{array}$ \\
\hline Constant & $\begin{array}{c}1.568^{* * *} \\
(0.079)\end{array}$ & $\begin{array}{c}1.488^{\star * *} \\
(0.081)\end{array}$ & $\begin{array}{c}1.552^{* * *} \\
(0.077)\end{array}$ & $\begin{array}{c}1.549^{\star \star *} \\
(0.077)\end{array}$ \\
\hline Observations & 58,740 & 48,003 & 58,740 & 58,740 \\
\hline Number of groups & 26 & 26 & 26 & 26 \\
\hline & 56089.5 & 42104.1 & 55351 & 55351.1 \\
\hline
\end{tabular}

\begin{tabular}{lcccccccc}
\hline VARIANCE COMPONENTS & Int. & Model 1 & Int. & Model 2 & Int. & Model 3 & Int. & Model 4 \\
\hline Between Variance & 0.185 & 0.148 & 0.169 & 0.131 & 0.185 & 0.133 & 0.185 & 0.133 \\
Within Variance & 0.0109 & 0.00571 & 0.0108 & 0.00581 & 0.0109 & 0.00554 & 0.0109 & 0.00553 \\
Total Variance & 0.1959 & 0.15371 & 0.1798 & 0.13681 & 0.1959 & 0.13854 & 0.1959 & 0.13853 \\
\hline \% EXPLAINED VARIANCE & Int. & Model 1 & Int. & Model 2 & Int. & Model 3 & Int. & Model 4 \\
\hline \% Exp. Between Var. & & 20.00 & & 22.49 & & 28.11 & & 28.11 \\
\% Exp. Within Var. & & 47.61 & & 46.20 & & 49.17 & & 49.27 \\
\% Exp. Total Var. & & 21.54 & & 23.91 & & 29.28 & & 29.29 \\
\hline
\end{tabular}

Robust standard errors in parentheses; ${ }^{* * *} \mathrm{p}<0.01,{ }^{* *} \mathrm{p}<0.05,{ }^{*} \mathrm{p}<0.1 ;$ std. $=$ standardised; D. = Dummy MODELS ARE WEIGHTED; Controls include age, age2, and a dummy for missing test scores 
Table 7: Younger vs. older workers (age > 45 vs. age $<45$ )

Sample: Fulltime workers; Mixed model; DV: Trimmed ln hourly wage

\begin{tabular}{|c|c|c|c|c|c|c|c|c|}
\hline VARIABLES & & $\begin{array}{c}\text { Model } 1 \\
\text { Fulltime } \\
\end{array}$ & & $\begin{array}{l}\text { Model } 2 \\
\text { Fulltime } \\
\end{array}$ & & $\begin{array}{c}\text { Model } 3 \\
\text { Fulltime }\end{array}$ & & $\begin{array}{c}\text { Model } 4 \\
\text { Fullime }\end{array}$ \\
\hline \multirow[t]{2}{*}{ Age Dummy (D.=1, age >=45) } & & $0.106^{* * *}$ & & $0.175^{\star * *}$ & & $0.128^{* * *}$ & & $0.121^{* * *}$ \\
\hline & & $(0.019)$ & & $(0.020)$ & & $(0.019)$ & & $(0.018)$ \\
\hline \multirow[t]{2}{*}{ Importance of dig. skills (std.) } & & $0.215^{\star * *}$ & & $0.182^{* * *}$ & & $0.165^{\star * *}$ & & $0.166^{* * *}$ \\
\hline & & $(0.013)$ & & $(0.010)$ & & $(0.015)$ & & $(0.015)$ \\
\hline \multirow[t]{2}{*}{ Proficiency dig. PS-skills (std.) } & & & & $0.083^{* * *}$ & & & & \\
\hline & & & & $(0.006)$ & & & & \\
\hline \multirow[t]{2}{*}{ Required skill level (std.) } & & & & & & $0.070^{* * *}$ & & $0.054^{* *}$ \\
\hline & & & & & & $(0.027)$ & & $(0.026)$ \\
\hline \multirow[t]{2}{*}{ Underskilled in dig. P-S (D.) } & & & & & & $-0.089^{* * *}$ & & $-0.091^{* * *}$ \\
\hline & & & & & & $(0.009)$ & & $(0.013)$ \\
\hline \multirow[t]{2}{*}{ Overskilled in dig. P-S (D.) } & & & & & & $0.096^{* * *}$ & & $0.083^{* * *}$ \\
\hline & & & & & & $(0.011)$ & & $(0.012)$ \\
\hline \multirow[t]{2}{*}{ Req. skills*Age $>=45$ (D. =1) } & & & & & & & & $0.040^{* * *}$ \\
\hline & & & & & & & & $(0.011)$ \\
\hline \multirow[t]{2}{*}{ Underskilled*Age >=45 (D.=1) } & & & & & & & & -0.003 \\
\hline & & & & & & & & $(0.015)$ \\
\hline \multicolumn{2}{|l|}{ Overskilled * Age >=45 (D. =1) } & & & & & & & $\begin{array}{c}0.093^{* * *} \\
(0.025)\end{array}$ \\
\hline Constant & & $\begin{array}{c}2.546^{* * *} \\
(0.074)\end{array}$ & & $\begin{array}{c}2.531^{* * *} \\
(0.072)\end{array}$ & & $\begin{array}{c}2.543^{* * *} \\
(0.070)\end{array}$ & & $\begin{array}{c}2.544^{* * *} \\
(0.071)\end{array}$ \\
\hline Observations & & 58,761 & & 48,016 & & 58,761 & & 58,761 \\
\hline Number of groups & & 26 & & 26 & & 26 & & 26 \\
\hline $\mathrm{BIC}$ & & 61326.8 & & 47226 & & 60405.2 & & 60260.6 \\
\hline VARIANCE COMPONENTS & Int. & Model 1 & Int. & Model 2 & Int. & Model 3 & Int. & Model 4 \\
\hline Between Variance & 0.185 & 0.15 & 0.169 & 0.134 & 0.185 & 0.13 & 0.185 & 0.131 \\
\hline Within Variance & 0.0109 & 0.00606 & 0.0108 & 0.00623 & 0.0109 & 0.0058 & 0.0109 & 0.00584 \\
\hline Total Variance & 0.1959 & 0.15606 & 0.1798 & 0.14023 & 0.1959 & 0.1358 & 0.1959 & 0.13684 \\
\hline$\%$ EXPLAINED VARIANCE & Int. & Model 1 & Int. & Model 2 & Int. & Model 3 & Int. & Model 4 \\
\hline \% Exp. Between Var. & & 18.92 & & 20.71 & & 29.73 & & 29.19 \\
\hline \% Exp. Within Var. & & 44.40 & & 42.31 & & 46.79 & & 46.42 \\
\hline$\%$ Exp. Total Var. & & 20.34 & & 22.01 & & 30.68 & & 30.15 \\
\hline
\end{tabular}




\section{Rabustness, sensitivity, and additional analyses}

We run a series of checks to assess the robustness of our findings (see appendices to this chapter). Given the special imputation procedure that we used to assign skill match/mismatch values for the respondents who did not take the problem-solving test, we repeat our main model (see Table 2), excluding respondents with missing test scores. We obtain results that point in the same direction, although effect sizes are different (Table A3, Model 1 in the appendix). It seems like we underestimate the penalty related to underskilling by assigning values to those workers who did not take the test. By contrast, for overskilling we seem to overestimate the average marginal effect. What, then, is the most appropriate model? We know from the literature that the group of adults who did not take the test is selective, and generally at the lower end of the proficiency scale (see Table 1 or OECD, 2016c). If we would leave out the respondents with missing test scores, we would generally overestimate the effect of underskilling because we selectively leave out people who have lower skills. However, we can also not generally assume that these respondents are underskilled because many of them work in jobs that require (very) low proficiency levels in digital problem-solving skills. Against this background, we should use the model in which we impute the scores and be aware that the size of the coefficients is underestimated in the case of underskilling and overestimated in the case of overskilling.

Given the large differences in the amount of missings across countries, we repeat our main model again, using only the data for those countries with less than $20 \%$ missing test scores (Table A3, Model 2). Although the effect sizes are somewhat different (which is what we would have expected based on the reduced sample), the results point in the same direction. This means that our main findings are not driven by countries with extremely high percentages of missing test scores. To assess whether our results change if we include micro confounders, we run an additional model in which we control for individual and job-related characteristics, finding that our main results are robust (Table A3, Model 3). We furthermore repeat our main model, leaving out one country at a time. We do so to check whether our results are driven by single countries, which is not the case (Table A3a).

\section{Conclusion and Discussion}

In all industrialised countries, the increasing adaptation of digital technologies at workplaces leads to a profound and persistent transformation of work and skill requirements of jobs (Frey and Osborne, 2017; OECD, 2016e; 2016f; Brynjolfsson and McAfee, 2014; Autor and Dorn, 2013; Acemoglu and Autor, 2011). The ubiquitous availability of IC technology induces specific forms of tasks that demand information-processing and digital problemsolving (Brynjolfsson and McAfee, 2014; Acemoglu and Autor, 2011; Levy, 2010; Autor, 140 
Levy, and Murnane, 2002). This leads to a situation, in which digital problem-solving skills are thought to be key skills for everybody (OECD, 2016d), as these skills allow workers throughout the occupational spectrum to be productive and to generate adequate performance in $21^{\text {st }}$ century labour markets. Recent breakthroughs in ever more advanced technologies and increasing automation are thought to further exacerbate that trend (e.g. Brynjolfsson and McAfee, 2014). We may, therefore, think of digital problem-solving as "future skills", as it is exactly these types of key skills that will become more important in the near future while the required skills are still not fully taught in education systems (OECD, 2016a; 2016g). Throughout societies, however, social groups are unequally equipped with skills and knowledge needed to deal with profound and irreversible technology-induced changes (see e.g. Goldin and Katz, 2010.

Not much is known yet about individual skill-to-job matches, and particularly shortages, in digital problem-solving skills and their relation with wages and inequalities. How does the digital skills divide - e.g. younger and older workers or between high and low educated workers - translate into group-specific returns to skills? And will wage inequalities (e.g. between socio-economic status groups, gender or age groups) be exacerbated or reduced? When it comes to future skills and present wages, a systematic and thorough assessment of social inequalities is the main gap in the literature. In our paper, we investigate mismatches, and particularly shortages, in digital problem-solving skills. We look at wage gaps to see how digital problem-solving skills explain wage inequalities between social groups, controlling for individual differences in skill proficiency. Our research is based on objective skills measurements for representative samples of adult workers in 26 industrial countries, as provided by the Programme for the International Assessment of Adult Competencies (PIAAC). We develop a skill matching model to show that when it comes to digital problem-solving skills and wages, the future is now: surplus skills pay off, while shortages in digital skills entail wage penalties. Our analyses show that wage inequalities - e.g. between men and women, the upper and lower SES groups, educational attainment and age groups - can only partly be explained by differences in skill proficiency: generally, wage inequalities are more related to a social group premium rather than a skill premium.

However, our most important finding is that digital problem-solving skills seem to be (re)shaping group-specific wage inequalities - with the potential to narrow e.g. the divide between socio-economic status groups. We find that an investment in high levels of digital problem-solving skills pays off more for workers with a lower socio-economic status (SES) than for the higher SES group, and for low and medium educated workers more than for graduates. This leads us to the - tentative - conclusion that digital problem-solving skills could serve as potential emancipatory lever, narrowing wage gaps between SES groups. Based on the economic theory of discrimination, we argued that high SES workers are 
positively discriminated when it comes to wages due to generally higher expectations concerning their proficiency. However, we find that when higher SES work in occupations that require a lot of digital problem-solving skills, their wage premium is even smaller than for low SES workers, while they still get compensated despite that. One might argue that the higher SES worker generally has higher skills, but the premium that they get is not based on high levels of digital problem-solving skills, but most likely based on other skills or e.g. cultural capital. Additional analyses using literacy skills provide further support for this explanatory mechanism. Compared to literacy, which is known to be highly related to parental education and i.e. socio-economic status (see e.g. PISA 2015 results; OECD, 2016h), digital problem-solving skills is generally more open and accessible for all SES groups. Further research is necessary to assess the potential of problem-solving skills as social emancipation lever. But based on our findings, we conclude that digital problemsolving skills may re-shape wage inequalities and may serve to narrow the divide between socio-economic status groups.

Our analyses on differential wage returns for male vs. female workers also show that digital problem-solving skills could potentially be a lever to reduce the gender pay gap: If women work in jobs that require a high level of digital problem-solving skills and/or have excess skills, they get higher wage returns than men. High levels of digital problem-solving skills pay off more for women than for men. This could be explained by a positive discrimination of women that make it into jobs that require a high level of digital problem-solving or that have surplus skills. By contrast, differential wage effects between migrants and natives can be explained by differences in skill proficiency, which is also in line with the literature (Nanos and Schluter, 2014: 5). However, against the background of the increasing importance of digital problem-solving skills for employability as well as inclusion in digital societies, we are inclined to further investigate the potential of digital problem-solving skills to serve as social emancipatory lever. While our analyses merely explain variance, further research should, for example, try to link variables causally, further more trying to assess the caveat about missing data for digital problem-solving skills as well as using a broader assessment of cognitive and non-cognitive skills (e.g. ideation skills) that will be increasingly important when the future becomes now. 


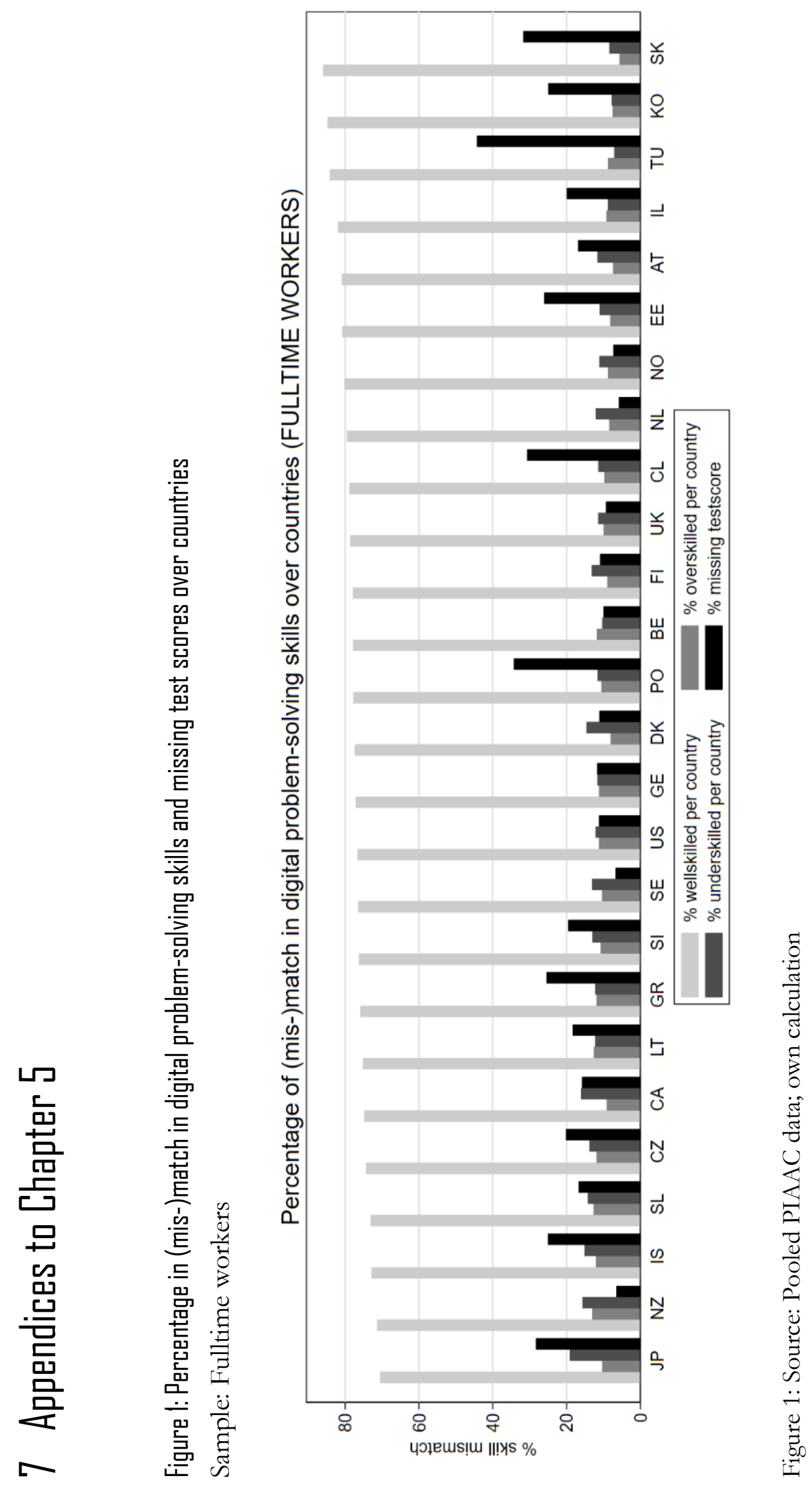




\section{Additional Material l: Background information on how we treat respondents who did not take the problem-solving test}

Around $19 \%$ of our working sample - the fulltime workers - did not take the computerbased problem-solving test in PIAAC ${ }^{37}$. There are various reasons for the refusal, a lack of computer-skills being one of them. Respondents who did not want to take the test at the computer also have a missing test score, not only those with insufficient computer skills. The assessment of the skill (mis-)match value is based on a comparison between skills possessed by workers and skills required by the workplace. If they are in a job that does not require digital problem-solving skills, even workers that completely lack those skills must be considered as well-matched. Following the logic of the Realised Matches Approach (RMA) to measure skill mismatch, we decided to use a special procedure to impute adequate skill mismatch values for respondents with missing test scores in the PS-TRE skill domain.

For those respondents, we make use of the PS-TRE proficiency levels in PIAAC to define the individual match/mismatch. The problem-solving scale has a range from zero to 500 (OECD, 2016b). The score boundaries for item classification for the PS-TRE domain are defined as follows: an individual score of 0-240 points is classified as "below level 1", 241290 is defined as level 1, 291-340 is level 2, and scores between 341 and 500 are classified as level 3. Our imputation routine is as follows: We compare the posterior mean for each ISCO 2-digit-country-cell with these PS-TRE proficiency levels. People who did not take the PS-TRE test are included in the following way: If the posterior mean in a certain occupation in a certain country is below the PS-TRE proficiency level 1 or level 1, we define respondents that did not take the test as wellskilled. This gives a share of $12 \%$ underskilled over all 26 countries. Based on what we know about the prevalence of the mismatch phenomenon in the other PIAAC skill domains, this is a realistic value. If the posterior mean of an occupation-country-cell equals level 2 (or if it would be level 3, but this does not exist), we define respondents with missing test scores as underskilled. By having a missing test score dummy in all our statistical models, we effectively control for the imputation.

\footnotetext{
${ }^{37}$ In the assessment of digital problem-solving, Japan's respondents performed best with an average score of 294, followed by Finland (289) and Australia (289). Greece (257), Turkey (253), and Chile (252) have the lowest average scores (OECD, 2016b: 17). Digital problem-solving skills correlate highly with the other skill domains measured in PIAAC (correlation with literacy $=0.77$; with numeracy $=0.73$ ), which is less strong than the correlation between literacy and numeracy (0.82). All three PIAAC skill domains measure different dimensions of the respondent's skills set (OECD, 2016b).
} 
Additional Material 2: Background information on how we assess the importance of digital problemsolving skills on the level of accupations

Cedefop used scales from the O*NET which they collapsed into 13 dimensions that, together, form the so-called Occupational Skill Profiles (OSP). We make use of average values of the original O*NET scales for each ISCO 2-digit category for each country. Particularly, we use data of the following six scales:

1. Complex problem solving

2. Processing information

3. Analysing data or information

4. Programming skills

5. Knowledge of computers and electronics

6. Practical skills in interacting with computers

The first three scales thereby capture problem-solving whereas scales 4 to 6 capture ICT skills. We assess the importance of each skill based on a scale from 1 to 5 (available upon request).

We use orthogonal factor analysis, which aims at explaining the outcome of $\mathrm{p}$ variables in the data matrix X using fewer variables, the so-called factors. These factors are interpreted as latent (unobserved) common characteristics, in our case of the underlying scales that capture digital problem-solving. The first unrotated factor (a normalised variable) thereby binds most of the common variation of the underlying scales. Using this factor, we extract $89.8 \%$ of the common information of the six OSP scales that we use. We find that factor 1 covers $89.8 \%$ of the information available (= explained variance of the six underlying scales). The eigenvalue of factor 1 is very high (4.78), also compared to factor $2(0.34)$ that only captures $6 \%$ more of the total variance. We use factor 1 to obtain a score for each occupation, which we then introduce in our statistical models as micro-level control variable. 
Table Al: Descriptive analyses: skill mismatch and missing test scares aver countries Sample: Fulltime workers

\begin{tabular}{|c|c|c|c|c|c|}
\hline Country & $\begin{array}{c}\text { Country } \\
\text { sample size } \\
\text { (Freq.) }\end{array}$ & $\begin{array}{l}\text { Missing test } \\
\text { score } \\
\text { PS-TRE (\%) }\end{array}$ & $\begin{array}{c}\text { Underskilled } \\
\%\end{array}$ & $\begin{array}{c}\text { Wellskilled } \\
\%\end{array}$ & $\begin{array}{c}\text { Overskilled } \\
\%\end{array}$ \\
\hline Austria & 2,064 & $\begin{array}{c}349 \\
(16.91 \%)\end{array}$ & $\begin{array}{c}241 \\
(11.68 \%)\end{array}$ & $\begin{array}{c}1,670 \\
(80.91 \%)\end{array}$ & $\begin{array}{c}153 \\
(7.41 \%)\end{array}$ \\
\hline Belgium & 1,986 & $\begin{array}{c}198 \\
(9.97 \%)\end{array}$ & $\begin{array}{c}205 \\
(10.32 \%)\end{array}$ & $\begin{array}{c}1,546 \\
(77.84 \%)\end{array}$ & $\begin{array}{c}235 \\
(11.83 \%)\end{array}$ \\
\hline Canada & 2,403 & $\begin{array}{c}380 \\
(15.81 \%)\end{array}$ & $\begin{array}{c}387 \\
(6.01 \%)\end{array}$ & $\begin{array}{c}1,797 \\
(47.78 \%)\end{array}$ & $\begin{array}{c}219 \\
(9.11 \%)\end{array}$ \\
\hline Chile & 1,815 & $\begin{array}{c}557 \\
(30.69 \%)\end{array}$ & $\begin{array}{c}207 \\
(11.40 \%)\end{array}$ & $\begin{array}{c}1,431 \\
(78.84 \%)\end{array}$ & $\begin{array}{c}177 \\
(9.75 \%)\end{array}$ \\
\hline Czech Republic & 2,144 & $\begin{array}{c}433 \\
(20.20 \%)\end{array}$ & $\begin{array}{c}296 \\
(13.84 \%)\end{array}$ & $\begin{array}{c}1,593 \\
(74.30 \%)\end{array}$ & $\begin{array}{c}255 \\
(11.89 \%)\end{array}$ \\
\hline Denmark & 3,353 & $\begin{array}{c}372 \\
(11.09 \%)\end{array}$ & $\begin{array}{c}489 \\
(14.58 \%)\end{array}$ & $\begin{array}{c}2,594 \\
(77.36 \%)\end{array}$ & $\begin{array}{c}270 \\
(8.05 \%)\end{array}$ \\
\hline Estonia & 3,414 & $\begin{array}{c}890 \\
(26.07 \%)\end{array}$ & $\begin{array}{c}377 \\
(11.04 \%)\end{array}$ & $\begin{array}{c}2,758 \\
(80.79 \%)\end{array}$ & $\begin{array}{c}279 \\
(8.17 \%)\end{array}$ \\
\hline Finland & 2,621 & $\begin{array}{c}286 \\
(10.91 \%)\end{array}$ & $\begin{array}{c}345 \\
(13.16 \%)\end{array}$ & $\begin{array}{c}2,042 \\
(77.91 \%)\end{array}$ & $\begin{array}{c}234 \\
(8.93 \%)\end{array}$ \\
\hline Germany & 2,142 & $\begin{array}{c}251 \\
(11.72 \%)\end{array}$ & $\begin{array}{c}250 \\
(11.67 \%)\end{array}$ & $\begin{array}{c}1,652 \\
(77.12 \%)\end{array}$ & $\begin{array}{c}240 \\
(11.20 \%)\end{array}$ \\
\hline Greece & 833 & $\begin{array}{c}212 \\
(25.45 \%)\end{array}$ & $\begin{array}{c}102 \\
(12.24 \%)\end{array}$ & $\begin{array}{c}632 \\
(75.87 \%)\end{array}$ & $\begin{array}{c}99 \\
(11.88 \%)\end{array}$ \\
\hline Ireland & 1,790 & $\begin{array}{c}357 \\
(19.94 \%)\end{array}$ & $\begin{array}{c}158 \\
(8.83 \%)\end{array}$ & $\begin{array}{c}1,467 \\
(81.96 \%)\end{array}$ & $\begin{array}{c}165 \\
(9.22 \%)\end{array}$ \\
\hline Israel & 1,829 & $\begin{array}{c}458 \\
(20.04 \%)\end{array}$ & $\begin{array}{c}277 \\
(15.14 \%)\end{array}$ & $\begin{array}{c}1,332 \\
(72.83 \%)\end{array}$ & $\begin{array}{c}220 \\
(12.03 \%)\end{array}$ \\
\hline Japan & 2,416 & $\begin{array}{c}684 \\
(28.31 \%)\end{array}$ & $\begin{array}{c}463 \\
(19.16 \%)\end{array}$ & $\begin{array}{c}1,703 \\
(70.49 \%)\end{array}$ & $\begin{array}{c}250 \\
(10.35 \%)\end{array}$ \\
\hline Korea & 2,518 & $\begin{array}{c}628 \\
(24.94 \%)\end{array}$ & $\begin{array}{c}195 \\
(7.74 \%)\end{array}$ & $\begin{array}{c}2,133 \\
(84.71 \%)\end{array}$ & $\begin{array}{c}190 \\
(7.55 \%)\end{array}$ \\
\hline Lithuania & 2,286 & $\begin{array}{c}420 \\
(18.37 \%)\end{array}$ & $\begin{array}{c}280 \\
(12.25 \%)\end{array}$ & $\begin{array}{c}1,718 \\
(75.15 \%)\end{array}$ & $\begin{array}{c}288 \\
(12.60 \%)\end{array}$ \\
\hline Netherlands & 1,787 & $\begin{array}{c}104 \\
(5.82 \%)\end{array}$ & $\begin{array}{c}216 \\
(12.09 \%)\end{array}$ & $\begin{array}{c}1,420 \\
(79.46 \%)\end{array}$ & $\begin{array}{c}151 \\
(8.45 \%)\end{array}$ \\
\hline New Zealand & 2,379 & $\begin{array}{c}156 \\
(6.56 \%)\end{array}$ & $\begin{array}{c}373 \\
(15.68 \%)\end{array}$ & $\begin{array}{c}1,696 \\
(71.29 \%)\end{array}$ & $\begin{array}{c}310 \\
(13.03 \%)\end{array}$ \\
\hline Norway & 2,208 & $\begin{array}{c}162 \\
(7.34 \%)\end{array}$ & $\begin{array}{c}245 \\
(11.10 \%)\end{array}$ & $\begin{array}{c}1,769 \\
(80.12 \%)\end{array}$ & $\begin{array}{c}194 \\
(8.79 \%)\end{array}$ \\
\hline Poland & 3,109 & $\begin{array}{c}1,066 \\
(34.29 \%)\end{array}$ & $\begin{array}{c}362 \\
(11.64 \%)\end{array}$ & $\begin{array}{c}2,418 \\
(77.77 \%)\end{array}$ & $\begin{array}{c}329 \\
(10.58 \%)\end{array}$ \\
\hline Singapore & 2,736 & $\begin{array}{c}534 \\
(19.52 \%)\end{array}$ & $\begin{array}{c}355 \\
(12.98 \%)\end{array}$ & $\begin{array}{c}2,086 \\
(76.24 \%)\end{array}$ & $\begin{array}{c}295 \\
(10.78 \%)\end{array}$ \\
\hline Slovakia & 2,148 & $\begin{array}{c}682 \\
(31.75 \%)\end{array}$ & $\begin{array}{c}181 \\
(8.43 \%)\end{array}$ & $\begin{array}{c}1,846 \\
(85.94 \%)\end{array}$ & $\begin{array}{c}121 \\
(5.63 \%)\end{array}$ \\
\hline Slovenia & 1,983 & $\begin{array}{c}332 \\
(16.74 \%)\end{array}$ & $\begin{array}{c}282 \\
(14.22 \%)\end{array}$ & $\begin{array}{c}1,449 \\
(73.07 \%)\end{array}$ & $\begin{array}{c}252 \\
(12.71 \%)\end{array}$ \\
\hline Sweden & 2,237 & $\begin{array}{c}150 \\
(6.71 \%)\end{array}$ & $\begin{array}{c}293 \\
(13.10 \%)\end{array}$ & $\begin{array}{c}1,711 \\
(76.49 \%)\end{array}$ & $\begin{array}{c}233 \\
(10.42 \%)\end{array}$ \\
\hline
\end{tabular}




\begin{tabular}{l|c|c|ccc} 
& & 545 & 87 & 1,036 & 108 \\
Turkey & 1,231 & $(44.27 \%)$ & $(7.07 \%)$ & $(84.16 \%)$ & $(8.77 \%)$ \\
United Kingdom & & 294 & 361 & 2,477 & 313 \\
& \multirow{2}{*}{ United States } & $(9.33 \%)$ & $(11.46 \%)$ & $(78.61 \%)$ & $(9.93 \%)$ \\
& \multirow{2}{*}{2,178} & 245 & 264 & 1,669 & 245 \\
& & $(11.25 \%)$ & $(12.12 \%)$ & $(76.63 \%)$ & $(11.25 \%)$ \\
\hline \multirow{2}{*}{ Total } & & & & \\
& \multirow{2}{*}{$\mathbf{5 8 , 7 6 1}$} & $\mathbf{1 0 , 7 4 5}$ & $\mathbf{7 , 2 9 1}$ & $\mathbf{4 5 , 6 4 5}$ & $\mathbf{5 , 8 2 5}$ \\
& & $(\mathbf{1 8 . 2 9 \% )}$ & $\mathbf{( 1 2 . 4 1 \% )}$ & $\mathbf{( 7 7 . 6 8 \% )}$ & $\mathbf{( 9 . 9 1 \% )}$ \\
\hline
\end{tabular}

NOTE: ${ }^{1}$ Numbers in parentheses display percentage of (mis-)matched workers in the respective country, excluding PIAAC-respondents who did not take the problem-solving test.

Figure Al: Missing PSTRE-test scores aver ISCD 2-digit categories and level of impartance
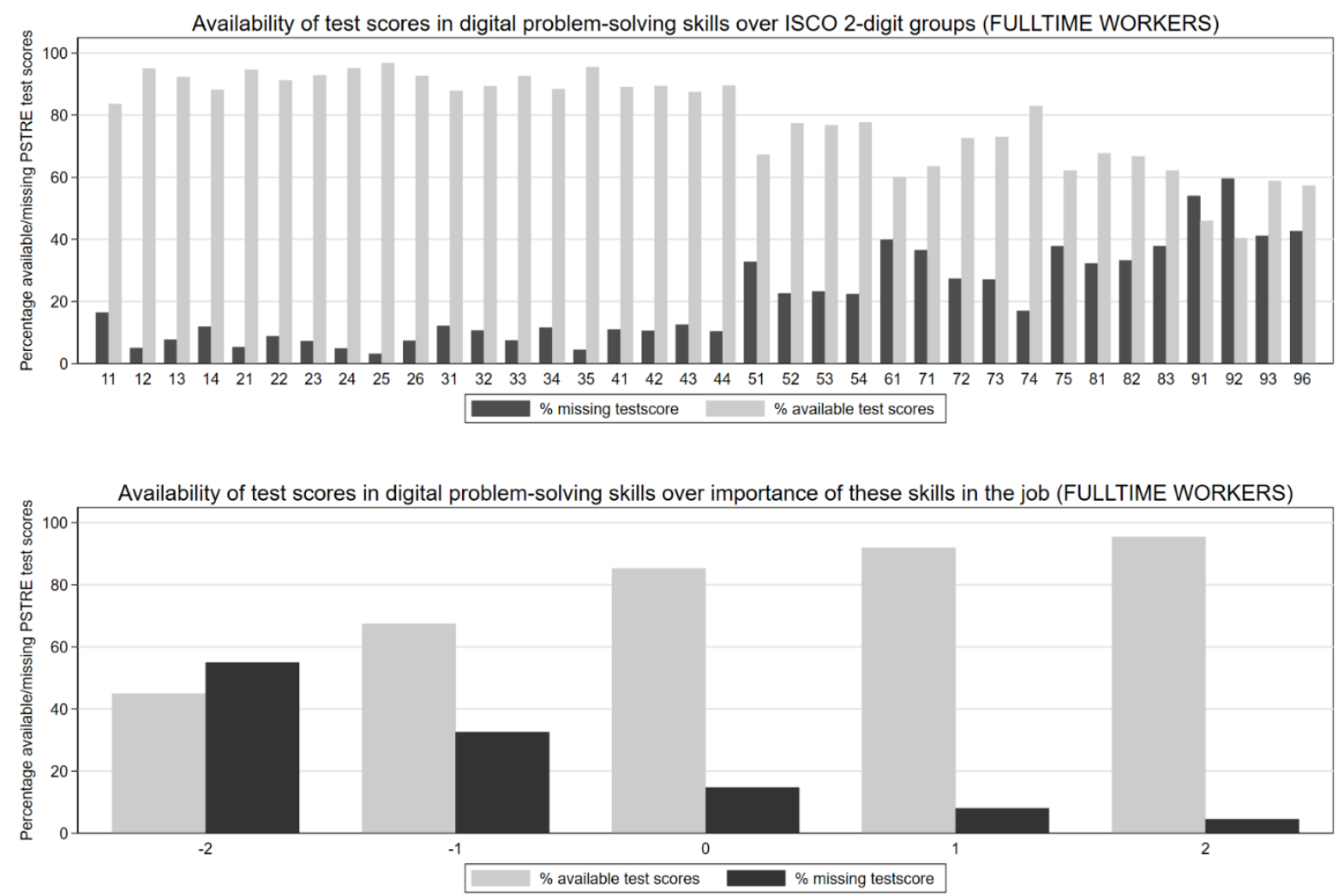

Figure A2: Source: Pooled PIAAC data; own calculation 
Table AZ: Additional analyses using LITERACY SKILLS - SES analysis

Sample: Fulltime workers; Mixed model; DV: Trimmed ln hourly wage

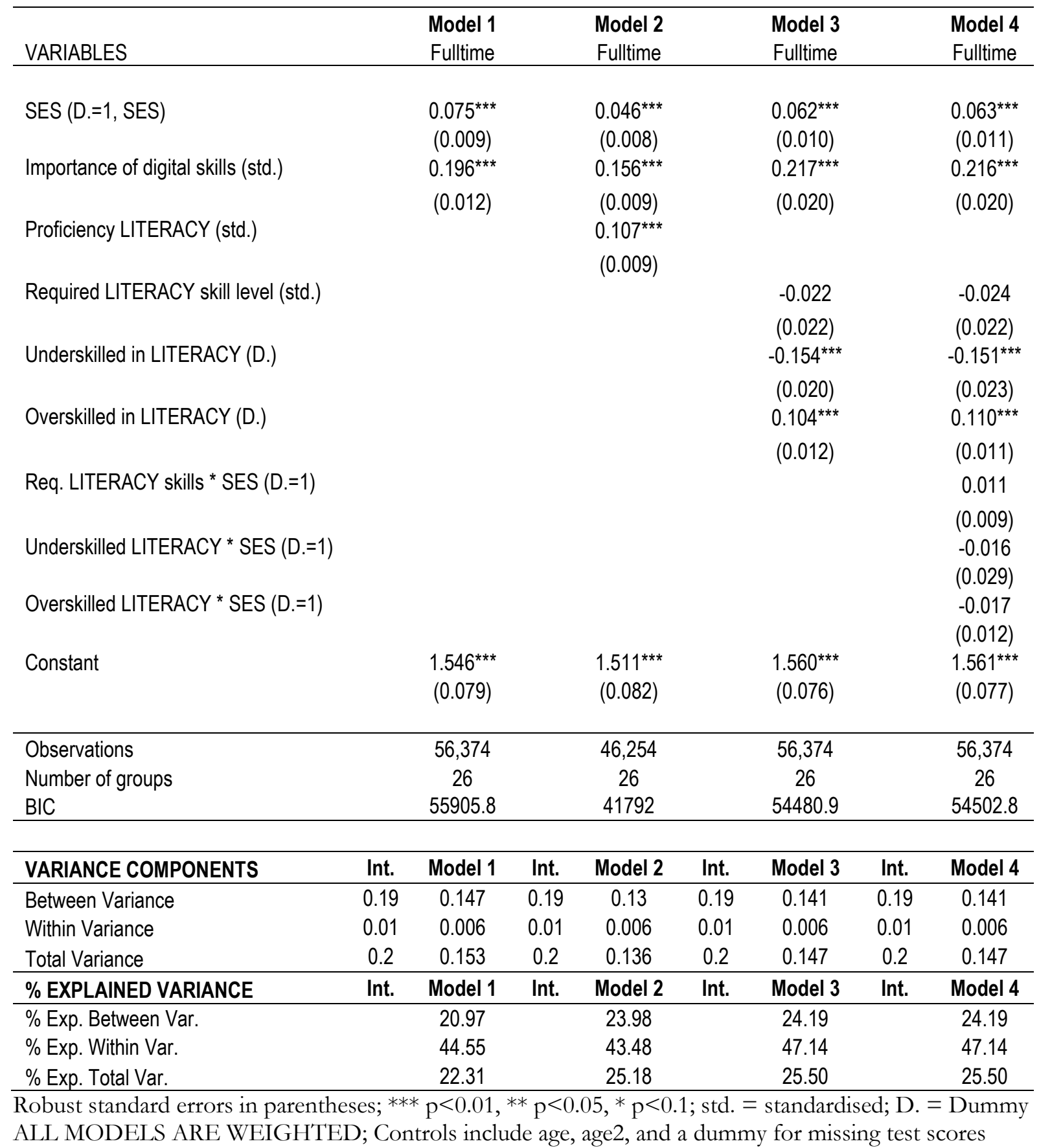


Table A3: Rabustness checks MAIN MODEL

Sample: Fulltime workers; Mixed model; DV: Trimmed ln hourly wage

Legend: $\quad$ Model 1: Main model, excluding respondents with missing PS-TRE test scores

Model 2: Main model, excluding countries with more than 20\% missing test scores

Model 3: Main model, including additional micro controls

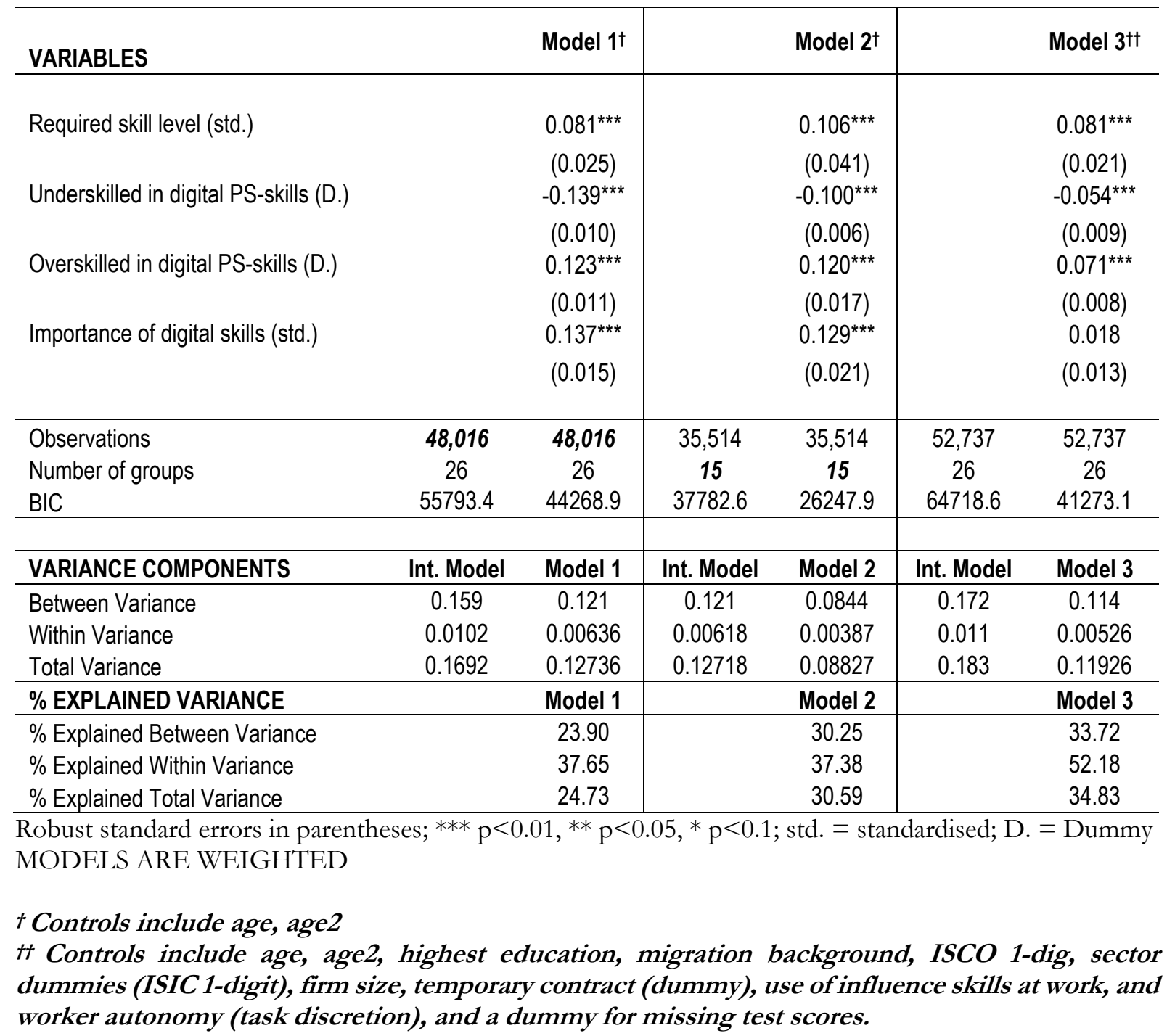




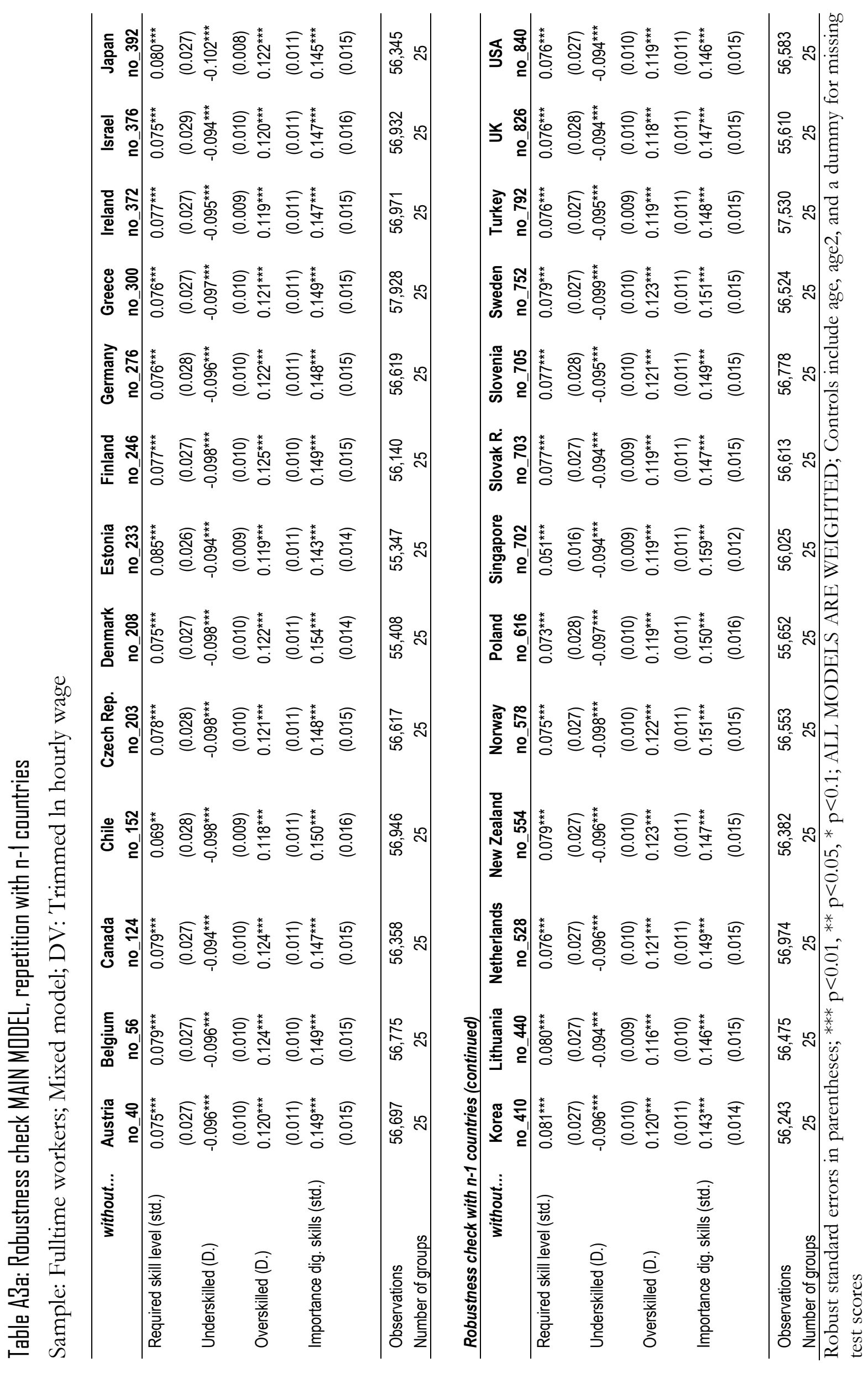


Table A4: Additional analysis - Whole sample, including part-time workers

Sample: WHOLE SAMPLE; Mixed model; DV: Trimmed ln hourly wage

\section{Model 1}

VARIABLES

Whole sample

$\begin{array}{lc}\text { Required skill level (std.) } & 0.087^{* \star *} \\ \text { Underskilled in digital PS-skills (D.) } & (0.022) \\ & -0.083^{\star \star *} \\ \text { Overskilled in digital PS-skills (D.) } & (0.010) \\ & 0.096^{\star * \star} \\ \text { Importance of digital skills (std.) } & (0.010) \\ & 0.143^{\star * \star} \\ \text { Gender Dummy = 1, female } & (0.013) \\ \text { Part-time employment Dummy = 1 } & -0.171^{* \star *} \\ & (0.020) \\ & 0.091^{* \star} \\ & (0.041)\end{array}$

\begin{tabular}{lc}
\hline Observations & 72,004 \\
Number of groups & 26 \\
BIC & 74121.7 \\
\hline
\end{tabular}

\begin{tabular}{lcc}
\hline VARIANCE COMPONENTS & Int. Model & Model 1 \\
\hline Between Variance & 0.163 & 0.115 \\
Within Variance & 0.00965 & 0.00526 \\
Total Variance & 0.17265 & 0.12026 \\
\hline \% EXPLAINED VARIANCE & & Model 1 \\
\hline \%xp. Between Var. & & 29.45 \\
\% Exp. Within Var. & & 45.49 \\
\% Exp. Total Var. & & 30.34 \\
\hline
\end{tabular}

Robust standard errors in parentheses; ${ }^{* * *} \mathrm{p}<0.01,{ }^{* *} \mathrm{p}<0.05,{ }^{*} \mathrm{p}<0.1 ;$ std. $=$ standardised; D. $=$ Dummy MODELS ARE WEIGHTED; Controls include age, age2, and a dummy for missing test scores 

Chapter 6

\section{Conclusion and Discussion}

"In times of great change, learners inherit the earth; while the learned find themselves beautifully equipped to deal with a world that no longer exists."

Eric Hoffer 
SKILL MATCHING - i.e. the match between the individual skills supply and skill demands of jobs - has become a persistent matter of analytical concern (Buchanan et al., 2017: 11). In the last decades, the increased global competition and changes in the work force qualification level have led to a labour market situation, where it got more difficult to find the right worker for the right job (Flisi et al., 2016). One major reason for this also lies in the increasing implementation of new technologies at workplaces and automation, also of tasks and processes that have been thought to always require human skills and intelligence. These technological innovations profoundly and irreversibly alter skills needs at work, affecting jobs throughout the occupational structure. While changing skill demands are nothing new, the current change is enormous, of large scope, and occurring fast due to the increasing adoption of Artificial Intelligence (AI), robotics, and the combination of the two. Against the background of a mass participation in higher education, individual returns to skill acquisition have become a concern (e.g. Buchanan et al., 2017). The question arises whether workers are being up-skilled with qualifications, while jobs are being de-skilled through technology and management - or re-skilled in terms of a new character of skills that are currently not (or too little) taught in education systems (Warhurst, Tilly and Gatta, 2017: 72; Braverman, 1974). In Europe and beyond, the phenomenon of skill-to-job mismatch is found to be pervasive, widespread, and with significant consequences for individuals, enterprises, labour markets, and societies (Cedefop, 2018; Felstead, Duncan and Gallie, 2017; Livingstone, 2017; Green and Henseke, 2016; Levels, van der Velden and Allen, 2014b; Perry, Wiederhold and Ackermann-Piek, 2014; Green, 2013; Pellizzari and Fichen, 2013; Desjardins and Rubenson, 2011; Quintini, 2011; Cedefop, 2010 and others). Research has shown that with further automation, the incidence of mismatch is more likely to increase than to improve (McKee-Ryan and Harvey, 2011: 963 cf. Livingstone, 2017: 295). Social groups are unequally equipped with skills and knowledge needed to deal with the profound and irreversible qualitative changes of work and employment. The race between changing demands for, and supply of, skills provides a challenge when it comes to preventing rising levels of inequality in labour markets and in societies more generally (Green, 2013: 69). Although there is a large body of scientific literature, there is still a lot that science does not sufficiently understand about skill-to-job matching and related outcomes.

\section{What does my thesis do and why?}

The skill matching challenge requires new insights into determinants and outcomes of skillto-job matches and mismatches and new evidence across countries. Advanced market economies have generations of adults working, and their jobs are changing or demanding 
new or different skills. Some jobs will disappear, new jobs we do not know yet will come into being, and many other jobs change (or will soon change) a lot. This is why my thesis sets out to investigate the phenomenon of skill matching, aiming at the provision of new explanations and evidence for the adult workforce for 30 industrial countries. With my research, I seek to provide answers to the following questions:

- How well are key skills being deployed in paid work across countries?

- How well and how can collective actors address the challenge of allocating the right people to the right jobs? To what extent can the likelihood that workers find a job for which they have the right skills be explained by characteristics of labour market arrangements and education systems?

- Do skills, skill use, and mismatches have a broader impact on society with potential social outcomes? How do skill use and skill mismatch relate to non-monetary outcomes and potential social outcomes?

- And what about the increasing adoption of digital technologies at workplaces - to what extent do mismatches in digital problem-solving skills matter for wages? Do mismatches in these skills affect all workers in the same way - or are there (new) wage inequalities and group-specific returns to digital skills?

While these desiderata of knowledge are important to fill, linking theoretical concepts of skill-to-job matches to reliable and valid empirical indicators is still work in progress. My thesis contributes to a new and better understanding of the skill (mis-)match phenomenon, providing new knowledge and challenging old findings concerning determinants and outcomes of skill-to-job (mis-)matches. The first part of the thesis is dedicated to a comprehensive theoretical framework outlined in CHAPTER 2. With this framework, I provide details and background information about the concepts, approaches, measures and arguments that are needed to conduct theory-based empirical research on skill matching and outcomes. The theoretical framework is followed by a series of empirical chapters. In these, I provide new cross-country evidence for macro level determinants and individual outcomes of skill-to-job (mis-)matches. CHAPTER $\mathbf{3}$ explores the macro-micro link between national social policies and optimal skill matching. I give new insights concerning the relation between institutional characteristics of labour markets, social insurance schemes, the institutional setup of education systems and skill matching. With CHAPTER 4, I furthermore take into account that the academic interest in skills and mismatches rests, at least partly, upon the concern that skills are not only vital for the proper functioning of labour markets and economies, but also for societies and democracies (European Commission, 2016). In this chapter, I investigate non-monetary and potential social 
outcomes that are related to skill mismatches as they are entangled with the experience of individual self-efficacy at work, which is e.g. evidenced by a full and productive use of one's skills and talent. Exploring the importance of skill use, mismatches, and the relation between individual experiences at work and psychological orientations, I combine classical theoretical reasoning with advanced statistical modelling based on recent micro data. I make use of different skill mismatch measures, including a new measure for the skill match, the 'effective skill' model as developed by van der Velden and Bijlsma (2018). Against the background of technology-induced changes in work environments and skill demands,

CHAPTER 5 finally examines what I consider "future skills": digital problem-solving skills. These skills are key to ensure that workers remain both productive in labour markets and included societies. While increasing automation is thought to further exacerbate the importance of digital problem-solving skills, evidence suggests that shortages in these skills are widespread. I use micro data for adult workers in many countries to investigate mismatches, and particularly shortages, in digital problem-solving skills and their relation with wages and wage inequalities across countries and social groups.

\section{How dalda it?}

My cross-national empirical research is based on the Survey of Adult Skills from the OECD's Programme for the International Assessment of Adult Competencies (PIAAC). This recent survey provides internationally comparable and high-quality measurements of individual skill proficiency and skill use for representative samples of the workforces of a large number of industrial countries. I use data from 30 countries, namely Austria, Belgium (Flanders), Canada, Chile, Cyprus, the Czech Republic, Denmark, Estonia, Finland, France, Germany, Greece, Ireland, Israel, Italy, Japan, South Korea, Lithuania, the Netherlands, New Zealand, Norway, Poland, Singapore, the Slovak Republic, Slovenia, Spain, Sweden, Turkey, the United Kingdom (England and Northern Ireland), and the United States. Together, these countries represent around 75\% of the worldwide GDP (Falck, Heimisch and Wiederhold, 2016: 8). The country samples comprise objective competency assessments of the adult workforce between the ages 16-65. The PIAAC survey is designed to provide valid and reliable estimates of adult's competencies in information-processing skills that are key skills for everybody in advanced market economies (OECD, 2016a).

However, what are 'key skills' and why should scientists investigate them? PIAAC assesses the proficiency and skill use of adults in three information-processing skill domains: literacy, numeracy and problem solving in technology-rich environments, which I refer to as digital 
problem-solving skills ${ }^{38}$ (OECD, 2016a: 16). The skill domains measured in PIAAC capture the general cognitive ability to grasp meaning and relevant new information which the respondents did not have before (OECD, 2016a). This new information can be presented in words, sentences, different types of texts - or in numerical sense as in the case of numeracy. These information-processing skills can be deployed at all proficiency levels from very basic to very complex. They are crucial for the full integration in knowledgebased economies, education and training and furthermore for social and civic life in modern societies. Information-processing is considered a key skill because it is highly transferable and relevant to multiple situations at work and in daily life, "general" in the sense that it is relevant to all individuals, "learnable" and, therefore, subject to the influence of policy (OECD, 2016a: 16 and 96). It is exactly these types of skills that will become ever more important in changing labour markets and digital economies and societies.

How do I measure skill-to-job matches? There is no common conceptual approach about how to measure skill matches/mismatches and about what constitutes an adequate indicator. I, therefore, make use of several different skill mismatch measures, namely the Realised Matches Approach (RMA), Job Requirement Approach (JRA) and Worker SelfAssessment (WSA). Moreover, I apply a new measure for the skill match, the 'effective skill' model as developed by van der Velden and Bijlsma (2018). The intuitive understanding of this measure is simple: Skills can have no effect if they are not put to productive use - and, vice versa, using skills can only have a small effect if proficiency is low.

All mismatch measures have advantages and disadvantages. The Realised Matches Approach (RMA) is a commonly used statistical approach, capturing the deviation of the individual skill proficiency from the mean proficiency in each occupation in each country (van der Velden and Bijlsma, 2018; Flisi et al., 2016; Perry, Wiederhold, and AckermannPiek, 2014; Pellizzari and Fichen, 2013). The main theoretical issue that arises with this approach is the forced equilibrium where, by definition, the 'average' worker is defined as well-matched. The Job Requirement Approach (JRA) captures (mis-)matches between the skills that workers possess and the (frequency of) skill use at the job (see Green et al., 2013). One theoretical issue here is that skill use is not necessarily a good proxy for skill requirements, and that skill proficiency and skill use are closely interlinked and can therefore not be treated as two different forces. For the Worker Self-Assessment Approach (WSA), workers are asked directly about the required level of skills. Although this approach is easy to implement in surveys, it bears several problems, the most pressing one being the lack of

\footnotetext{
${ }^{38}$ This shorthand contains the two components of the PIAAC framework for these types of skills: Technology-rich environments and problem-solving skills (PIAAC Expert Group, 2009; also see chapter 2).
} 
an objective anchor (see Allen and van der Velden, 2005) and the risk of social bias ("talking up one's own job"). The Effective Skill Measure is a newly developed approach that was particularly designed to investigate productivity. It provides and new an enlightening theoretical perspective. However, the measure is also based on a RMA and therefore subject to the same issues.

To assess key skills and skill use at work, PIAAC used a combination of computer assisted personal interviews and scenario-based assessments, providing paper and pencil alternatives where applicable and necessary. The survey furthermore provides extensive micro data on the social background of the respondents, concerning, among other things, employment status, job characteristics, educational attainment and personal characteristics (OECD, 2016a; 2016b). All analyses provided in my thesis are restricted to workers who were in paid employment at the time the survey was conducted in the respective country, and whose current main status was not "student" or "apprentice/intern". My research covers representative samples of adult workers aged 16 to 65 years. Depending on the analyses, the working samples compile data of up to $\mathrm{n}=72.000$ dependent workers. The PIAAC data allow for the identification of proficiency differences between sub-groups of the population, to examine skill use at work and in daily life, as well as to determine the impact of skills and skill use on labour market outcomes and life chances more generally (OECD, 2016a). The PIAAC data appropriately measure and relate to the theoretical concepts and underlying social phenomena that I am interested in.

Using skill matches and mismatches as dependent and independent variable, I provide new cross-country evidence based on advanced statistical modelling. The main source of evidence are weighted multilevel mixed-effects regression models, with binary or continuous dependent variables. The statistical modelling is accompanied by descriptive analyses for social groups and cross-country comparisons. Why did I choose this approach? PIAAC data contain individual nested in sampling clusters (characterised by specific weighting procedures) nested in countries. I resort to multilevel modelling to properly take into account country level errors, taking into account the derived plausible values (PVs) and using the implemented PIAAC replicate weights whenever possible and appropriate. Using different approaches to measure skill-to-job matches, I deal with recognised policy indicators as well as with indicators other than those usually tested to explain the macromicro link between national policies and the incidence of skill matching at the individual level. When it comes to outcomes, I restrict all analyses to the micro level while considering potential social outcomes of skills, skill use at work, and mismatches. 


\section{What daes my research tell us that we did not know befare?}

Exploring macro level determinants of skill matching, I investigate social policies and the challenge of allocating the right people to the right jobs in CHAPTER 3. With a special focus on differences between labour market insiders and outsiders, I investigate the extent to which job-worker matches are associated with the institutional setup of school systems, employment protection legislation (EPL), unemployment benefits, and activating labour market policies. I make use of well-known policy indicators as provided e.g. by the OECD, but furthermore resort to a composite indicator that captures the mix of enforcing and enabling labour market policies. With these analyses, I can provide evidence for two things that we did not know before: First, higher EPL is associated with more skill matching, i.e. higher shares of optimal matching. This is a very robust finding. A possible explanation is that the regulation of the dismissal process is also relevant when it comes to hiring. Because the costs of dismissals are so high in countries with strict job security provisions such as EPL, employers make sure to allocate the right person (either directly or through extra onthe-job training). Second, my analyses show that it is insightful to use indicators other than those usually tested: I provide cross-country evidence that strict enforcement does not lead countries into the right direction when it comes to optimal matching as strict enforcement is associated with a higher share of suboptimal matches (i.e. more skill mismatch). Strict enforcing policies force people into employment, e.g. because turning down a job offer would lead to sanctions in unemployment benefits. In countries with strict enforcement, workers therefore must either stay in a job or pick up a job, even if that job does not match their skills. This enforcement appears to have adverse effects concerning skill-based worker-job matches.

When it comes to individual outcomes of skills, skill use and skill mismatches, previous evidence merely exists for wages. CHAPTER 4 builds on the discussion that skills have a broader impact, also affecting non-monetary outcomes inside and outside the work environment. I contribute to the literature by shedding new light on old findings about job satisfaction, furthermore filling gaps in knowledge about the broader impact and potential social outcomes of skills and mismatches. I furthermore contribute to research by applying the new 'effective skill' concept as developed by van der Velden and Bijlsma (2018). Highlighting the importance of skill use at work, my analyses disentangle skill use and skill proficiency as related but distinct dimensions of quality of working life. What we did not know before is this: Once I use objective indicators for the skill match (and I make use of all measures that are currently available), there is no relation between overskilling and job satisfaction - not even if I look at young entrants to the labour markets only or when I 
include wages and other relevant micro level confounders. In fact, job satisfaction is driven by skill use, not by proficiency or mismatches.

My analyses also provide new insights into the broader impact of skills and mismatches outside the work environment. This link is established in the literature: E.g. Kohn and Schooler (1983) have shown empirically that the experience e.g. of an effective use of one's own skills contributes to an orientation that allows the worker to see society as so constituted that individual efficacy is both possible and useful. As work, society and self are distinct but entangled aspects of reality, spill over effects can be expected, shaping the perception of the own efficacy also in other domains of life such as the political system. The experience of self-direction and efficacy at work may also contribute to an open and flexible orientation towards others, forming the basis for social trust. Testing hypotheses based on this theoretical reasoning, my analyses show that workers who can fully exploit their skills are more likely to approve a positive perception of political efficacy and trust in others. However, my thesis cannot test these mechanisms based on a causal design, which is why further research is necessary.

CHAPTER 5 is dedicated to recent developments concerning the increasing adoption of digital technologies at workplaces and the recognition of the idea that digital problem-solving skills are key skills, enabling people to fully participate in economies and societies of the $21^{\text {st }}$ century. While increasing automation is thought to further exacerbate the importance of digital problem-solving skills, evidence suggests that shortages in these skills are widespread. With this chapter, I assess how the digital skills divide translates into groupspecific returns to skills and mismatches. Based on classical sociological reasoning concerning human capital theory and labour market discrimination, I systematically compare sub-groups of workers. These groups are defined by socio-economic status, gender, age, educational attainment and migration background. Doing so, my analyses help to fill the main gap in the literature concerning digital skills: a thorough assessment of social inequalities. Drawing on PIAAC micro data, I build a skill matching model to show that skill-to-job matches in digital problem-solving skills matter for wages: shortages are damaging, while a skills surplus is profitable. However, digital problem-solving skills reshape wage inequalities with the potential to serve as an emancipatory lever, narrowing the divide between socio-economic status groups. These key skills may also help to reduce the gender wage gap, as high levels of digital problem-solving skills appear to pay off more for women than for men.

\section{How do my findings fit with or contradict the rest of the literature in this field?}

When it comes to returns to skill mismatches, most of my findings fit with previous studies: surplus skills pay off, while underskilling entails penalties (see e.g. Duncan and Hoffman, 
1981; Hartog, 2000 and others). Some findings - e.g. concerning the relation between skill mismatches and social outcomes such as political efficacy and social trust - build on classical theoretical reasoning (as provided e.g. by Kohn and Schooler, 1983), which has not been backed up yet based on objective and high-quality micro data. Using such data, I provide evidence for a present concern surrounding the broader impact of skills and mismatches for contemporary societies. Other findings have no comparison in previous studies. This holds e.g. for the potential of digital problem-solving skills to narrow the divide between socio-economic status groups and the gender wage gap as well as for the relation between skill matching and the mix of enforcing and enabling activation measures that characterises labour market policies of advanced economies. When it comes to job satisfaction, however, I clearly contradict most of the rest of the literature in this field. Previous studies usually find that overskilling negatively affects job satisfaction and wellbeing (see e.g. Allen and van der Velden, 2001), while I find no relation at all.

How do I explain the differences of findings? There are two reasons: First, former studies claiming that skill mismatches negatively affect job satisfaction, are usually not based on objective assessments of the skill match. Due to a lack of data before the PIAAC survey was released, previous studies often had to rely on worker self-assessments of the skill match. However, job satisfaction, too, is a subjective indicator, and the correlation between different subjective variables is endogenous and does not tell us much about 'real' skill mismatches and outcomes. If I measure mismatches subjectively, I find the same negative correlation. The second reason lies in the model specification: Generally, it is the combination of skill supply and demand that determines individual labour market outcomes. Evidence suggests that returns to education and skill-to-job matches/ mismatches are therefore best explained by matching models (see e.g. Groot and Maassen van den Brink, 2000; Hartog, 2000). Previous studies often do not appropriately control for skill requirements of jobs, which may lead to misleading conclusions.

\section{What are the value-added parts and main policy implications?}

There are six most value-added (or original) parts of my thesis that I would like to highlight here.

The FIRST VALDRISATION ADDENDUM relates to the policy-related macro-micro link, exploring an urgent topic - skill matching - and the political economy of skill utilisation. The use of composite policy indicators for enforcing and enabling activating policy measures contributes to the literature and provides policy-relevant insights as these indicators allow for a deeper investigation of different aspects of activating labour market policies and their respective relation with skill matching. Although more research is necessary, my analyses 
indicate that different activating labour market policies have diverse effects: Strict enforcement is associated with more skill mismatch, while enabling policies may serve as a lever to promote skill-based worker-job matches, which is important for a productive use of skills and talent. A relevant policy implication - particularly for the current times of great changes in skill demands -, is that strict enforcing policies do not lead countries into the right direction when it comes to allocating the right workers to the right jobs. Enforcements contributes to a situation where individuals are forced into employment, irrespective of the skill match and other criteria that may be of importance both for the deployment of talent and for individual economic and non-monetary outcomes. Enforcing policies should therefore be evaluated critically, taking into account mismatches between workers and jobs as potential policy outcome. By contrast, more emphasis on enabling activation measures may be useful as it appears that these policies seem to promote skill matching. These policies seem to help individuals to find their way into jobs that match their skills, thereby contributing to a situation, in which employers and - in aggregate - economies can profit from the right employee on the right job. However, more and better composite policy indicators are needed to further investigate the diverse mix of activating policies that form the heart of central labour market reforms that took and still take place in many countries. Here, interdisciplinary research that brings together different social sciences could be of great use. This would allow for a better integration of perspectives and knowledge of, for example, political scientists and sociologists, allowing for a deeper examination of the effects of national and/or supra-national policies on micro level outcomes.

The SECDND VALDRISATION ADDENDUM relates to new insights about potential effects of employment protection legislation (EPL). It is a long standing finding that the regulation of the dismissal process also affects employers' hiring decision making, which is discussed controversially in the academic discourse. My research adds a new aspect to the discussion, namely the positive relation between EPL and skill matching. From the perspective of skillbased worker-job matches, a stricter EPL contributes to a situation that allows both employers and employees to fully exploit talent. A critical evaluation of job security provisions such as EPL should consider this finding, assessing the whole range of outcomes that these policies may affect, and taking into account the need for skill-based job-worker matches.

The THIRD VALDRISATION ADDENDUM lays in the provision of new empirical evidence based on the new van der Velden/Bijlsma (2018) 'effective skill measure'. I consider this a valueadded part because the effective skill logic is key for understanding the relation between skills, skill use, mismatches and outcomes, highlighting the importance of skill use at work as a crucial dimension of quality of working life. Moreover, the comparison of different 
skill mismatch measures shows that informed and careful choices are needed when choosing a mismatch measure. My research adds value to mismatch research, showing that the existing measures are not interchangeable, and that the dependent variables should determine which measure is used.

This relates to the FOURTH VALORISATION ADDENDUM. Based on a theory-driven specification of skill matching models, my thesis shows that job satisfaction is driven by skill use, not skill proficiency or mismatches. As outlined before, this is a value-added part as it sheds new light on old findings, contributing to a better understanding of underlying mechanisms. In general, satisfaction strongly relates to meeting expectations. People with certain skills expect that these skills are actually used in their work. My findings lead to two main policy implications: (1) Policies addressing job satisfaction should focus on skill utilisation rather than primarily on the issue of overskilling; and (2) policies, particularly but not exclusively at the level of firms and managerial practices, should take into account skill matches and promote the full use of each workers' potential, designing workplaces and also training mechanisms in a way that allows workers' to do what they are best at, allowing for a positive employee experience. Again, in the current times of great change where it is increasingly challenging for employers to find workers that match their jobs, firm level policies should seek to promote a positive employee experience that allows both the worker and the employer to fully exploit skills and talent.

The FIFTH VALORISATION ADDENDUM lies in the adoption of classical theoretical reasoning in combination with advanced statistical modelling. Building on sociological literature by Kohn (1977) and Kohn and Schooler (1983) my thesis can show that skills, skill use and mismatches are related to psychological orientations and values that are important even outside the work environment and that - in aggregate - are vital for societies and democracies. Kohn and Schooler (1983) show that the more a worker experiences that he can be efficacious, the more likely it is that the same worker will believe in self-direction and efficacy. As work, society and self are distinct but entangled aspects of reality, we would expect spill over effects to all kinds of contexts: If people experience self-efficacy (e.g. at work), we would expect that they will be more likely to believe that they can be efficacious also in other domains of life such as the political system. Self-direction and a positive perception of the own efficacy may also contribute to an open and flexible orientation towards others, forming the basis for social trust. An individual's positive attitude towards social trust and political efficacy has externalities that benefit other people, contributing to social cohesion and hence social capital (McMahon, 2009: 223; also see European Commission, 2016). Therefore, we refer to political efficacy and social trust as potential social outcomes. The most important policy implication based on this is that skill-to-job 
matches, and skill utilisation, have a broader impact, potentially also for societies and democracies. However, these analyses are congruent with theoretical expectations but cannot proof the theory to be true. Further research is necessary to give more detailed policy implications.

The SIXTH VALDRISATION ADDENDUM is the following: My research on digital problem-solving skills and their relation with wage inequalities addresses a topic of current and even more future importance. My research shows that these key skills can potentially serve as emancipatory lever, helping to address inequalities between social groups. Although further research is necessary, this may have important policy implications. Digital problem-solving skills are very likely to increase in importance, which is why education but also enabling labour market policies should focus on a broad promotion of these key skills, including them into education and schooling but also workplace training schemes. Particularly, women, low educated (that may also be highly affected by the implementation of innovative technologies, such as e.g. chatbots and voicebots, at their workplaces) and other social groups that often find themselves in adverse labour market situations should get access to training. This is an important policy implication, as increasing labour market inequality (e.g. related to shortages in digital problem-solving skills) is to be expected if a further development of these skills is not broadly promoted. Again, the concern is that technological innovations in combination with shortages in the skills needed to deal with these changes may lead to increasing levels of social inequality. The promotion of digital problem-solving skills, particularly for the mentioned social groups, could be a channel through which these challenges could potentially be addressed before they even fully arise. Reducing skill mismatch could emerge as a new channel, through which effective policies could contribute to a higher labour productivity, reduce social and labour market inequalities, and enhance individual outcomes at the same time (see McGowan and Andrews, 2015b: 3; OECD, 2013).

\section{What is the limit of my research?}

Generally, there are three overarching questions in skill (mis-)match research: (1) How can skill (mis-)match be explained?, (2) what are the consequences?, and (3) how can we measure both? My thesis provides new insights concerning all three questions. However, I do not provide definite answers. PIAAC data provide new and unique opportunities to conduct research on skill-to-job matches. The survey is the only dataset that provides objective skills measurements and internationally harmonised data for representative sample of the working age population of a large number of countries. Nevertheless, the data also comes with some disadvantages, the most pressing one being the fact that PIAAC 
is a cross-sectional survey. In an ideal world, we would have longitudinal data, linked employee-employer data, and valid information about skills requirements of jobs that are based on an up-to-date job analyst approach. Or we would have valid instrumental variables to assess causes and consequences, e.g. through the implementation of field experiments at workplaces, effectively controlling for unobserved heterogeneity. However, as I am bound to the existing survey data, I must pinpoint to the fact that none of the analyses presented in this thesis do allow causal inferences. I use regression-based methods to explore the extent to which one can observe theoretically expected explanations for variances in the best data available. As such, my analyses provide new knowledge and valuable insights and explanations for cross-country variances.

Concerning the measurement of skill mismatches, I am largely bound to the Realised Matches Approach (RMA) for most of my analyses, although I do make use of the alternative indicators. Like every measure, the RMA entails disadvantages. Some scholars consider the use of the RMA as inferior to other measures, particularly compared to the job analyst approach (see Leuven and Oosterbeek, 2011: 293). The main reason for this is that the RMA does not only reflect requirements but is the result of demand and supply forces. A statistical problem derives from the fact that occupations are very heterogeneous, containing occupations that might differ substantially regarding their skill requirements. The main theoretical issue that arises is the forced equilibrium where, by definition, the 'average' worker is defined as well-matched, although this is questionable. However, the empirical evidence provided in my thesis is strong enough in terms of quantity and quality to sustain all conclusions that I draw.

\section{What should follow-on research do?}

Against the background of recent technological innovations and their increasing adoption at workplaces of all occupational levels, the importance of skill matching and skill utilisation for multiple outcomes should be studied further. My analyses strongly suggest that skill use drives job satisfaction. If this is the case, then further research could investigate how the employee experience and the perception of the quality of working life is affected by changing skills demands and changes in skill use due to technological innovations at the workplace. Artificial Intelligence (AI), particularly if combined with Robotic Process Automation (RPA) in integrative systems, is of increasing importance here, as it changes what workers do and how, taking over some tasks while generating others. Here, a (quasi) experimental setting would be needed to establish causal effects, while objective measures of (increases in) productivity are as valuable as an investigation of skill utilisation and different dimensions of satisfaction, self-direction, and quality of working life. 
When it comes to skill matching as both dependent and independent variable, it would also be relevant to zoom in on the firm-level, assessing the impact of organisational structures and managerial practices that affect both the allocation of workers to jobs and the use of skills and talent, potentially affecting outcomes inside and outside the work environment. Task-related self-efficacy increases the likelihood of being engaged in more challenging tasks, thus increasing skill levels, self-direction, self-efficacy - and probably also the potential of firms to engage with and adopt complex technologies. Follow-on studies could further explore the potential of PIAAC as well as the effective skill logic (van der Velden and Bijlsma, 2018) as theoretical framework for the investigation of the relation between skills, mismatches, and multiple outcomes. Thereby, it would be particularly important to include the PIAAC domain of digital problem-solving skills as well as non-cognitive skills. Related to this, another open question for further research is whether the work that is left for humans to do can be considered "good work" from a normative point of view. The second cycle of PIAAC will hopefully widen the possibilities for in-depth research on the outlined topics and provide opportunities to close knowledge gaps concerning soft skills and non-cognitive skills as well as mismatches in these skills and related outcomes.

An important (and urgent) starting point for follow-on research is also provided by the last chapter "The Future is Now". It is very likely that the importance of digital problem-solving skills increases with increasing adoption of information and communication technology and cognitive systems. Generally, digital problem-solving skills appear to be less related to school curricula and to socio-economic status. My analyses show that digital problemsolving pays off specifically for medium and low educated workers as well as for workers with lower socio-economic status. Moreover, I show that these skills may also help to reduce the gender wage gap, as high levels of digital problem-solving skills appear to pay off more for women than for men. The idea of digital problem-solving skill as a lever of social emancipation deserves more analytical consideration and theoretical reasoning. Is it, for example, possible that there is a time window for digital problem skills to work as emancipatory lever? As soon as elites incorporate these skills, associating the potential of social closure, digital problem-solving may probably no longer be as open and accessible for all social classes as it is today. Against the current changes in skill demands and the increasing importance of digital problem-solving skills further research could seek to establish causal effects of digital problem-solving skills on multiple outcomes at all levels.

Further research could also focus on the growth of the service economy and related changes in the character of skills that are demanded in digitalised economies and "new collar work". Related to this, there is a growing analytical interest in workplace training and informal learning - which both is of importance when it comes to tackling the skill matching challenge. Follow-on research could try to discern the best environment within workplaces 
to lever skill utilisation and a full and productive use of talent as well as new ways of learning and workplace training. This analytical challenge is as pressing as political, societal and economical concerns. With outdated skills, workers run the risk to be unable to deal with tomorrow's world of work. Skill matching is therefore a topic with present as much as future relevance. The key to both the adoption of new technologies and dealing with related consequences may well lie in reskilling and in the broad promotion of key informationprocessing skills for everybody. It would be great to explore if and how AI could help with this, e.g. through algorithm based individual career advice which is based on large scale key skill assessments and directly interwoven with platform-based training opportunities that allow the learners to inherit the future. 



\section{Bibliography}

Acemoglu, D. (2002). "Technical Change, Inequality, and the Labor Market", Journal of Economic Literature, vol. 40(1), (Mar., 2002), pp. 7-72.

Acemoglu, D. and Autor, D. (2011). "Skills, tasks and technologies: Implications for employment and earnings", in (O. Ashenfelter and D. Card, eds.), Handbook of labour economics, vol. 4b, pp. 1043-1171, Amsterdam: Elsevier B.V.

Allen, J. and van der Velden, R. (2001). "Educational mismatches versus skill mismatches: effects on wages, job satisfaction, and on-the-job-search", Oxford Economic Papers, vol. 53(3), pp. 434-452.

Allen, J. and van der Velden, R. (2002). "When Do Skills Become Obsolete, and When Does It Matter?", in (A. de Grip, J. van Loo and K. Mayhew, eds.), The Economics of Skills Obsolescence: Theoretical Innovations and Empirical Applications, Research in Labour Economics, vol. 21, pp. 27-50, Oxford: Elsevier Science Ltd.

Allen, J. and van der Velden, R. (2005). “The role of self-assessment in measuring skills”, REFLEX Working Paper Series, no. 2, Maastricht: Research Centre for Education and the Labour Market (ROA).

Allen, J. and van der Velden, R. (2009). Report on the Large-scale Graduate Survey: Competencies and Early Labour Market Careers of Higher Education Graduates, Lifelong Learning Program, European Commission, Ljubljana: Faculty of Social Sciences, University of Ljubljana.

Allen, J. and van der Velden, R. (2013). "Skills for the 21 $1^{\text {st }}$ Century: Implications for Education", in (L. R. Smith, ed.), Higher Education: Recent Trends, Emerging Issues and Future Outlook, pp. 1-40, New York: Nova Science Publishers.

Allen, J., Levels, M., and van der Velden, R. (2013). "Skill mismatch and skill use in developed countries: Evidence from the PIAAC study", ROA Research Memorandum (ROA-RM-2013/17), Maastricht: Research Centre for Education and the Labour Market (ROA).

Allen, J. and Bijlsma, I. (Forthcoming). "Skill Profiles of Occupations: Robust Multi-level Estimates Based on PIAAC Data - A methodology for robust multi-level estimates 
of aggregates based on a limited number of observations", $R O A$ Technical Report, Maastricht: Research Centre for Education and the Labour Market (ROA).

Allmendinger, J. (1989). "Educational systems and labour market outcomes", European Sociological Review, vol. 5, pp. 231-250.

Allmendinger, J and Leibfried, S. (2005). "Bildungsarmut. Zum Zusammenhang von Sozialpolitik und Bildung“", in (M. Opielka, ed.), Bildungsreform als Sozialreform. Zum Zusammenhang von Bildungs- und Sozialpolitik, pp. 45-60, Wiesbaden: Springer VS.

Altonji, J. G. and Pierret, C. R. (2001). "Employer learning and statistical discrimination", The Quarterly Journal of Economics, vol. 116(1) (Feb., 2001), pp. 313-350.

Amado, C. A. F., Santos, S. P., and São José, M. S. (2018). "Measuring and decomposing the gender pay gap: A new frontier approach", European Journal of Operational Research, vol. 271(1), pp. 357-373.

Ashenfelter, O. and Card, D. (eds.) (2011). Handbook of labour economics, vol. 4b, pp. 10431171, Amsterdam: Elsevier B.V.

Autor, D. H., Levy, F., and Murnane, R. J. (2002). "The Skill Content of Recent Technological Change: An Empirical Exploration", Quarterly Journal of Economics, vol. 118, pp. 1279-1334.

Autor, D. H. and Dorn, D. (2013). "The Growth of Low-Skill Service Jobs and the Polarization of the US Labor Market", American Economic Review, vol. 103(5), pp. 1553-1597.

Autor, D. H. and Price, B. V. (2013). The changing task composition of the US labor market: An update of Autor, Levy, and Murnane (2003), doi: http://economics.mit.edu/files/9758 (last accessed 09-Jan-2019).

Autor, D. and Salomons, A. (2018). Is Automation Labor-Displacing? Productivity Growth, Employment, and the Labor Share, doi: https://economics.mit.edu/files/15420 (last accessed 18-Dec-2018).

Bandura, A. (1977). "Self-efficacy: Toward a unifying theory of behavioural change", Psychological Review, vol. 84(2), pp. 191-215.

Barbieri, P. (2009). "Flexible Employment and Inequality in Europe", European Sociological Review, vol. 25(6), pp. 621-628.

Barbieri, P., Cutuli, G., and Passaretta, G. (2018). "Institutions and the school-to-work transition: disentangling the role of the macro-institutional context", Socio-Economic Review, vol. 16(1), pp. 161-183. 
Becker, G. S. (1962). "Investment in Human Capital: A Theoretical Analysis", The journal of political economy, vol. 70(9), pp. 9-49.

Becker, G. S. (1971). The Economics of Discrimination, 2nd edition, Chicago: The University of Chicago Press.

Benz, M. and Frey, B. (2008). "The value of doing what you like: Evidence from the selfemployed in 23 countries", Journal of Economic Behaviour and Organization, vol. 68, pp. 445-455.

Bills, D. B. (2003). "Credentials, Signals, and Screens: Explaining the Relationship Between Schooling and Job Assignment", Review of Educational Research, vol. 73(4), pp. 441469.

Bills, D. B. (2004). The Sociology of Education and Work, Oxford and Victoria: Blackwell.

Blau, F. and Kahn, L. (2003). "Understanding international differences in the gender pay gap", Journal of Labor Economics, vol. 21(1), pp. 106-144.

Bol, T. and van de Werfhorst, H. (2012). "Measuring Educational Diversity: Tracking, Vocational Orientation, and Standardization”, AMCIS Working Paper, no. 1, January 2012.

Bol, T., and van de Werfhorst, H. (2014). Educational Systems Dataset, version 4 (last update: November 2014), doi: http://thijsbol.com/data (last accessed 02-Feb-2019).

Boll, C., Leppin, J., Rossen, A., and Wolf, A. (2016). "Overeducation - New evidence for 25 European countries", LAB Discussion Paper, no. 35, Nürnberg: Institute for the Employment Research (IAB).

Bol, T., Ciocca Eller, C., van de Werfhorst, H., and DiPrete, T. (2019). "School-to-work linkages, Educational Mismatches, and Labor Market Outcomes", American Sociological Review, vol. 84(2), pp. 275-307.

Bonoli, G. (2010). “The Political Economy of Active Labour-Market Policy”, Politics \& Society, vol. 38(4), pp. 435-457.

Borghans, L. and ter Weel, B. (2004). "Are Computer Skills the New Basic Skills? The Returns to Computer, Writing and Math Skills in Britain", Labour Economics, vol. 11(1), pp. 85-98.

Borgonovi, F. and Burns, T. (2015). "The educational roots of trust", OECD Education Working Papers, no. 119, Paris: OECD Publishing.

Braverman, H. (1974). Labour and Monopoly Capital, New York: Monthly Review Press. 
Bryan, M. L. and Jenkins, S. P. (2015). "Multilevel modelling of country effects: A cautionary tale", European Sociological Review, vol. 32(1), pp. 1468-2672.

Brynjolfsson, E. and McAfee, A. (2014). The Second Machine Age: Work, Progress, and Prosperity in a Time of Brilliant Technologies, New York: W. W. Norton Company.

Bryson, J. (2017). "Disciplinary Perspectives on Skill”, in (C. Warhurst, K. Mayhew, D. Finegold, and J. Buchanan, eds.), The Oxford Handbook of Skills and Training, pp. 1735, Oxford: Oxford University Press.

Buchanan, J., Scott, L., Yu, S., Shutz, H., and Jakubauskas, M. (2010). Skill Utilisation: An Overview of Current Approaches to Measurement and Improvement, Sydney: Workplace Research Centre, University of Sydney.

Buchanan, J., Finegold, D., Mayhew, K., and Warhurst, C. (2017). "Introduction. Skills and Training: Multiple Targets, Shifting Terrain", in (C. Warhurst, K. Mayhew, D. Finegold, and J. Buchanan, eds.), The Oxford Handbook of Skills and Training, pp. 116, Oxford: Oxford University Press.

Büchel, F., de Grip, A., and Mertens, A. (eds.) (2003). Overeducation in Europe. Current Issues in Theory and Policy, Cheltenham, UK, Northampton, MA: E. Elgar.

Buhr, D., Christ, C., Frankenberger, R., Fregin, M.-C., Schmid, J., and Trämer, M. (2016). On the path towards Welfare 4.0? Digitalization of the welfare state in the fields of labour, bealthcare and innovation policy: A European comparison, London: Friedrich-EbertStiftung.

Busemeyer, M. R. and Thelen, K. A. (2015). "Non-standard employment and systems of skill formation in European countries", in (W. Eichhorst and P. Marx, eds.), Nonstandard employment in post-industrial labour markets, pp. 401-430, Cheltenham: Elgar.

Cedefop. (2010). The skill matching challenge: Analysing skill mismatch and policy implications, Luxembourg: Publications Office of the European Union.

Cedefop. (2015). "Quantifying skill needs in Europe. Occupational skills profiles: methodology and application", Research Paper, no. 30, Luxembourg: Publications Office of the European Union.

Cedefop. (2018). "Insights into skill shortages and skill mismatch: learning from Cedefop's European skills and jobs survey", Cedefop reference series, vol. 106, Luxembourg: Publications Office of the European Union.

Chiswick, B. R. and Miller, P. W. (2008). "Why is the payoff to schooling smaller for immigrants?", Labour Economics, vol. 15(6), pp. 1317-1340. 
Chiswick, B. R. and Miller, P. W. (2009). "The international transferability of immigrants' human capital skills", Economics of Education Review, vol. 28(2), pp. 162-169.

David, S. A., Boniwell, I., and Ayers, A. C. (eds.) (2013). The Oxford Handbook of Happiness, Oxford and New York: Oxford University Press.

De Grip, A., van Loo, J., and Mayhew, K. (eds.) (2002). “The Economics of Skills Obsolescence: Theoretical Innovations and Empirical Applications", Research in Labour Economics, vol. 21, pp. 27-50, Oxford: Elsevier Science Ltd.

De La Rica, S. and Gortazar, L. (2017). "Digitalization at work, Job Tasks and Wages: Cross-Country evidence from PIAAC”, GLO Discussion Paper, no. 22, Maastricht: Global Labor Organization (GLO).

Desjardins, R. and Schuller, T. (2006). "Introduction: Understanding the Social Outcomes of Learning", in Measuring the Effects of Education on Health and Civic Engagement. Proceedings of the Copenhagen Symposium (OECD 2006), pp. 1-18, Paris: OECD Publishing.

Desjardins, R. and Rubenson, K. (2011). "An Analysis of Skill Mismatch Using Direct Measures of Skills", OECD Education Working Papers, no. 63, Paris: OECD Publishing.

De Vreyer, P., Layte, R., Wolbers, M. H. J., and Hussain, A. (2000). “The Permanent Effects of Labour Market Entry in Times of High Unemployment”, in: Gallie, D., and S. Paugam (eds.), Welfare Regimes and the Experience of Unemployment in Europe, pp. 134 52, Oxford: Oxford University Press.

Dingeldey, I. (2007). "Between workfare and enablement - The different paths to transformation of the welfare state: A comparative analysis of activating labour market policies", European Journal of Political Research, vol. 46, pp. 823-851.

Dingeldey, I. (2011). Der Aktivierende Wohlfahrtsstaat. Governance der Arbeitspolitik in Dänemark, Grossbritannien und Deutschland, Frankfurt a. M.: Campus Verlag.

Duncan, G. and Hoffman, S. (1981). "The incidence and wage effects of overeducation", Economics of Education Review, vol. 1(1), pp. 75-86.

Dustmann, C. and van Soest, A. (2002). "Language and the earnings of immigrants", Industrial and labor relations review, vol. 55(3), pp. 473-491.

Eichhorst, W. (2007). „Der Arbeitsmarkt in Deutschland: Zwischen Strukturreformen und sozialpolitischem Reflex“, IZA Discussion Paper, no. 3194, Bonn: Institute for the Study of Labor (IZA). 
Eichhorst, W. and Marx, P. (2011). "Reforming German labor market institutions: A dual path to flexibility", Journal of European Social Policy, vol. 21(1), pp. 73-86.

Eichhorst, W. and Marx, P. (2015). Non-standard employment in post-industrial labour markets, Cheltenham: Elgar.

Elliot, S. W. (2017). "Projecting the Impact of Information Technology on Work and Skills in the 2030s", in (C. Warhurst, K. Mayhew, D. Finegold, and J. Buchanan, eds.), The Oxford Handbook of Skills and Training, pp. 557-575, Oxford: Oxford University Press.

Emmenegger, P., Häusermann, S., Palier, B., and Seeleib-Kaiser, M. (eds.) (2012). The Age of Dualization: The Changing Face of Inequality in Deindustrializing Societies, pp. 201-225, Oxford: Oxford University Press.

Esping-Andersen, G. (1990). The three worlds of welfare capitalism, Princeton: Princeton University Press.

Esping-Andersen, G. (2006). "Warum brauchen wir eine Reform des Sozialstaats? Gøsta Esping-Andersen beantwortet von Jens Alber gestellte Fragen“, Leviathan, vol. 34(1), pp. 61-81.

Estévez-Abe, M., Iversen, T., and Soskice, D. (2001). "Social protection and the formation of skills: A reinterpretation of the welfare state", in (P. A. Hall and D. Soskice, eds.), $V$ arieties of capitalism. The institutional foundations of comparative advantage, pp. 145-183, Oxford/New York: Oxford University Press.

European Commission EC. (2013). "The skill mismatch challenge in Europe", in (European Commission, ed., 2013a), Employment and social developments in Europe 2012, Chapter 6, pp. 351-394, Brussels: European Union, doi: https://publications.europa.eu/en/publication-detail/-/publication/1542f940a31d-4c6a-aa19-37b728c2de1a (last accessed 09-Jan-2019).

European Commission EC. (ed.) (2013a). Employment and social developments in Europe 2012, Brussels: European Union, doi: https://publications.europa.eu/en/publicationdetail/-/publication/1542f940-a31d-4c6a-aa19-37b728c2de1a (last accessed 09Jan-2019).

European Commission EC. (2015). Monitoring the Digital Economy and Society 2016-2021, doi: http://ec.europa.eu/eurostat/documents/341889/725524/Monitoring+the+Digit al+Economy+\%26+Society+2016-2021/7df02d85-698a-4a87-a6b1-7994df7fbeb7 (last acc-essed: 20-Mar-2019), Brussels: European Union.

European Commission EC. (2016). “A New Skills Agenda for Europe. Working together to strengthen human capital, employability and competitiveness", Communication from 
the Commission to the European Parliament, The Council, The European Economic and Social Committee and The Committee of the Regions, Brussels: European Union, doi: https:/ / ec.europa.eu/transparency/regdoc/rep/1/2016/EN/1-2016-381-EN-F11.PDF (last accessed 09-Jan-2019).

European Commission EC. (2018a). Digital Economy and Society Index Report DESI 2018 Human Capital, Digital Inclusion and Skills, Brussels: European Union, doi: https:/ / ec.europa.eu/digital-single-market/en/desi (last accessed: 20-Mar-2019).

European Commission EC. (2018b). Women in the Digital Age, Brussels: European Union, doi: https://ec.europa.eu/digital-single-market/en/news/increase-gender-gapdigital-sector-study-women-digital-age (last accessed: 20-Mar-2019).

Falck, O., Heimisch, A., and Wiederhold, S. (2016). "Returns to ICT Skills", OECD Education Working Papers, no. 134, Paris: OECD Publishing.

Felstead, A., Gallie, D., and Green, F. (2017). "Measuring skills stock, job skills, and skills mismatch", in (C. Warhurst, K. Mayhew, D. Finegold, and J. Buchanan, eds.), The Oxford Handbook of Skills and Training, pp. 321-342, Oxford: Oxford University Press.

Fleisher, M. S., and Tsacoumis, S. (2018). O*NET: Analyst Occupational Skills Ratings: Procedures Updates, Raleigh: National Centre for O*NET Development.

Flisi, S., Goglio, V., Meroni, E., Rodrigues, M., and Vera-Toscano, E. (2014). Occupational mismatch in Europe: Understanding overeducation and overskilling for policy making. European Commission Joint Research Centre Institute for the Protection and Security of the Citizen, Report EUR 26618 EN.

Flisi, S., Goglio, V., Meroni, E., Rodrigues, M., and Vera-Toscano, E. (2016). "Measuring Occupational Mismatch: Overeducation and Overskill in Europe - Evidence from PIAAC”, Social Indicators Research, vol. 131(3), pp. 1211-1249.

Freeman, R. (1976). The Overeducated American, New York: Academic Press.

Fregin, M.-C. (2013). “Generation Ungewiss - Berufseinsteiger auf dem Weg ins Abseits? Empirische Vergleiche zur Chancenentwicklung von befristet beschäftigten Arbeitsmarkteinsteiger/innen“, SOEPpapers on multidisciplinary panel data research at DIW Berlin, no. 58, Berlin: Deutsches Institut für Wirtschaftsforschung (DIW).

Fregin, M.-C. (2017). "The impact of social policies on skill mismatch - Conceptual framework of an international comparative empirical study", in (J. Schmid, K. Amos, J. Schrader, and A. Thiel, eds.), Governance und Interdependenz von Bildung. Internationale Studien und Vergleiche, Baden-Baden: Nomos. 
Frey, C. B. and Osborne, M. (2016). "The Future of Employment: How Susceptible are Jobs to Computerisation?”, Technological Forecasting and Social Change, vol. 114, pp. 254-280.

Gangl, M. (2004). "Institutions and the structure of labour market matching in the United States and West Germany”, European Sociological Review, vol. 20(3), pp. 171-187.

Gangl, M. (2006). "Scar Effects of Unemployment: An Assessment of Institutional Complementarities", American Sociological Review, vol. 71, pp. 986-1013.

Gebel, M. (2017). „Der Übergang vom Bildungssystem in den Arbeitsmarkt im europäischen Vergleich. Die Rolle von Bildungs- und Arbeitsmarktinstitutionen“, in (J. Schmid, K. Amos, J. Schrader and A. Thiel, eds.), Governance und Interdependenz von Bildung. Internationale Studien und Vergleiche, Baden-Baden: Nomos.

Giddens, A. (1998). "Equality and the social investment state", in (I. Hargreaves and I. Christie, eds.), Tomorrow's politics. The third way and beyond, pp. 25-40, London: Demos.

Giesselmann, M. (2012). Die Auswirkungen arbeitsmarktpolitischen Wandels auf die materiellen Lebensbedingungen von Erwerbstätigen in Deutschland. Empirische Vergleiche in der Zeit- und Länderdimension. Dissertation, Universität zu Köln, Wirtschafts- und Sozialwissenschaftliche Fakultät.

Gilbert, N. (2002). Transformation of the welfare state. The silent surrender of public responsibility. Oxford: Oxford University Press.

Goldin, C. D. (1986). "Monitoring costs and occupational segregation by sex: A historical analysis." Journal of Labor Economics, vol. 4(1), pp. 1-27.

Goldin, C. D. and Katz, L. F. (2010). The Race between Education and Technology: The Evolution of US Educational Wage Differentials, 1890-2005, Cambridge, MA: Belknap Press.

Goos, M. and Manning, M. (2007). "Lousy and Lovely Jobs: The Rising Polarization of Work in Britain", Review of Economic and Statistics, vol. 89(1), pp. 118-133.

Goos, M., Manning, A., and Salomons, A. (2014). "Explaining job polarization: routinebiased technological change and offshoring", American Economic Review, vol. 104(8), pp. 2509-2526.

Green, F. and Zhu, Y. (2010). "Overqualification, job dissatisfaction, and increasing dispersion in the returns to graduate education", Oxford Economic Papers, vol. 62(4), pp. 740-763.

Green, F. (2013). Skills and skilled work - An economic and social analysis. Oxford: Oxford University Press. 
Green, F., Felstead, A., Gallie, D., and Inanc, H. (2013). Job-Related Well-Being in Britain: First Findings from the Skills and Employment Survey 2012, London: Centre for Learning and Life Chances in Knowledge Economies and Societies, Institute of Education.

Green, F. and Henseke, G. (2016). "Should governments of OECD countries worry about graduate underemployment?", ECOPOL, vol. 32(4), pp. 514-537.

Gregory, T., Salomons, A., and Zierahn, U. (2019): „Racing With or Against the Machine? Evidence from Europe", IZA Discussion Paper, no. 12063, Bonn: IZA.

Groot, W. and Maassen van den Brink, H. (2000). "Overeducation in the labor market: a meta-analysis", Economics of Education Review, vol. 19(2), pp. 149-158

Gross, M. (1998). Bildungssysteme und soziale Ungleichheit - Die Strukturierung sozialen Handelns im internationalen Vergleich, Dissertation, Humboldt-Universität Berlin.

Gross, M. (2015). Klassen, Schichten, Mobilität. Eine Einführung, 2. Aufl., Wiesbaden: Springer VS.

Grugulis, I., Holmes, C., and Mayhew, K. (2017). "The Economic and Social Benefits of Skills", in (C. Warhurst, K. Mayhew, D. Finegold, and J. Buchanan, eds.), The Oxford Handbook of Skills and Training, pp. 372-398, Oxford: Oxford University Press.

Hall, P. A. and Soskice, D. (eds.) (2001). Varieties of Capitalism - The institutional foundations of comparative advantage, Oxford: Oxford University Press.

Handel, M. J. (2017). "Measuring Job Content: Skills, Technology, and Management Practices", in (C. Warhurst, K. Mayhew, D. Finegold, and J. Buchanan, eds.), The Oxford Handbook of Skills and Training, pp. 92-123, Oxford: Oxford University Press.

Hanushek, E. A. and Woessmann, L. (2015a): The knowledge capital of nations: Education and the economics of growth. Cambridge (MA): MIT Press.

Hanushek, E.A., Schwerdt, G., Wiederhold, S. and Woessmann, L. (2015b). "Returns to skills around the world: Evidence from PIAAC", European Economic Review, vol. 73(2015), pp. 103-130.

Hargreaves, I. and Christie, I. (eds.) (1998). Tomorrow's politics. The third way and beyond, London: Demos.

Hartog, J. (2000). “Overeducation and Earnings: Where Are We, Where Should We Go?”, Economics of Education Review, vol. 19, pp. 131-147.

Heisig, J. P. and Solga, H. (2014). "Skills Inequalities in 21 Countries. PIAAC results for prime-age adults", WZB Discussion Papers, SP I 2014-503, Berlin: Wissenschaftszentrum Berlin (WZB). 
Heisig, J. P. and Solga, H. (2017). "How returns to skills depend on formal qualifications: Evidence from PIAAC", OECD Education Working Papers, no. 163, Paris: OECD Publishing.

Heisig, J. P., Schaeffer, M. and Giesecke, J. (2017). "The costs of simplicity: Why multilevel models may benefit from accounting for cross-cluster differences in the effects of controls", American Sociological Review, vol. 82(4), pp. 796-827.

Heyes, J., Tomlinson, M. and Whitworth, A. (2017). "Underemployment and well-being in the UK before and after the Great Recession", Work, employment and society, vol. 31(1), pp. 71-89.

Holmes, C. and Mayhew, K. (2012). Is the UK Labour Market Polarising? London: Resolution Foundation.

Holmes, C. and Mayhew, K. (2015). Over-qualification and skills mismatch in the graduate labour market. Policy Report, August 2015, London: CIPD.

Holmes, C. (2017), "The Individual Benefits of Investing in Skills”, in (C. Warhurst, K. Mayhew, D. Finegold, and J. Buchanan, eds.), The Oxford Handbook of Skills and Training, pp. 345-371, Oxford: Oxford University Press.

Humburg, M., and van der Velden, R. (2017): "What is expected of higher education graduates in the twenty-first century?”, in (C. Warhurst, K. Mayhew, D. Finegold, and J. Buchanan, eds.), The Oxford Handbook of Skills and Training, pp. 201-220, Oxford: Oxford University Press.

Judge, T. A. and Bono, J. E., and Locke, E. A. (2000). "Personality and job satisfaction: The mediating role of job characteristics", Journal of Applied Psychology, vol. 85(2), pp. 237-249.

Judge, T. A. and Bono, J. E. (2001). "Relationship of core self-evaluations traits - selfesteem, generalised self-efficacy, locus of control and emotional stability - with job satisfaction and job performance", Journal of Applied Psychology, vol. 86(1), pp. 80-92.

Knotz, C. M. (2012). "Measuring the 'new balance of rights and responsibilities' in labor market policy. A quantitative overview of activation strategies in 20 OECD countries", ZeS-Working Paper, no. 6/2012, Bremen: Universität Bremen, Zentrum für Sozialpolitik (ZeS).

Kohn, M. L. (1977). Class and Conformity. A study in values. Second Edition, Chicago: The University of Chicago Press.

Kohn, M. L. and Schooler, C. (1983). Work and Personality: An Inquiry Into the Impact of Social Stratification, Norwood: Ablex Publishing Corporation. 
Korpi, T. and Tåhlin, M. (2009). "Educational Mismatch, Wages, and Wage Growth: Overeducation in Sweden, 1974-2000”, Labour Economics, vol. 16, pp. 183 193.

Kupfer, A. (2014). "The Interrelation of Twenty-first Century Education and Work from a Gender Perspective”, International Studies in Sociology of Education, vol. 24(1), pp. 113125.

Lane, M. and Conlon, G. (2016). "The Impact of Literacy, Numeracy and Computer Skills on Earnings and Employment Outcomes”, OECD Education Working Papers, no. 129, Paris: OECD Publishing.

Lauder, H., Brown, P., and Ashton, D. (2017). "Theorizing Skill Formation in the Global Economy", in (C. Warhurst, K. Mayhew, D. Finegold, and J. Buchanan, eds.), The Oxford Handbook of Skills and Training, pp. 401-423, Oxford: Oxford University Press.

Lavrijsen, J. and Nicaise, I. (2012). Characteristics of educational systems: How they influence outcomes in the short and the long run, Leuven: Steunpunt SSL.

Leuven, E., Oosterbeek, H., and van Ophem, H. (2004). "Explaining international differences in male skill wage differentials by differences in demand and supply of skill", The Economic Journal, vol. 114(495), pp. 466-486.

Levels, M., van der Velden, R., and di Stasio, V. (2014a). "From school to fitting work: How education-to-job matching of European school leavers is related to educational system characteristics", Acta Sociologica, vol. 57(4), pp. 341-361.

Levels, M., van der Velden, R. and Allen J. (2014b). "Educational mismatches and skill mismatches: New empirical tests of old hypotheses", Oxford Economic Papers, vol. 66(4), pp. 959-982.

Levy, F. (2010). "How Technology Changes Demands for Humans Skills", OECD Education Working Papers, no. 45, Paris: OECD Publishing.

Lindbeck, A., and Snower, D. (1988). The Insider-Outsider Theory of Employment and Unemployment, Cambridge, MA: MIT Press.

Livingstone, D. W. (2017). "Skill under-utilization", in (C. Warhurst, K. Mayhew, D. Finegold, and J. Buchanan, eds.), The Oxford Handbook of Skills and Training, pp. 281300, Oxford: Oxford University Press.

Martin, C. J. (2017). "Skill Builders and the Evolution of National Vocational Training Systems", in (C. Warhurst, K. Mayhew, D. Finegold, and J. Buchanan, eds.), The Oxford Handbook of Skills and Training, pp. 36-53, Oxford: Oxford University Press. 
Mayer, K. U. and Müller, W. (1986). “The state and the structure of the life course”, in (A. B. Soerensen, F. E. Weinert, and L. R. Sherrod, eds.), Human development and the life course, pp. 217-245, Hillsdale (NJ): Erlbaum.

Mayhew, K (2016). "Human Capital, Growth and Inequality", Welsh Economic Review, vol. 24, pp. 23-27, doi: http://doi.org/10.18573/j.2016.10052 (last accessed: 08-Mar2019).

McGowan, M. A. and Andrews, D. (2015a). "Labour market mismatch and labour productivity: Evidence from PIAAC data”, OECD Economics Department Working Papers, vol. 1209, Paris: OECD Publishing, doi: https://www.oecd.org/eco/growth/Labour-Market-Mismatch-and-LabourProductivity-Evidence-from-PIAAC-Data.pdf (last accessed 08-Jan-2019).

McGowan, M. A. and Andrews, D. (2015b). "Skill mismatch and public policy in OECD countries", OECD Economics Department Working Papers, vol. 1210. Paris: OECD Publishing. doi: https://www.oecd.org/eco/growth/Skill-mismatch-and-publicpolicy-in-OECD-countries.pdf (last accessed 08-Jan-2019).

McKee-Ryan, F. M. and Harvey, J. (2011). "“I have a job, but...": A Reviews of Underemployment", Journal of Management, vol. 37(4), pp. 962-996.

McMahon, W. W. (2009). Higher Learning - Greater Good. The Private and Social Benefits of Higher Education, Baltimore: The Job Hopkins University Press.

Mincer, J. (1974). Schooling, Experience, and Earnings. New York: NBER.

Mood, C. (2010). "Logistic Regression: Why We Cannot Do What We Think We Can Do, and What We Can Do About It", European Sociological Review, vol. 261, February 2010, pp. 67-82.

Müller, W. and Gangl, W. (eds.) (2003). Transitions from Education to Work in Europe: The Integration of Youth into EU Labor Markets, Oxford: Oxford University Press.

Nanos, P. and Schluter, C. (2014). "The composition of wage differentials between migrants and natives", European Economic Review, vol. 65(23).

Noelke, C. (2011). "The consequences of employment protection legislation for the youth labour market”, Working Papers - Mannheimer Zentrum für Europäische Sozialforschung, vol. 144, Mannheim: Mannheimer Zentrum für Europäische Sozialforschung (ZES).

Ochsenfeld, F. (2018). "The Relational Nature of Employment Dualization: Evidence from Subcontracting Establishments", European Sociological Review, vol. 34(3), pp. 304-331.

OECD. (2004). "Employment protection regulation and labour market performance", OECD employment outlook 2004, pp. 61-125, Paris: OECD Publishing.

180 
OECD. (2007). Education at a Glance 2007, Paris: OECD Publishing.

OECD. (2012). Closing the Gender Gap: Act Now, Paris: OECD Publishing, doi: http://dx.doi.org/10.1787/9789264179370-en (last accessed: 20-Mar-2019).

OECD. (2013a). Employment and labour markets: Key tables from OECD, doi: http://dx.doi.org/10.1787/20752342-table9 (last accessed 13-Feb-2018).

OECD. (2013b). OECD skills outlook 2013: First international report of the Survey of Adult Skills (PIAAC), Paris: OECD Publishing.

OECD. (2013c). Benefit \& Wages Replacement Rates, doi: http://www.oecd.org/social/benefits-and-wages.htm (last accessed 02-Jan-2018).

OECD. (2015a). Education at a Glance 2015: OECD Indicators, Paris, OECD Publishing.

OECD. (2015b). OECD skills outlook 2015: Youth, skills and employability, Paris: OECD Publishing.

OECD. (2016a). The survey of adult skills: Reader's companion, Second Edition, OECD Skills Studies, Paris: OECD Publishing. doi: 10.1787/9789264204027-en (last accessed 08-Jan-2019).

OECD. (2016b). Technical report of the Survey of Adult Skills (PIAAC) (2nd Edition), Paris: OECD Publishing.

OECD. (2016c). Skills Matter: Further results from the Survey of Adult skills, OECD Skills Studies, Paris: OECD Publishing, doi: http://dx.doi.org/10.1787/9789264258051en (last accessed 08-Jan-2019).

OECD. (2016d). "ICTS and Jobs: Complements or Substitutes?”, OECD Digital Economy Papers, vol. 259, Paris: OECD Publishing.

OECD. (2016e). Getting skills right: Assessing and Anticipating Changing Skill Needs, Paris: OECD Publishing.

OECD. (2016f). "Skills for a Digital World", OECD Digital Economy Papers, vol. 250, Paris: OECD Publishing.

OECD. (2016g). "New Skills for a Digital Economy", OECD Digital Economy Papers, vol. 258, Paris: OECD Publishing.

OECD. (2016h). PISA 2015 Results (Volume I): Excellence and Equity in Education, PISA, Paris: OECD Publishing.

OECD. (2017). OECD Skills Outlook 2017: Skills and Global Value Chains, Paris: OECD Publishing. 
OECD. (2018). Employment protection annual time series data 1985-2015, doi: https://www.oecd.org/els/emp/EPL-timeseries.xlsx (last accessed 13-Feb-2018).

Oosterbeek, J. (2000). "Introduction to special issue on overschooling", Economics of Education Review, vol. 19(2), pp. 129-130.

Opielka, M. (ed.) (2005). Bildungsreform als Sozialreform. Zum Zusammenhang von Bildungs- und Sozialpolitik, Wiesbaden: Springer VS.

Oreopoulos, P. (2009). "Why do skilled immigrants struggle in the labour market? A field experiment with 600 resumes", American Economic Journal: Economic Policy, vol. 3(4), pp. 148-171.

Palier, B. and Thelen, K. A. (2012). "Dualization and Institutional Complementarities: Industrial Relations, Labor Market, and Welfare State Changes in France and Germany", in (P. Emmenegger, S. Häusermann, B. Palier and M. Seeleib-Kaiser, eds.), The Age of Dualization: The Changing Face of Inequality in Deindustrializing Societies, pp. 201-225, Oxford: Oxford University Press.

Pellizzari, M. and Fichen, A. (2013). "A New Measure of Skills Mismatch, Theory and Evidence from the Survey of Adult Skills (PIAAC)", OECD Social, Employment and Migration Working Papers, no. 153, Paris: OECD Publishing.

Perry, A., Wiederhold, S., and Ackermann-Piek, D. (2014). "How can skill mismatch be measured? New approaches with PIAAC", Methods, Data, Analyses, vol. 8(2), pp. 137-174.

Perry, A. (2017). "Are over-qualified immigrants mismatched according to their actual skills? An international comparison of labor market placement in OECD countries", GESIS Papers, no. 2017/19, Köln: GESIS.

PIAAC Expert Group in Problem Solving in Technology-Rich Environments (2009), "PIAAC Problem Solving in Technology-Rich Environments: A Conceptual Framework", OECD Education Working Papers, no. 36, Paris: OECD Publishing.

Quintini, G. (2011). “Over-Qualified or Under-Skilled: A Review of Existing Literature”, OECD Social, Employment and Migration Working Papers, no. 121, Paris: OECD Publishing.

Quintini, G. (2014), "Skills at Work: How Skills and their Use Matter in the Labour Market”, OECD Social, Employment and Migration Working Papers, no. 158, Paris: OECD Publishing.

Rammstedt, B. (2013). Grundlegende Kompetenzen Erwachsener im internationalen Vergleich: Ergebnisse von PIAAC 2012, Münster: Waxmann. 
Salthouse, T. A. (2006). "Mental exercise and mental ageing: Evaluating the validity of the "use it or lose it" hypothesis", Perspectives on Psychological Science, vol. 1(1), pp. 68-87.

Sanromá, E., Ramos, R., and Simón, H. (2015). "Portability of human capital and immigrant overeducation in Spain", Population Research and Policy Review, vol. 34(2), pp. 223-241.

Schleicher, A. and Thorn, W. (2016). Proposal for an extended module of non-economic outcomes in the second cycle of PLAAC, Internal Memo, Paris: OECD.

Schmid, J. (2010). Woblfahrtsstaaten im Vergleich. Soziale Sicherung in Europa: Organisation, Finanzierung, Leistungen und Probleme, Wiesbaden: Springer VS.

Schmid, J. and Buhr, D. (2015). Wirtschaftspolitik, 2nd edition, Paderborn: UTB.

Schmid, J., Amos, K., Schrader, J., and Thiel, A. (eds.) (2017). Governance und Interdependenz. von Bildung. Internationale Studien und Vergleiche, Baden-Baden: Nomos.

Seibert, H. and Solga, H. (2005). „Gleiche Chancen dank einer abgeschlossenen Ausbildung? Zum Signalwert von Ausbildungsabschlüssen bei ausländischen und deutschen jungen Erwachsenen“, Zeitschrift für Soziologie, vol. 34(5), pp. 364-382.

Sellami S., Verhaest, D., and van Trier, W. (2018). "How to measure field-of-study mismatch? A comparative analysis of the different methods", LABOUR, vol. 32(4), pp. 141-173.

Sesselmeier, W., Funk, L. and Waas, B. (2010). Arbeitsmarkttheorien. Eine ökonomisch-juristische Einführung, 3rd edition, Heidelberg: Springer.

Shavit, Y. and Müller, W. (eds.) (1998). From School to Work. A Comparative Study of Educational Qualifications and Occupational Destinations, Oxford: Clarendon Press.

Sloane, P. J. (2003). "Much ado About Nothing? What does the Overeducation Literature Really Tell us?" in (Büchel, F., A. de Grip and A. Mertens), Overeducation in Europe. Current Issues in Theory and Policy, pp. 11-48, Cheltenham, UK, Northampton, MA: E. Elgar.

Smith, L. R. (ed.) (2013). Higher Education: Recent Trends, Emerging Issues and Future Outlook, New York: Nova Science Publishers.

Smith, C. (2017). "Skill Demands and Development in the Advanced Economies", in (C. Warhurst, K. Mayhew, D. Finegold, and J. Buchanan, eds.), The Oxford Handbook of Skills and Training, pp. 491-508, Oxford: Oxford University Press.

Snijders, T. and Bosker, R. J. (2012). Multilevel analysis. An introduction to basic and advanced multilevel modelling, $2^{\text {nd }}$ edition, Los Angeles: Sage. 
Solomon, W., Polachek, K.. Pouliakas, K., Russo, G., and Tatsiramos, K. (eds.) (2017). Skill Mismatch in Labor Markets, Research in Labor Economics, vol. 45, Emerald Publishing Limited.

Soerensen, A. B., Weinert, F. E., and Sherrod, L. R. (eds.) (1986). Human development and the life course, Hillsdale (NJ): Erlbaum.

Spence, M. (1973). "Job market signalling”, The Quarterly Journal of Economics, vol. 87(3), pp. $355-374$.

Susskind, R. and Susskind, D. (2017). The Future of the Professions: How Technology will transform the work of human experts, Oxford: Oxford University Press.

Van der Velden, R. and Wolbers, M. (2003). "The integration of young people into the labor market within the European Union: the role of institutional settings", in (Müller, W. and M. Gangl, eds), Transitions from Education to Work in Europe: The Integration of Youth into EU Labor Markets, pp.186-211, Oxford: Oxford University Press.

Van der Velden, R. and Verhaest, D. (2017). "Are Skill Deficits Always Bad? Toward a Learning Perspective on Skill Mismatches", in (W. Solomon, K. Polachek, K. Pouliakas, G. Russo, and K. Tatsiramos, eds.), Skill Mismatch in Labor Markets, Research in Labor Economics, vol. 45, pp. 305-343, Emerald Publishing Limited.

Van der Velden, R. and Bijlsma, I. (2018). "Effective skill: A new theoretical perspective on the relation between skills, skill use, mismatches, and wages", Oxford Economic Papers, vol. 71(1), pp. 1-21.

Van Hek, M., Kraaykamp, G., and Wolbers, M. H. J. (2016). "Comparing the gender gap in educational attainment: the impact of emancipatory contexts in 33 cohorts across 33 countries", Educational Research and Evaluation, vol. 22(5-6), pp. 260-282.

Verhaest, D. and van der Velden, R. (2013). "Cross-country Differences in Graduate Overeducation", European Sociological Review, vol. 29(3), pp. 642-653.

Verhaest, D. and Verhofstadt, E. (2016). “Overeducation and job satisfaction. The role of job demands and control", International Journal of Manpower, vol. 37(3), pp. 456-473.

Verhaest, D., Sellami, S., and van der Velden, R. (2017). "Differences in horizontal and vertical mismatches across countries and fields of study", International Labour Review, vol. 156(1), pp. 1-23.

Verhaest, D., Lavrijsen, J., van Trier, W., Nicaise, I., and Omey, E. (2018). "General education, vocational education and skill mismatches: short-run versus long-run effects", Oxford Economic Papers, vol. 70(4), pp. 974-993. 
Vossemer, J. and Schuck, B. (2016). "Better Overeducated than Unemployed? The Shortand Long-Term Effects of an Overeducated Labour Market Re-entry", European Sociological Review, vol. 32(2), pp. 251-265.

Warhurst, C. and Findlay, P. (2012). "More Effective Skills Utilisation: Shifting the Terrain of Skills Policy in Scotland”, SKOPE Research Paper, no. 107, January 2012.

Warhurst, C., Mayhew, K., Finegold, D., and Buchanan, J. (2017). The Oxford Handbook of Skills and Training, Oxford: Oxford University Press.

Warhurst, C., Tilly, C., and Gatta, M. (2017). “A New Social Construction of Skill”, in (C. Warhurst, K. Mayhew, D. Finegold, and J. Buchanan, eds.), The Oxford Handbook of Skills and Training, pp. 72-91, Oxford: Oxford University Press.

Warr, P. (2007). Work, Happiness, and Unhappiness, New York: Routledge.

Warr, P. (2013). "Jobs and job-holders: Two sources of happiness and unhappiness", in (S. A. David, I. Boniwell and A. C. Ayers, eds.), The Oxford Handbook of Happiness, pp. 733-750, Oxford and New York: Oxford University Press.

Warr, P. and Inceoglu, I. (2018). "Work Orientations, Well-Being and Job Content of SelfEmployed and Employed Professionals", Work, Employment and Society, vol. 32(2), pp. 292-311.

Wolbers, M. H. J. (2003). "Job Mismatches and their Labour-Market Effects among School-Leavers in Europe", European Sociological Review, vol. 19, pp. 249-266.

Wolbers, M. H. J. (2007). "Patterns of Labour Market Entry: A Comparative Perspective on School-to-Work Transitions in 11 European Countries", Acta sociologica, vol. 50, pp. 189-210. 



\section{Valorisation Addendum}

Matching the right worker to the right job got increasingly difficult during the last decades. There are various reasons for that, e.g. an increased global competition, changes in the work force qualification level but also the fast and widespread implementation of innovative technologies that alter skills demands of workplaces throughout the occupational structure. Social groups are unequally equipped with the skills and knowledge needed to deal with the profound and irreversible transformation of work and employment. Against this background, the phenomenon of SKILL-TD-JDB MISMATCH - i.e. mismatch between the individual skills supply and skill demands of jobs - has become a matter of scientific concern. While a large body of scientific literature exists, major gaps remain in the understanding of determinants and outcomes of skill (mis-)matches. With my dissertation, I seek to contribute to the creation of knowledge concerning the following research questions: To what extent can the likelihood that workers find a job for which they have the right skills be explained by characteristics of labour market arrangements and education systems? Do skills, skill use, and mismatches have a broader impact on society in terms of non-monetary and potential social outcomes? And what about the increasing adoption of digital technologies at workplaces - to what extent do mismatches in digital problemsolving skills matter for wages? Do shortages in these skills affect all workers in the same way - or are there (new) wage inequalities?

While these desiderata of knowledge are important to fill, linking theoretical concepts of skill-to-job matches to valid empirical indicators is still work in progress. Therefore, the first part of my dissertation is dedicated to a comprehensive theoretical framework, which I outline in CHAPTER 2. It is followed by a series of empirical studies, providing new crosscountry evidence for macro level determinants and individual outcomes of skill-to-job (mis)matches. CHAPTER $\mathbf{3}$ explores the macro-micro link between social policies and optimal skill

matching. In CHAPTER 4, I investigate non-monetary and potential social outcomes that are related to skill mismatches. Exploring the importance of skill use and the individual experiences at work, I thereby make use of several distinct mismatch measures. CHAPTER $\mathbf{5}$ examines digital problem-solving skills, particularly investigating shortages in these skills and wage inequalities. To sum up, CHAPTER $\mathbf{6}$ provides an overall conclusion and comprehensive discussion, highlighting the most relevant findings as well as their (policy) 
implications while evaluating limitations of my analyses and providing recommendations for further research. My research is cross-national, using data from OECD's Programme for the International Assessment of Adult Competencies (PIAAC). This recent survey provides internationally comparable measurements of skill proficiency in key informationprocessing skills and the use of these skills at work for representative samples of the workforces of more than 30 industrial countries. As there is no common conceptual approach to measure skill matches/mismatches, I make use of several different skill mismatch measures. Using skill matches and mismatches as dependent and independent variable, I provide new cross-country evidence based on advanced statistical modelling.

The findings of this dissertation are valuable to policy makers, the academic community, organisations and institutions as well as policy makers, next to individuals. However, what are the most VALUE-ADDED AND DRIGINAL PARTS of my research? The first addendum relates to the examination of the macro-micro link between social policies and skill matching at the individual level. My research provides new insights for PDLICY MAKERS as it reveals opposite outcomes of enforcing vs. enabling activating labour market policies (ALMPs): Strict enforcement is associated with more skill mismatch, while enabling policies may serve as a lever to promote skill-based worker-job matches, which is important for a productive use of skills and talent. Particularly for the current episode of great changes in skill demands strict enforcement does not help to allocate the right workers to the right jobs, whereas enabling services seem to be more promising as it appears that these policies seem to promote skill matching. As employers and - in aggregate - economies can profit from a full and productive use of skills and talent, this is important knowledge for policy makers at different levels and institutions. Knowledge about heterogenous outcomes of enforcing versus enabling activating labour market policies could furthermore help to structure the political debate and inform policy makers about the optimal design of redistributive as well as activating policy measures. However, it is not advisable to directly apply the findings of this dissertation. Before this can be done, more research must be conducted. This includes, for example, studies that establish the causal effects of social policies on individual labour market outcomes. Nevertheless, academic knowledge and evidence-based decision making can help to create acceptance of these policies. The findings of the thesis at hand are a first step towards understanding the relation between social policies and the phenomenon of skill matching.

My dissertation also provides original insights for ACADEMIA as it shows the need for more and better composite policy indicators that help to differentiate policies in a more finegrained way when investigating the diverse mix of activating measures are at the heart of central labour market reforms that took and still take place in many countries. This brings 
me to the second addendum: the new insights that I provide concerning employment protection legislation and their relation with individual labour market outcomes. While it is a long standing finding that the regulation of the dismissal process also affects employers' hiring decision making, my findings add a new aspect to the discussion, namely the positive relation between EPL and skill matching. This is important knowledge for both policy makers and scientists as, at least to my knowledge, this relation has not been studied before. The third addendum lays in the provision of new empirical evidence based on the new van der Velden/Bijlsma (2018) 'effective skill measure', which can be of use for further research in this field. The 'effective skill'-logic is key for understanding the relation between skills, skill use, mismatches and outcomes as it pinpoints the importance of skill use at work as a crucial dimension of quality of working life. Besides, the comparison of the commonly used skill mismatch measures shows that the choice of the approach must be made carefully as the available measures are not interchangeable. The empirical findings presented in this thesis provide evidence that the dependent variable should determine the choice of a mismatch measure.

Understanding the importance of a full and productive use of the own skills and talent can inform organisational development and firm-based policies, particularly (but not exclusively) in times of great change due to digitalisation and/or the implementation of intelligent machines and process automation at workplaces. Related to this, the fourth addendum is also relevant for DRGANISATIDNS AND DECISIDN MAKERS AT THE FIRM LEVEL. Job satisfaction is driven by skill use, not skill proficiency or mismatches. Two policy implications can be drawn from this: (1) Policies addressing job satisfaction should focus on skill utilisation rather than primarily on the issue of overskilling; and (2) policies, particularly but not exclusively at the level of firms and managerial practices, should promote the full use skills and talent, designing workplaces and also training mechanisms in a way that allows workers to do what they are best at. This knowledge could be relevant for firm level policies that seek to promote a positive employee experience.

Skill use and skill matching may have a broader impact, also outside the work environment. Here, my thesis provides interesting insights for DEMDCRACIES AND CIVIL SDCIETIES based on the fifth addendum, which lies in the empirical evidence that skills, skill use and mismatches are related to psychological orientations and values that are important even outside the work environment and that - in aggregate - are vital for societies and democracies. However, while these analyses are congruent with theoretical expectations, they cannot proof the theory to be true. Further research is necessary to give more detailed policy implications. 
The sixth addendum is related to the importance of digital problem-solving skills. Against the background of recent labour market developments, these skills are very likely to become more important, which is why education but also enabling labour market policies should focus on a broad promotion of these key skills, including them into EDUCATION SYSTEMS AND WORKPLACE TRAINING SCHEMES. Particularly, women, low educated (that may also be highly affected by innovative technologies) and other social groups and individuals that find themselves in adverse labour market situations should get access to training in digital problem-solving skills. This is an important policy implication, as increasing labour market inequality (e.g. related to shortages in digital problem-solving skills) is to be expected if a further development of these skills is not broadly promoted. Designing policies to foster the development and distribution of digital problem-solving skills particularly for vulnerable groups at the labour market, such as women, migrants, and low educated and/or low skilled workers may help to effectively tackle rising inequality. The challenges of the knowledge economy and changing demands for skills in times of digitalisation and automation require new and more insights into skill matching and individual labour market outcomes, and new cross-country evidence for adult workforces. Moreover, the promotion of research in this field could help to co-create policies that effectively tackle social inequality and help foster economic development as well as social cohesion. 


\section{English Abstract}

SKILL MATCHING - i.e. the match between skills supply and labour market demands - has become a persistent matter of analytical concern. In the last decades, the increased global competition and changes in the work force qualification level have led to a labour market situation, where it got increasingly difficult to find the right worker for the right job. In Europe and beyond, the phenomenon of skill-to-job mismatch is found to be pervasive, widespread, and with significant consequences for individuals, economies and societies. Research has shown that with technological innovations, the incidence of mismatch is more likely to increase than to improve. Although there is a large body of scientific literature, major questions concerning skill-to-job matching and related outcomes still lack answers. My thesis sets out to fill several gaps, providing new knowledge and cross-country evidence for the adult workforces of 30 industrial countries.

I first develop a CDMPREHENSIVE THEDRETICAL FRAMEWDRK, providing details about the concepts, approaches and measurements needed for theoretical considerations about determinants and outcomes of skill-to-job (mis)matches and theory-based empirical research. With a series of empirical chapters, I then explore macro level determinants and micro level outcomes of skill-to-job matches across countries. My research is based on the Survey of Adult Skills from the OECD's Programme for the International Assessment of Adult Competencies (PIAAC). This recent survey provides unique and high-quality measurements of individual skill proficiency and skill use for representative samples of the workforces of a large number of industrialised countries. Conducting cross-national empirical studies, the main source of evidence are multilevel mixed-effects regression models, using skill-to-matches as dependent or independent variable.

With a special focus on differences between labour market insiders and outsiders, the FIRST EMPIRICAL CHAPTER investigates the extent to which job-worker matches are associated with the institutional setup of school systems, employment protection legislation (EPL), unemployment benefits, and activating labour market policies. I make use of well-known policy indicators as provided by the OECD, but furthermore resort to a composite indicator that captures the mix of enforcing and enabling labour market policies. With these analyses, I can provide evidence for two things that we did not know before: First, higher EPL is associated with more skill matching. This is a very robust finding. A possible 
explanation may be that the regulation of the firing process is also relevant when it comes to hiring. Because the costs of dismissals are so high in countries with strict job security provision such as EPL, employers make sure to allocate the right person to the right job (either directly or through extra on-the-job training). Second, my analyses show that it is insightful to use indicators other than those usually tested: I provide cross-country evidence that strict enforcement does not lead countries into the right direction when it comes to skill-to-job matching as it is associated with more skill mismatch. Strict enforcing policies force people into employment, e.g. because turning down a job offer would lead to sanctions in unemployment benefits. In countries with strict enforcement, workers therefore have to either stay in a job or take up a job, even if that job does not match their skills. Strict enforcement appears to have adverse effects concerning skill-based worker-job matches.

The SECDND EMPIRICAL CHAPTER departs from the observation that the academic interest in skills and mismatches rests, at least partly, upon the concern that skills are not only vital for the proper functioning of labour markets and economies, but also for societies and democracies. I investigate job satisfaction and potential social outcomes of skill mismatches. Exploring the importance of skill use, skill-based job-worker mismatches, and the relation between individual experiences at work and individual psychological orientations and values. I combine classical theoretical reasoning with advanced statistical modelling based on recent and internationally comparable micro data for representative samples of the work forces of 30 countries. Thereby, I make use of different skill mismatch measures, including a new measure for the skill match, the 'effective skill' model as developed by van der Velden and Bijlsma (2018). I contribute to the literature by shedding new light on old findings about job satisfaction. What was not known before is this: Once I use objective indicators for the skill match (and I make use of all measures that are currently available), there is no relation between overskilling and job satisfaction - not even if I look at young entrants to the labour markets only or when I include wages and other relevant micro level confounders that are known to be related to job satisfaction. In fact, job satisfaction is driven by skill use, not by proficiency or mismatches. With this, I contradict previous results. Why? There are two major reasons: The first reason is that previous studies often relied on worker' subjective assessment of the skill match due to a lack of objective measures before the PIAAC survey was conducted. The second reason lies in the model specification. Previous studies often do not appropriately control for skill requirements of jobs using theory-driven matching models.

My analyses also provide new insights into the broader impact of skills and mismatches outside the work environment. This link is established in the literature: E.g. Kohn and Schooler (1983) have shown empirically that the experience e.g. of an effective use of one's 
own skills contributes to an orientation that allows the worker to see society as so constituted that individual efficacy is both possible and useful. As work, society and self are distinct but entangled aspects of reality, spill over effects can be expected to shape the perception of the own efficacy also in other domains of life, such as the political system. The experience of self-direction and efficacy at work may furthermore contribute to an open and flexible orientation towards others, forming the basis for social trust. Accordingly, workers that can fully exploit their skills are more likely to approve a positive perception of political efficacy and trust in other people.

The THIRD EMPIRICAL CHAPTER is dedicated to recent developments concerning the increasing adoption of digital technologies at workplaces, recognising that problem-solving skills are key to ensure that workers remain both productive in labour markets and included societies. While increasing automation is thought to further exacerbate the importance of digital problem-solving skills, evidence suggests that shortages in these skills are widespread. How does the digital skills divide translate into group-specific returns to skills? Will wage inequalities related to gender, age, migration background, socio-economic status or educational achievement be exacerbated or reduced? A thorough assessment of social inequalities is the main gap in the literature surrounding digital skills. With this chapter, I assess how the digital skills divide translates into group-specific returns to skills and mismatches. Based on classical sociological reasoning concerning human capital theory and labour market discrimination, I systematically compare sub-groups of workers. These groups are defined by socio-economic status, gender, age, educational attainment and migration background. Doing so, my analyses help to fill the main gap in the literature concerning digital skills: a thorough assessment of social inequalities. Drawing on PIAAC micro data, I build a skill matching model to show that skill-to-job matches in digital problem-solving skills matter for wages: shortages are damaging, while a skills surplus is profitable. However, digital problem-solving skills re-shape wage inequalities with the potential to serve as an emancipatory lever, narrowing the divide between socio-economic status groups. These key skills may also help to reduce the gender wage gap, as high levels of digital problem-solving skills appear to pay off more for women than for men. 



\section{Nederlandse Samenvatting}

SKILL MATCHING - ofwel de aansluiting tussen het aanbod van vaardigheden en de vraag op de arbeidsmarkt - is een hardnekkige kwestie waarvan het belang in afgelopen decennia is toegenomen. De intensivering van de wereldwijde concurrentie en de veranderingen in het kwalificatieniveau van de beroepsbevolking hebben geleid tot een situatie op de arbeidsmarkt waarin het steeds moeilijker is geworden om de juiste werknemer voor de juiste baan te vinden. In Europa en daarbuiten is 'skill-to-job mismatch' - ofwel een discrepantie tussen vaardigheden en baan - een diepgaand fenomeen dat aanzienlijke gevolgen heeft voor individuen, economieën en maatschappijen. Uit onderzoek blijkt dat het aantal gevallen van dergelijke mismatches waarschijnlijk eerder zal toenemen dan verbeteren als gevolg van technologische innovaties. Ondanks de grote hoeveelheid wetenschappelijke literatuur over dit onderwerp, zijn er nog altijd geen antwoorden op belangrijke vragen met betrekking tot skill-to-job matching. Met dit proefschrift beoog ik een aantal van deze hiaten in de literatuur te dichten door nieuwe wetenschappelijke inzichten te leveren over mismatches onder de volwassen beroepsbevolking van 30 verschillende industrielanden.

Ten eerste ontwikkel ik een uitgebreid THEDRETISCH KADER waarin wordt ingegaan op de concepten, benaderingen en maatstaven die nodig zijn voor empirisch onderzoek naar de determinanten en gevolgen van skill-to-job (mis)matches. Vervolgens bestudeer ik in een reeks van hoofdstukken de determinanten op macroniveau en gevolgen op microniveau van skill-to-job matches in verschillende landen. Mijn onderzoek is gebaseerd op de enquête over vaardigheden van volwassenen van het OESO-programma voor de internationale beoordeling van competenties van volwassenen (PIAAC). Deze onlangs uitgezette enquête biedt unieke en hoogwaardige maatstaven van individuele vaardigheidsbeheersing en vaardigheidstoepassing onder representatieve steekproeven van de beroepsbevolking van een groot aantal industrielanden. Bij het uitvoeren van internationale empirische studies wordt de belangrijkste bron van bewijs gevormd door zogenoemde multilevel mixed-effects regressiemodellen, waarbij skill-to-job matches worden gebruikt als afhankelijke of onafhankelijke variabele.

In het EERSTE EMPIRISCHE HDOFDSTUK wordt onderzocht in welke mate de aansluiting tussen banen en werknemers samenhangt met de institutionele opzet van onderwijssystemen, wetgeving op het gebied van werknemersbescherming, werkloosheidsuitkeringen en 
activerend arbeidsmarktbeleid. In deze studie wordt een specifieke focus gelegd op de verschillen tussen jongere en oudere werknemers. Ik maak niet alleen gebruik van bekende beleidsindicatoren, verstrekt door de OESO, maar ook van een samengestelde indicator die een mix van handhavend en faciliterend arbeidsmarktbeleid weerspiegelt. Op basis van deze analyses komen twee boodschappen naar voren. Ten eerste is er een verband tussen een sterkere wetgeving voor de bescherming van werknemers en een hogere mate van skill matching. Een mogelijke verklaring voor dit verband is dat de regeling omtrent de ontslagprocedure bepalend is voor de rekrutering van personeel. De hoge kosten die gepaard gaan met ontslaan van werknemers geven werkgevers een prikkel om een goede aansluiting tussen de vaardigheden van werknemers en banen tot stand te brengen. Ten tweede blijkt uit mijn analyses dat het gebruik van andere indicatoren dan gewoonlijk verhelderend werkt: ik lever internationaal bewijs dat strikte handhaving van arbeidsmarktbeleid niet resulteert in een hogere mate van skill mismatch. Dergelijk beleid zorgt ervoor dat mensen worden gedwongen om snel werk te vinden, bijvoorbeeld omdat het afwijzen van een baanaanbod zou leiden tot een sanctie inzake de werkloosheidsuitkering. In landen met strikte handhaving moeten werknemers daarom ofwel hun baan behouden ofwel een baan aannemen, zelfs als deze baan niet aansluit bij hun vaardigheden.

In het TWEEDE EMPIRISCHE HODFDSTUK komt naar voren dat de wetenschappelijke interesse in vaardigheden en mismatches ten minste gedeeltelijk voortkomt uit het feit dat vaardigheden niet alleen essentieel zijn voor het goed functioneren van arbeidsmarkten en economieën, maar ook voor maatschappijen en democratieën. In dit hoofdstuk bestudeer ik werktevredenheid en de mogelijke maatschappelijke gevolgen van skill mismatches. Door het belang van vaardigheidstoepassing, mismatches en de relatie tussen de ervaringen op het werk en de psychologische houdingen van individuen te onderzoeken, combineer ik klassieke theoretische modellen met geavanceerde statistische technieken op basis van onlangs verkregen microdata. Ik maak gebruik van verschillende methoden om skill mismatch te meten, waaronder een nieuwe meetmethode: het 'effective skill'-model dat is ontwikkeld door Van der Velden en Bijlsma (2018). Ik draag bij aan de literatuur over dit onderwerp door nieuw licht te werpen op bestaande bevindingen over werktevredenheid. Wat we voorheen niet wisten, is het volgende: zodra ik gebruikmaak van objectieve indicatoren van skill match (en ik maak gebruik van alle meetmethoden die op dit moment beschikbaar zijn), is er geen verband tussen overkwalificatie en werktevredenheid - zelfs niet als ik uitsluitend kijk naar jonge nieuwkomers op de arbeidsmarkt of wanneer ik relevante verstorende variabelen op microniveau, zoals lonen, meeneem in de analyse. Integendeel, werktevredenheid wordt bepaald door vaardigheidstoepassing, niet door bekwaamheid of mismatches. Dit is in strijd met eerdere bevindingen. Waarom? Er zijn 
twee belangrijke redenen: ten eerste berustten eerdere studies dikwijls op subjectieve beoordelingen van de skill match door de werknemer, vanwege een gebrek aan objectieve meetresultaten voordat de PIAAC-enquête werd uitgevoerd. De tweede reden houdt verband met de modelspecificatie. In eerdere studies werd dikwijls niet voldoende rekening gehouden met de vaardigheidseisen van banen bij het gebruik van theoriegestuurde matchingmodellen. Mijn analyses bieden ook nieuwe inzichten in de bredere invloed van vaardigheden en mismatches buiten de werkomgeving. Dit verband is vastgelegd in de literatuur: zo hebben Kohn en Schooler (1983) empirisch aangetoond dat, bij een werknemer die ervaart dat hij/zij bijvoorbeeld effectief gebruikmaakt van zijn eigen vaardigheden, dit gevoel bijdraagt aan een houding waardoor hij/zij in staat is om de maatschappij te zien als een stelsel waarin individuele effectiviteit zowel mogelijk als nuttig is. Aangezien werk, maatschappij en 'zelf' afzonderlijke maar met elkaar verweven aspecten van de werkelijkheid zijn, kunnen hiervan uitstralingseffecten worden verwacht die het beeld beïnvloeden dat het individu heeft van zijn eigen effectiviteit op ook andere levensgebieden, zoals het politieke systeem. De ervaring van zelfsturing en zelfeffectiviteit op het werk kan tevens bijdragen aan een open en flexibele houding ten opzichte van anderen, wat de basis voor maatschappelijk vertrouwen vormt. Zodoende zijn werknemers die hun vaardigheden ten volle kunnen benutten, eerder geneigd om een positief beeld van politiek zelfvertrouwen te hebben en vertrouwen in anderen te hebben.

Het DERDE EMPIRISCHE HODFDSTUK is gewijd aan recente ontwikkelingen met betrekking tot het toenemende gebruik van digitale technologieën op de werkplek, waarbij probleemoplossende vaardigheden als essentieel worden beschouwd om ervoor te zorgen dat werknemers zowel productief op de arbeidsmarkt als opgenomen in de maatschappij blijven. Hoewel de toenemende automatisering naar verwachting het belang van digitale probleemoplossende vaardigheden verder zal vergroten, lijkt er een grootschalig tekort aan dergelijke vaardigheden te zijn. Hoe vertaalt de kloof in digitale vaardigheden zich naar het groepspecifieke rendement op vaardigheden? Zullen loonongelijkheden met betrekking tot geslacht, leeftijd, migratieachtergrond, sociaaleconomische status of onderwijsprestaties verergeren of verminderen? Een grondige beoordeling van maatschappelijke ongelijkheden vormt de grootste lacune in de literatuur over digitale vaardigheden. In dit hoofdstuk ga ik na hoe de kloof in digitale vaardigheden zich verhoudt tot het groepspecifieke rendement op vaardigheden en mismatches. Op basis van klassieke sociologische theorieën over menselijk kapitaal en discriminatie op de arbeidsmarkt, vergelijk ik op systematisch wijze subgroepen van werknemers. Deze groepen worden gedefinieerd door sociaaleconomische status, geslacht, leeftijd, opleidingsniveau en migratieachtergrond. Op deze manier kan ik met mijn analyses de belangrijkste lacune in de literatuur over digitale vaardigheden dichten: een grondige beoordeling van maatschappelijke ongelijkheden. Op basis van PIAAC- 
microdata creëer ik een skill matching-model om aan te tonen dat skill-to-job matches op het gebied van digitale probleemoplossende vaardigheden van belang zijn voor lonen: een tekort is schadelijk, terwijl een overschot aan vaardigheden voordelig is. Echter, digitale probleemoplossende vaardigheden geven loonongelijkheden een nieuwe vorm en kunnen mogelijk fungeren als emancipatorische hefboom, waardoor de kloof tussen sociaaleconomische statusgroepen kleiner wordt. Met behulp van deze essentiële vaardigheden zou tevens de loonkloof tussen mannen en vrouwen kunnen worden verkleind, aangezien een hoog niveau van digitale probleemoplossende vaardigheden meer lijkt te lonen voor vrouwen dan voor mannen. 


\section{Deutsche Zusammenfassung}

SKILL MATCHING - die Passung der Kompetenzen individueller Beschäftigter zu den Kompetenzanforderungen ihres jeweiligen Arbeitsplatzes - hat sich in unterschiedlichen Disziplinen zu einem wichtigen Forschungsthema entwickelt. Der verschärfte globale Wettbewerb und ein im Durchschnitt steigendes Qualifikationsniveau der Erwerbsbevölkerung haben es den letzten Jahrzehnten erschwert, die richtigen Beschäftigten für die richtigen Arbeitsplätze $\mathrm{zu}$ finden. Stimmen die Kompetenzanforderungen eines Arbeitsplatzes und die vorhandenen Kompetenzen des*der Arbeitnehmer*in nicht überein, spricht man von skill mismatch oder skill-to-job mismatch. Im Gegensatz zu education mismatch bezieht sich skill mismatch nicht auf formale Über- oder Unterqualifikation, sondern auf die Differenz zwischen tatsächlich vorhandenen und am Arbeitsplatz nachgefragten Kompetenzen.

In Europa und darüber hinaus ist das Phänomen des skill mismatch relativ weit verbreitet. Der mismatch zwischen Kompetenz und Anforderung hat erhebliche Auswirkungen auf Arbeitnehmer und Arbeitnehmerinnen, aber auch auf Volkswirtschaften und Gesellschaften: Mangelnde Passung erlaubt es Arbeitnehmer*innen nicht, ihr Potenzial adäquat auszuschöpfen. Und sie erlaubt es Gesellschaften nicht, das Potenzial, das ihnen durch ihre Arbeitskräfte zur Verfügung steht, voll zu nutzen und in Wirtschaftswachstum und gesellschaftlichen Fortschritt zu überführen. Wissenschaftliche Untersuchungen zeigen, dass vor dem Hintergrund technologischer Innovationen und digitalen Wandels die Häufigkeit von skill mismatch eher zu- als abnimmt. Fähigkeiten und Kenntnisse, die erforderlich sind, um mit den tiefgreifenden und unumkehrbaren qualitativen Veränderungen von Arbeit und Beschäftigung schritthalten zu können, sind dabei zwischen sozialen Gruppen von Erwerbstätigen ungleich verteilt. Der Wettlauf zwischen sich wandelnden Kompetenzanforderungen auf der einen Seite und dem Angebot von Qualifikationen und Kompetenzen auf der anderen Seite ist eine der zentralen Herausforderung und Gestaltungsaufgaben unserer Zeit - nicht zuletzt, wenn es darum geht, eine Zunahme sozialer Ungleichheit zu verhindern. Trotz vieler Studien und des hohen Interesses an der Thematik, sind zentrale Fragen zu Ursachen und Folgen von skillto-job (mis-)matches noch unbeantwortet. Meine Dissertation zielt darauf ab, mehrere Forschungslücken zu schließen und neues Wissen auf Basis international vergleichbarer Daten für 30 Industrieländer zu generieren. 
Zunächst entwickle ich den THEDRETISCHEN RAHMEN, der Details und Hintergründe aller Konzepte, Ansätze und Messmethoden liefert, die für die theoretisch-fundierte, empirische Erforschung und Modellentwicklung erforderlich sind. Darauf aufbauend untersuche ich mit einer Reihe von empirischen Studien die Determinanten und Auswirkungen von skill (mis-)matches sowie das Zusammenspiel von Makro- und Mikroebene. Meine Forschung basiert auf Daten des 'OECD Programme for the International Assessment of Adult Competencies' (OECD Survey of Adult Skills, PIAAC). Dieser Survey liefert neue und qualitativ hochwertige, objektive Messungen des individuellen Qualifikationsniveaus und der Nutzung von Kompetenzen am Arbeitsplatz für repräsentative Stichproben der 16-65jährigen Erwerbsbevölkerung aus über 30 Ländern.

DIE ERSTE EMPIRISCHE STUDIE im Rahmen meiner Dissertation untersucht das Zusammenspiel zwischen Sozialpolitik und optimalem skill matching: Wie hängt skill matching mit dem institutionellen Aufbau von Schulsystemen, der Gesetzgebung zum Kündigungsschutz (EPL), Regelungen zu Arbeitslosengeld und sozialer Absicherung sowie mit Maßnahmen aktivierender Arbeitsmarktpolitik zusammen? Mit dieser Studie lege ich besonderen Fokus auf die Unterschiede zwischen jungen Arbeitsmarkteinsteiger*innen und etablierten Arbeitnehmer*innen (das heißt zwischen Arbeitsmarktoutsidern und -insidern) und untersuche die Wirkung wohlfahrtsstaatlicher Arrangements mit Blick auf optimales skill matching. Für die Modellentwicklung greife ich auf die oft genutzten Makroindikatoren zurück, die zum Beispiel von der OECD zur Verfügung werden. Darüber hinaus nutze ich Indikatoren, die die arbeitsmarktpolitische Mischung aus Verhaltensregeln für Leistungsbezieher und Sachleistungen (wie zum Beispiel Arbeitsvermittlung) quantifizieren (Knotz, 2012). Diese Indikatoren erlauben eine Differenzierung von Rechten und Pflichten von Arbeitslosen und ermöglichen eine Analyse der differenzierenden Wirkungen von ,fördernden“ und ,fordernden` Instrumenten der aktivierenden Arbeitsmarktpolitik.

Die Studie liefert zwei zentrale Erkenntnisse. Erstens belegt sie einen positiven statistischen Zusammenhang zwischen Kündigungsschutz und skill matches am Arbeitsplatz. Je höher der Kündigungsschutz, desto höher die Wahrscheinlichkeit von skill-to-job matches. Dieses robuste Ergebnis wird durch diverse Sensitivitätsanalysen gestützt. Als Erklärung ziehe ich in Betracht, dass gesetzliche Regelungen zum Kündigungsschutz auch im Einstellungsprozess relevant sind: Je höher die Kosten, die der*die Arbeitgeber*in für den Fall einer Entlassung zu erwarten hat, desto eher neigen Arbeitgeber*innen dazu, die Passung zwischen Arbeitnehmer*in und Arbeitsplatz bereits im Einstellungsprozess sicherzustellen oder durch qualifizierende Maßnahmen zu verbessern. Ein zweites zentrales Ergebnis meiner Analysen bezieht sich auf den Mehrwert der Nutzung anderer als der gängigen Makroindikatoren: Durch die Nutzung von Indikatoren, die die 
wohlfahrtsstaatliche Mischung aus Zwangs- und Fördermaßnahmen im Rahmen aktivierender Arbeitsmarktpolitik quantifizieren, kann ich zeigen, dass der Zwang zur Arbeitsmarktbeteiligung mit einem höheren Anteil von skill mismatches korreliert. In Ländern mit strenger Durchsetzung müssen Arbeitnehmer*innen eher entweder einen Arbeitsplatz behalten oder einen Arbeitsplatz annehmen, auch wenn dieser Arbeitsplatz nicht ihren Kompetenzen entspricht. Während ,fordernde‘ Maßnahmen negativ mit skillto-job matching korrelieren, gilt für ,fördernde‘ Maßnahmen tendenziell das Gegenteil.

DIE ZWEITE EMPIRISCHE STUDIE setzt an der Beobachtung an, dass das akademischwissenschaftliche Interesse an skill-to-job mismatches zumindest teilweise auf der Sorge beruht, dass Kompetenzen und die Passung zum Arbeitsplatz nicht nur relevant für das reibungslose Funktionieren von Produktionssystemen und Volkswirtschaften sind, sondern auch für Gesellschaften und funktionierende Demokratien. Davon ausgehend untersuche ich Arbeitszufriedenheit als einen zentralen Aspekt von Arbeitsqualität und mögliche soziale Auswirkungen von skill mismatches. Um die Bedeutung von skill matching und den Zusammenhang zwischen individuellen Erfahrungen am Arbeitsplatz und psychologischen Orientierungen und Werthaltungen zu erforschen, kombiniere ich klassische theoretische Ansätze mit statistischen Modellen. Ich benutze verschiedene Verfahren zur Messung des skill-to-job matching, darunter ein neues Maß, das von van der Velden und Bijlsma (2018) entwickelte ,effective skill'-Modell.

Mein Beitrag zum Stand der Forschung liegt unter anderem darin, neues Licht auf bestehende Erkenntnisse zu Arbeitszufriedenheit zu werfen. Im Gegensatz zu vorherigen Studien kann ich auf Basis meiner Forschung zeigen, dass kein Zusammenhang besteht zwischen Über- bzw. Unterqualifikation (skill mismatches) und Arbeitszufriedenheit, wenn die Messung auf Basis objektiver und valider Indikatoren für die Kompetenzpassung basiert. Dies gilt auch, wenn das Sample auf junge Berufsanfänger*innen reduziert wird und wenn Löhne und andere relevante Einflussgrößen auf der Mikroebene im Modell kontrolliert werden. Tatsächlich wird die Arbeitszufriedenheit durch die Nutzung tatsächlich vorhandener Kompetenzen am Arbeitsplatz und nicht durch das Kompetenzniveau als solches oder einen mismatch bestimmt. Dies steht im Widerspruch zum Stand der Forschung. Warum? Ich diskutiere zwei Gründe für diesen Widerspruch: Erstens stützten sich frühere Studien oft auf die subjektive Wahrnehmung der Qualifikationspassung durch die Befragten - und nicht auf objektive Messungen auf Basis von Kompetenztests, wie sie für Erwachsene erstmals im Rahmen von PIAAC international vergleichend durchgeführt wurden. Eine Korrelation zwischen zwei subjektiv gemessenen Indikatoren ist jedoch endogen: wenn Beschäftigte sich zum Beispiel unterfordert fühlen, fühlen sie sich auch unzufriedener. Dieser Zusammenhang zwischen subjektiven Größen sagt allerdings noch nichts aus über den Zusammenhang zwischen 
einem objektiven skill mismatch und Arbeitszufriedenheit. Der zweite Grund liegt in der Modellspezifikation: Frühere Studien kontrollieren den Qualifikationsbedarf von Arbeitsplätzen oft nicht angemessen mit Hilfe von theoriebasierten Matching-Modellen und können daher Auswirkungen von mismatches nicht adäquat erfassen.

Darüber hinaus liefert meine Forschung neue Erkenntnisse über soziale und (im Aggregat) potenziell gesellschaftliche Auswirkungen von Kompetenzen und skill-to-job mismatches. Dieser Zusammenhang findet sich bereits in der klassischen soziologischen Literatur (u.a. Kohn und Schooler, 1983). Frühere Forschung zeigt, dass die Erfahrung von (Selbst)Wirksamkeit, zum Beispiel durch den Einsatz der eigenen Fähigkeiten und Kompetenzen am Arbeitsplatz, dazu beiträgt, dass Menschen eine innere Haltung entwickeln, die es ihnen ermöglicht, Gesellschaft als so zu konstituiert betrachten, dass individuelle Wirksamkeit sowohl möglich als auch nützlich ist. Kurz gesagt: Wer in einen Bereich der Gesellschaft (zum Beispiel bei der Arbeit) die Erfahrung macht, dass er*sie wirksam sein kann, neigt eher dazu, von der eigenen Wirksamkeit auch in anderen Bereichen (wie zum Beispiel dem politischen System) überzeugt zu sein. Arbeitswelt, Gesellschaft und Selbst sind unterschiedliche, aber verschränkte Aspekte der Realität, die sich wechselseitig beeinflussen. Daher besteht ein Zusammenhang zwischen der Erfahrung der eigenen Wirksamkeit, beispielsweise am Arbeitsplatz, und der Wahrnehmung der eigenen Wirksamkeit in anderen Lebens- und Gesellschaftsbereichen, wie zum Beispiel dem politischen System. Die Erfahrung von Selbstwirksamkeit am Arbeitsplatz kann zudem zu einer offeneren und flexibleren Haltung gegenüber anderen Menschen beitragen und so die Grundlage für soziales Vertrauen bilden, das seinerseits wichtig für eine lebendige Demokratie ist.

DIE DRITTE EMPIRISCHE STUDIE widmet sich aktuellen technologischen Entwicklungen im Zusammenhang mit dem Einsatz digitaler Technologien am Arbeitsplatz. Ausgangspunkt ist die Beobachtung, dass digitale Problemlösekompetenz, das heißt die Kompetenz zur Lösung von Problemen mittels digitaler Technologie, für die Sicherstellung nachhaltiger Beschäftigungsfähigkeit und gesellschaftlicher Integration von Arbeitnehmer*innen von zentraler Bedeutung ist. Während davon ausgegangen wird, dass die Bedeutung digitaler Problemlösungskompetenzen durch Digitalisierung und Automatisierung weiter zunimmt, zeigen wissenschaftliche Studien, dass ein Mangel an diesen Kompetenzen (,underskilling) relativ weit verbreitet ist. Was bedeutet das für soziale (Un-)Gleichheit? Sind Bildungsrenditen gruppenspezifisch ungleich verteilt? Werden sich die Lohnunterschiede in Bezug auf Geschlecht, Alter, Migrationshintergrund, sozioökonomischen Status oder Bildungsabschluss verschärfen oder verringern? Eine systematische Untersuchung des Zusammenhangs zwischen digitalen Kompetenzen und sozialer Ungleichheit ist eine zentrale Lücke im aktuellen Stand der Forschung. 
Meine Dissertation setzt hier an und untersucht Zusammenhänge zwischen digitalen Kompetenzen und Löhnen im internationalen Vergleich. Basierend auf Humankapitaltheorie und der Theorie der statistischen Diskriminierung vergleiche ich systematisch soziale Gruppen von Erwerbstätigen. Diese Gruppen werden nach sozioökonomischem Status, Geschlecht, Alter, Bildungsabschluss und Migrationshintergrund definiert. Auf der Grundlage von PIAAC-Mikrodaten erstelle ich ein skill-matching-Modell, mit dem sich empirisch zeigen lässt, dass die Passung zwischen digitalen Problemlösekompetenzen und den Arbeitsplatzanforderungen für die Löhne relevant ist: ein Mangel an digitalen Kompetenzen wirkt sich negativ auf das Lohnniveau aus, während ein Qualifikationsüberschuss profitabel ist. Digitale Problemlösekompetenz steht zudem in Zusammenhang mit Lohnungleichheit. Meine Analysen zeigen, dass digitale Problemlösekompetenzen als eine Art „emanzipatorischer Hebel“ wirken und dazu beitragen können, Lohnungleichheiten zum Beispiel zwischen sozioökonomischen Statusgruppen zu verringern. Im Zeitalter der Digitalisierung ist digitales Problemlösen eine Schlüsselkompetenz, die zudem dazu beitragen kann, das Lohngefälle zwischen den Geschlechtern zu verringern, da sich ein hohes Maß an digitalen Problemlösekompetenzen für Frauen mehr auszahlt als für Männer. 



\section{Author Biography}

MARIE-CHRISTINE FREGIN was born in October 1984 in Stuttgart, Germany. She studied Sociology, Political Science and Geography at the University of Tübingen, Germany, and at the Benemérita Universidad Autónoma de Puebla in Puebla, Mexico.

Starting in 2017, she did her PhD as external candidate at the Research Centre for Education and the Labour Market (ROA) at Maastricht University. Her research focuses on skill matching and outcomes as well as on adult education, digital skills, and the effects of the implementation of Artificial Intelligence (AI) at workplaces for workers and jobs.

In April 2019, she started a position as Postdoctoral Research Fellow at the Wissenschaftszentrum Berlin (WZB). Seconded to ROA Maastricht, she is currently part of the EU-Horizon 2020 consortium 'Technological inequality - understanding the relation between recent technological innovations and social inequalities (TECHNEQUALITY)'.

Besides, Marie-Christine Fregin works as research fellow and academic consultant at INPUT Consulting gGmbH in Stuttgart. Combining social science with Design Thinking methods, she is involved in applied research and development projects on workplace digitalisation. At INPUT Consulting she has implemented new ways of work in the German energy sector. Furthermore, she is currently responsible for investigating the impact of AI, and particularly IBM Watson AI technology, at workplaces, conducting field experiments in the industry and telecommunication sector within the scope of the 'IBM Watson Application Study'. This study is conducted in cooperation with ROA Maastricht, and jointly funded by IBM and Vereinte Dienstleistungsgewerkschaft Ver.di in cooperation with the German Federal Ministry of Labour and Social Affairs (BMAS). 



\section{RDA Dissertation Series}

1. Lex Borghans (1993), Educational Choice and Labour Market Information, Maastricht, Research Centre for Education and the Labour Market.

2. Frank Cörvers (1999), The Impact of Human Capital on International Competitiveness and Trade Performance of Manufacturing Sectors, Maastricht, Research Centre for Education and the Labour Market.

3. Ben Kriechel (2003), Heterogeneity Among Displaced Workers, Maastricht, Research Centre for Education and the Labour Market.

4. Arnaud Dupuy (2004), Assignment and Substitution in the Labour Market, Maastricht, Research Centre for Education and the Labour Market.

5. Wendy Smits (2005), The Quality of Apprenticeship Training, Conflicting Interests of Firms and Apprentices, Maastricht, Research Centre for Education and the Labour Market.

6. Judith Semeijn (2005), Academic Competences and Labour Market Entry: Studies Among Dutch Graduates, Maastricht, Research Centre for Education and the Labour Market.

7. Jasper van Loo (2005), Training, Labor Market Outcomes and Self-Management, Maastricht, Research Centre for Education and the Labour Market.

8. Christoph Meng (2005), Discipline-Specific or Academic? Acquisition, Role and Value of Higher Education Competencies, Maastricht, Research Centre for Education and the Labour Market.

9. Andreas Ammermüller (2007), Institutional Effects in the Production of Education: Evidence from European Schooling Systems, Maastricht, Research Centre for Education and the Labour Market.

10. Bart Golsteyn (2007), The Ability to Invest in Human Capital, Maastricht, Research Centre for Education and the Labour Market.

11. Raymond Montizaan (2010), Pension Rights, buman capital development and well-being, Maastricht, Research Centre for Education and the Labour Market.

12. Annemarie Nelen (2012), Part-Time Employment and Human Capital Development, Maastricht, Research Centre for Education and the Labour Market.

13. Jan Sauermann (2013), Human Capital, Incentives, and Performance Out-comes, Maastricht, Research Centre for Education and the Labour Market

14. Harald Ulrich Pfeifer (2013), Empirical Investigations of Costs and Benefits of Vocational Education and Training, Maastricht, Research Centre for Education and the Labour Market. 
15. Charlotte Büchner (2013), Social Background, Educational Attainment and Labor Market Integration: An Exploration of Underlying Processes and Dynamics, Maastricht, Research Centre for Education and the Labour Market.

16. Martin Humburg (2014), Skills and the Employability of University Graduates, Maastricht, Research Centre for Education and the Labour Market.

17. Jan Feld (2014), Making the Invisible Visible, Essays on Overconfidence, Discrimination and Peer Effects, Maastricht, Research Centre for Education and the Labour Market.

18. Olga Skriabikova (2014), Preferences, Institutions, and Economic Outcomes: an Empirical Investigation, Maastricht, Research Centre for Education and the Labour Market.

19. Gabriele Marconi (2015), Higher Education in the National and Global Economy, Maastricht, Research Centre for Education and the Labour Market.

20. Nicolas Salamanca Acosta (2015), Economic Preferences and Financial Risk-Taking, Maastricht, Research Centre for Education and the Labour Market.

21. Ahmed Elsayed Mohamed (2015), Essays on Working Hours, Maastricht, Research Centre for Education and the Labour Market.

22. Roxanne Amanda Korthals (2015), Tracking Students in Secondary Education, Consequences for Student Performance and Inequality, Maastricht, Research Centre for Education and the Labour Market.

23. Maria Zumbuehl (2015), Economic Preferences and Attitudes: Origins, Behavioral Impact, Stability and Measurement, Maastricht, Research Centre for Education and the Labour Market.

24. Anika Jansen (2016), Firms' incentives to provide apprenticeships - Studies on expected short-and longterm benefits, Maastricht, Research Centre for Education and the Labour Market.

25. Jos Maarten Arnold Frank Sanders (2016), Sustaining the employability of the low skilled worker: Development, mobility and work redesign, Maastricht, Research Centre for Education and the Labour Market.

26. Marion Collewet (2017), Working hours: preferences, well-being and productivity, Maastricht, Research Centre for Education and the Labour Market.

27. Tom Stolp (2018), Sorting in the Labor Market: The Role of Risk Preference and Stress, Maastricht, Research Centre for Education and the Labour Market.

28. Frauke Meyer (2019), Individual motives for (re-) distribution, Research Centre for Education and the Labour Market.

29. Maria Ferreira Sequeda (2019), Human Capital Development at School and Work, Research Centre for Education and the Labour Market.

30. Marie-Christine Fregin (2019), Skill Matching and Outcomes: New Cross-Country Evidence, Research Centre for Education and the Labour Market. 